Florida International University FIU Digital Commons

$11-5-2014$

\title{
Novel Approaches for the Synthesis of C-5 Modified Pyrimidine Nucleosides
}

Yong Liang

Florida International University, ylian004@fiu.edu

DOI: $10.25148 /$ etd.FI14110716

Follow this and additional works at: https://digitalcommons.fiu.edu/etd

Part of the Organic Chemistry Commons

\section{Recommended Citation}

Liang, Yong, "Novel Approaches for the Synthesis of C-5 Modified Pyrimidine Nucleosides" (2014). FIU Electronic Theses and Dissertations. 1591.

https://digitalcommons.fiu.edu/etd/1591

This work is brought to you for free and open access by the University Graduate School at FIU Digital Commons. It has been accepted for inclusion in FIU Electronic Theses and Dissertations by an authorized administrator of FIU Digital Commons. For more information, please contact dcc@fiu.edu. 


\section{FLORIDA INTERNATIONAL UNIVERSITY}

Miami, Florida

NOVEL APPROACHES FOR THE SYNTHESIS OF C-5 MODIFIED PYRIMIDINE NUCLEOSIDES

A dissertation submitted in partial fulfillment of

the requirements for the degree of

DOCTOR OF PHILOSOPHY

in

CHEMISTRY

by

Yong Liang

2014 
To: Interim Dean Michael R. Heithaus

College of Arts and Sciences

This dissertation, written by Yong Liang, and entitled Novel Approaches for the Synthesis of C-5 Modified Pyrimidine Nucleosides, having been approved in respect to style and intellectual content, is referred to you for judgment.

We have read this dissertation and recommend that it be approved.

Kevin O'Shea

David Becker

Piero Gardinali

M. Alejandro Barbieri

Stanislaw F. Wnuk, Major Professor

Date of Defense: November 5, 2014

The dissertation of Yong Liang is approved.

Interim Dean Michael R. Heithaus College of Arts and Sciences

Dean Lakshmi N. Reddi University Graduate School

Florida International University, 2014 


\section{DEDICATION}

I dedicate this work to my wife Pingping Liang, my parents and sister for their love and support.

Without their understanding and encouragement, the completion of this work would not have been possible.

感谢我的家人对我的支持与鼓励，我爱你们！ 


\section{ACKNOWLEDGMENTS}

The accomplishment of this dissertation would not have been possible without the guidance and the help of several individuals who in one way or another contributed the countless time and valuable assistance. It is my great pleasure to express my gratitude to all of them in my humble acknowledgment.

First and foremost, I would like to thank my major professor Dr. Stanislaw Wnuk for the opportunity to study and work in his group from the visiting scholar at the beginning, to master graduate student, to Ph.D. graduate student. I would like to express my utmost gratitude to his endless support, supervision, guidance, friendship and believing in me. I do appreciate everything he has done for me!

I would also like to thank Dr. Kevin O'Shea, Dr. David Becker, Dr. Piero Gardinali, and Dr. M. Alejandro Barbieri for their valuable time, advice and constant support during the past 5 years.

Many thanks go to all the faculty and staff members of the chemistry department, stock room, NMR facility and MS facility for the support, help and coordination.

My sincere thanks also go to GPSC, the dean's office of the College of Arts \& Sciences for travel funding, Department of Chemistry \& Biochemistry for the Graduate Student Research Award and Teaching Assistant Fellowship as well as Graduate School for Dissertation Year Fellowship.

I would like to thank my lab mates for their support and patience. You guys are always here in my good and bad moments. Because of you, these five years are full of memories. I am forever grateful.

Finally, I wish to express my appreciation to those who have helped me in any respect during my five years study at FIU, as well as expressing my apology that I could not mention personally one by one. 


\section{ABSTRACT OF THE DISSERTATION \\ NOVEL APPROACHES FOR THE SYNTHESIS OF C-5 MODIFIED PYRIMIDINE \\ NUCLEOSIDES}

by

Yong Liang

Florida International University, 2014

Miami, Florida

Professor Stanislaw F. Wnuk, Major Professor

The antiviral or anticancer activities of C-5 modified pyrimidine nucleoside analogues validate the need for the development of their syntheses. In the first half of this dissertation, I explore the Pd-catalyzed cross-coupling reaction of allylphenylgermanes with aryl halides in the presence of $\mathrm{SbF}_{5} / \mathrm{TBAF}$ to give various biaryls by transferring multiple phenyl groups, which has also been applied to the 5-halo pyrimidine nucleosides for the synthesis of 5-aryl derivatives. To avoid the use of organometallic reagents, I developed Pd-catalyzed direct arylation of 5-halo pyrimidine nucleosides. It was discovered that 5-aryl pyrimidine nucleosides could be synthesized by Pd-catalyzed direct arylation of $N^{3}$-free 5-halo uracil and uracil nucleosides with simple arenes or heteroaromatics in the presence of TBAF within $1 \mathrm{~h}$. Both $N^{3}$-protected and $N^{3}$ free uracil and uracil nucleosides could undergo base-promoted Pd-catalyzed direct arylation, but only with electron rich heteroaromatics.

In the second half of this dissertation, 5-acetylenic uracil and uracil nucleosides have been employed to investigate the hydrogermylation, hydrosulfonylation as well as hydroazidation for the synthesis of various functionalized 5-vinyl pyrimidine nucleosides. Hydrogermylation of 5alkynyl uracil analogues with trialkylgermane or tris(trimethylsilyl)germane hydride gave the corresponding vinyl trialkylgermane, or tris(trimethylsilyl)germane uracil derivatives. During the hydrogermylation with triphenylgermane, besides the vinyl triphenylgermane uracil derivatives, 
5-[2-(triphenylgermyl)acetyl]uracil was also isolated and characterized and the origin of the acetyl oxygen was clarified. Tris(trimethylsilyl)germane uracil derivatives were coupled to aryl halides but with decent yield. Iron-mediated regio- and stereoselective hydrosulfonylation of the 5-ethynyl pyrimidine analogues with sulfonyl chloride or sulfonyl hydrazine to give 5-(1-halo-2tosyl)vinyluracil nucleoside derivatives has been developed. Nucleophilic substitution of the 5-( $\beta$ halovinyl)sulfonyl nucleosides with various nucleophiles have been performed to give highly functionalized 5-vinyl pyrimidine nucleosides via the addition-elimination mechanism. The 5-( $\beta$ keto)sulfonyluracil derivative has also been synthesized via the aerobic difunctionalization of 5ethynyluracil analogue with sulfinic acid in the presence of catalytic amount of pyridine. Silver catalyzed hydroazidation of protected 2'-deoxy-5-ethynyluridine with $\mathrm{TMSN}_{3}$ in the presence of catalytic amount of water to give 5-( $\alpha$-azidovinyl)uracil nucleoside derivatives was developed. Strain promoted Click reaction of the 5-( $\alpha$-azidovinyl)uracil with cyclooctyne provide the corresponding fully conjugated triazole product. 


\section{TABLE OF CONTENTS}

CHAPTER

PAGE

1. INTRODUCTION

1.1. Activities of purine and pyrimidine nucleosides and nucleotides......................................... 1

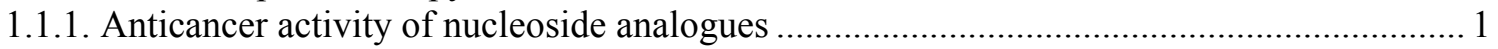

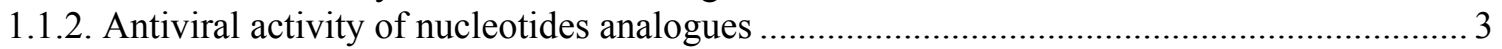

1.2. Biological activities of 5 -modified pyrimidine nucleosides ................................................ 4

1.3. Synthesis of the C-5 modified pyrimidine nucleosides via Pd-catalyzed cross-coupling reactions

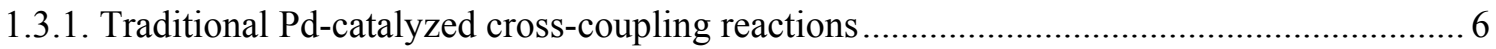

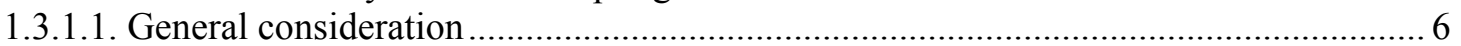

1.3.1.2. Application of the traditional Pd-catalyzed cross-coupling reaction to the synthesis of C-5 modified pyrimidine nucleosides

1.3.2. Direct activation and its application in Pd-catalyzed cross-coupling reactions................... 10

1.3.2.1. Single C-H functionalzation via Pd-catalyzed cross-coupling reactions..................... 11

1.3.2.2. Double $\mathrm{C}-\mathrm{H}$ functionalization via $\mathrm{Pd}$-catalyzed cross-coupling reactions .................... 14

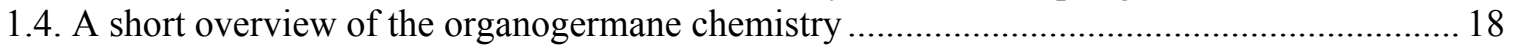

1.4.1. Application of organogermanes to Pd-catalyzed cross-coupling reactions ......................... 18

1.4.2. Biological activity of the germanium containing compounds ......................................... 20

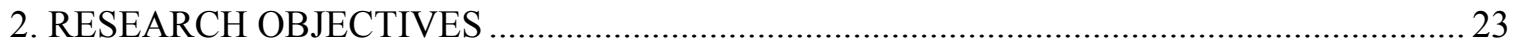

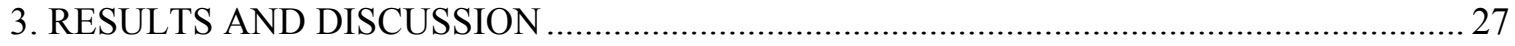

3.1. Synthesis of 5-aryluracil nucleosides via Pd-catalyzed cross coupling reactions.................... 27

3.1.1. Coupling reactions of 5-halouracil nucleosides with chloro(phenyl)germanes.................. 27

3.1.1.1. Developing a general procedure for transfer of phenyl group(s) from chloro(phenyl)germanes to aryl halides mediated by TBAF ............................................. 27

3.1.1.2. Attempted TBAF-promoted coupling of 1-N-benzyl-5-iodouracil with

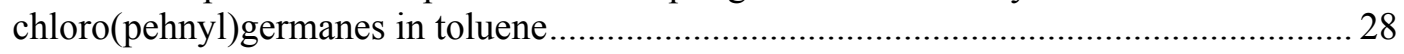

3.1.2. Coupling reactions of 5-halouracil nucleosides with allyl(phenyl)germanes.................... 29

3.1.2.1. Developing a general procedure for transfer of phenyl group(s) from allyl(phenyl)germanes to aryl halides mediated by $\mathrm{SbF}_{5} / \mathrm{TBAF}$.......................................2

3.1.2.2. Attempted $\mathrm{SbF}_{5} / \mathrm{TBAF}-$ promoted coupling of 1-N-benzyl-5-iodouracil with

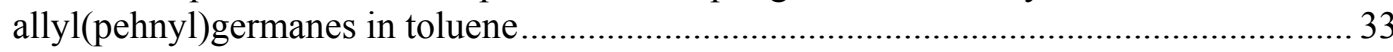

3.1.3. Direct arylation of 5-halouracils and 5-halouracil nucleosides with arenes and

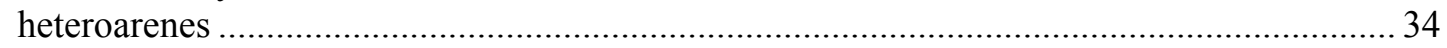

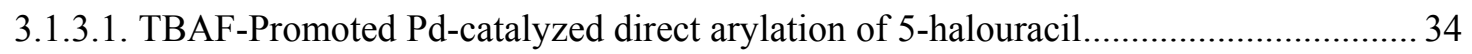

3.1.3.2. Base promoted Pd-catalyzed direct arylation of 5-halo uracil.................................. 38

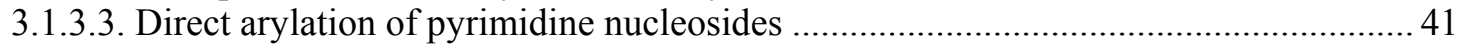

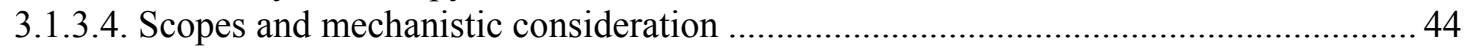

3.2. Synthesis of highly functionalized 5-vinyluracil nucleosides from 5-acetylene substrates .... 46

3.2.1. Hydrogermylation of 5-ethynyluracil nucleosides ..................................................... 46

3.2.1.1. Synthesis of 5-[2-(germyl)vinyl]uracil and 5-[2-(triphenylgermyl)acetyl]uracil

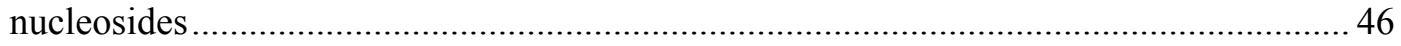

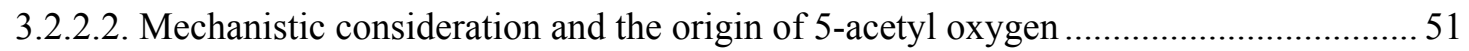

3.2.1.3. Application of the 5-[2-(germyl)vinyl]uracil to organic synthesis ............................. 54 
3.2.2. Iron-mediated regio- and stereoselective hydrosulfonylation of 5-ethynyluracil

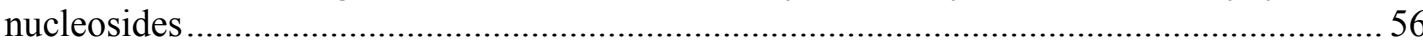

3.2.2.1. Synthesis of 5-(1-chloro-2-tosyl)vinyl uracil nucleosides........................................ 58

3.2.2.2. Application of 5-(1-chloro-2-tosyl)vinyl uracil nucleosides to organic synthesis ...... 61

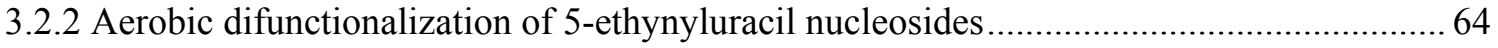

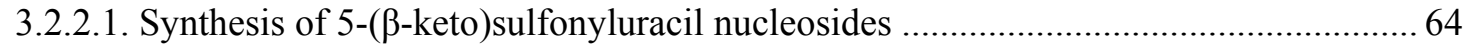

3.2.2.2. Application of 5-( $\beta$-keto)sulfonyluracil nucleosides to organic synthesis .................... 66

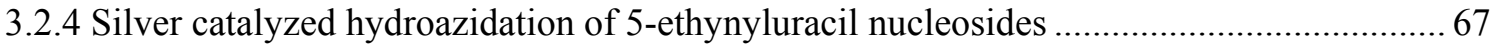

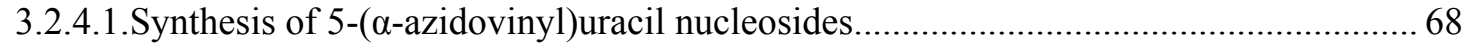

3.2.4.1. Application of 5-( $\alpha$-azidovinyl)uracil nucleosides to organic synthesis ..................... 69

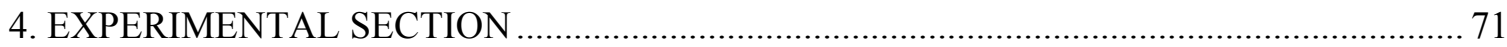

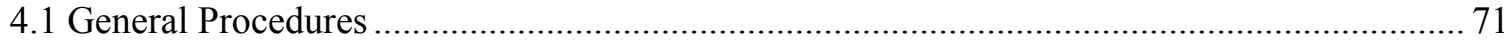

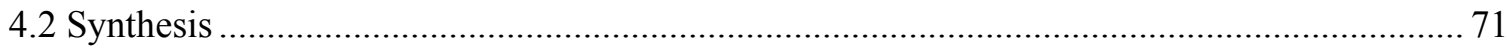

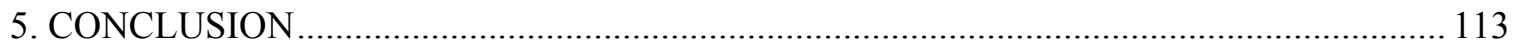

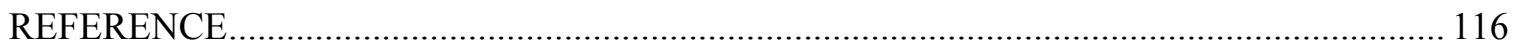

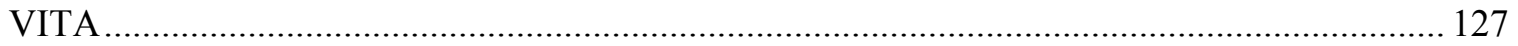




\section{LIST OF TABLES}

TABLE

PAGE

1. FDA approved anticancer purine and pyrimidine nucleoside analogues ............................... 2

2. Antiviral properties of purine and pyrimidine nucleoside analogues................................... 3

3. Coupling of diallyl(diphenyl)germane 82 with 1-iodonaphthalene $87 \mathrm{~b}$ promoted by $\mathrm{SbF}_{5} \ldots . .31$

4. Coupling of allyl(phenyl)germanes $81-83$ with aryl halides promoted by $\mathrm{SbF}_{5} \ldots \ldots \ldots \ldots \ldots \ldots . . . . . . . .32$

5. Effect of the reaction parameters in the direct arylation of 1-N-benzyl-5-iodouracil 1a with

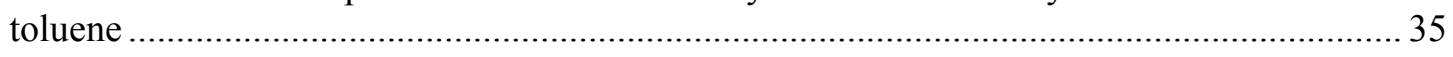

6. Direct arylation of 5-halouracils 78 with and electron-rich arenes and heteroaromatics ........ 37

7. Effect of the reaction parameters in the base-promoted direct arylation of 1- $N$-benzyl-5-

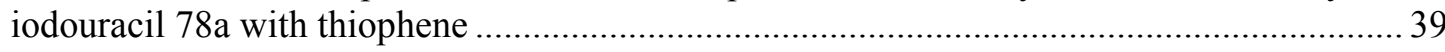

8. $\mathrm{Cs}_{2} \mathrm{CO}_{3}$ Promoted direct arylation of 5-halouracils 78 with electron-rich heteroaromatics .... 40

9. Direct arylation of 5-iodouracil nucleosides with electron-rich heteroaromatics ................... 42

10. Hydrogermylation of 5-ethynyluracil and related nucleosides with germane hydrides .......... 48

11. Hydrogermylation of 1- $N$-benzyl-5-ethynyluracil with triphenylgermane ............................ 51 


\section{LIST OF FIGURES}

FIGURE

PAGE

1. Structure of anticancer/antiviral nucleoside analogues ....................................................... 4

2. General mechanism for Pd-catalyzed cross-coupling reaction.......................................... 7

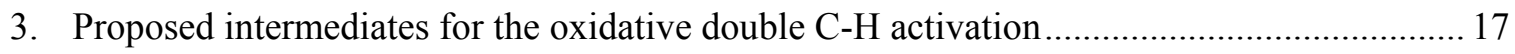

4. Biological activities of germanium containing compounds .............................................. 21

5. ${ }^{19} \mathrm{~F}$ NMR analysis of the allylgermanes cleavage upon treatment of $\mathrm{SbF}_{5} / \mathrm{C} \ldots \ldots \ldots \ldots \ldots \ldots \ldots \ldots . . . . . . . . . . .30$

6. The plausible intermediates for the Pd-catalyzed direct arylation of 5-halouracils: (A) Electrophilic aromatic palladation assisted by C4-alkoxide; (B) Direct proton abstraction

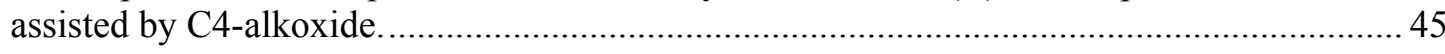

7. Proposed decomposition route for 5-[2-(triphenylgermyl)acetyl]uracils 146 and $147 \ldots \ldots . . .52$

8. Synthesis of vinylsulfone modified DNA and cross coupling with $\mathrm{p} 53$ protein .....................58

9. Proposed mechanism for the $\mathrm{Fe}(\mathrm{III})$ mediated hydrosulfonylation of 5-ethynyluracil nucleosides

10. Proposed mechanism for the synthesis of 5 -( $\beta$-keto)sulfonyluracil via aerobic difunctionalization 


\section{LIST OF SCHEMES}

SCHEME

PAGE

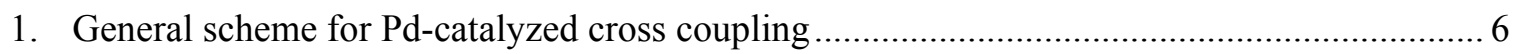

2. Synthesis of C-5 modified pyrimidine nucleosides via Heck reaction.................................... 8

3. Synthesis of C-5 modified pyrimidine nucleosides via Sonogashira reaction ........................ 9

4. Synthesis of C-5 modified pyrimidine nucleosides via Suzuki reaction ................................ 9

5. Synthesis of C-5 modified pyrimidine nucleosides via Hiyama reaction............................... 10

6. Synthesis of C-5 modified pyrimidine nucleosides via Stille reaction .................................. 10

7. Direct C-H arylation of uracil analogues with aryl bromide ............................................... 12

8. Catalyst controlled single $\mathrm{C}-\mathrm{H}$ functionalization of uracil analogues ................................... 12

9. Regioselective $\mathrm{C}-\mathrm{H}$ arylation of uracil analogues with arylboronic acids ............................. 13

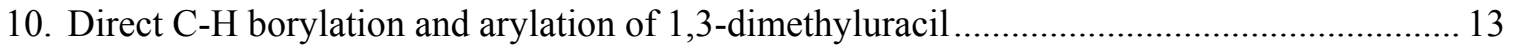

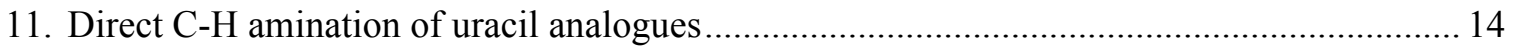

12. Pd-Catalyzed double $\mathrm{C}-\mathrm{H}$ functionalization of 1,3-protected uracil analogue ........................ 14

13. Synthesis of 2-uracilyl pyridines via Pd-catalyzed double $\mathrm{C}-\mathrm{H}$ functionalization.................. 15

14. Synthesis of uracil dimmers via Pd-catalyzed double $\mathrm{C}-\mathrm{H}$ functionalization ......................... 16

15. Synthesis of 5-alkenyl uracil and uracil nucleosides via Pd-catalyzed double $\mathrm{C}-\mathrm{H}$

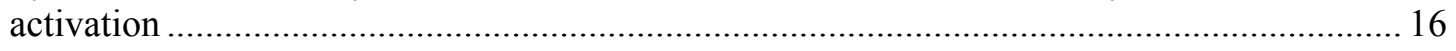

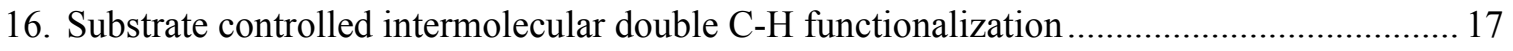

17. Substrate controlled intramolecular Pd-catalyzed double $\mathrm{C}-\mathrm{H}$ functionalization ................... 17

18. Catalyst/solvent controlled alkenylation of indole ........................................................ 18

19. Pd-catalyzed cross-coupling of germatrane derivatives 46 with aryl bromides .................... 19

20. Pd-catalyzed cross-coupling of tri(fur-2-yl)german and tri(fur-2-yl)phenylgerman with

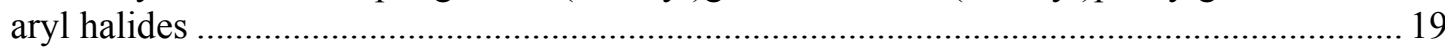

21. Synthesis of alkenyl arenes via vinyl tris(trimethylsilyl)germanes ..................................... 20

22. Photo-induced Pd-catalyzed cross-coupling of bis(2-naphthylmethyl)arylgermens with aryl bromides 
24. Proposed synthesis of 5-aryl uracil nucleosides by Pd-catalyzed coupling with organogermanes (path A) or direct arylation (path B).

25. Proposed synthesis of 5-vinylgermyl uracil nucleosides by hydrogermylation and application to Pd-catalyzed coupling with aryl halides (path A) or halodegermylation (path B)

26. Proposed synthesis of 5-( $\beta$-halo)vinyl sulfonyl pyrimidine nucleosides by hydrosulfonylation of 63 with sulfonyl chloride (path A) or sulfonyl hydrazide (path B) and its application to the nucleophilic substitution

27. Proposed synthesis of 5-( $\beta$-keto) sulfonyl pyrimidine nucleosides by hydrogermylation of 63 with sulfinic acid and its application to electrophilic substitution

28. Proposed synthesis of 5-( $\alpha$-azido)vinyl pyrimidine nucleosides by hydroazidation of 63 with $\mathrm{TMSN}_{3}$

29. Synthesis of 1-phenylnaphthalene via chlorophenylgermanes

30. TBAF promoted cross-coupling of 5-iodouracil with chloro(triphenyl)germane .28

31. Selective cleavage the allyl-Ge bond of allylphenylgermanes with $\mathrm{SbF}_{5} / \mathrm{C}$

32. Proposed mechanism for the $\mathrm{SbF}_{5}$ promoted transfer of phenyl group from Ge center

33. $\mathrm{SbF}_{5}$ Mediated Pd-catalyzed cross-coupling of 5-iodouracil 78 with allyl(triphenyl)germane 83

34. TBAF or base promoted coupling of 5-iodocytidine analogues with furan

35. TBAF or base promoted direct arylation of 3-bromo-2-pyridone. .44

36. Pd-catalyzed direct $\mathrm{C}-\mathrm{H}$ arylation of uracil with 4-iodoanisole 45

37. Synthetic route for the preparation of 5-ethynyluracil and ${ }^{18} \mathrm{O}$-labeled 5-ethynyluracil. 50

38. A plausible pathway for the formation of 5-[(2-triphenylgermyl)acetyl]uracil 147 during radical addition of $\mathrm{Ph}_{3} \mathrm{GeH}$ to 5-acetylenic substrate 135

39. Proposed route for the thermal degradation of 5-[(2-triphenylgermyl)acetyl]uracil 146 into the 5-acetyl product 152 .

40. Hydrogermylation of 5-ethynyluracil and uracil nucleosides 123, 127 and135 with $\left(\mathrm{Me}_{3} \mathrm{Si}\right)_{3} \mathrm{GeH}$ and attempted Pd-catalyzed cross-coupling of the resulting vinyl germanes with alkenyl or aryl halides .....

41. Radical halodegermylation and deprotection of vinyl trimethylgermane uracil nucleoside with NBS and methanolic ammonia. 
42. Synthesis of 5-(1-chloro-2-tosyl)vinyl uracil via hydrosulfonylation of 1-N-benzyl-5ethynyluracil with tosyl chloride

43. Synthesis of 5-[(E)-( $\beta$-chloro)vinyl]sulfonyl uracil via hydrosulfonylation of 5ethynyluracil with tosyl hydrazide in the presence of $\mathrm{FeCl}_{3}$

44. Synthesis of 5-[(E)-( $\beta$-bromo)vinyl]sulfonyl uracil via hydrosulfonylation of 5ethynyluracil with tosyl hydrazide in the presence of $\mathrm{FeBr}_{3}$

45. Synthesis of 5-[(E)-( $\beta$-chloro)vinyl]sulfonyl uracil nucleosides via hydrosulfonylation......

46. Nucleophilic substitution of (E)-1-N-benzyl-5-(1-chloro-2-tosyl)vinyluracil with methanolic ammonia

47. Synthesis of nucleophile substituted vinyl sulfonyl uracil nucleoside analogues via addition-elimination mechanism

48. Proposed mechanism for the nucleophilic substitution of 5-[(1-halo-2-tosyl)vinyl]uracil and uracil nucleosides

49. Phosphorylation of 2'-deoxy-5-[(1-halo)-2-tosyl]vinyluridine 168 and the synthesis of functionalized nucleotide

50. Reported synthetic route for the preparation of $\beta$-keto sulfones

51. Synthesis of 5-[( $\beta$-keto)sulfonyl]uracil via aerobic difunctionalization of 5-ethynyluracil 135

52. Proposed mechanism for the electrophilic substitution of 5-[(2-sulfonyl)acetyl]uracil and uracil nucleosides

53. Synthesis of 5-[(2-benzyl-2-sulfonyl)acetyl]uracil via the electrophilic substitution .....

54. Synthesis of 5-azido-2'-deoxyuridine via two different pathways 68

55. Synthesis of 5-(azidomethyl)-2'-deoxyuridine from thymidine 68

56. Silver catalyzed hydroazidation of 5-ethynyluridine and click reaction

57. Strain promoted copper free Click reaction of 5-[( $\alpha$-azido)vinyl $]$ uridine 198 with cyclooctyne 199

58. Proposed route for the synthesis of 5-( $\alpha$-azido)vinyl functionalized nucleotide .70 


\section{LIST OF ABBREVIATIONS}

\begin{tabular}{|c|c|}
\hline 5'-araCTP & 5'-arabinofuranosylcytosine triphosphate \\
\hline $5-F d U$ & 5-fluoro-2'-deoxyuridine \\
\hline $5-\mathrm{FU}$ & 5-fluorouracil \\
\hline Abs & absorbance \\
\hline $\mathrm{ACCN}$ & 1,1'-azobis(cyclohexanecarbonitrile) \\
\hline Ar & aromatic (NMR) \\
\hline AZT & 3'-Azido-3'-deoxythymidine \\
\hline$\beta$ & beta \\
\hline $\mathrm{Bn}$ & benzyl \\
\hline br & broad (NMR) \\
\hline BVDU & (E)-5-(2-bromovinyl)-2'-deoxyuridine \\
\hline$t-\mathrm{Bu}$ & tert-butyl \\
\hline calcd & calculated (HRMS) \\
\hline CID & collision-induced dissociation (HRMS) \\
\hline CMD & concerted metalation-deprotonation \\
\hline CMV & cytomegalovirus \\
\hline${ }^{\circ} \mathrm{C}$ & degrees Celsius \\
\hline$\delta$ & delta \\
\hline $\mathrm{d}$ & doublet (NMR) \\
\hline DCM & dichloromethane \\
\hline $\mathrm{dCK}$ & deoxycytidine kinase \\
\hline $\mathrm{dCTP}$ & deoxycytidine triphosphate \\
\hline DMAP & 4-(N,N-dimethylamino)pyridine \\
\hline DMF & $N, N$-dimethylformamide \\
\hline
\end{tabular}




\begin{tabular}{|c|c|}
\hline DMSO & dimethylsulfoxide \\
\hline DNA & deoxyribonucleic acid \\
\hline ESI & electrospray ionization \\
\hline Et & ethyl \\
\hline FDA & U.S. Food and Drug Administration \\
\hline FUra & 5-fluorouracil \\
\hline$\lambda$ & gamma \\
\hline $\mathrm{g}$ & $\operatorname{gram}(\mathrm{s})$ \\
\hline h & hour(s) \\
\hline $\mathrm{HBV}$ & hepatitis B virus \\
\hline hENT1 & human Equilibrative Nucleoside Transporter 1 \\
\hline HIV & human immunodeficiency virus \\
\hline HSV & herpes simplex virus \\
\hline HPLC & high performance liquid chromatography \\
\hline HRMS & high resolution mass spectroscopy \\
\hline $\mathrm{Hz}$ & hertz \\
\hline$J$ & coupling constant in $\mathrm{Hz}$ (NMR) \\
\hline $\mathrm{L}$ & liter(s) \\
\hline $\mathrm{m}$ & milli; multiplet (NMR) \\
\hline$\mu$ & micro \\
\hline M & moles per liter \\
\hline MGP & methylgermanium(IV) porphyrin \\
\hline $\min$ & minute(s) \\
\hline mol & mole(s) \\
\hline MS & mass spectrometry \\
\hline
\end{tabular}




\begin{tabular}{|c|c|}
\hline$m / z$ & mass to charge ratio (MS) \\
\hline NBS & $N$-bromosuccinimide \\
\hline NIS & $N$-iodosuccinimide \\
\hline NMR & nuclear magnetic resonance \\
\hline NRTI & nucleotide reverse transcriptase inhibitors \\
\hline NT & nucleoside transporter \\
\hline$p$ & para \\
\hline $\mathrm{Pd}_{2}(\mathrm{dba})_{3}$ & tris(dibenzylideneacetone)dipalladium $(0)$ \\
\hline $\mathrm{Pd}(\mathrm{OAc})_{2}$ & palladium(II) acetate \\
\hline$\%$ & percentage \\
\hline q & quartet (NMR) \\
\hline quin & quintet (NMR) \\
\hline RNA & ribonucleic acid \\
\hline $\mathrm{rt}$ & room temperature \\
\hline $\mathrm{s}$ & second(s); singlet (NMR) \\
\hline SAR & structure activity relationship \\
\hline SET & single electron transfer \\
\hline $\mathrm{t}$ & triplet (NMR) \\
\hline TBAF & tetra- $N$-butylammonium fluoride \\
\hline TBHP & tert-butyl hydroperoxide \\
\hline TEA & triethylamine \\
\hline THF & tetrahydrofuran \\
\hline TK & thymidine kinase \\
\hline TLC & thin layer chromatography \\
\hline TMS & trimethylsilyl \\
\hline
\end{tabular}


$t_{\mathrm{R}}$

UV-VIS ultraviolet visible

vs

VV

VZV retention time (HPLC)

versus

vaccinia virus

varicella zoster virus 


\section{INTRODUCTION}

\subsection{Activities of purine and pyrimidine nucleosides and nucleotides}

It is known that both pyrimidine and purine nucleosides are the basic building blocks for DNA and RNA, which contain the genetic information that is passed from one generation to the next. The sugar linked purine and pyrimidine nucleosides were connected by phosphates to form the backbone for the DNA or RNA, whereas, the different heterobases interact with one and another in a certain pattern via hydrogen bond to form the double helix structure for DNA. The sequence of nucleoside bases in DNA is considered as the genetic information, which can be replicated by the DNA polymerase enzyme to RNA with high accuracy. In April 2003, the completion of the human genome sequence was announced. ${ }^{1}$

Natural or synthesized purine and pyrimidine nucleosides are found to possess some important biological activities, which could be applied in biology, biotechnology or pharmaceutical development. ${ }^{2}$ With the research development, nucleoside analogues have attracted much more attention because of the wide application in the anticancer and antiviral area.

The active nucleoside analogues of these compounds can be considered as " prodrugs", which need to be activated by normal metabolic process, such as phosphorylation. Both pyrimidine and purine nucleoside analogues are currently used clinically as antimetabolite drugs and share the similar mechanism. They cross into cells with the help of the nucleoside transporter and followed the metabolic pathway to be converted to nucleotide analogues, which could inhibit one or more enzymes that are critical for the DNA synthesis. ${ }^{3}$

\subsubsection{Anticancer activity of nucleoside analogues}

Until 2014, only 14 nucleoside-based drugs have been approved by the U.S. Food and Drug Administration (FDA) for the treatment of cancer (Table 1). ${ }^{4}$ Approximately $10 \%$ of the anticancer drugs are nucleoside analogues; six of these drugs were approved during the 19962014 and there are more nucleoside analogues in the clinical trial stage. The approval of 
nucleosides analogues as anticancer drugs by FDA indicates that synthesis of base/sugarmodified nucleoside analogues is one of the most effective methods for the development of new drugs for cancer.

Table 1. FDA approved anticancer purine and pyrimidine nucleoside analogues

\begin{tabular}{lll}
\hline \multicolumn{1}{c}{ Drug } & \multicolumn{1}{c}{ Catagory } & \multicolumn{1}{c}{ Year } \\
\hline 5-aza-2'-deoxycytidine (Decitabine) & 2'-Deoxycytidine & 2006 \\
O'-methylarabinofuranosyl guanine (Nelarabine) & Guanosine & 2005 \\
5-aza-cytidine (Azacitidine) & 2'-Deoxyadenosine & 2004 \\
2'-fluoro-2'-deoxyarabinofuranosyl-2-chloroadenine (Clofarabine) & Cytidine & 2004 \\
N'-pentyloxycarbonyl-5'-deoxy-5-fluorocytidine (Capecitabine) & Cytidine & 1998 \\
2,2-difluoro-2'-deoxycytidine (Gemcitabine) & 2'-Deoxycytidine & 1996 \\
2-chloro-2'-deoxyadenosine (Cladribine) & 2'-Deoxyadenosine & 1992 \\
2'-deoxycoformycin (Pentostatin) & Adenosine & 1991 \\
Arabinofuranosyl-2-fluoroadenine (Fludarabine) & Purine analogue & 1991 \\
5-fluoro-2'-deoxyuridine (Floxuridine) & 2'-Deoxyuridine & 1970 \\
Arabinofuranosylcytosine (Cytarabine) & Cytidine & 1969 \\
6-thioguanine (Lanvis) & Guanine & 1966 \\
5-fluorouracil (Adrucil) & Uracil & 1962 \\
6-mercaptopurine (Purinethol) & Purine & 1953 \\
\hline
\end{tabular}

Taking cytarabine (1- $\beta$-D-arabinofuranosylcytosine) as example, it is the anticancer drug in hematological malignanciesone, which is one of the first pyrimidine nucleoside analogs approved in 1969. Cytarabine is transported into the cell with the assistance of human Equilibrative Nucleoside Transporter 1 (hENT1), ${ }^{5,6}$ followed by the phosphorylation of deoxycytidine kinase (dCK) and nucleotide kinases to give 5'-arabinofuranosylcytosine triphosphate (5'-araCTP). ${ }^{7}$ The anticancer activity of $5^{1}$-araCTP is characterized as the inhibitor of DNA polymerase $\alpha^{8}$ and incorporation into DNA instead of deoxycytidine triphosphate (dCTP) to interrupt DNA synthesis. 5'-Arabinofuranosylcytosine monophosphate is also able to incorporate into DNA to inhibit the DNA synthesis by preventing the DNA chain extension. ${ }^{9}$ However, the biological anticancer 
activity could be disabled by cytidine deaminase and cytoplasmic 5'-nucleotidase to give inactive arabinosyluridine.

\subsubsection{Antiviral activity of nucleotides analogues}

During the past two decades, nucleoside analogues have become reliable antiviral agents in the treatment of different kinds of virus, such as herpes simplex virus (HSV), hepatitis B virus (HBV), human immunodeficiency virus (HIV) and others. ${ }^{2}$ Some of the antiviral nucleoside analogues are listed in Table 2.

Table 2. Antiviral properties of purine and pyrimidine nucleoside analogues

\begin{tabular}{lll}
\hline \multicolumn{1}{c}{ Drug } & \multicolumn{1}{c}{ Category } & Year \\
\hline 2'-deoxy-2'-fluoro-2'-methyluridine-5'-phosphate (Sofosbuvir) & Thymidine & 2013 \\
Tenofovir disoproxil fumarate, mixture of purine analogues (Tenofovir) & Purine & 2008 \\
1-2-deoxy- $\beta$-L-erythro-pentofuranosylthymine (Telbivudine) & Thymidine & 2006 \\
5-fluoro-1-(2R,5S)-[2-(hydroxymethyl)-1,3-oxathiolan-5-yl]cytosine (Emtricitabine) & Cytidine & 2006 \\
(1S,3R,4S)-4-Hydroxy-3-(hydroxymethyl)-2-methylidenecyclopentylguanosine (Entecavir) & Guanosine & 2005 \\
2',3'-didehydro-2',3'-dideoxythymidine (Stavudine) & Thymidine & 2001 \\
2',3'-dideoxy-3'-thiacytidine (Lamivudine) & Cytidine & 1998 \\
2',3'-didehydro-2',3'-dideoxythymidine (Stavudine) & Thymidine & 1994 \\
3'-azido-3'-deoxythymidine (Zidovudine) & Thymidine & 1987 \\
2-amino-1,9-dihydro-9-[(2-hydroxyethoxy)methyl]-6H-purin-6-one (Acyclovir) & Guanosine & 1982 \\
(E)-5-(2-bromovinyl)-2'-deoxyuridine (Brivudine) & Uridine & 1980 \\
9- $\beta$-D-arabinofuranosyladenine (Vidarabine) & Adenosine & 1976 \\
5-ethyl-2'-deoxyuridine (Edoxudine) & Thymidine & 1969 \\
5-iodo-2'-deoxyuridine (Idoxuridine) & Uridine & 1962 \\
\hline
\end{tabular}

The inhibition mechanism of the antiviral nucleoside analogues is similar to the anticancer agents mentioned above. First of all, the antiviral nucleoside analogues are transported into the cells by the Nucleoside Transporters (NTs), followed by the phosphorylation to give nucleotide analogues. Then, the resulting nucleotides repress the viral reproduction by incorporation into the nascent viral DNA chain which leads to the chain termination. The compound 3'-azido-3'deoxythymidine (AZT) is the first U.S. government-approved drug for the treatment of HIV, 
which is a nucleoside analogue reverse-transcriptase inhibitor (NRTI). It can significantly inhibit the replication of the virus ${ }^{10}$ but cannot completely prevent viral replication. ${ }^{11}$

\subsection{Biological activities of 5-modified pyrimidine nucleosides}

Structure-activity relationship (SAR) studies indicated that the pyrimidine base bearing electron-withdrawing groups or conjugated substitutions at C5 position confer the biological activity of the nucleoside analogues, ${ }^{4,12-18}$ such as antiviral, ${ }^{19-24}$ anticancer, ${ }^{4,25}$ or antibacterial. ${ }^{26,27}$

Examples of pyrimidine nucleoside analogues with modification at C5 position include 5fluorouracil (1, FUra), 5-ethyl-2'-deoxyuridine (2, Edoxudine), (E)-5-(2-bromovinyl)-2'deoxyuridine $^{22,28}$ (3, BVDU), 5-aza-2'-deoxycytidine ${ }^{4,25}$ (4, Decitabine) and 5-fluoro-1-(2R,5S)[2-(hydroxymethyl)-1,3-oxathiolan-5-yl]cytosine (5, Emtricitabine) (Figure 1) which have potent antiviral properties. Pronounced cytotoxity and significant antiviral activity have been reported for 1-( $\beta$-D-arabinofuranosyl)-5-ethenyluracil ${ }^{29}$ and 5-ethynyl-2'-deoxyuridine ${ }^{30}$ as well.

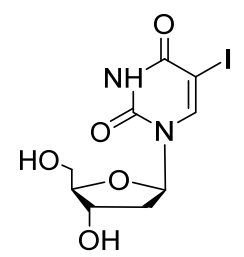

1, Idoxuridine

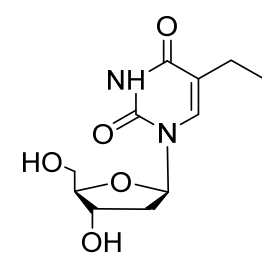

2, Edoxudine

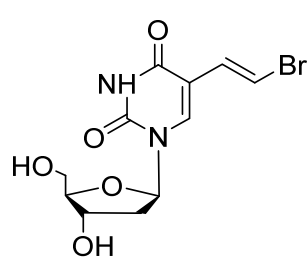

3, BVDU

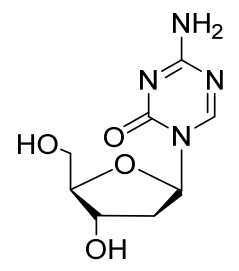

4, Decitabine

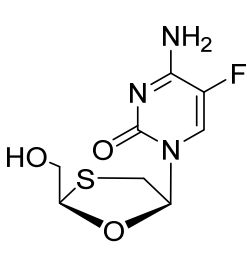

5, Emtricitabine

Figure 1.Structure of anticancer/antiviral nucleoside analogues

The 5-iodo-2'-deoxyuridine (1, Idoxuridine) is the first antiviral agent topically to treat herpes simplex keratitis. Later on, sugar and/or base modified nucleoside analogues have been synthesized and studied in detail. ${ }^{4,31}$ The 5-ethyl-2'-deoxyuridine (2, Edoxudine) was the first antiviral nucleoside analogue approved by the FDA in 1969, however it is not currently used clinically. The (E)-5-(2-bromovinyl)-2'-deoxyuridine $(3, \quad \text { BVDU })^{28}$ and bicyclic furanopyrimidine-2-one nucleoside analogues which display remarkable antiviral potency against the varicella zoster virus (VZV), ${ }^{32}$ are highly potent and selective antiviral drugs. The 5-aza-2'deoxycytidine (4, Decitabine) was approved by FDA in 2006 for injection for the treatment of 
patients with myelodysplastic syndromes (MDS). ${ }^{33}$ Emtricitabine (5) was approved by FDA in 2006 as well and used for the treatment of HIV infection in adults and children.

It is also worthy to note that the C5-aryl or C5-heteroaryl pyrimidine nucleoside analogues possess intrinsic fluorescence because of the extended conjugation system. These types of pyrimidine nucleoside analogues usually show special fluorescence with the irradiation by UV light, which could be employed as the molecular beacons for detecting the presence of abasic sites of oligonucleotide, ${ }^{34}$ determination of the RNA structure, ${ }^{35}$ exploring RNA folding and recognition, ${ }^{36}$ as well as studing the intramolecular electron $\operatorname{transfer}^{37}$ or electron injection in to DNA $^{38,39}$ and so on. ${ }^{40,41}$ Among the 5-arylated pyrimidine nucleoside analogues, the 5-(2furyl)uridine and 5-(2-thienyl)-2'-deoxyuridine analogues display the strongest florescence, owing to the high conjugation between the electron rich furan or thiophene with the pyrimidine base. Thus they have been incorporated into RNA and DNA fragments using phosphoramidite solid support technology and used as fluorescent probes. ${ }^{34,36,42,43}$ The 5-aryl and 5-(2-thienyl) modified 2'-deoxyuridine (or cytidine) triphosphates can also be used as the substrates for DNA polymerases and for DNA staining and electrochemical labels. ${ }^{44-46}$

\subsection{Synthesis of the C-5 modified pyrimidine nucleosides via Pd-catalyzed cross-coupling reactions}

The transition metal catalyzed cross-coupling reactions have contributed significantly for the synthesis of biaryl compounds. One of the most important transition metal for the cross coupling reactions is the Palladium $(\mathrm{Pd})$. With few exceptions, two different activated components are required. One is the organometallic, alkene (Heck reaction), or alkyne (Sonogashira reaction) and the other is the halides or triflates.

The Pd-catalyzed reaction was first introduced by Dr. Richard Heck in 1970s. ${ }^{47}$ Later many Pd-catalyzed cross coupling reactions were published with different substrates, and the methodology became one of the most important methods to build the $\mathrm{C}-\mathrm{C}$ bond. There are some 
reasons for the popularity of the Pd-catalyzed coupling reaction. First of all, the coupling reaction can be carried out under mild conditions, which usually could inhibit the formation of the unwanted byproduct, or in other words, give the desired product in high yield selectively. Second, a wide range of functional groups could be tolerated by the Pd-catalyzed coupling reactions. Addition of ligands usually could increase the yield and decrease the reaction time or temperature by lowering the reaction barrier. Because of the important contribution of the Stille reaction, Heck reaction and Suzuki reaction in the organic synthesis, natural product synthesis or pharmaceutical application, 2010 chemistry Nobel Prize was awarded jointly to Richard F. Heck,

Ei-ichi Negishi and Akira Suzuki. ${ }^{48}$

\subsubsection{Traditional Pd-catalyzed cross-coupling reactions}

\subsubsection{General consideration}

The Pd-catalyzed cross-coupling reactions, such as Suzuki, Hiyama, Stille, Negishi and Kumada reaction, share some common similarity. They all need the organometallic 6 (e.g., B, Si, $\mathrm{Sn}, \mathrm{Zn}, \mathrm{Mg}$ ) and aryl halides or pseudohalides 7 for the coupling reaction to work properly (Scheme 1).

$$
\begin{array}{ccc}
R-M-R_{n}^{\prime \prime}+R^{\prime}-X & \frac{P d}{-X M n_{n}^{\prime}} & R-R^{\prime} \\
6 & 7 & 8
\end{array}
$$

\section{Scheme 1. General scheme for Pd-catalyzed cross coupling}

The general mechanism for the Pd-catalyzed cross-coupling reaction involves three basic steps (Figure 2). Initially, Pd insert into the $\mathrm{sp}^{2}$-hybridized $\mathrm{C}-\mathrm{X}$ bond via a concerted three-center intermediate to give intermediate $\mathbf{B}$, followed by transmetalation which involve the cleavage of the X-M bond and the formation of the new bond between the carbon of $\mathbf{6}$ and the palladium center to give intermediate $\mathbf{C}$, and reductive elimination to give the coupled product $\mathbf{8}$ with the regeneration of the palladium catalyst $\mathbf{A}$. Oxidative insertion step is usually considered as the rate determining step of the catalytic cycle. The presence of anionic ligands (e.g., OAc) could also 
accelerate the oxidative insertion step by the formation of $\left[\mathrm{Pd}(\mathrm{OAc})\left(\mathrm{PR}_{3}\right)_{\mathrm{n}}\right]^{-}$to make the palladium more nucleophilic.

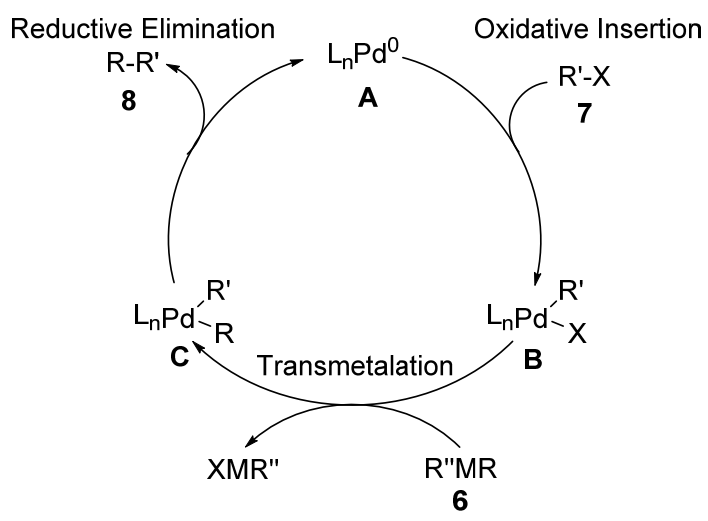

Figure 2. General mechanism for Pd-catalyzed cross-coupling reaction

\subsubsection{Application of the traditional Pd-catalyzed cross-coupling reaction to the synthesis of C-5 modified pyrimidine nucleosides}

Since the C-5 modified pyrimidine nucleosides possess important biological activities, the synthesis of these pyrimidine nucleosides have been studied in detail. The Pd-catalyzed crosscoupling reactions, which have developed rapidly during the last 40 years, are one of the most important methodologies used for the formation of new carbon-carbon bond. Thus, 5-aryl pyrimidine nucleosides have been directly synthesized by: i) aromatic photo-substitution of 5iodouracil nucleoside with poly substituted arenes or vice versa, ${ }^{49-51}$ ii) Pd-catalyzed coupling reaction employing 5-chloromercuripyrimidine nucleoside, ${ }^{51,52}$ or iii) Pd-catalyzed coupling reaction of 5-halopyrimidine nucleosides with organometallic, e.g., organolithium and organozinc compounds, which are required to be freshly prepared, ${ }^{49}$ as well as organotin, organosilican and

organoboron. ${ }^{12,30,37,53-60}$ The synthesis of numerous 5-substituted pyrimidine nucleosides via Pdassisted routes have been reviewed. ${ }^{12}$

\section{$\underline{\text { Heck Coupling }}$}

The Heck reaction ${ }^{47}$ can build the $\mathrm{C}-\mathrm{C}$ bond by coupling of an unsaturated halide (or triflate) with an alkene in the presence of base and palladium catalyst. It could also be employed to 
synthesize the C-5 substituted pyrimidine nucleosides. ${ }^{61}$ Trans-3-(5-uridylyl)propenoate (10), which is an important precursor of BVDU, was first synthesized by Bergstrom ${ }^{62}$ with 5chloromercuriuridine and methyl acrylate in the presence of $\mathrm{Li}_{2} \mathrm{PdCl}_{4}$ in methanol. Later on, in order to eliminate the toxic mercury, Bergstrom ${ }^{56}$ employed the improved Heck condition ${ }^{63}$ to synthesize compound $\mathbf{1 0}$ in 53\% with 5-iodo-2'-deoxyuridine 9. (E)-5-(2-Bromoethenyl)-2deoxyuridine 11, one of the most potent anti-herpes simplex virus (HSV) drug, was obtained from 10 by basic hydrolysis followed by decarboxylation and bromination at $60{ }^{\circ} \mathrm{C}$ with $\mathrm{NBS}^{64}$ (Scheme 2).

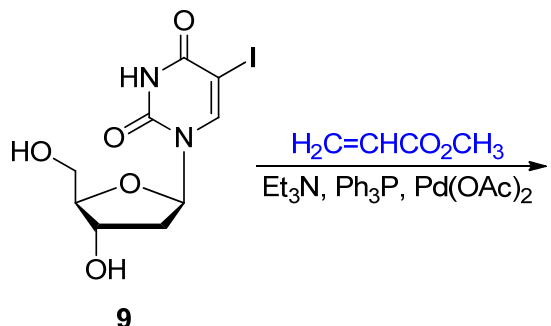

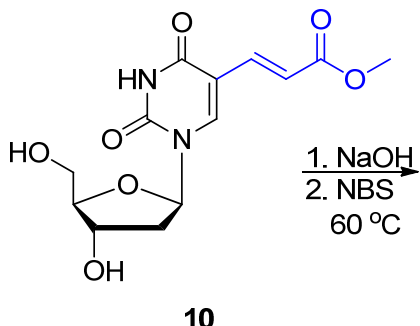

10

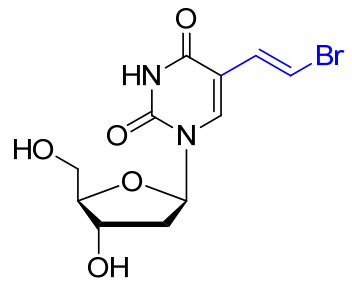

11

Scheme 2. Synthesis of C-5 modified pyrimidine nucleosides via Heck reaction

\section{Sonogashira Coupling}

Sonogashira coupling ${ }^{65}$ is a useful tool to synthesize the alkynyl aryl or vinyl derivatives by the reaction of terminal alkynes with aryl or vinyl halides in the presence of Pd catalyst and copper(I) co-catalyst under the amine condition. Even though both 5-alkynyl- and 5-ethynyl- 2'deoxyuridines have been studied as potent inhibitor of HSV-1, HSV-2, and vaccinia virus (VV), the biological activity is too low to be considered as good antiviral agents. ${ }^{22,66}$ The 5 -alkynyl pyrimidine nucleosides $\mathbf{1 3}$ could be synthesized by the Sonogashira reaction of 5-iodo-2'deoxyuridine 9 with several of terminal alkynes. ${ }^{30,67}$

Further treatment of $\mathbf{1 3}$ with $\mathrm{CuI}$ and $\mathrm{Et}_{3} \mathrm{~N} / \mathrm{MeOH}$ at reflux condition gave the bicyclic furanopyrimidine derivative 12. Surprisingly, the parent bicyclic furanopyrimidine compound 12a does not possess activity either against HSV-1, HSV-2, cytomegalovirus (CMV), or varicella zoster virus (VZV) ${ }^{68}$ However, the long chain bicyclic analogues display surprising and unique 
biological profiles, especially for $\mathbf{1 2 b}$ bearing $n$-octyl group which is more active against VZV than the reference compound acyclovir. ${ }^{67}$ When $\mathrm{R}=\mathrm{TMS}$, desilylation of $\mathbf{1 3}$ with TBAF at $0{ }^{\circ} \mathrm{C}$ gave 5-ethynyl pyrimidine analogue, which could be converted to $\mathbf{1 1}$ by the selective hydrogenation (Scheme 3). ${ }^{30}$

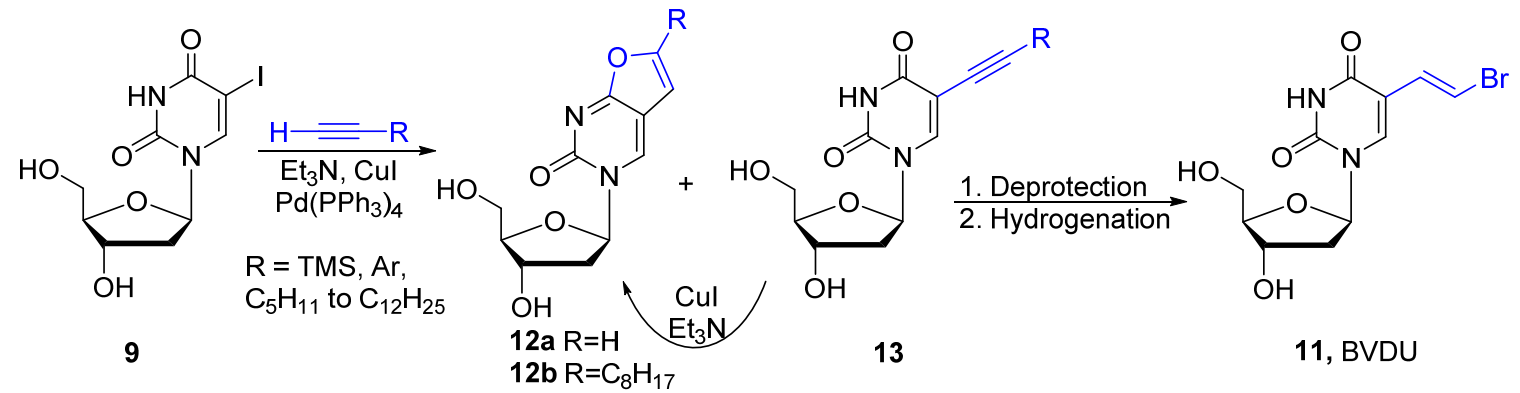

Scheme 3. Synthesis of C-5 modified pyrimidine nucleosides via Sonogashira reaction

\section{Suzuki Coupling}

The Suzuki reaction which couples organoboronic acid and aryl halides in the presence of palladium under basic conditions is another useful tool to build the carbon-carbon bond. ${ }^{69-71} 5$ aryl pyrimidine nucleoside derivatives $\mathbf{1 5}$ could be obtained from the reaction of protected 5-iodo pyrimidine substrates 14 with organoboronic acid (Scheme 4). ${ }^{17,37,54}$

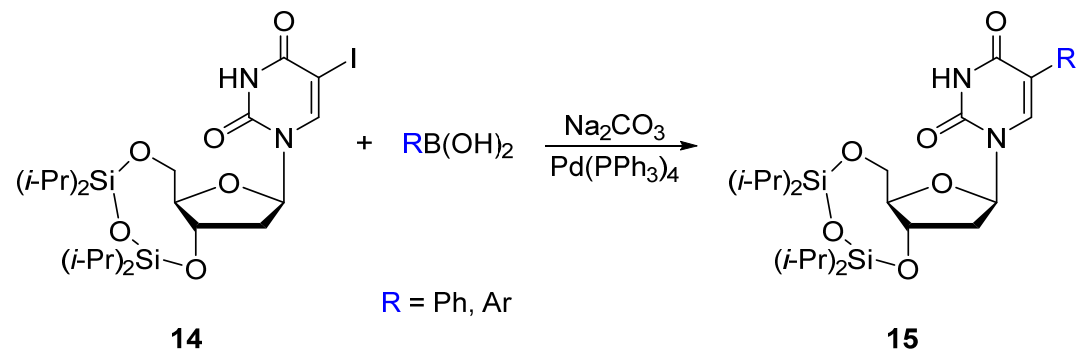

Scheme 4. Synthesis of C-5 modified pyrimidine nucleosides via Suzuki reaction

\section{Hiyama Coupling}

Hiyama reaction ${ }^{72,73}$ is $\mathrm{Pd}$ catalyzed cross-coupling reaction of organosilanes with organic halides, which is promoted by fluoride ion. ${ }^{74-76}$ The organofluorosilanes could be used as the starting material directly or generated in vivo. C-5 Vinyl modified pyrimidine nucleoside 
analogues 16 and 17 could be synthesized by the reaction of 5-iodo pyrimidine substrate 9 with fluorovinylsilane ${ }^{77}$ in the presence of TBAF at $60{ }^{\circ} \mathrm{C}$ (Scheme 5).

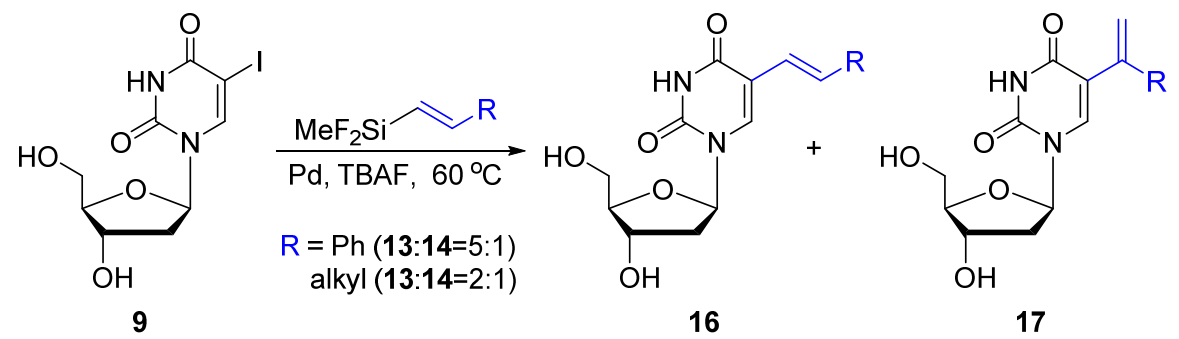

Scheme 5. Synthesis of C-5 modified pyrimidine nucleosides via Hiyama reaction

\section{$\underline{\text { Stille Coupling }}$}

Stille reaction, ${ }^{78,79}$ which involves the coupling of an organotin compound with organic halides or triflates via Pd-catalyzed coupling reaction, is another powerful tool to synthesize the C-5 modified pyrimidine nucleoside derivatives. It could tolerate different type of functional groups existed in the substrates. And various organotin reagents have been utilized for the synthesis of 5-substituted pyrimidine nucleosides 19 (Scheme 6). ${ }^{57}$

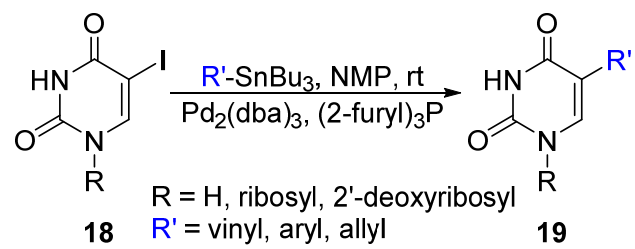

Scheme 6. Synthesis of C-5 modified pyrimidine nucleosides via Stille reaction

\subsubsection{Direct activation and its application in Pd-catalyzed cross-coupling reactions}

With the research in progress, the Pd-catalyzed coupling-reactions can also occur with only one activated substrate under certain conditions (single $\mathrm{C}-\mathrm{H}$ functionalization); sometimes activation was not required at all (double $\mathrm{C}-\mathrm{H}$ activation).

Direct arylation of aromatic rings with aryl halides or pseudo halides, which eliminate the usage of organometallic substrates, has been recently established as excellent protocols for the synthesis of biaryls and begun to compete with traditional Pd-catalyzed cross-couplings. ${ }^{80-85}$ It has been noted that both intra- ${ }^{86-88}$ or intermolecularly ${ }^{87,89-95}$ direct arylations can proceed 
smoothly, especially with electron-rich heteroaromatics. ${ }^{83}$ One of the advantages is that either organic halides or organometallic reagents can be substituted by simple arenes as partners in cross-coupling processes. Such approaches are more atom efficiency in terms of sustainable chemistry. Extensive investigations have been made to improve our understanding of how the transition metals catalyze the cleavage and functionalization of the inert $\mathrm{C}-\mathrm{H}$ bonds effectively. Since Pd is one of the most commonly used transition metal catalyst for the C-H functionalization, I will focus my dissertation on the Pd-catalyzed C-H functionalization.

\subsubsection{Single $\mathrm{C}-\mathrm{H}$ functionalzation via Pd-catalyzed cross-coupling reactions}

As discussed above the 5-arylated pyrimidine nucleoside could be synthesized by the traditional Pd-catalyzed cross coupling reactions in good yield under the mild condition; however, multistep preparation of pre-activated organometallic substrates is required. Coupling products with toxic organotin residues might be a problem for biological studies as well. Thus, the $\mathrm{C}-\mathrm{H}$ direct arylation of the pyrimidine nucleosides have been developed as an alternative method to avoid such problems.

\subsection{Direct arylation at C5/C6 position of uracil nucleosides}

Kim and coworkers reported that the coupling of 1,3-dimethyluracil 20 with electron rich aryl bromides 21 in the presence of $\mathrm{Pd}(\mathrm{OAc})_{2}$ and $\mathrm{Cs}_{2} \mathrm{CO}_{3}$ at $130{ }^{\circ} \mathrm{C}$ for $12 \mathrm{~h}$ gave 1,3-dimethyl-5aryluracil 22 in decent yield (35-79\%) along with C6-arylated regioisomer $\mathbf{2 3}$ in 0-25\% (Scheme 7). ${ }^{96}$ It's the typical selectivity problem observed during the $\mathrm{C}-\mathrm{H}$ functionalization of uracil base. Moreover, when 1-(tetrahydrofuran-2-yl)-3-benzyluracil was employed as the substrate to mimic the glycosidic bond of the nucleoside, the sever decomposition was observed under the regular coupling condition. Lowering the reaction temperature allowed the isolation of the corresponding product in $55 \%$ with $\mathrm{N} 3$ protecting group. 


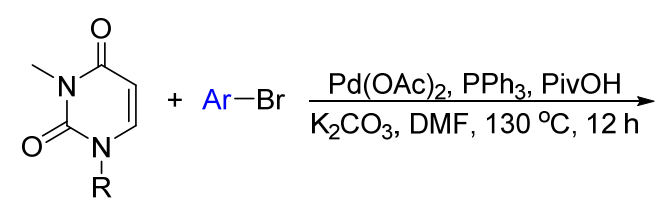

20

21

$\mathrm{R}=$ methyl, tetrahydrofuran-2-yl

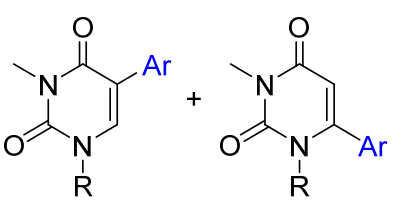

22

23

\section{Scheme 7. Direct C-H arylation of uracil analogues with aryl bromide}

Hocek and his group found that the 1,3-protected uracil analogues 20 could couple with aryl iodine in the presence of Pd catalyst and cesium carbonate to give the 5-arylated uracil analogues 22, but with even higher temperature $\left(160{ }^{\circ} \mathrm{C}\right)$ and longer time $(48 \mathrm{~h})$ (Scheme 8)..$^{68,69}$ Interestingly, when the reaction was carried out with addition of $\mathrm{CuI}$ as the co-catalyst, the $\mathrm{C} 6$ arylated product $\mathbf{2 3}$ was obtained as the major isomer but in low yield. If the reaction was carried out without Pd catalyst, $\mathbf{2 3}$ was observed as the only product.

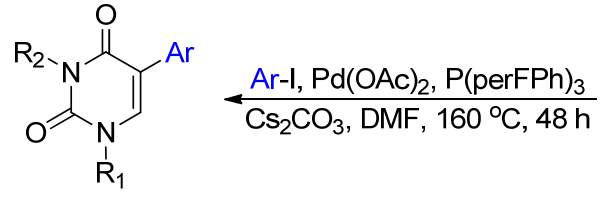

22<smiles>[R]n1ccc(=O)n([R2])c1=O</smiles>

20

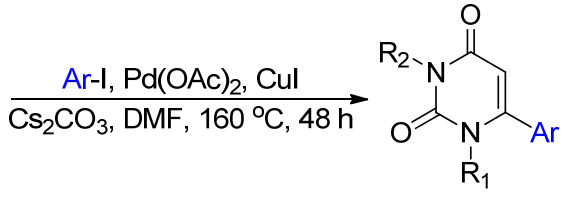

23

\section{Scheme 8. Catalyst controlled single $\mathrm{C}-\mathrm{H}$ functionalization of uracil analogues}

To obtain the natural uracil analogues, several of protecting groups (e.g., Bn, PMB) need to be installed at $\mathrm{N} 3$ position of $\mathbf{2 0}$ and later removed under different conditions; some of them were too harsh to give deprotected uracil in good yield. The application of methodology to nucleoside substrates was not discussed at all. It is believed that the coupling precede via concerted metalation deprotonation (CMD) mechanism, while the cupper catalyzed condition might proceed with deprotonation-cupration mechanism.

Instead of coupling to aryl halides, 1,3-protected uracil $\mathbf{2 0}$ could also couple with boronic acid in the presence of $\mathrm{Pd}$ and ligand (1,10-phenanthroline) at $90{ }^{\circ} \mathrm{C}$ for $16 \mathrm{~h}$ to give 6-aryluracil analogues 23 as the exclusive product (Scheme 9). ${ }^{97}$ Interestingly, when the protected uracil analogues $\mathbf{2 0}$ coupled with simple arylboronic acid, 6-arylated products $\mathbf{2 3}$ were obtained in 
moderate yield exclusively, whereas, when the heteroaromatic boronic acids were employed as the activated component, 20 was recovered unchanged. Similar results were obtained when protected uracil analogues were replaced with free uracil or protected uridine analogues. So, this optimized condition shows some limitations that only work for specific substrates.<smiles>[R1]n1ccc(=O)n([R])c1=O</smiles>

20

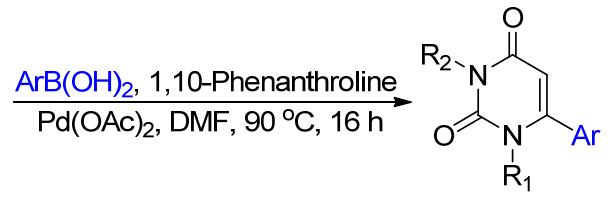

23

Scheme 9. Regioselective C-H arylation of uracil analogues with arylboronic acids

\subsection{Other $\mathrm{C}-\mathrm{H}$ functionalization $\mathrm{C} 5 / \mathrm{C} 6$ position of uracil nucleosides}

Iridium catalyzed $\mathrm{C}-\mathrm{H}$ borylation of $\mathbf{2 0}$ in the presence of ligand at $80{ }^{\circ} \mathrm{C}$ gave unseparable 5borylated uracil intermediates 21 with 5,6-diborylated uracil analogue. Successive electrophilic trifluoromethylation with Togni reagent yielded 5-trifluoromethyluracil 24 in 21\% (Scheme 10). Alternatively, $\mathbf{2 4}$ could also be obtained by the selective C-H trifluoromethylation of $\mathbf{2 0}$ with $\mathrm{NaSO}_{2} \mathrm{CF}_{3}$ in the presence of tert-butyl hydroperoxide. ${ }^{98}$ Another $\mathrm{C}-\mathrm{H}$ direct arylation of $\mathbf{2 4}$ with aryl halide gave various products with $\mathbf{2 0}$ as the major component. C-6 Arylated products $\mathbf{2 3}$ and 25 were only obtained in small quantity due to the instability of the trifluoromethyl group at C-5 position under the basic condition.

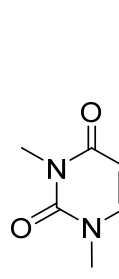

20
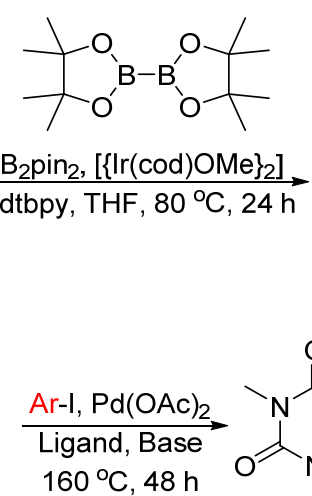

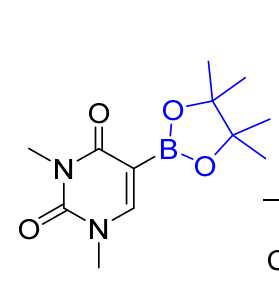

21

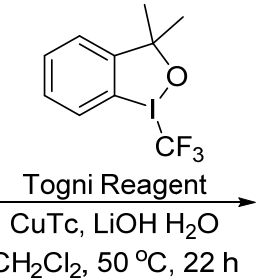

$\mathrm{CH}_{2} \mathrm{Cl}_{2}, 50^{\circ} \mathrm{C}, 22 \mathrm{~h}$

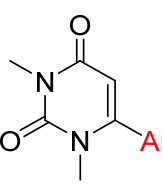

23

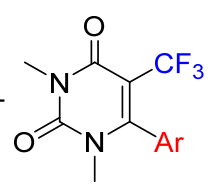

25

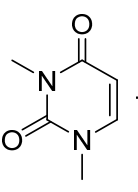

20

Scheme 10. Direct C-H borylation and arylation of 1,3-dimethyluracil 
Selective C-H amination product could be synthesized by the coupling of 1,3-dimethyluracil 20 and 4-bromoaniline in the presence of indolyliodonium tosylate (Scheme 11). ${ }^{99}$ The iodonium salt intermediate $\mathbf{2 5}$ was responsible for the regioselectivity $\left(S_{E} A r\right)$, followed by the amination gave the corresponding product 27 in $65 \%$ yield (Scheme 8).

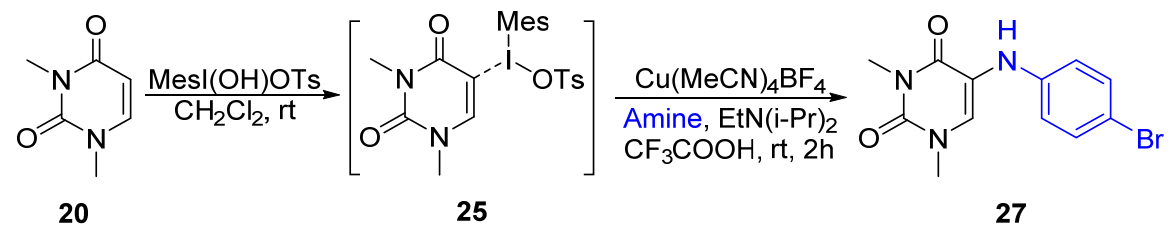

Scheme 11. Direct C-H amination of uracil analogues

\subsubsection{Double C-H functionalization via Pd-catalyzed cross-coupling reactions}

1.3.2.2.1. Direct arylation at C5/C6 position of uracil nucleosides

Double C-H functionalization reactions employ two unfunctionalized components, which could build the $\mathrm{C}-\mathrm{C}$ bond without the pre-activation of any components. Pd-catalyzed crosscoupling of 1,3-dimethyluracil $\mathbf{2 0}$ with arenes $\mathbf{2 8}$ in the presence of pivalic acid and silver acetate under the reflux condition gave 1,3-dimethyl-5-aryluracil 22 as the minor product and 1,3dimethyl-6-aryluracil $\mathbf{2 3}$ as the major product (Scheme 12). ${ }^{96}$ It is believed that reaction went through a concerted metalation-deprotonation $(\mathrm{CMD})$ processes via $\mathrm{Pd}^{\mathrm{II}}(\mathrm{L})(\mathrm{OPiv})$ species by deprotonation of the more acid hydrogen at C6 of uracil ring, followed by another concert metalation-deprotonation to give the 6-arylated uracil product 23. Analogously, the C5-C5' and C5-C6' dimer or even $\mathrm{C} 5-\mathrm{C} 5{ }^{\prime}$ and $\mathrm{C} 6-\mathrm{C} 5{ }^{\prime}$ trimer could be synthesized under the similar condition. $^{100}$

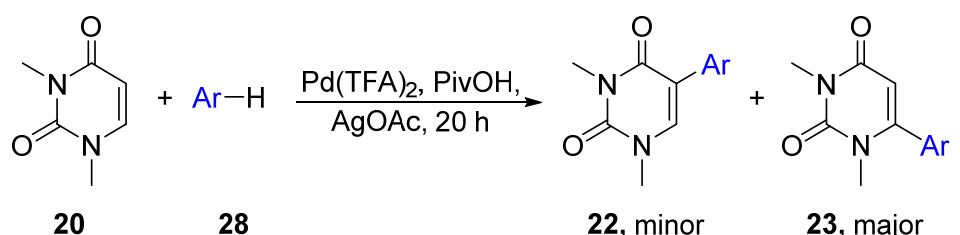

Scheme 12. Pd-Catalyzed double C-H functionalization of 1,3-protected uracil analogue 
The Pd-catalyzed cross-couplings of unfunctionalized uracil analogues $\mathbf{2 0}$ with pyridine- $N$ oxide 29 in presence of $\mathrm{Pd}(\mathrm{OAc})_{2}$ and silver carbonate at $140{ }^{\circ} \mathrm{C}$ for $12 \mathrm{~h}$ gave $\mathrm{C}-5$ modified uracil product $\mathbf{3 0}$ with high regioselectivity and good yield. ${ }^{101} \mathrm{~N}$-oxide analogue $\mathbf{3 0}$ was readily reduced by $\mathrm{PCl}_{3} /$ pyridine to give the pyridine derivative 31 (Scheme 13). Comparing to the traditional Pd-catalyzed coupling reaction, the highly selective double $\mathrm{C}-\mathrm{H}$ functionalization does not need to activate any component of the substrates. It is believed that the electrophilic palladation occurs preferentially at the C-5 position of uracil. Subsequent coordination with pyridine $N$-oxide to give active $\mathrm{Pd}(\mathrm{II})$ complex, followed by the reductive elimination to give coupling product $\mathbf{3 1}$.

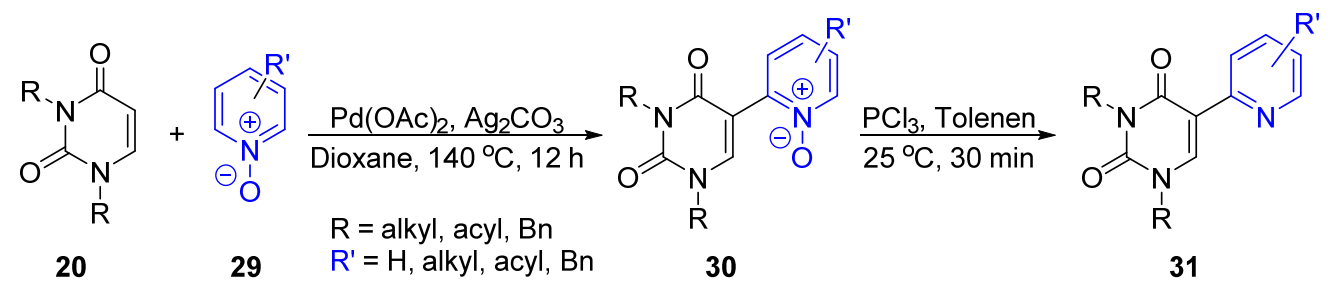

Scheme 13. Synthesis of 2-uracilyl pyridines via Pd-catalyzed double C-H functionalization

\subsection{Other $\mathrm{C}-\mathrm{H}$ functionalization at $\mathrm{C} 5 / \mathrm{C} 6$ position of uracil nucleosides}

Fully protected uracil could undergo the self-C-H functionalization to give a mixture of 5-5', 6-6' or 5-6' dimmers in the presence of Pd(TFA) 2 and AgOAc (Scheme 14). ${ }^{100}$ When the reaction was stirred at $120^{\circ} \mathrm{C}$ for $4 \mathrm{~h}$, the $5-5^{\prime}$ dimmer 32 was the major regioisomer, whereas, when the reaction was stirred at $80^{\circ} \mathrm{C}$ for $16 \mathrm{~h}$, the 5-6' dimmer 33 was the major regioisomer. Interestingly, the reaction of 1,3,5-trimethyluracil or 1,3,6-trimethyluracil did not yield these dimmers under the similar condition. The steric effect of the methyl group either at C5 or C6 position of the uracil base might be responsible for the failure of the reaction. The sugar protected uridine and/or 2'deoxyuridine analogues also underwent these base-dimmer reactions. 


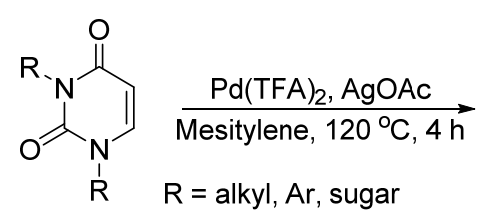

20

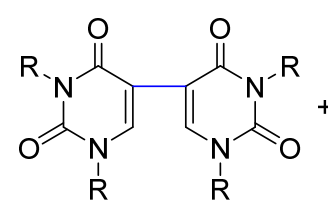

32, 5-5' dimer

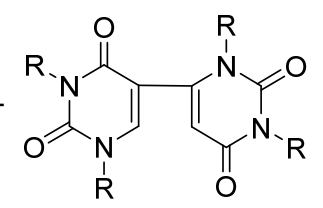

33, 5-6' dimer

Scheme 14. Synthesis of uracil dimmers via Pd-catalyzed double C-H functionalization

The 5-alkenyl substituted uracil or uracil nucleoside derivatives could also be synthesized via the Pd-catalyzed double $\mathrm{C}-\mathrm{H}$ functionalization. ${ }^{102}$ Thus, treatment of 1,3-protected uracil analogues 20 with terminal alkenes 34 in the presence of $\mathrm{Pd}(\mathrm{OAc})_{2}, \mathrm{Ag}_{2} \mathrm{CO}_{3}$ and pivalic acid at $60{ }^{\circ} \mathrm{C}$ gave E-5-alkenyluracil derivatives 35 with excellent region- and stereoselectivity (Scheme 15). However, it is worth to mention that these coupling conditions were only compatible with the fully protected uracil or uracil nucleosides and no examples of unprotected or N1 or N3 protected uracil were given.

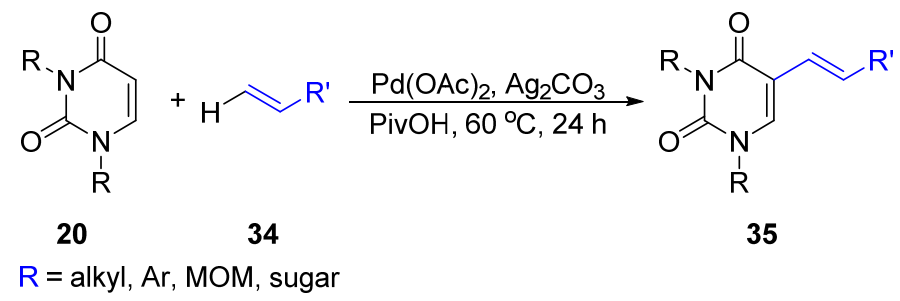

\section{Scheme 15. Synthesis of 5-alkenyl uracil and uracil nucleosides via Pd-catalyzed double C-H activation}

The Pd-catalyzed intermolecular oxidative cross coupling of two different heteroaromatic rings to form the unsymmetrical hetero-biaryls has been reported recently by You. ${ }^{103}$ The methodology has also been applied to the purine analogues. Thus treatment of 1,3-diethyl xanthine $\mathbf{3 6}$ with 2-methylthiophene or furan $\mathbf{3 7}$ in the presence of $\mathrm{Pd}$ and $\mathrm{Cu}$ catalysts gave the bisheteroaromatic products $\mathbf{3 8}$ in excellent yield, which indicated the tolerance of free NH group at imidazole ring at purine skeleton (Scheme 16). Thiophene, furan or other fused electron rich heteroaromatics 37 not only couple with purine analogues but also the pyridine $N$-oxide. Thus, the different electron density between the two heteroaromatic components is believed to be the key point for the reactivity and selectivity in the two metalation ${ }^{104}$ steps of the catalytic circle. 


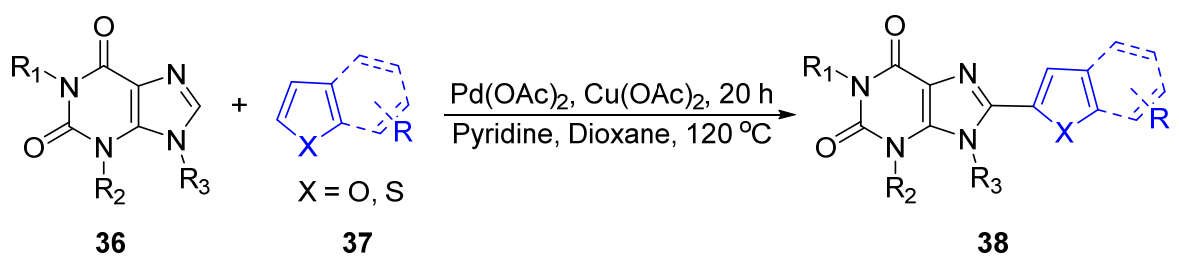

Scheme 16. Substrate controlled intermolecular double C-H functionalization

It has been proposed that the regioselective electrophilic $\mathrm{C}-\mathrm{H}$ substitution $\left(\mathrm{S}_{\mathrm{E}} \mathrm{Ar}\right)$ with $\mathrm{Pd}(\mathrm{OAc})_{2}$ to give $\alpha$-thienylpalladium(II) intermediate A (Figure 3). Followed by the concerted metalation-deprotonation (CMD) process to give the heterocoupling intermediate, which might be the rate determining step. The $\mathrm{Cu}$ salt seems to be crucial for the coupling reaction, since, both catalytic efficiency and regioselectivity were dramatically increased with the addition of substoichiometric amount the copper salt.

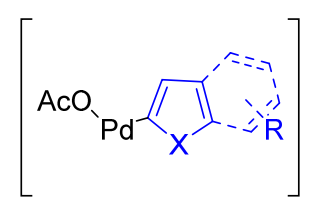

A

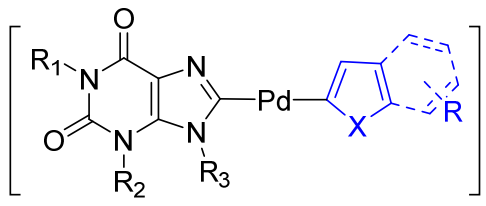

B

Figure 3. Proposed intermediates for the oxidative double $\mathrm{C}-\mathrm{H}$ activation

Multi-fused heteroaromatics $\mathbf{4 0}$ could also be obtained via the intramolecular double $\mathrm{C}-\mathrm{H}$ activation with benzimidazole or purine analogues 39 in the presence of Pd catalyst and silver salt as the oxidant (Scheme 17). ${ }^{105}$ With the addition of iodobenzene, it is possible to construct the seven, eight, or nine member ring bearing two phenyl groups with cooperation of iodobenzene, which is synthetically difficult. However, the double $\mathrm{C}-\mathrm{H}$ activation was performed in the acidic mediates at $110{ }^{\circ} \mathrm{C}$ for $24 \mathrm{~h}$, which will limit the scope of the substrates.<smiles>[R]c1ccccc1-c1ccccc1-c1nc2c(=O)n([R])c(=O)n([R2])c2n1C</smiles>

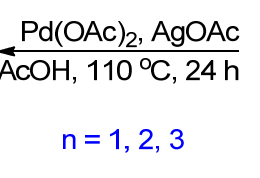

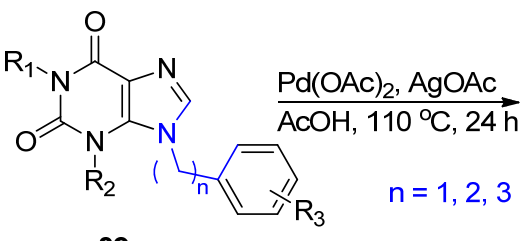

39

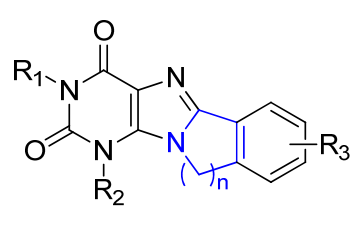

40

Scheme 17. Substrate controlled intramolecular Pd-catalyzed double C-H functionalization 
Catalyst/solvent controlled Pd-catalyzed oxidative heck reaction ${ }^{106}$ omit the need for preactivation of the substrates. According to the reactivity of indole, the palladation and Heck coupling reaction are preferred to take place at the C-3 position. ${ }^{107}$ However the reaction site could be changed by the addition of other additives or solvent via the migration of the C3-Pd-X bond to the C2-position. Treatment of indole 42 with alkene 43 in the presence of $\operatorname{Pd}(\mathrm{OAc})_{2}$ as catalyst at $70{ }^{\circ} \mathrm{C}$ yield two different products under the different oxidants and solvents (Scheme 18). When $\mathrm{Cu}(\mathrm{OAc})_{2}$ was used as the oxidant in a mixture of DMF-DMSO, C3-functionalized product 44 was obtained exclusively. However, when tert-butyl benzyl peroxide was employed as the reoxidizing agent in the mixture of dioxane and $\mathrm{AcOH}$, the $\mathrm{C}-\mathrm{H}$ functionalization was directed to the $\mathrm{C} 2$ position to give 45 . If the $N$-protected indole was used as the substrate, no alkenylation product was observed at either $\mathrm{C} 2$ or $\mathrm{C} 3$ position under the similar condition, indicating the crucial role of the free $\mathrm{NH}$ moiety.

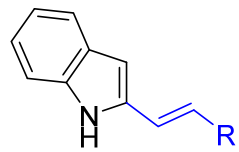

45
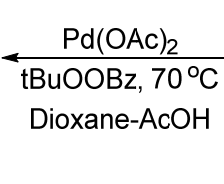

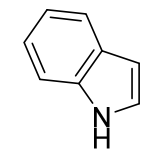

42

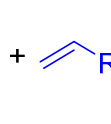

43
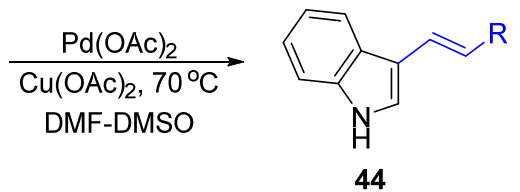

Scheme 18. Catalyst/solvent controlled alkenylation of indole

\subsection{A short overview of the organogermane chemistry}

Even though germanium is located between silicon and tin in the Group IVA in the periodical table, the application of organogermanes to Pd-catalyzed cross couplings has received much less attention comparing to Hiyama (organosilicane) and Stille (organotin) reactions. ${ }^{76,78,108}$ Because of the relative high cost and low reactivity of germanium, both the chemistry and biological activity of organogermanium are still under developed so far.

\subsubsection{Application of organogermanes to Pd-catalyzed cross-coupling reactions}

Even though the chemistry ${ }^{109}$ of organogermanium compounds could not compete with organosilicon or organotin compounds yet, considerable amount work have been done to the Pd 
catalyzed cross-coupling area. Kosugi and coworkers ${ }^{110}$ found that Pd-catalyzed cross-coupling of the carbagermatranes $\mathbf{4 5}$ with aryl bromides $\mathbf{2 1}$ in the presence of ligand yielded corresponding products 47 in excellent yields (Scheme 19). Higher reactivity of the carbagermatrane analogues have been observed toward Stille-type coupling than the corresponding organotributylgermanes.

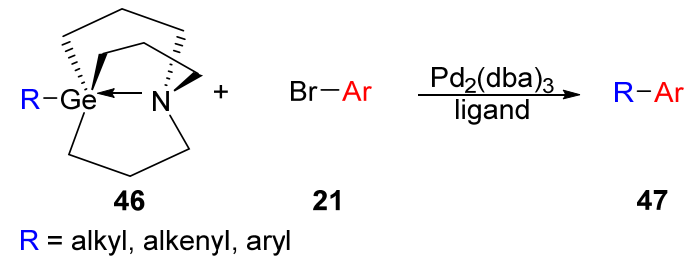

Scheme 19. Pd-catalyzed cross-coupling of germatrane derivatives 46 with aryl bromides

Oshima and coworkers ${ }^{111}$ reported the Pd-catalyzed cross-coupling of tri(2-furyl)germane $\mathbf{2 8}$ with alkenyl or aryl halides in the presence of base to give aryltri(2-furyl)germane 49 which coupled with another aryl halides in the presence TBAF gave various biaryls (Scheme 20). It has found that the heteroaryl-Ge bond of $\mathbf{4 9}$ could be selective cleaved by the TBFA to form $\operatorname{ArGe}(\mathrm{OH})_{3}$ or germanoxanes in situ, which are crucial for the coupling to proceed smoothly. Nucleophilic hypervalent organogermanium species, such as $\left[\mathrm{ArGe}(\mathrm{OH})_{3} \mathrm{~F}\right]^{-}$, was formed by the attack of the excess fluoride ion, followed by the transmetalation and reductive elimination to give biaryls.

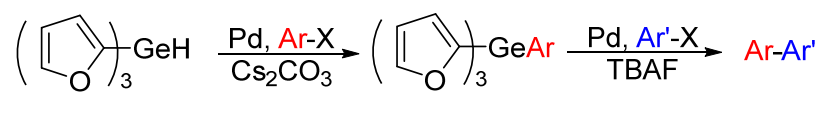

$48 \quad 49$

Scheme 20. Pd-catalyzed cross-coupling of tri(fur-2-yl)german and tri(fur-2-yl)phenylgerman with aryl halides

Wnuk and coworkers ${ }^{112,113}$ noticed that vinyl-Ge(TMS) $)_{3}$ bond of $\mathbf{5 1}$ could be selectively cleaved upon the treatment of hydrogen peroxide under the basic condition $\left(\mathrm{NaOH} / \mathrm{H}_{2} \mathrm{O}_{2}\right)$ or tertbutyl peroxide $(t-\mathrm{BuOOH} / \mathrm{KH})$ by generation of the reactive germanol or germanoxane intermediate. Followed by the Pd-catalyzed cross-couplings with alkenyl or aryl halides in the presence of $\mathrm{Pd}\left(\mathrm{PPh}_{3}\right)_{4}$ gave the corresponding coupling product 52 (Scheme 21). It is worthy to mention that the $E$-isomer of vinylgermane $\mathbf{5 1}$ gave $E$-isomer product only, while Z-isomer of 
vinylgermane 51 gave a mixture of $E / Z$ coupling products. The methodology is also applicable to the $\alpha$-flouro vinylgermane substrates.

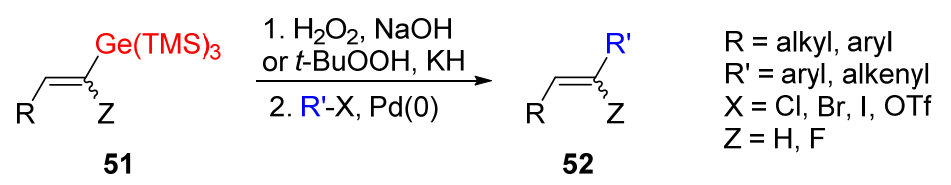

\section{Scheme 21. Synthesis of alkenyl arenes via vinyl tris(trimethylsilyl)germanes}

Spivey and coworkers ${ }^{114,115}$ found that upon irradiation of bis-(2naphthylmethyl)arylgermanes $\mathbf{5 3}$ with light in the presence of $\mathrm{Cu}(\mathrm{BF})_{4}$ gave difluorogermane intermediate 54 by the elimination of 2 equiv. of 2-naphthylmethlene methyl ether. Followed by the Pd-catalyzed cross-coupling reaction of $\mathbf{5 4}$ with aryl bromide in the presence of TBAF gave various biaryls 55 (Scheme 22).

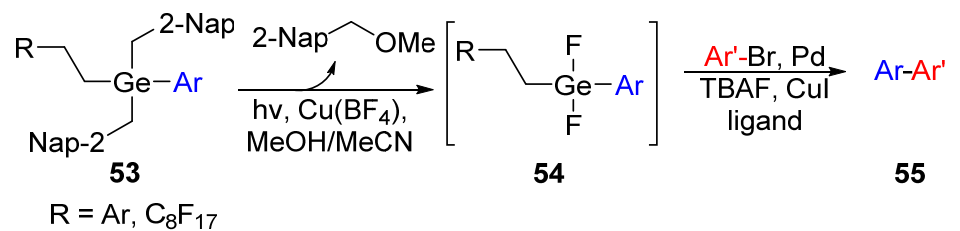

Scheme 22. Photo-induced Pd-catalyzed cross-coupling of bis(2-naphthylmethyl)arylgermens with aryl bromides

Maleczka and coworkers ${ }^{116}$ observed that vinyl-Ge $(\mathrm{Bu})_{3}$ bond of $\mathbf{7 4}$ could be cleaved under the base condition, followed by the Pd catalyzed cross-coupling with phenyl iodine to give corresponding products 75 (Scheme 23). It has been stated that the substituents at the allylic position could affect the regio- and stereoselectivity.

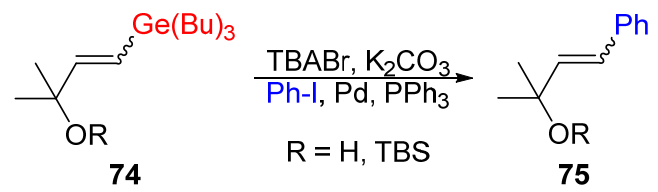

Scheme 23. Pd-catalyzed cross-coupling of tri(butyl)vinylgermanes 74 with iodobenzene

\subsubsection{Biological activity of the germanium containing compounds}

Biological activities ${ }^{12,113}$ of organogermanium compounds have been reviewed and a few biologically active germane-modified nucleoside analogues have been developed. Even though 
germanium is not considered as the essential element for any living organism, but germaniumcontaining heterocyclic compounds are usually less toxic than their carbon and silicon analogues, ${ }^{117}$ so more and more biological test have been done on organogermanium compounds. ${ }^{118}$ Since germanium plays an important role in stimulation of iron consumption and hemoglobin production, dietary germanium supplements became very popular in the 1970s. Later on, the first organogermanium complementary medicine propagermanium (bis(2carboxyethylgermanium) sesquioxide) showed up in Japan under the trade name Serocion in 1994. Nowadays, there are lots of organogermanium compounds have been synthesized which possess antioxidant, ${ }^{119,120}$ antiviral, ${ }^{121}$ anti-tumor, ${ }^{117,122-126}$ anticancer, ${ }^{127-129}$ antiarthritic, ${ }^{130}$ antimalarial and immunoregulatory ${ }^{130}$ activity and radio protective property. ${ }^{131}$

In 1999, Lukevics and coworkers found that triphenylgermylisoxazoline $\mathbf{5 8}$ is a very active antitumor germanium-containing compound (Figure 4). ${ }^{117}$ Spirogermanium $\mathbf{5 9}$ is also another very important germanium-containing compound which has antitumor, ${ }^{125}$ antiarthritic, antimalarial and immunoregulator activity. ${ }^{128,129,131}$

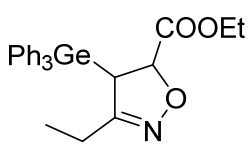

58, Germylisoxazoline (Antitumor)

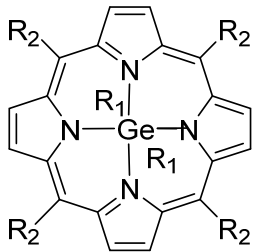

61, MGP (Antitumor) $\mathrm{R}_{1}=\mathrm{Me}, \mathrm{R}_{2}=\mathrm{Ar}$

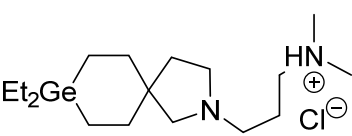

59, Spirogermanium (anti-tumour, anti-malarial)<smiles>[R]n1cc(C(C)C)c(=O)[nH]c1=O</smiles>

62

$\mathrm{R}=\mathrm{H}$, tetrafuranyl 2'-deoxyribosyl

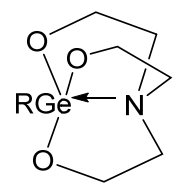

60, Germatrane, (Antitumor) $\mathrm{R}=$ alkyl, (hetero)aryl<smiles>CC(C)c1cn([C@H]2CC(O)C(CO)O2)c(=O)[nH]c1=O</smiles>

63

Figure 4. Biological activities of germanium containing compounds 
Germatrane 60 also shows the antitumor activity, and its toxicity is depending on the substitution groups which are attached to the germanium atom. ${ }^{131,132}$ The antitumor activity of methylgermanium(IV) porphyrin (MGP) 61 was studied by Miyamoto in $1983 .{ }^{122}$ The germanium containing nucleoside analogues also shows promising biological activities. The 5trimethylgermyluracil and 1-(2-tetrahydrofuranyl)-5-trimethylgermyluracil $\mathbf{6 2}$ exhibit cytotoxicity to melanoma B16 cells. ${ }^{133}$ The $\alpha$ and $\beta$ anomer of 2'-deoxy-5-trimethylgermyluridine 63, which is one of the few known examples of germanium-containing nucleoside analogues, display different properties. $\alpha$-anomer could inhibit the replication of HSV-1 in vitro and block incorporation of thymidine and DNA of ovarian cancer cell, while $\beta$-anomer does not work as well as the other isomer. ${ }^{121}$ 


\section{RESEARCH OBJECTIVES}

The research objectives of this dissertation were to develop novel methods for the preparation of 5-modified pyrimidine nucleosides and to explore their possible applications as biochemical probes.

The first objective of this dissertation was to develop a new procedure for the arylation of the uracil nucleosides at C5 via Pd catalyzed cross coupling reaction employing organogermanes as nucleophilic coupling substrates. On the basis of our finding ${ }^{75,134}$ that transfer of phenyl groups from the phenyl(chloro)germanes to the Pd-activated aryl halides is facilitated by the presence of TBAF, I developed the synthesis of 5-aryluracil nucleosides of type 65 by Pd-catalyzed crosscoupling between arylchlorogermanes and 5-halouracil substrates 64 promoted by TBAF (path A, Scheme 24).

Since the traditional Pd-catalyzed cross-coupling reaction involves the usage of organometallic reagents, in the second objective of my dissertation, I developed a novel methodology for the synthesis of 5-arylated uracil nucleosides of type $\mathbf{6 5}$ via Pd catalyzed direct arylation of the 5-halouracil substrates 64 with simple arenes or heteroaromatics, which avoids the use of organometallic nucleophiles (path B, Scheme 24). Optimization of direct arylation using various fluoride bases (e.g., $\mathrm{CsF}, \mathrm{KF}$ or TBAF) or regular bases (e.g., $\mathrm{Cs}_{2} \mathrm{CO}_{3}, \mathrm{~K}_{2} \mathrm{CO}_{3}$ or $\mathrm{NaOH}$ ) promoters as well as mechanistic considerations would be explored.

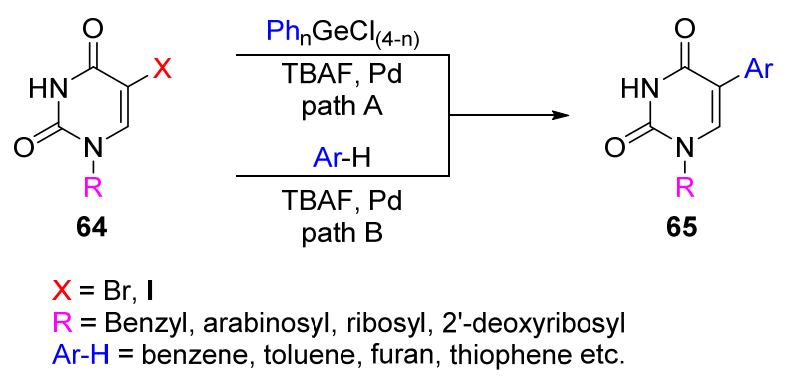

Scheme 24. Proposed synthesis of 5-aryl uracil nucleosides by Pd-catalyzed coupling with organogermanes (path A) or direct arylation (path B) 
Since hydrogermylations of alkyl or arylalkynes usually give vinylgermanes in good yields, and vinyl tris(trimethylsilyl)germanes are known to be good substrates in the Pd-catalyzed crosscoupling reactions with alkenyl/aryl halides, ${ }^{112,113}$ I prepared a series of pyrimidine nucleosides modified at the C-5 position with vinylgermane units. Thus radical hydrogermylation of 5ethynyluracil nucleosides $\mathbf{6 6}$ with alkyl-, aryl- or tris(trimethylsilyl)germane should produce the corresponding 5-modified vinylgermanes 67 (Scheme 25). I investigated the application of the nucleosides for the synthesis of highly conjugated C5 modified pyrimidine nucleoside analogues 68 via the Pd catalyzed cross-coupling (path A, Scheme 25). Halodegermylation of 67 with electrophilic halogens (e.g., NBS, NIS) was explored to develop an alternative synthesis of the important 5-halovinyl pyrimidine nucleosides 69 (path B, Scheme 25).

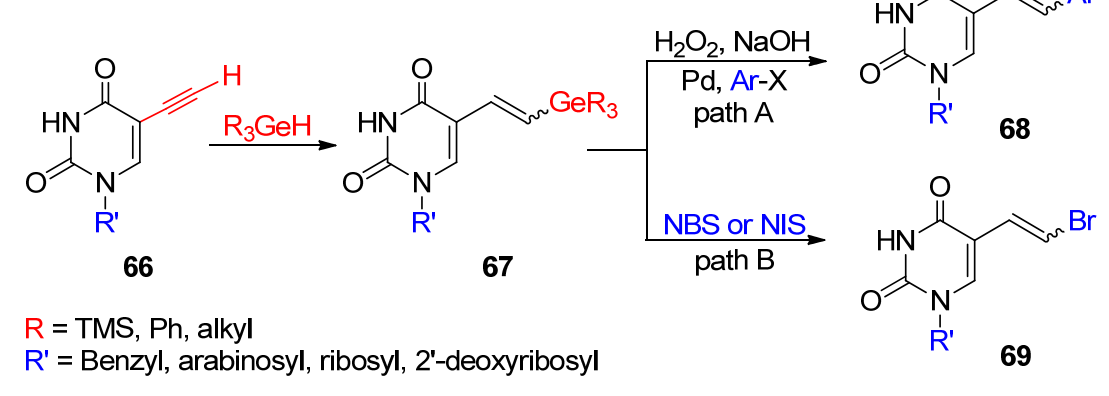

Scheme 25. Proposed synthesis of 5-vinylgermyl uracil nucleosides by hydrogermylation and application to Pdcatalyzed coupling with aryl halides (path A) or halodegermylation (path B)

To further investigate the chemistry of 5-ethynyl pyrimidine nucleosides, I synthesized a series of novel 5-( $\beta$-halo)vinyl sulfonyl analogues 70. Thus, the synthesis of 5 - $(\beta$-halo)vinyl sulfonyl pyrimidine analogues would be explored via Fe(III) mediated regio- and stereoselective hydrosulfonylation of 5-ethynyl analogues $\mathbf{6 6}$ with aryl/alkyl sulfonyl chloride in the presence of triphenylphosphine (path A, Scheme 26). Alternatively, iron halide catalyzed hydrosulfonylation with sulfonylhydrazides in the presence of a catalytic amount of tert-butyl hydroperoxide (TBHP) would also be explored (path B, Scheme 26$)$. Since, the 5-( $\beta$-halo)vinyl sulfonyl analogues 70 can serve as an excellent Michael acceptors, e.g., as electrophiles to form covalent adducts with 
nucleophile. I studied the addition of typical nucleophiles (e.g., propanethiol, $n$-butylamine) and the corresponding model amino acids (e.g., lysine, cysteine) to these novel 5-modified nucleosides. Kinetics and chemical yields of such Michael addition reaction would be "tuned up" by incorporation of electron donating group (EDG) or electron withdrawing group (EWG) on the aromatic ring of the sulfonyl compounds. I expected that the addition of nucleophiles to such Michael acceptors should occur via an addition-elimination reaction with the elimination of halides and formation of the vinyl adducts.

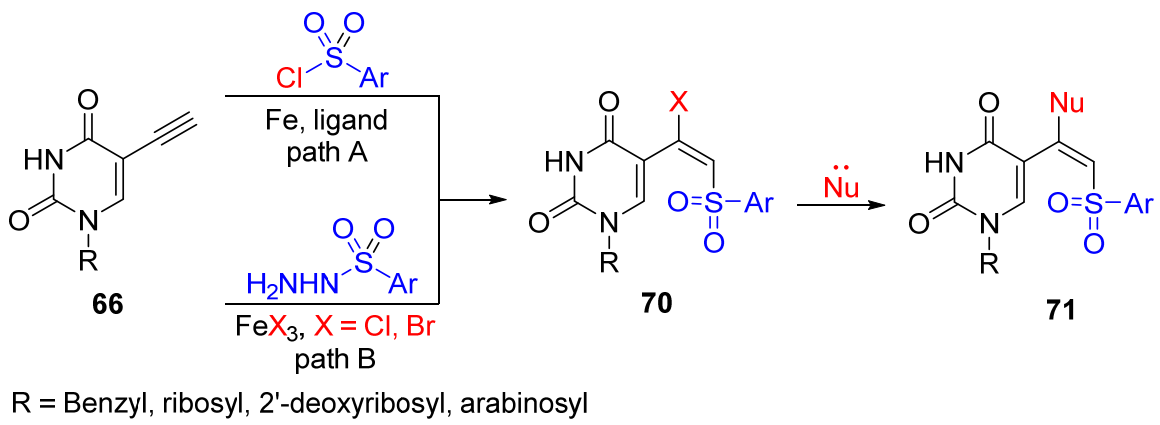

Scheme 26. Proposed synthesis of 5-( $\beta$-halo)vinyl sulfonyl pyrimidine nucleosides by hydrosulfonylation of 63 with sulfonyl chloride (path A) or sulfonyl hydrazide (path B) and its application to the nucleophilic substitution

I expect that direct aerobic difunctionalization of 5-ethynyl nucleoside analogues $\mathbf{6 6}$ with sulfinic acid in the presence of a catalytic amount of pyridine could serve as an access to the 5- $(\beta$ keto)sulfonyl pyrimidine nucleoside analogues 72 (Scheme 27). Since the methylene protons adjacent to ketone and sulfonyl groups are quite acidic with $\mathrm{pKa}$ around 12, it was envisioned that after deprotonation by base, the corresponding carbon ion could be methylated (e.g., MeI or $S$ Adenosyl methionine) or trapped (e.g., proximal protein electrophiles) by electrophiles to give $\mathbf{7 3}$.

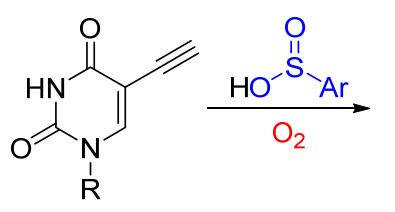

66<smiles></smiles>

72<smiles>[R]n1cc(C(=O)C([CH])S([Z17])(=O)=O)c(=O)[nH]c1=O</smiles>

73

$\mathrm{R}=$ Benzyl, ribosyl, 2'-deoxyribosyl, arabinosyl 
I have also planned to explore the synthesis of 5-( $\alpha$-azido)vinyl pyrimidine nucleosides $\mathbf{4 2}$ via silver-catalyzed hydroazidation of 5-ethynyl substrates 66 (Scheme 28). Since 5-azido uracil analogues are photo labile, and their application to click chemistry is under development, I am planning to utilize these 5-( $\alpha$-azido)vinyl analogues $\mathbf{7 4}$ in copper free click chemistry with the ring strained cyclooctyne to synthesize 5-( $\alpha$-1,2,3-triazol)vinyl pyrimidine nucleosides which could be further incorporated into DNA or RNA as fluorescent probes.

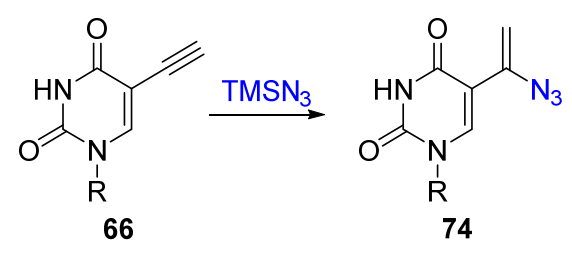

$\mathrm{R}=$ Benzyl, ribosyl, 2'-deoxyribosyl, arabinosyl

Scheme 28. Proposed synthesis of 5-( $\alpha$-azido)vinyl pyrimidine nucleosides by hydroazidation of 63 with $\mathrm{TMSN}_{3}$ 


\section{RESULTS AND DISCUSSION}

\subsection{Synthesis of 5-aryluracil nucleosides via Pd-catalyzed cross coupling reactions}

\subsubsection{Coupling reactions of 5-halouracil nucleosides with chloro(phenyl)germanes}

\subsubsection{Developing a general procedure for transfer of phenyl group(s) from}

chloro(phenyl)germanes to aryl halides mediated by TBAF

Most recently, we have reported the TBAF-promoted synthesis of biaryls via Pd-catalyzed cross coupling of trichloro(phenyl)-, dichloro(diphenyl)-, and chloro(triphenyl)germanes 75-77 with aryl halides in "wet" toluene. ${ }^{75,134-136}$ It has been stated that the presence of chloride was necessary for organogermanes to generate the active fluorophenylgermane intermediate in situ, ${ }^{137}$ which are believed to be the active intermediates in transferring of phenyl groups from Ge atom to Pd-activated aryl halides. Thus coupling of $\mathbf{7 5}$ with 1-iodonaphathalene in the presence of $\mathrm{Pd}_{2}(\mathrm{dba})_{3}$ gave 55 in high yield (Scheme 29). Additional amounts of water have been proven to be necessary for multiple transfers of the phenyl group from the germane center. It has also been shown that the coupling efficiency of arylchlorogermanes is comparable to that of the more developed organotin or organosilane substrates.

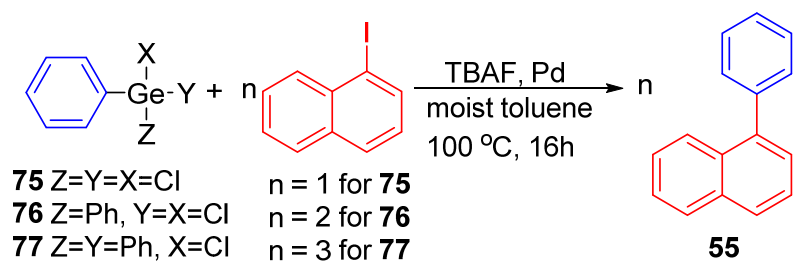

Scheme 29. Synthesis of 1-phenylnaphthalene via chlorophenylgermanes

On the basis of these findings and the available knowledge on the susceptibility of organogermanes toward coupling, it appears that the reaction is promoted either by: (i) intramolecular chelation of a pendant Lewis basic heteroatom which renders the Ge center "permanently" pentavalent ${ }^{110}$ or (ii) coordination of a heteroatom activated Ge center with an external Lewis basic ligand (e.g., fluoride, hydroxide, etc.), which is also rendering the Ge center pentavalent. ${ }^{75,110,115,134}$ Even though the mechanism of fluoride/base activated Pd-catalyzed cross- 
coupling reaction of organogermanes with aryl/alkenyl halides is still unclear, such reactions have been achieved. ${ }^{75,112,113,134,135}$

\subsubsection{Attempted TBAF-promoted coupling of 1-N-benzyl-5-iodouracil with chloro(pehnyl)germanes in toluene}

In order to achieve the first objective of my dissertation, which was synthesis of 5-arylated pyrimidine nucleosides employing 5-halo substrates to couple with organogermanes as the coupling partner, efforts have been taken to develop model coupling between 5-halouracil and chloro(phenyl)germanes, which have been used as the substrates for selective transfer of phenyl groups from the germyl center. ${ }^{75,112,136,138}$ Thus, I applied the optimal coupling condition to 5-halo pyrimidine nucleosides for the synthesis of 5-aryl analogues. Treatment of 1-N-benzyl-5iodouracil 78a with triphenylchlorogermanes 77 in the presence of tetra- $N$-butylammonium fluoride (TBAF, $1 \mathrm{M} / \mathrm{THF}$ containing $5 \%$ of water) and $\mathrm{Pd}_{2}(\mathrm{dba})_{3}$ catalyst in toluene at $100{ }^{\circ} \mathrm{C}$ for 16 h gave 1- $N$-benzyl-3- $N$-butyl-5-phenyluracil 79b as well as the $N^{3}$-butylated reduction product 80a (Scheme 30).

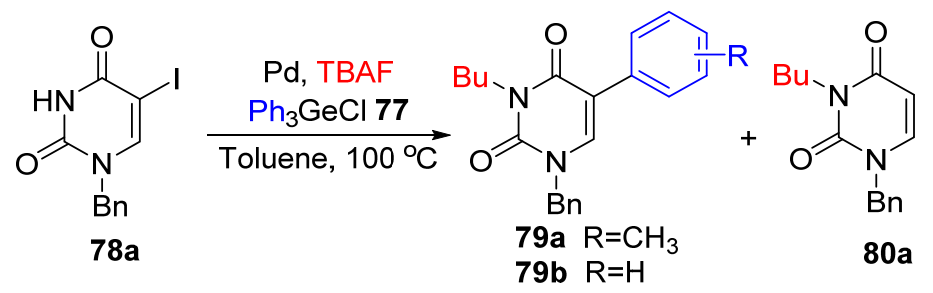

Scheme 30. TBAF promoted cross-coupling of 5-iodouracil with chloro(triphenyl)germane

However, after careful analysis of GC-MS spectra, it was surprising to find that there is a mixture of 1-N-benzyl-3- $N$-butyl-5-(o,m,p-methylphenyl)uracil products 79a which likely derive from the coupling of $\mathbf{7 8 a}$ with toluene. In order to clarify and simplify the reaction, 78a was heated in toluene alone in the presence of TBAF and $\mathrm{Pd}_{2}(\mathrm{dba})_{3}$ at $100{ }^{\circ} \mathrm{C}$ for $18 \mathrm{~h}$. As expected, mixture of 5-(o,m,p-methylphenyl)uracil products 79a was obtained in $75 \%$ (combined yield for 
all three isomers) along with a small amount of $N^{3}$-butylated reduction product 80a. (See Chapter 3.1.3 for detail discussion)

\subsubsection{Coupling reactions of 5-halouracil nucleosides with allyl(phenyl)germanes}

Although the chemistry of allylgermanes is well established, ${ }^{139,140}$ the application of allyl (phenyl)germane to the selective transfer of phenyl groups from a germanyl center by Pdcatalyzed cross-coupling reaction with aryl halides has not been investigated.

\subsubsection{Developing a general procedure for transfer of phenyl group(s) from allyl(phenyl)germanes to aryl halides mediated by $\mathrm{SbF}_{5} / \mathrm{TBAF}$}

\subsubsection{Optimization for selective transfer of phenyl groups from germane center}

On the basis of our experience and literature research, $\mathrm{SbF}_{5}$ was found to be a suitable reagent to selectively cleave Ge-allyl bonds and to generate reactive germanate species for subsequent transmetalation. Treatment of allyl(phenyl)germanes $\mathbf{8 3}$ or $\mathbf{8 2}$ with $\mathrm{SbF}_{5}$ (0.25-0.5 equiv) intercalated in graphite ${ }^{141}$ in toluene $\left(0.5-1 \mathrm{~h}, 50^{\circ} \mathrm{C}\right)$ resulted in disappearance of the germane substrates (TLC, ${ }^{1} \mathrm{HNMR}$ ). In order to demonstrate that the fluoro(phenyl)germanes are the resulting active intermediates, selective deallylation was carried out in benzene- $d_{6}$ at room temperature and $50{ }^{\circ} \mathrm{C}$ side by side (Scheme 31 ).

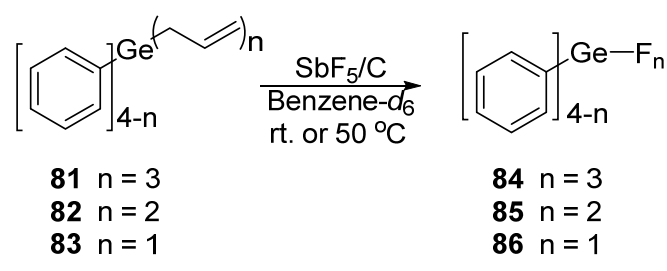

Scheme 31. Selective cleavage the allyl-Ge bond of allylphenylgermanes with $\mathrm{SbF}_{5} / \mathrm{C}$

The progress of the reaction was monitored by TLC, which showed the disappearance of the starting material in $1 \mathrm{~h}$. The ${ }^{19} \mathrm{~F}$ NMR spectra also indicated the formation of fluorogermane intermediates. Reactions with $\mathbf{8 2}$ and $\mathbf{8 3}$ showed the clean formation of the fluorogermanes $\mathrm{Ph}_{3} \mathrm{GeF}$ (s, $\delta$-202.3 ppm; Figure 5; 1 and 2) and $\mathrm{Ph}_{2} \mathrm{GeF}_{2}(2 \times \mathrm{s}, \delta$-165.2, and -167.4 ppm; Figure 5; 3 and 4), respectively, with spectroscopic data in agreement with the reported values. ${ }^{75,115,136}$ 
However, analogous treatment of $\mathbf{8 1}$ with $\mathrm{SbF}_{5}$ gave a cluster of peaks at $\delta-140.2$ to $-159.7 \mathrm{ppm}$ (Figure 5; 5 and 6). It is noteworthy that when $\mathbf{8 1 , 8 2}$, or $\mathbf{8 3}$ was treated with TBAF only under the same condition, no Ge-allyl bond cleavage was observed for any of the substrates.

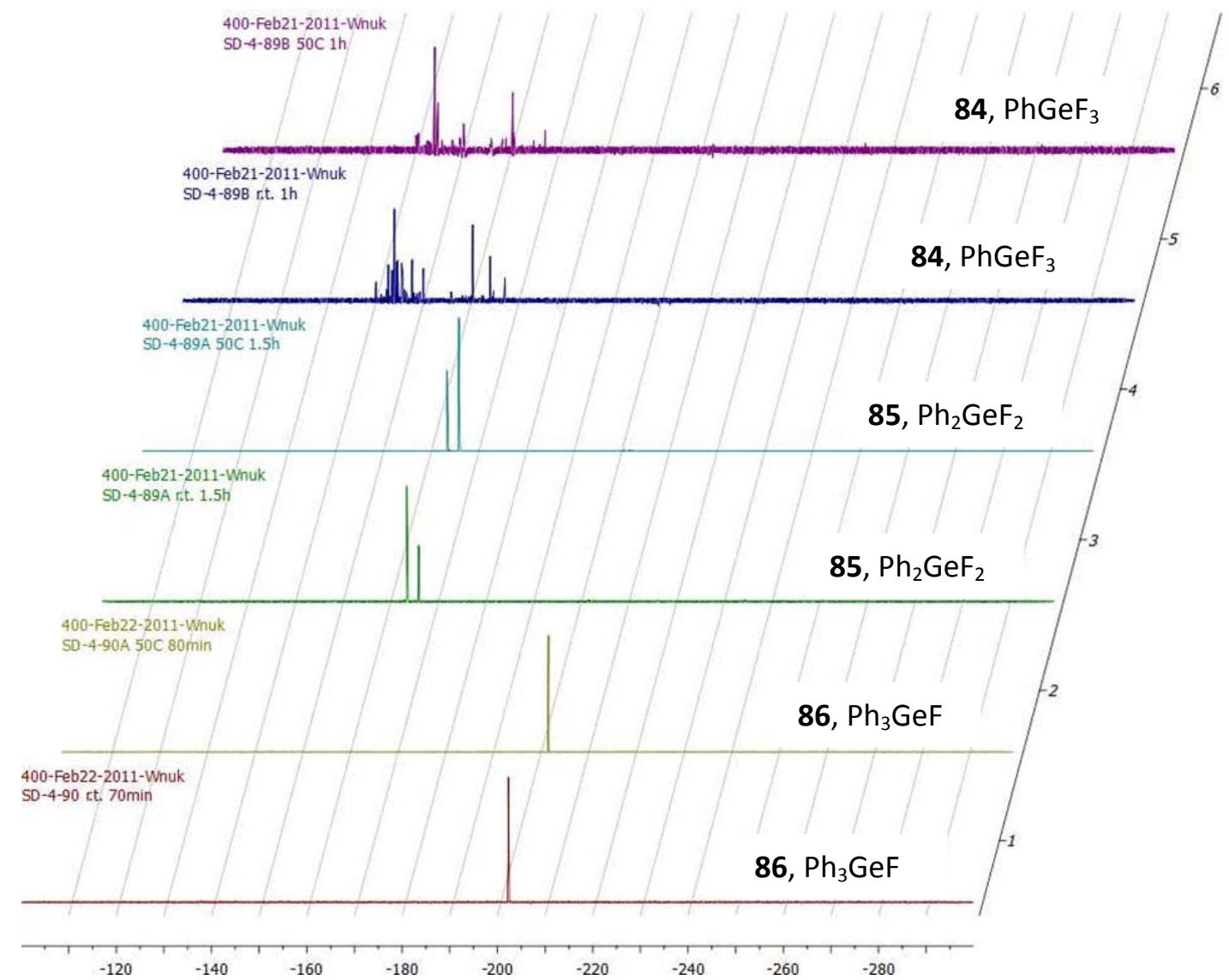

Figure 5. ${ }^{19} \mathrm{~F}$ NMR analysis of the allylgermanes cleavage upon treatment $\mathrm{of} \mathrm{SbF}_{5} / \mathrm{C}$

Optimizations were performed to find the best coupling condition. Thus, treatment of the fluorogermane generated in situ from $\mathbf{8 2} / \mathrm{SbF}_{5}$ with $\mathbf{8 7 b}$ in TBAF/toluene resulted in transfer of phenyl groups from Ge producing biaryl $\mathbf{8 8 b}$ in addition to the homocoupling byproduct $\mathbf{8 9 b}$ (Table 3). Treatment of $\mathbf{8 2}$ with $\mathrm{SbF}_{5} / \mathrm{C}$ alone, as a fluoride source, failed to give coupling product $\mathbf{8 8 b}$. It was found that at least 3 equiv. of TBAF was required to give $\mathbf{8 8 b}$ in maximum yield (Entries 1-5). The yield was increased dramatically when couplings were carried out with addition of a measured amount of water ( 10-30 equiv; Entries 6-8), which was consistent with 
the previous finding. ${ }^{75,134}$ As expected, two phenyl groups were transferred upon the treatment with the combination of $\mathrm{SbF}_{5} / \mathrm{TBAF}$ in moist toluene, which has been shown the TBAF promoted cross-couplings of $\mathrm{Ph}_{2} \mathrm{GeCl}_{2}$ with aryl halides. ${ }^{75,134,136}$ It is worthy to mentioning that the newly developed method here proceeds with the selective cleavage of the allyl-Ge bond of $\mathbf{8 1 - 8 3}$ with $\mathrm{SbF}_{5}$ by generation of fluorogermanes $\mathbf{8 4 - 8 6}$ in situ, which allows transfer of phenyl groups, differs from the previous developed protocol that allow selectively transfer of allyl groups from 81-83 upon treatment with base. ${ }^{135,136}$ Thus transfer of phenyl or allyl groups from a Ge center could be chemoselective, depending on the activation protocol.

Table 3. Coupling of diallyl(diphenyl)germane 82 with 1 -iodonaphthalene $87 \mathrm{~b}$ promoted by $\mathrm{SbF}_{5}$
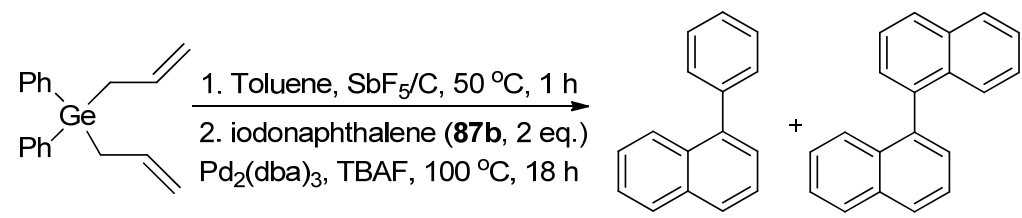

82

88b

89b

\begin{tabular}{ccccc}
\hline Entry & Germane $^{a}$ & TBAF $^{b}$ (equiv.) & Yield (\%) $^{c, d}$ & $\begin{array}{c}\text { Ratio }^{d} \\
\mathbf{8 8 b}: 89 b\end{array}$ \\
\hline 1 & $\mathbf{8 2}$ & 1 & 43 & $4.4: 1$ \\
2 & $\mathbf{8 2}$ & 2 & 53 & $3.9: 1$ \\
3 & $\mathbf{8 2}$ & 3 & $60(54)$ & $3.8: 1$ \\
4 & $\mathbf{8 2}$ & 4 & 47 & $2.0: 1$ \\
5 & $\mathbf{8 2}$ & 5 & 44 & $1.3: 1$ \\
6 & $\mathbf{8 2}$ & $3^{e}$ & $67(59)$ & $5.2: 1$ \\
7 & $\mathbf{8 2}$ & $3^{f}$ & $72(62)$ & $4.5: 1$ \\
8 & $\mathbf{8 2}$ & $3^{g}$ & 68 & $6.1: 1$ \\
\hline
\end{tabular}

\footnotetext{
${ }^{a}$ Couplings were performed on $0.14 \mathrm{mmol}$ scale of germane $82(0.04 \mathrm{M})$ with 2 eqiuv of $\mathbf{8 7 b}$ and 0.05 equiv of Pd catalyst. ${ }^{b}$ Commercial available $1 \mathrm{M}$ THF solution containing $5 \% \mathrm{H}_{2} \mathrm{O} .{ }^{c}$ The yield was calculated based upon transferring of two phenyl groups from 82. Isolated yield in parenthesis. ${ }^{d}$ Based on GC-MS of the crude reaction mixture. ${ }^{e}$ With the addition of $25 \mu \mathrm{L}$ of $\mathrm{H}_{2} \mathrm{O} .{ }^{f}$ With the addition of $50 \mu \mathrm{L} \mathrm{H}_{2} \mathrm{O} .{ }^{g}$ With the addition of $75 \mu \mathrm{L} \mathrm{H}_{2} \mathrm{O}$.
}

\subsection{Extension of the method to other aryl halides}

Various biaryls have been synthesized with the optimal conditions and the results are summarized in table 4. Treatment of $\mathbf{8 1}, \mathbf{8 2}$, or $\mathbf{8 3}$ with $\mathrm{SbF}_{5} / \mathrm{C}$ generated active organofluorogermane intermediates in situ, followed by subsequent TBAF-promoted Pd- 
catalyzed cross-coupling reactions with 1,2 , or 3 equiv. of aryl halides respectively afforded biaryls $\mathbf{8 8 b - 8 8 d}$ in good to excellent yields. Couplings with 1-bromonaphthalene also gave $\mathbf{8 8 b}$, but the yield is lower compared to 1-iodonaphthalene $\mathbf{8 8 b}$. It is worth mentioning that more than one phenyl groups has been transferred during the cross-coupling reaction and aryl halides bearing electron donating groups (entries 2, 5, and 8) gave better yields and ratios compared to the cases with electron withdrawing groups (entries 3, 6 and 9).

Table 4. Coupling of allyl(phenyl)germanes 81-83 with aryl halides promoted by $\mathrm{SbF}_{5}$

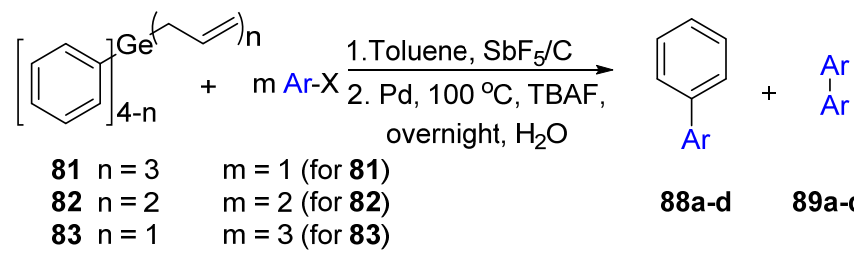

\begin{tabular}{cccccc}
\hline \multirow{2}{*}{ Entry } & Germane $^{a}$ & Halide & Product & $\begin{array}{c}\text { Yield } \\
(\%)^{b}\end{array}$ & $\begin{array}{c}\text { Ratio } \\
\mathbf{8 8 : 8 9}\end{array}$ \\
\hline 1 & $\mathbf{8 1}$ & 1-bromonaphthalene & $\mathbf{8 8 e}$ & 45 & $15: 1$ \\
2 & $\mathbf{8 1}$ & $(4) \mathrm{CH}_{3} \mathrm{OPhI}$ & $\mathbf{8 8 c}$ & 91 & $20: 1$ \\
3 & $\mathbf{8 1}$ & $(4) \mathrm{CF}_{3} \mathrm{PhI}$ & $\mathbf{8 8 d}$ & 49 & $1.9: 1$ \\
4 & $\mathbf{8 2}$ & 1-bromonaphthalene & $\mathbf{8 8 b}$ & 73 & $2.3: 1$ \\
5 & $\mathbf{8 2}$ & $(4) \mathrm{CH}_{3} \mathrm{OPhI}$ & $\mathbf{8 8 c}$ & 95 & $1.8: 1$ \\
6 & $\mathbf{8 2}$ & $(4) \mathrm{CF}_{3} \mathrm{PhI}$ & $\mathbf{8 8 d}$ & 69 & $1: 1$ \\
7 & $\mathbf{8 3}$ & 1-bromonaphthalene & $\mathbf{8 8 b}$ & 46 & $3.3: 1$ \\
8 & $\mathbf{8 3}$ & $(4) \mathrm{CH}_{3} \mathrm{OPhI}$ & $\mathbf{8 8 c}$ & 104 & $1.6: 1$ \\
9 & $\mathbf{8 3}$ & $(4) \mathrm{CF}_{3} \mathrm{PhI}$ & $\mathbf{8 8 d}$ & 75 & $1: 1.5$ \\
\hline
\end{tabular}

${ }^{a}$ Couplings were performed on $0.14 \mathrm{mmol}$ scale of $\mathbf{8 1 - 8 3}(0.04 \mathrm{M})$ with 0.05 equiv of $\mathrm{Pd}_{2}(\mathrm{dba})_{3}$ and 1.0 (for 81), 2.0 (for 82), or 3.0 (for 83) equiv of aryl halides and TBAF/(1M/THF, 3 equiv)/water $(50 \mu \mathrm{L}) .{ }^{b}$ Based upon transferring of one, two, or three phenyl groups from $\mathbf{8 1 , 8 2}$, or 83, respectively. Isolated yield in parenthesis. ${ }^{c}$ Determined by GC-MS of the crude reaction mixture.

\subsection{Proposed mechanism for the selective transfer of phenyl groups from}

\section{allyl(phenyl)germanes}

Contrary to what has been discovered by a previous group member, that allyl could be selectively transferred under basic conditions in the presence of Palladium to give the allylation product, ${ }^{136}$ this methodology allows for the selective transfer of the phenyl group from a Ge center thereby yielding biaryls upon treatment with $\mathrm{SbF}_{5} / \mathrm{C}$ and $\mathrm{TBAF}$ (Scheme 32). Initially, the 
allyl-Ge bond of $\mathbf{8 3}$ was selectively cleaved upon treatment with $\mathrm{SbF}_{5}$ to give fluorophenylgermanes 86 in situ, followed by the treatment of TBAF to yield the active pentafluorogermanate intermediates 90, which were readily coupled with Pd-activated aryl halides B. After the transmetalation and reductive elimination, various biaryls $\mathbf{8 8}$ were obtained and organogermane $\mathbf{D}$ will go to the next circle until there is no phenyl group available.

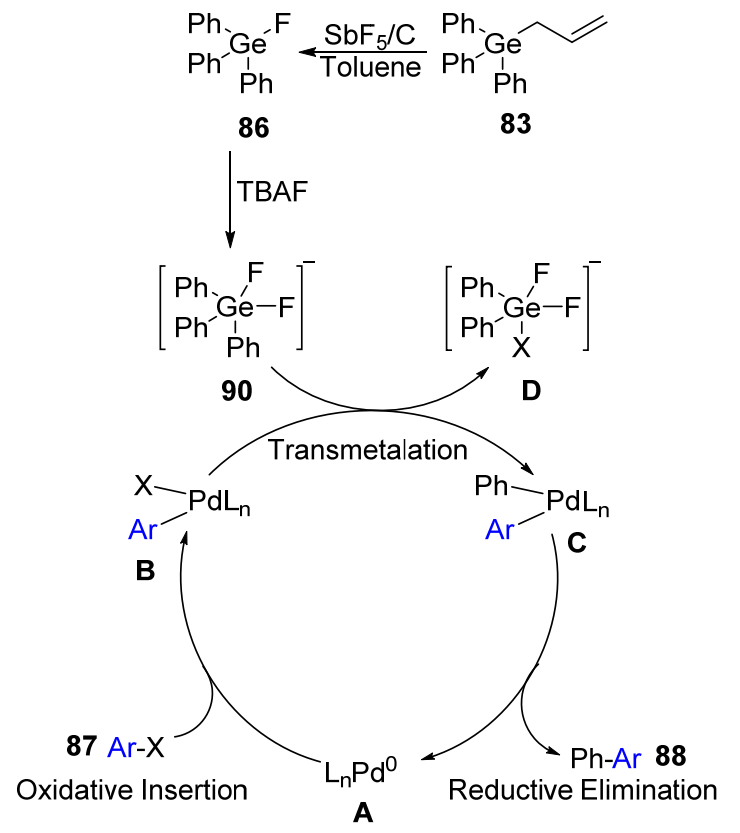

Scheme 32. Proposed mechanism for the $\mathrm{SbF}_{5}$ promoted transfer of phenyl group from Ge center

\subsubsection{Attempted $\mathrm{SbF}_{5} / \mathrm{TBAF}$-promoted coupling of 1-N-benzyl-5-iodouracil with} allyl(pehnyl)germanes in toluene

In order to further explore the synthesis of 5-arylated pyrimidine nucleosides employing 5halouracil substrates in coupling reactions with organogermanes, TBAF-promoted Pd-catalyzed cross-coupling reactions of 5-halouracil have also been applied to allyl(phenyl)germanes 81-83. Thus, treatment of allyl(triphenyl)germane 83 with $\mathrm{SbF}_{5} / \mathrm{C}\left(0.25\right.$ equiv) in toluene at $50{ }^{\circ} \mathrm{C}$ for $1 \mathrm{~h}$ leads to the formation of active fluoro(phenyl)germane species $\mathbf{8 6}$, which was then followed by the vacuum filtration to give a clear solution that was used directly for the next step (Scheme 33). 1-N-benzyl-5-iodouracil 78a, TBAF (1M/THF), and $\operatorname{Pd}_{2}(\mathrm{dba})_{3}$ were added to the crude 
material from the last step at ambient temperature under nitrogen atmosphere and the resulting brownish mixture was stirred at $100{ }^{\circ} \mathrm{C}$ for $18 \mathrm{~h}$. However, no coupling product was observed. Thus, no further studies were performed.

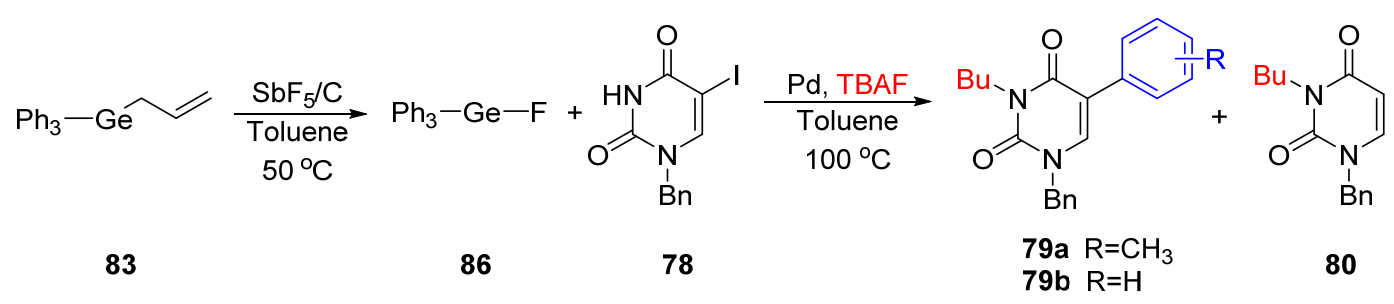

Scheme 33. $\mathrm{SbF}_{5}$ Mediated Pd-catalyzed cross-coupling of 5-iodouracil 78 with allyl(triphenyl)germane 83

\subsubsection{Direct arylation of 5-halouracils and 5-halouracil nucleosides with arenes and heteroarenes}

Intrigued by the unexpected result and after reviewing the literature, it was found that direct arylation of the 3-N unprotected uracil analogues has not been reported. The currently available methods for direct 5-arylation of the uracil analogues were noted to be either not suitable for the natural (3-N-unsubstituted) uracils $^{142}$ or caused cleavage of the nucleoside glycosidic bond. ${ }^{96}$ Because of the importance of the enolization between the 4-oxo group and the hydrogen at the 3-N position in the biology and chemistry of RNA/DNA, as well as in nucleoside-derived drug metabolism, it was deemed of interest to explore the direct arylation of 5-halopyrimidine nucleosides with arenes, which would supplement the well-established Suzuki and Stille approaches.

\subsubsection{TBAF-Promoted Pd-catalyzed direct arylation of 5-halouracil}

To continue with the previous funding (Scheme 30 in Chapter 3.1.1.2), the authentic samples of $\boldsymbol{m - 7 9 b}, \boldsymbol{o}-79 \mathrm{~b}$ and $\boldsymbol{p}-\mathbf{7 9 b}$ were synthesized via Suzuki coupling ${ }^{54}$ to elucidate the ratio of the three isomers. By comparing the retention time of each authetic isomer via $\mathrm{GC}$ and spiking the reaction mixture with the authentic sample, the ratio of ortho/meta/para was established as $3: 2: 1$. 
In order to eliminate the $N^{3}$-butylation during the coupling, the reaction was terminated after $6 \mathrm{~h}$.

However, besides an isomeric mixture of 79a, both $N^{3}$-butylated byproducts $\mathbf{8 0 a}$ and the reduced substrate 92 were also detected as byproducts in the crude reaction mixture (Table 5, entry 1).

Table 5. Effect of the reaction parameters in the direct arylation of 1- $N$-benzyl-5-iodouracil 1a with toluene

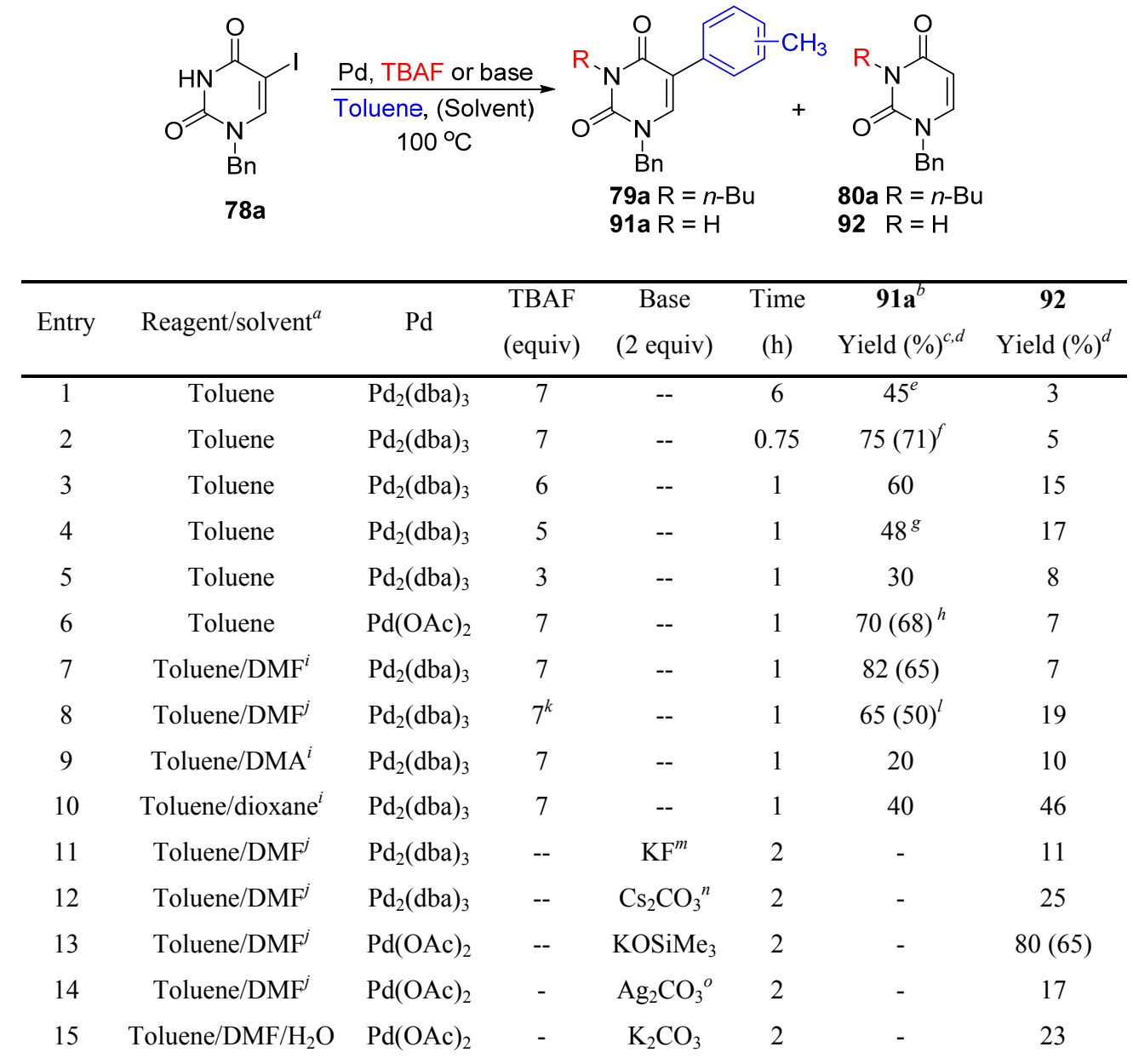

${ }^{a}$ Couplings were performed on $0.14 \mathrm{mmol}$ scale of 78a [0.05 M (entries 1-10) or $0.07 \mathrm{M}$ (entries 11-18)] with 0.05 equiv. of Pd catalyst. ${ }^{b}$ Mixture of $o / m / p$ isomers (3:2:1, GC-MS). ${ }^{c}$ Overall yield for $o / m / p$ isomers. ${ }^{d}$ Determined by GC-MS of the crude reaction mixture. Isolated yield in parenthesis. ${ }^{e}$ Also 80a (35\%) was formed. Longer reaction time $(18 \mathrm{~h})$ produced $79 \mathrm{a}$ in $85 \%$ yield (75\% isolated yield as mixture of $o / m / p$ isomers; $3.4: 2.3: 1) .{ }^{f} 70 \%$ yield at 90 ${ }^{\circ} \mathrm{C}$ for $1.5 \mathrm{~h} .40 \%$ yield at $80{ }^{\circ} \mathrm{C}$ for $4 \mathrm{~h} .{ }^{g} 35 \%$ with 4 equiv. of TBAF. ${ }^{h} 69 \%$ yield at $90{ }^{\circ} \mathrm{C}$ for $1.5 \mathrm{~h} .{ }^{i} 1: 1$ (v/v). ${ }^{j} 1: 9$ (v/v). ${ }^{k}$ When neat TBAF· $3 \mathrm{H}_{2} \mathrm{O}$ (7 equiv.) was used 91a (67\%) and $92(20 \%)$ were produced. ${ }^{l} 25 \%$ yield in 1:20 (v/v; toluene/DMF). ${ }^{m}$ Reaction with CsF also did not yield 91a. ${ }^{n}$ Attempts with different equivalents of bases (0.5-4.0) or prolonged reaction time $(4 \mathrm{~h})$ were also unsuccessful. ${ }^{\circ}$ Couplings also did not proceed in the presence of $\mathrm{Cs}_{2} \mathrm{CO}_{3}$ or AgOAc and their combination with pivalic acid.

After careful investigation of reaction time and temperature, it is found that the direct arylation of 78a can be completed in less than one hour $(45 \mathrm{~min})$ at $100{ }^{\circ} \mathrm{C}$ (entry 2). It is worth 
noting that no $N^{3}$-butylation was not observed (GC-MS) until $1.5 \mathrm{~h}$ at $100{ }^{\circ} \mathrm{C}$. Experimental data also showed that the amount of TBAF is crucial for the coupling to proceed smoothly and at least 7 equiv. of TBAF was required to give 91a in highest yield and with the best 91 a to 92 ratios (entries 2-5). $\mathrm{Pd}_{2}(\mathrm{dba})_{3}$ was the best catalyst but $\mathrm{Pd}(\mathrm{OAc})_{2}$ also gave 91a in similar yields compared to other tested Pd catalysts (entry 6). In order to increase the coupling efficiency and lower the ratio of toluene to $\mathbf{7 8 a}$, an inert solvent was sought, which is suitable for the direct arylation. Thus, the direct arylation was performed in 1:1 and 1:9 (v/v) mixture of toluene/DMF to give coupling product $91 \mathrm{a}$ in $82 \%$ and $65 \%$ respectively (entries 7 and 8). Replacement of the TBAF/THF solution with the same amount of neat TBAF $3 \mathrm{H}_{2} \mathrm{O}$ also gave 91a with similar yield (entry 8, footnote $\mathrm{k}$ ). It is noteworthy that each of these fluoride reagents introduced approximately the same amount of water to the reaction mixture and water is known to play multiple roles in enhancing the efficiency of the couplings including the formation of the reactive hydroxypalladium intermediates. ${ }^{75,136,143,144}$ Arylation of 78a with toluene in DMA and dioxane $(1: 1, \mathrm{v} / \mathrm{v})$ also gave 91a but in lower yields (entries 9 and 10), whereas, arylation was not successful in mixtures of toluene/THF $(1: 1 ; \mathrm{v} / \mathrm{v})$ at reflux, which is probably due to the much lower reaction temperature. Coupling of $\mathbf{7 8 a}$ with toluene in the presence of either of the fluoride sources, e.g., $\mathrm{CsF}$ or KF (2 equiv.), or bases, e.g., $\mathrm{Cs}_{2} \mathrm{CO}_{3}, \mathrm{Ag}_{2} \mathrm{CO}_{3}, \mathrm{~K}_{2} \mathrm{CO}_{3}$, or $\mathrm{KOSiMe}_{3}$, instead of TBAF, did not yield 91a (entries 11-15). No improvement was observed either by varying the amount or combination of bases, Pd catalysts, and reaction times (entry 12) or by addition of pivalic acid (entry 14). Even though $\mathrm{DMF} / \mathrm{H}_{2} \mathrm{O}(5: 1, \mathrm{v} / \mathrm{v})$ was tried as the medium to improve the solubility of inorganic salts, the arylation was still not successful (entry 15).

Determination of the generality of the TBAF-promoted direct arylation in couplings of 5halouracils 78a or $\mathbf{7 8 b}$ with various arenes and heteroaromatics is presented in Table 6 . Thus, treatment of 5-iodouracil 78a with benzene in DMF in the presence of TBAF (7 equiv.) at $100{ }^{\circ} \mathrm{C}$ for $1 \mathrm{~h}$ gave 5-phenyluracil $\mathbf{9 1 b}$ in $71 \%$ as a single product in addition to a small amount of the 
reduced substrate 92 (Table 6, entry 1). Arylation of 78a with $m$-xylene gave a mixture of the three regioisomers (88\%) from which the 2,4-dimethylphenyl isomer 91c was isolated in 55\% yield (entry 2).

Table 6. Direct arylation of 5-halouracils 78 with and electron-rich arenes and heteroaromatics

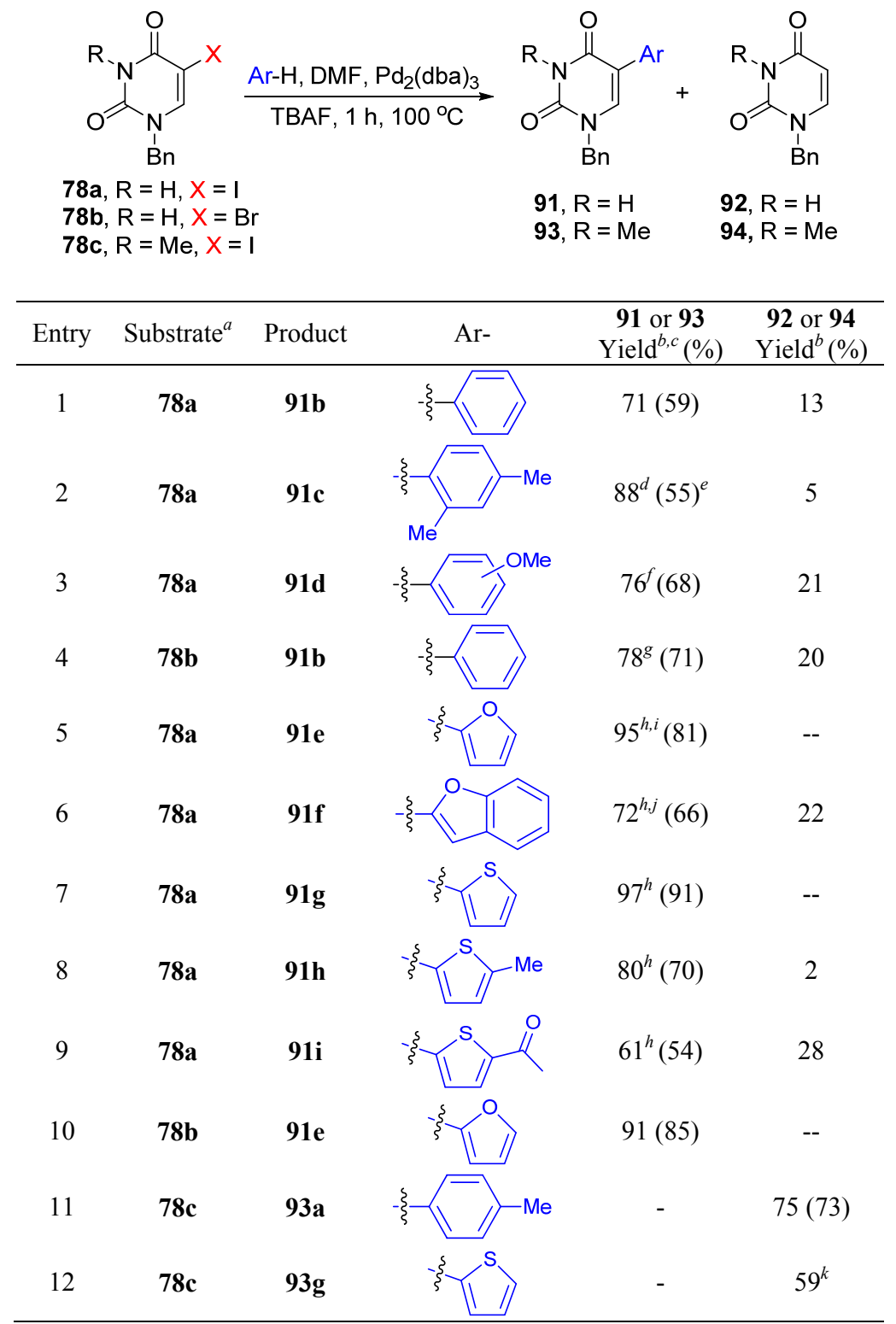

${ }^{a}$ Couplings were performed on $0.14 \mathrm{mmol}$ scale of $78(0.07 \mathrm{M})$ in the presence of 0.05 equiv. of Pd and 7 equiv. of TBAF unless otherwise noted. ${ }^{b}$ Determined by GC-MS of the crude reaction mixture. ${ }^{c}$ Isolated yield in parenthesis. ${ }^{d}$ Overall yield for three possible isomers (ratio, 14:5:1). ${ }^{e}$ Yield for 2,4-dimethylphenyl isomer of 91c. ${ }^{f}$ Overall yield for mixture of $o / m / p$ (ratio, 4:1:1) isomers. ${ }^{g}$ With 14 equiv. of TBAF. ${ }^{h}$ With 3.5 equiv. of TBAF. ${ }^{i} 77 \%$ at $90{ }^{\circ} \mathrm{C} .{ }^{j} 47 \%$ with benzofuran:78a ratio (1.5:1). ${ }^{k}$ Coupling with furan instead of thiophene also produced $94(60 \%)$. 
Arylation of 78a with anisole also gave 91d as a mixture of $o / \mathrm{m} / \mathrm{p}$ regioisomers in $76 \%$ (entry 3). As 79b, the ratio for the $o / m / p$ isomers of 91d was established by comparison with authentic samples prepared by Suzuki coupling. ${ }^{54}$ However, coupling of $\mathbf{7 8 a}$ with arenes bearing electron withdraw group (EWG) either failed (nitrobenzene) or gave the corresponding 5-arylated products in low yields (1,2,3,4,5-pentafluorobenzene, 15\%, GC-MS). Analogous treatment of 5bromouracil $\mathbf{7 8 b}$, prepared by bromination of 1 - $N$-benzyluracil with 1,3-dibromo-5,5dimethylhydantoin $(\mathrm{DBH})$ in the presence of TMSOTf, ${ }^{145}$ with benzene also proceeded smoothly to give $91 \mathbf{b}$ in $78 \%$ yield but 14 equiv. of TBAF was required (entry 4). Compared to the regular arenes, only 3.5 equiv. of TBAF was required for electron rich heteroaromatics to couple efficiently with 78a. Thus, coupling of 78a with furan gave 5-(2-furyl)uracil 91e in $95 \%$ yield as the only isomer (entry 5). Arylation of 78a with benzo[b]furan proceeded in good yield even with only a slight excess of heteroaromatics (benzo[b]furan/78a, 1.5:1, mol/mol; benzo[b]furan/DMF, $1: 100, \mathrm{v} / \mathrm{v}$; entry 6$)$. Reaction of 78a with thiophene gave 5-(2-thienyl)uracil $\mathbf{9 1 g}$ quantitatively (entry 7), while coupling with 2-substituted thiophenes provided single products $91 \mathbf{h}$ or $\mathbf{9 1 i}$ in good yield as well (entries 8 and 9). The 5-bromouracil $\mathbf{7 8 b}$ also coupled efficiently with furan under similar conditions to give 91e but 14 equiv. of TBAF was required (entry 10). It is worthy to note that TBAF-promoted direct $\mathrm{C}-\mathrm{H}$ arylation between $3-\mathrm{N}$-methyl-5-iodouracil $78 \mathrm{c}$ and toluene, furan or thiophene only gave the reduced product 94 (entries 11-12).

\subsubsection{Base promoted Pd-catalyzed direct arylation of 5-halo uracil}

Contrary to the unsuccessful coupling of 78a with simple arenes under the TBAF condition (Table 6, entries 11-18), the $\pi$-excessive heteroarenes did couple successfully with 5-iodouracil 78a in the presence of bases (Table 7). Initially, when 78a was heated with thiophene (15 equiv.) in $\mathrm{DMF}$ at $100{ }^{\circ} \mathrm{C}$ in the presence of $\mathrm{Pd}(\mathrm{OAc})_{2}$ and $\mathrm{K}_{2} \mathrm{CO}_{3}$ (2 equiv.) for $2 \mathrm{~h}$, only reduced product 92 was obtained (Table 7, entry 1). However, when the reaction was carried out in a mixture of $\mathrm{DMF} / \mathrm{H}_{2} \mathrm{O}(5: 1, \mathrm{v} / \mathrm{v})$, product $91 \mathrm{~g}$ was obtained in $75 \%$ yield (entry 2$)$. Apparently the 
increased solubility of $\mathrm{K}_{2} \mathrm{CO}_{3}$ in the $\mathrm{DMF} / \mathrm{H}_{2} \mathrm{O}$ mixture changed the outcome of the reaction dramatically. It also has been noted that the solubility of $\mathrm{K}_{2} \mathrm{CO}_{3}$ is very low in pure organic solvents ${ }^{146}$ (e.g., less than $1 \%$ of $\mathrm{K}_{2} \mathrm{CO}_{3}$ was dissolved in DMA after 30 min heating at $120{ }^{\circ} \mathrm{C}$ ). The yields were only slightly different when 1 or 4 equiv. of $\mathrm{K}_{2} \mathrm{CO}_{3}$ was used (entry 3 ).

Table 7. Effect of the reaction parameters in the base-promoted direct arylation of 1- $\mathrm{N}$-benzyl-5-iodouracil $78 \mathrm{a}$ with thiophene

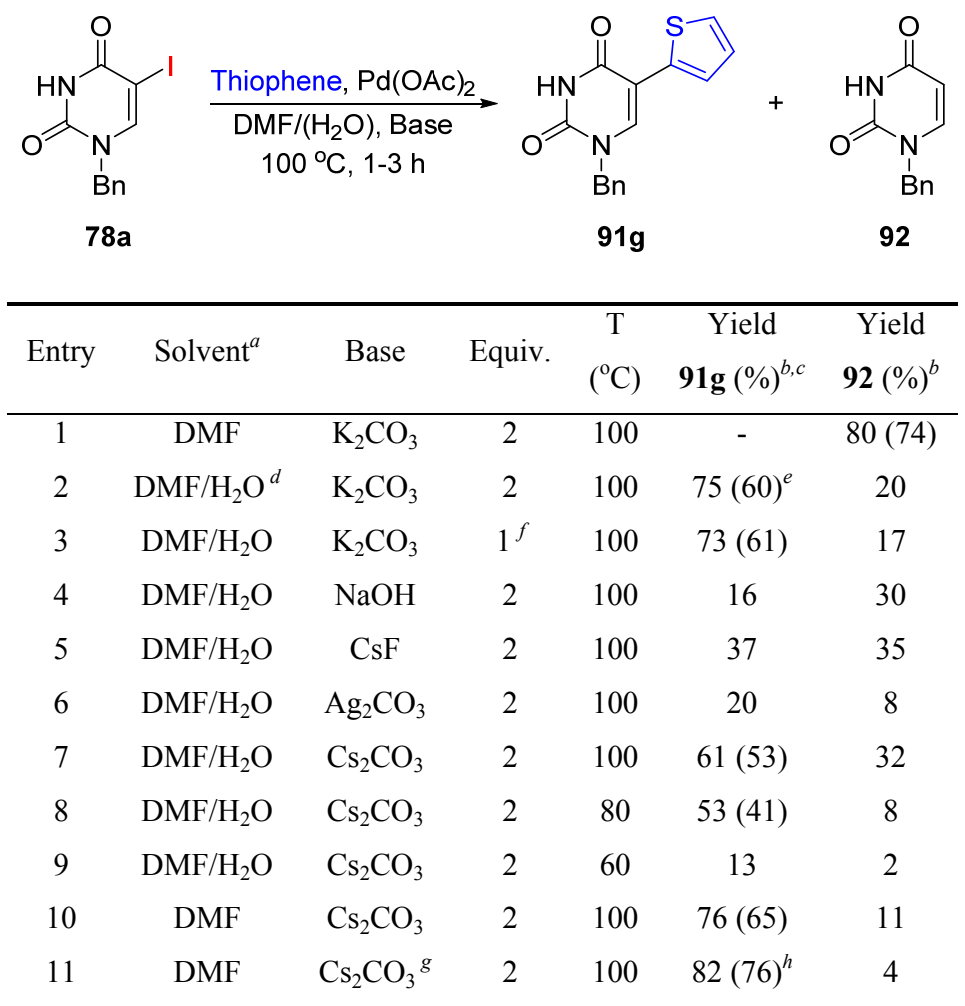

${ }^{a}$ Couplings were performed on $0.14 \mathrm{mmol}$ scale of $78 \mathrm{a}(0.05 \mathrm{M})$ with 0.05 equiv. of $\mathrm{Pd}(\mathrm{OAc})_{2} \cdot{ }^{b}$ Determined by GC-MS of the crude reaction mixture. ${ }^{c}$ Isolated yield in parenthesis. ${ }^{d} \mathrm{DMF} / \mathrm{H}_{2} \mathrm{O}(5: 1, \mathrm{v} / \mathrm{v}) .{ }^{e} \mathrm{Pd}_{2}(\mathrm{dba})_{3}$ gave $91 \mathrm{~g}$ in $36 \%$ isolated yield. ${ }^{f} 4$ equiv. of $\mathrm{K}_{2} \mathrm{CO}_{3}$ gave $91 \mathrm{~g}$ in $50 \%$ isolated yield. ${ }^{g}$ With addition of $\mathrm{PivOH}\left(1.25\right.$ equiv.). ${ }^{h} 80 \%$ yield with addition of $\mathrm{PivOH}$ (1.25 equiv.) and $\mathrm{Ag}_{2} \mathrm{CO}_{3}$ (1.0 equiv.).

Direct arylation in the presence of $\mathrm{NaOH}$ or $\mathrm{CsF}$ or $\mathrm{Ag}_{2} \mathrm{CO}_{3}$ gave $91 \mathrm{~g}$ in low yields (entries 4-6) but proceeded efficiently with $\mathrm{Cs}_{2} \mathrm{CO}_{3}$ (entry 7). Temperature also plays an important role in the direct arylation. Coupling at $80{ }^{\circ} \mathrm{C}$ for $2 \mathrm{~h}$ gave $91 \mathrm{~g}$ in $53 \%$ but with an increased ratio relative to 3 (entry 8 ), while reaction at $60{ }^{\circ} \mathrm{C}$ for $4 \mathrm{~h}$ produced $\mathbf{9 1 g}$ in only $15 \%$ (entry 9 ). Arylation of 78a in the presence of $\mathrm{Cs}_{2} \mathrm{CO}_{3}$ in DMF not only increased the yield but also the ratio $91 \mathrm{~g}$ to 92 (entry 10), and the result turned out to be even better with the addition of pivalic acid ${ }^{146}$ (entry 11 ). 
Generally, direct arylation of 78a promoted by TBAF gave the best results with $\operatorname{Pd}_{2}(\mathrm{dba})_{3}$ as the catalyst while base-promoted coupling proceeded more efficiently with $\mathrm{Pd}(\mathrm{OAc})_{2}$.

Other electron-rich heteroarenes have also been coupled to the 5-halouracils via the basepromoted C-H direct arylation (Table 8). Coupling of 78a with furan and thiophene in DMF in the presence of $\mathrm{Cs}_{2} \mathrm{CO}_{3}$ and $\mathrm{PivOH}$ at $100{ }^{\circ} \mathrm{C}$ for $2 \mathrm{~h}$ gave 91e and $91 \mathrm{~g}$ in $79 \%$ and $82 \%$, respectively, in addition to a small amount of reduced product 92 (Table 8, entries 1-2).

Table 8. $\mathrm{Cs}_{2} \mathrm{CO}_{3}$ Promoted direct arylation of 5-halouracils 78 with electron-rich heteroaromatics

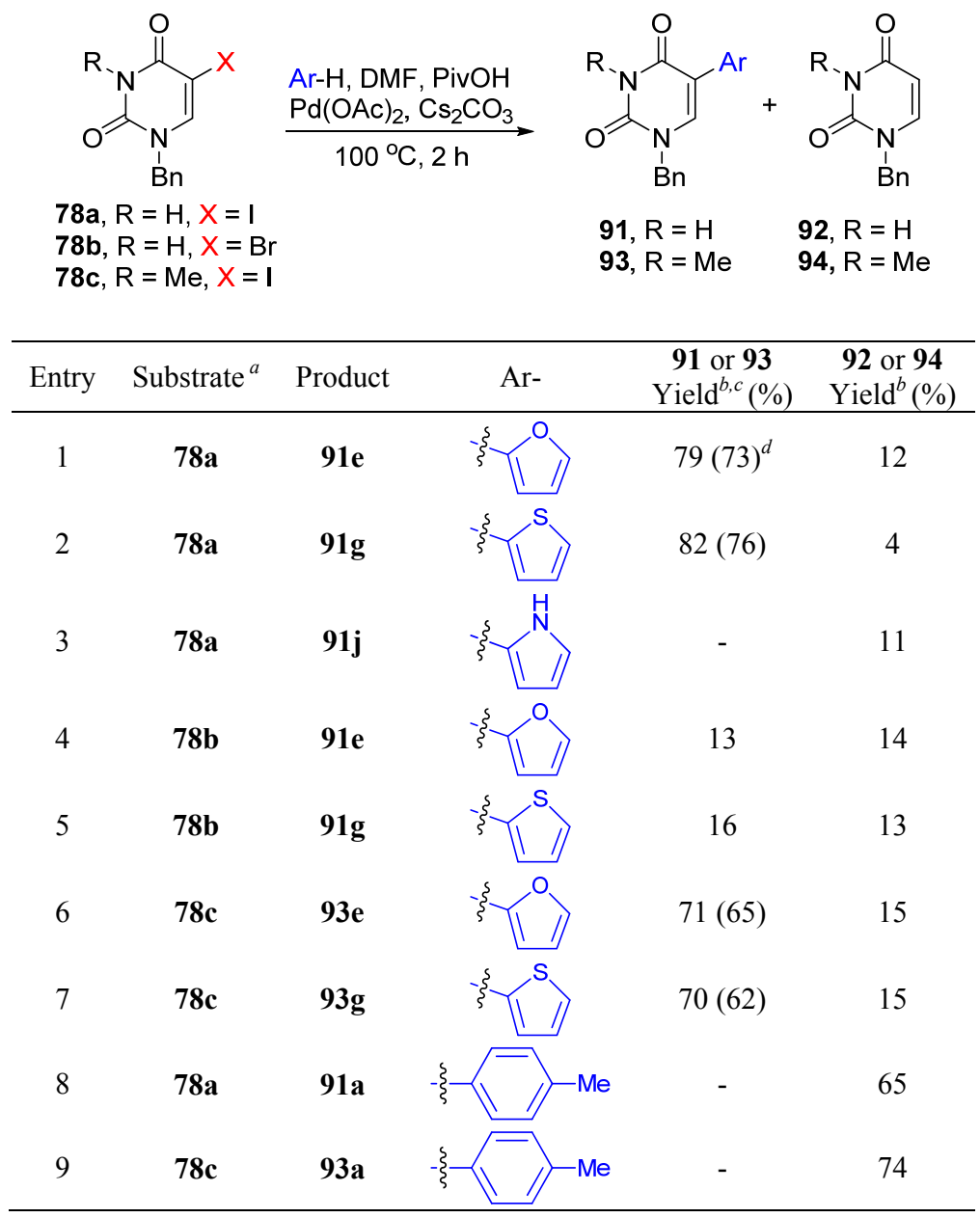

${ }^{a}$ Couplings were performed on $0.14 \mathrm{mmol}$ scale of 78 (0.05 M) with $\mathrm{Cs}_{2} \mathrm{CO}_{3}$ (2 equiv.), $\mathrm{PivOH}$ (1.25 equiv.), and $\mathrm{Pd}(\mathrm{OAc})_{2}$ (0.005 equiv.). ${ }^{b}$ Determined by GC-MS of the crude reaction mixture. ${ }^{c}$ Isolated yield in parenthesis. ${ }^{d}$ Coupling without addition of PivOH gave 91e in $65 \%$ yield.

However, coupling was not successful with pyrrole (entry 3). Analogously, 91e and 91g could also be obtained in lower yields by the direct arylation of 5-bromouracil $\mathbf{7 8 b}$ with furan and 
thiophene (entries 4 and 5). Surprisingly, contrary to the unsuccessful arylation of $78 \mathrm{c}$ with heteroarenes with TBAF (Table 6, entry 12), the base-promoted arylation of 78c with furan or thiophene gave coupling products 93e and 93g in good yield (entries 6 and 7). However, attempted coupling of the $N^{3}$-free 78a and $N^{3}$-protected 78c uracil substrates with simple arenes, e.g., benzene or toluene, in the presence of $\mathrm{Cs}_{2} \mathrm{CO}_{3}$ failed to give products (entries 8 and 9).

\subsubsection{Direct arylation of pyrimidine nucleosides}

Since our TBAF or base promoted direct arylation methodologies not only avoided the use of toxic organotin substrates ${ }^{42,43,147}$ but also worked efficiently with the $3-N$ unprotected uracil substrates, ${ }^{94,96,142}$ I will apply them to 5-halopyrimidine nucleosides for the synthesis of 5-arylated uracil nucleosides. Thus, treatment of 2',3',5'-tri- $O$-acetyl-1-( $\beta$-D-arabinofuranosyl)-5-iodouracil 95 with furan/DMF $(1: 9, \mathrm{v} / \mathrm{v})$ in the presence of TBAF (3.5 equiv.) and $\operatorname{Pd}_{2}(\mathrm{dba})_{3}$ afforded 5-(2furyl)uracil analogue $\mathbf{1 0 1}$ in $61 \%$ (Table 9, entry 1). Similarly, the acetyl group protected 2'deoxy-5-iodouridine $\mathbf{9 6}$ was also converted to $\mathbf{1 0 2}$ by coupling with furan (entry 2). Analogous treatment of 97 with furan, thiophene and 2-methylthiophene gave the corresponding products 103-105 in moderate yield (entries 3-5). It is obvious that our direct arylation conditions are not only compatible with natural nucleosides but also compatible with the commonly used acyl protection group. Followed by the deacetylation of $\mathbf{1 0 1}$ or $\mathbf{1 0 2}$ with methanolic ammonia at ambient temperature, the corresponding unprotected 5-arylated uracil nucleoside derivatives 106 (92\%) and 107 (95\%) were obtained. The TBAF-promoted direct arylation has also been applied to the unprotected nucleosides to check compatibility. Thus, subjection of $1-(\beta$-Darabinofuranosyl)-5-iodouracil 98, 2'-deoxy-5-iodouridine 99, and 5-iodouridine 100 with furan in the presence of TBAF and Pd-catalyst gave the corresponding 5-(2-furyl)uracil nucleoside analogues 106-108 in high yields (entries 6-8). 
Table 9. Direct arylation of 5-iodouracil nucleosides with electron-rich heteroaromatics

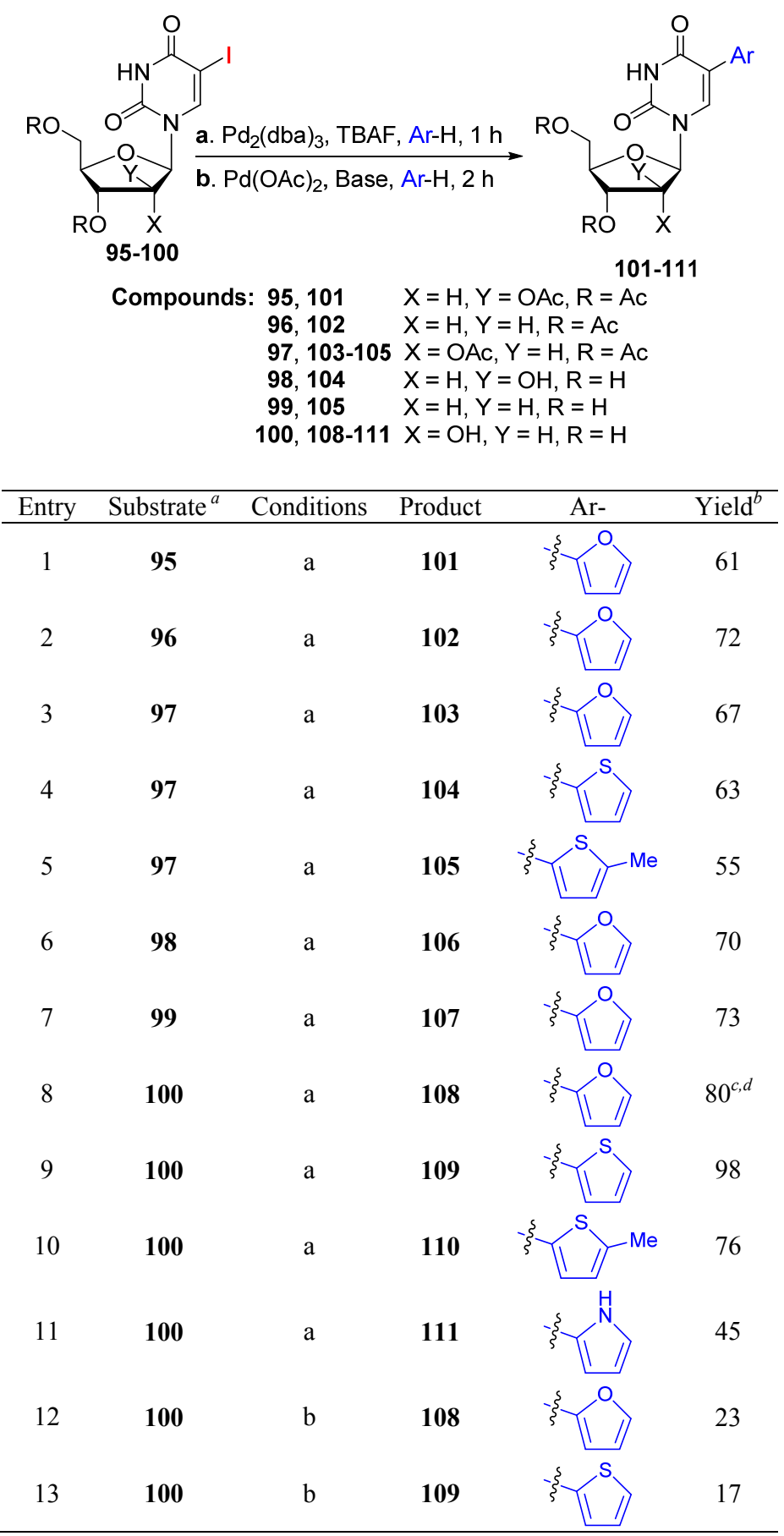

${ }^{a}$ Couplings were performed on $0.14 \mathrm{mmol}$ scale of nucleosides $(0.07 \mathrm{M})$ in the presence of 3.5 equiv. of TBAF and 0.05 equiv. of $\mathrm{Pd}$ catalyst. Ratio of $\mathrm{Ar}-\mathrm{H}$ to substrate nucleosides $15-20: 1 .{ }^{b}$ Isolated yields. ${ }^{c} 41 \%$ yield with $1.75: 1$ ratio of furan to $\mathbf{1 0 0}{ }^{d}$ Coupling on $1 \mathrm{mmol}$ scale of $\mathbf{1 0 0}$ gave $\mathbf{1 0 5}$ in $88 \%$ yield.

Coupling of $\mathbf{1 0 0}$ proceeded also with only a small excess of furan (1.75 equiv.) affording $\mathbf{1 0 8}$ in $41 \%$ isolated yield (entry 8 , footnote $c$ ). The 5-iodouridine 100 coupled efficiently with 
thiophene and 2-methylthiophene to give products 109 or 110 (entries 9 and 10). It was found that pyrrole was also able to couple with $\mathbf{1 0 0}$ to give 5-(2-pyrrolyl)uridine $\mathbf{1 1 1}$ in respectable yield (entry 11). This compound can be purified on a silica gel column but is somewhat unstable during storage or upon prolonged exposure to air. Base-promoted $\mathrm{C}-\mathrm{H}$ direct arylation also works smoothly with natural nucleosides, but the efficiency is not as good as the TBAF methodology. Treatment of $\mathbf{1 0 0}$ with furan or thiophene in the presence of $\mathrm{Cs}_{2} \mathrm{CO}_{3}$ and $\mathrm{Pd}$ catalyst at $100{ }^{\circ} \mathrm{C}$ for $2 \mathrm{~h}$ gave 5-arylated uracil nucleoside derivatives $\mathbf{1 0 8}$ or $\mathbf{1 0 9}$ in $23 \%$ and $17 \%$ isolated yield (entries 12 and 13). The cleavage of the glycosidic bond was observed during the arylation, which is consistent with the literature report. ${ }^{96}$

In the attempts to expand direct arylation to other pyrimidine systems, the 5-iodocytidine analogues were prepared by the modification of the existing procedure (Scheme 34). ${ }^{148,149}$ Stirring of 112 with acetyl chloride in $\mathrm{AcOH} / \mathrm{CHCl}_{3}(1: 1, \mathrm{v} / \mathrm{v})$ at ambient temperature for $40 \mathrm{~h}$ gave 2',3',5'-tri-O-acetylcytidine in $96 \%$, followed by iodination with $\mathrm{I}_{2} / \mathrm{HIO}_{3}$ gave 113 in $63 \%$.

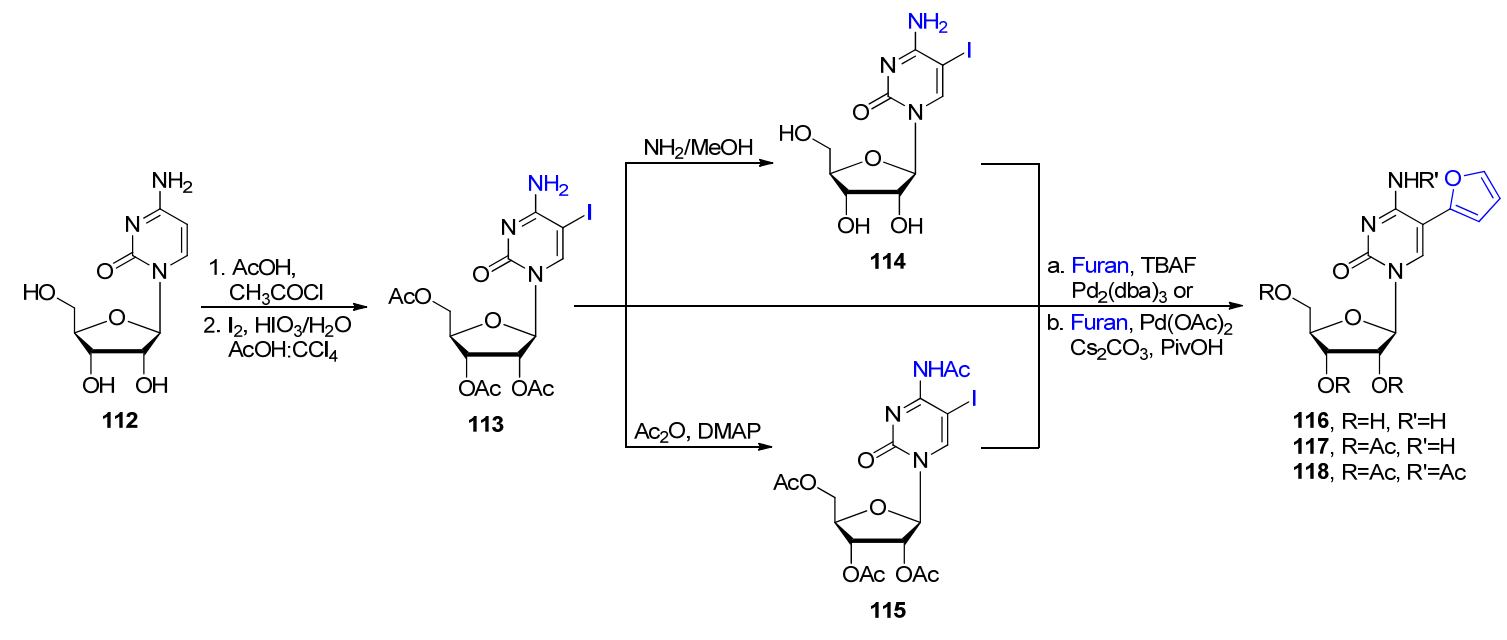

Scheme 34. TBAF or base promoted coupling of 5-iodocytidine analogues with furan

Unfortunately, direct arylation of $\mathbf{1 1 3}$ with furan employing either TBAF or the base protocol was not successful. Alternatively, the acetyl protecting groups of $\mathbf{1 1 3}$ were removed by the treatment with methanolic ammonia to give unprotected cytidine analogue 114. Acetylation of 113 was also carried out with acetic anhydride to give fully acetyl protected cytidine analogue 
115. Both 114 and $\mathbf{1 1 5}$ have been applied to the direct arylation with furan, however, none of these substrates worked successfully in the TBAF or base promoted direct arylation.

\subsubsection{Scopes and mechanistic consideration}

It is important to establish the generality of the direct arylation methodology. Thus the TBAF promoted direct arylation was expanded to other heterocyclic systems, which also have similar tautomerization between the oxo group and the hydrogen at the adjacent nitrogen atom. Treatment of 3-bromo-2-pyridone 119 with furan or thiophene in the presence TBAF and $\mathrm{Pd}_{2}(\mathrm{dba})_{3}$ without other additives added gave products $120(41 \%)$ and $121(37 \%)$ as well as the unchanged 119 (Scheme 35). Similarly, treatment of 119 with furan in the presence of $\mathrm{Cs}_{2} \mathrm{CO}_{3} / \mathrm{PivOH}$ and $\mathrm{Pd}(\mathrm{OAc})_{2}$ gave 120 in $49 \%$. Interestingly, few examples have been reported on the arylation and/or vinylation of the $N$-alkylated 3-halo-2-pyridones at 3 position using Suzuki ${ }^{150,151}$ or Stille ${ }^{152}$ or Negishi ${ }^{153}$ protocols.

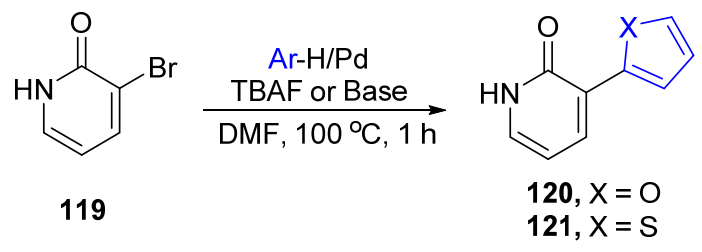

Scheme 35. TBAF or base promoted direct arylation of 3-bromo-2-pyridone

On the basis of literature reports and established mechanisms, ${ }^{80-83,88,146,154}$ direct arylation of 5-iodouracils is expected to occur via either electrophilic aromatic substitution (electrophilic palladation with nucleophilic arenes) or direct proton abstraction ( $\sigma$-bond metathesis). There is not sufficient data for speculation on the mechanism or the role of TBAF at this moment. However, it is clear that 1-N-benzyl-3- $N$-methyl-5-iodouracil (78c) did not undergo TBAFpromoted coupling with arenes because of the nonexistence of tautomerization. Thus, it is believed that the C4-alkoxide (enol form of uracil) may participate in the intramolecular processes of hydrogen abstraction via a six membered ring as depicted in structures $\mathbf{A}$ and $\mathbf{B}$ 
(Figure 6). It has also been noted that direct arylation was facilitated by using a Pd-coordinated carboxylate group, which assisted in intramolecular proton abstraction. ${ }^{146,154}$
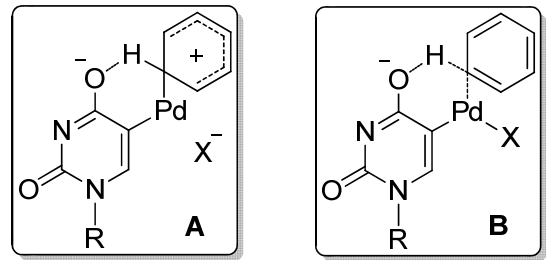

Figure 6. The plausible intermediates for the Pd-catalyzed direct arylation of 5-halouracils: (A) Electrophilic aromatic palladation assisted by $\mathrm{C} 4$-alkoxide; (B) Direct proton abstraction assisted by C4-alkoxide.

The TBAF promoted direct $\mathrm{C}-\mathrm{H}$ arylation methodology has also been applied to $1-\mathrm{N}$ benzyluracil 92 and aryl halides. Thus, treatment of 92 with 4-iodoanisole under the optimal conditions did not give uracil products either at the $\mathrm{C} 5$ or the $\mathrm{C} 6$ position. However, treatment of 92 with 4-iodoanisole (3 equiv.) in the presence of $\mathrm{TBABr} / \mathrm{Pd}(\mathrm{OAc})_{2} / \mathrm{AgCl}^{94}$ produced a mixture of $p$-91d (23\%) and $122(33 \%)$ in addition to the unchanged 92 (41\%, Scheme 36). No further efforts have been made to optimize the conditions for direct $\mathrm{C}-\mathrm{H}$ arylation of uracil analogues, since Hocek ${ }^{142,155}$ and $\mathrm{Kim}^{96}$ have reported the base-promoted direct $\mathrm{C}-\mathrm{H}$ arylation of 1,3- $\mathrm{N}$ diprotected uracils at C5 and/or C6 position(s) with aryl halides. They found that higher temperature $\left(130-160{ }^{\circ} \mathrm{C}\right)$ and longer reaction time $(12-48 \mathrm{~h})$ are required, which led to the rampant cleavage of the glycosidic bond. ${ }^{96}$<smiles>O=c1ccn(Br)c(=O)[nH]1</smiles>

92

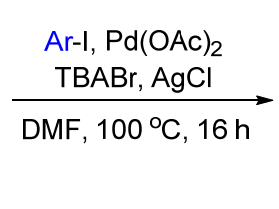

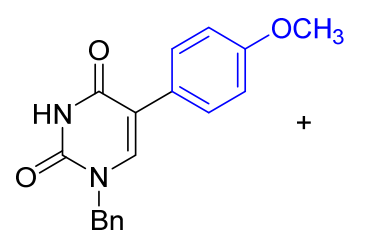

$p-91 d$

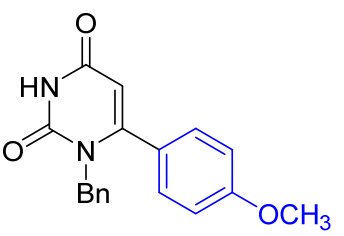

122

Scheme 36. Pd-catalyzed direct C-H arylation of uracil with 4-iodoanisole 


\subsection{Synthesis of highly functionalized 5-vinyluracil nucleosides from 5-acetylene substrates}

\subsubsection{Hydrogermylation of 5-ethynyluracil nucleosides}

I also investigated the hydrogermylation of the 5-ethynyluracil and uracil nucleosides with germane hydrides with different catalysts. The 5-[2-tris(trimethylsilyl)germanyl]vinyluracil nucleoside analogues have been explored in Pd-catalyst cross-coupling reactions with aryl halides as well as in halodegermylations.

\subsubsection{Synthesis of 5-[2-(germyl)vinyl]uracil and 5-[2-(triphenylgermyl)acetyl]uracil nucleosides}

On the basis of screening of all available methods for hydrogermylation of alkynes, such as $\operatorname{Pd}(0)$-catalyzed, ${ }^{136,156,157}$ Lewis acid-promoted, ${ }^{136,158,159}$ or radical-mediated ${ }^{136,160}$ processes, I have tested for the preparation of 5-[(2-germyl)vinyl]uracil nucleosides 124. The 1-(2,3,5-tri-O-acetyl$\beta$-D-arabinofuranosyl)-5-ethenyluracil ${ }^{161} 123$ was subjected to $\mathrm{Ph}_{3} \mathrm{GeH}$ in the presence of 1,1'azobis(cyclohexanecarbonitrile) (ACCN) in toluene at $90{ }^{\circ} \mathrm{C}$ (Method A) to give the vinyl germanes 124a as a mixture of regioisomers with the $Z$ isomer as the major product via antiaddition of the germyl radical to the triple bond (Table 10$)$. The ratio for $E \mathbf{- 1 2 4 a}(J=18.8 \mathrm{~Hz})$ and $Z$-124a $(J=13.5 \mathrm{~Hz})$ diastereomers was established as 5:95 by ${ }^{1} \mathrm{H}$ NMR spectroscopy, which was consistent with the literature report. ${ }^{160}$ Surprisingly, careful purification gave another new product, which was assigned (vide infra) as 5-[2-(triphenylgermyl)acetyl]uracil nucleoside derivative 126a (12\%; Table 10, entry 1$)$.

Subjection of $\mathbf{1 2 3}$ under the same condition with $\mathrm{Ph}_{3} \mathrm{GeH}$ in the absence of ACCN gave 124a in $60 \%$ with a better ratio $(E / Z, 3: 97)$ along with the $\beta$-keto germyl uracil nucleoside 126a in $15 \%$ (entry 2). Hydrogermylation of $\mathbf{1 2 3}$ with $\mathrm{Ph}_{3} \mathrm{GeH}$ in the presence of $\mathrm{Et}_{3} \mathrm{~B}^{162}$ in THF at $-78{ }^{\circ} \mathrm{C}$ (Method B) gave Z-vinyl germane 124a in 55\% as the only product (entry 3), while Z-124a was obtained in $28 \%$ at $0{ }^{\circ} \mathrm{C}$ as well as $\mathbf{1 2 6 a}$, which was not observed at $-78{ }^{\circ} \mathrm{C}$ (entry 4). Analogous treatment of 123 with $\mathrm{Ph}_{3} \mathrm{GeH}$ in the presence of $\mathrm{B}\left(\mathrm{C}_{6} \mathrm{~F}_{5}\right)_{3}{ }^{159}$ in $\mathrm{CH}_{2} \mathrm{Cl}_{2}$ at ambient temperature 
gave a trace amount of 124a. Hydrogermylation ${ }^{156}$ of $\mathbf{1 2 3}$ with $\mathrm{Ph}_{3} \mathrm{GeH}$ in the presence of $\mathrm{Pd}\left(\mathrm{PPh}_{3}\right)_{4}$ in THF gave a mixture of $E$-124a and a 5-[1-(triphenylgermyl)ethenyl] regioisomer in $73 \%$ with ratio of 3:2 (Method C). The similar regioisomer, which was formed by the addition of a germyl radical to the $\alpha$-carbon, was also observed. ${ }^{156}$ It is worthy to note that the $\beta$-keto germyl uracil nucleoside 126a was only observed with Method A or Method B at $0{ }^{\circ} \mathrm{C}$. Deacetylation of Z-124a with $\quad \mathrm{NH}_{3} / \mathrm{MeOH} \quad$ afforded the 1-( $\beta$-D-arabinofuranosyl)-5-[2(triphenylgermyl)acetyl]uracil Z-125a in $86 \%$. Hydrogermylation of $\mathbf{1 2 3}$ with trimethylgermane hydride $\left(\mathrm{Me}_{3} \mathrm{GeH}\right)^{162}$ by method B at $-78{ }^{\circ} \mathrm{C}$ did not give $\mathbf{1 2 4 b}$, while it could be obtained in $40 \%$ with low stereoselectivity $(E / Z, 13: 87)$ at ambient temperature (entry 6). Surprisingly, 5-2(trialkylgermyl)acetyl uracil nucleoside 126b was not observed at either $-78{ }^{\circ} \mathrm{C}$ or ambient temperature. Hydrogermylation of $\mathbf{1 2 3}$ with $\left(\mathrm{Me}_{3} \mathrm{Si}\right)_{3} \mathrm{GeH}$ by method A gave 5-2-(TTMSgermyl)ethenyl uracil analogue $Z-\mathbf{1 2 4 c}$ stereoselectively in $68 \%$ in $30 \mathrm{~min}$., but again, $\beta$-keto germyl uracil nucleoside 126c was not detected (entry 7). Hydrogermylation of 2',3',5'-tri- $O-p$ toluoyl-5-ethynyluridine 127 with $\mathrm{Ph}_{3} \mathrm{GeH}$ by Method $\mathrm{B}\left(-78{ }^{\circ} \mathrm{C} \rightarrow 0{ }^{\circ} \mathrm{C}\right)$ gave $129 \mathrm{a}$ in $40 \%$ along with the 5-[2-(triphenylgermyl)acetyl] product 133a in 13\% (entry 8). Analogous treatment of 127 with $\mathrm{Me}_{3} \mathrm{GeH}$ by Method $\mathrm{B}\left(0^{\circ} \mathrm{C} \rightarrow 25^{\circ} \mathrm{C}\right)$ yielded a mixture of stereoisomers $129 \mathrm{~b}$ in $41 \%$ (E/Z, 45:55; entry 9). Treatment of 127 with $\mathrm{TMS}_{3} \mathrm{GeH}$ by Method $\mathrm{B}\left(-78{ }^{\circ} \mathrm{C} \rightarrow 0{ }^{\circ} \mathrm{C}\right)$ yielded $Z$ 129c as the single isomer in $61 \%$ (entry 10 ). Hydrogermylation of 3 ',5'-di- $O$-p-toluoyl-5-ethynyl2'-deoxyuridine 128 with $\mathrm{Ph}_{3} \mathrm{GeH}$ by Method $\mathrm{B}\left(-78{ }^{\circ} \mathrm{C}\right.$ to $\left.0{ }^{\circ} \mathrm{C}\right)$ gave $Z-131 \mathrm{a}$ in $61 \%$ along with 134a in $12 \%$ (entry 11 ). 
Table 10. Hydrogermylation of 5-ethynyluracil and related nucleosides with germane hydrides
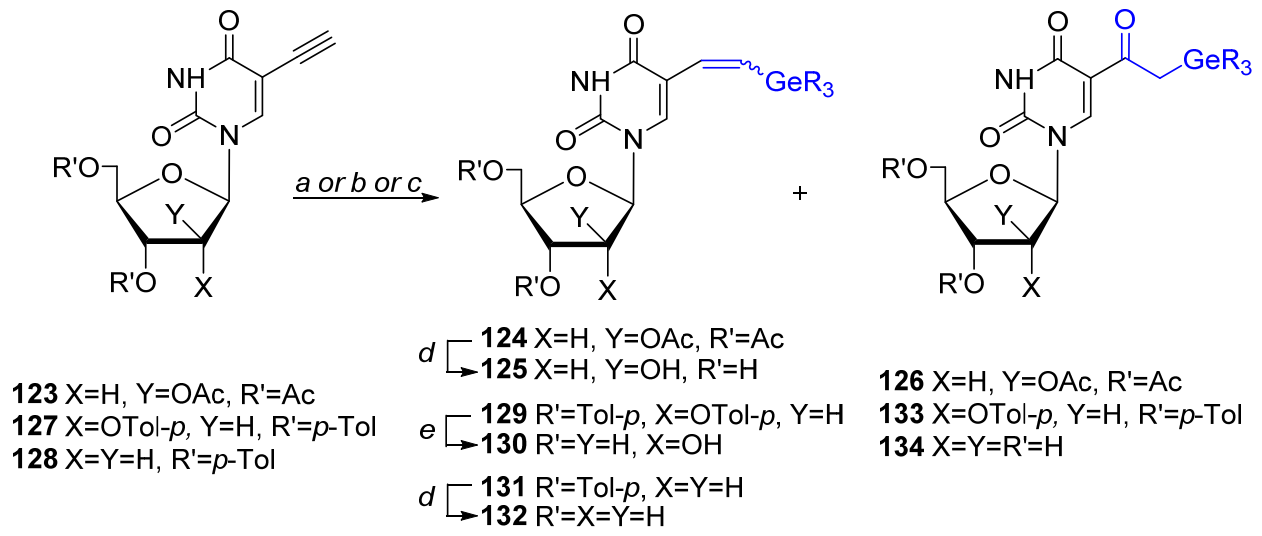

$126 \mathrm{X}=\mathrm{H}, \mathrm{Y}=\mathrm{OAc}, \mathrm{R}^{\prime}=\mathrm{Ac}$

$133 \mathrm{X}=\mathrm{OTOl}-p, \mathrm{Y}=\mathrm{H}, \mathrm{R}^{\prime}=p-\mathrm{Tol}$

$134 \mathrm{X}=\mathrm{Y}=\mathrm{R}^{\prime}=\mathrm{H}$

Compounds 124-134 Series: $\mathbf{a} \mathrm{R}=\mathrm{Ph}, \mathbf{b} \mathrm{R}=\mathrm{Me}, \mathbf{c} \mathrm{R}=\left(\mathrm{Me}_{3} \mathrm{Si}\right)_{3}$

(a) $\mathrm{R}_{3} \mathrm{GeH},(\mathrm{ACCN})$, toluene (THF, DMF), $90^{\circ} \mathrm{C}$;

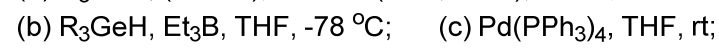

(d) $\mathrm{NH}_{3}, \mathrm{MeOH}$, rt.

(e) $\mathrm{MeONa} / \mathrm{MeOH} / \mathrm{r}$.t.;

\begin{tabular}{|c|c|c|c|c|c|c|c|c|c|}
\hline \multirow[b]{2}{*}{ Entry } & \multirow[b]{2}{*}{ Substrate } & \multirow[b]{2}{*}{$\operatorname{Method}^{a}$} & \multirow[b]{2}{*}{ Temp $\left({ }^{\circ} \mathrm{C}\right)$} & \multirow[b]{2}{*}{$\mathrm{R}_{3} \mathrm{GeH}$} & \multicolumn{3}{|c|}{ Vinyl Germanes } & \multicolumn{2}{|c|}{ Germyl Ketones } \\
\hline & & & & & Product & $\begin{array}{c}\text { Yield }^{b} \\
(\%)\end{array}$ & $\begin{array}{l}\text { Ratio }^{b} \\
(E / Z)\end{array}$ & Product & $\begin{array}{c}\text { Yield }^{b} \\
(\%)\end{array}$ \\
\hline 1 & 123 & $\mathrm{~A}$ & 90 & $\mathrm{Ph}_{3} \mathrm{GeH}$ & $124 \mathbf{a}^{c}$ & 47 & $0: 100$ & $126 a$ & 12 \\
\hline 2 & 123 & $\mathrm{~A}^{d}$ & 90 & $\mathrm{Ph}_{3} \mathrm{GeH}$ & $124 a$ & 60 & $3: 97$ & $126 a$ & 15 \\
\hline 3 & 123 & B & $-78 \rightarrow-60$ & $\mathrm{Ph}_{3} \mathrm{GeH}$ & $124 a$ & 55 & $0: 100$ & - & - \\
\hline 4 & 123 & B & 0 & $\mathrm{Ph}_{3} \mathrm{GeH}$ & $124 a$ & 28 & $0: 100$ & $126 a$ & 19 \\
\hline 5 & 123 & $\mathrm{C}$ & 5 & $\mathrm{Ph}_{3} \mathrm{GeH}$ & $124 a^{e}$ & 45 & 100:0 & - & - \\
\hline 6 & 123 & B & $0 \rightarrow 25$ & $\mathrm{Me}_{3} \mathrm{GeH}$ & $124 b$ & 40 & $15: 85$ & - & - \\
\hline 7 & 123 & A & $0 \rightarrow 25$ & $\left(\mathrm{Me}_{3} \mathrm{Si}\right)_{3} \mathrm{GeH}$ & $124 c^{f}$ & 68 & $0: 100$ & - & - \\
\hline 8 & 127 & B & $-78 \rightarrow 0$ & $\mathrm{Ph}_{3} \mathrm{GeH}$ & $129 a$ & 40 & $0: 100$ & $133 a$ & 13 \\
\hline 9 & 127 & $\mathrm{~B}$ & $0 \rightarrow 25$ & $\mathrm{Me}_{3} \mathrm{GeH}$ & $129 b$ & 41 & $45: 55$ & - & -- \\
\hline 10 & 127 & B & $-78 \rightarrow 0$ & $\left(\mathrm{Me}_{3} \mathrm{Si}\right)_{3} \mathrm{GeH}$ & $129 \mathrm{c}$ & 61 & $0: 100$ & - & - \\
\hline 11 & 128 & B & $-78 \rightarrow 0$ & $\mathrm{Ph}_{3} \mathrm{GeH}$ & $131 \mathrm{a}$ & 61 & $0: 100$ & $134 a$ & 12 \\
\hline 12 & 128 & $\mathrm{~A}^{g}$ & $100^{h}$ & $\mathrm{Ph}_{3} \mathrm{GeH}$ & $131 a^{i}$ & 33 & $0: 100$ & $134 a$ & 17 \\
\hline 13 & 128 & B & $0 \rightarrow 25$ & $\mathrm{Me}_{3} \mathrm{GeH}$ & 131b & 35 & $40: 60$ & - & - \\
\hline
\end{tabular}

${ }^{a}$ Method A: $\mathrm{R}_{3} \mathrm{GeH} / \mathrm{ACCN} /$ toluene/90 or $100{ }^{\circ} \mathrm{C}$; Method B: $\mathrm{R}_{3} \mathrm{GeH} / \mathrm{Et}_{3} \mathrm{~B} / \mathrm{THF} /-78$ or $0{ }^{\circ} \mathrm{C}$; Method C: $\mathrm{Pd}\left(\mathrm{PPh}_{3}\right)_{4} / \mathrm{THF} / \mathrm{rt} .{ }^{b}$ Isolated yield. ${ }^{c}$ Crude reaction mixture (E/Z-124a, 5:95). ${ }^{d}$ Without the presence of ACCN. ${ }^{e}$ In addition to $E \mathbf{- 1 2 4 a}$ the $\alpha$-addition product was formed as well $(\sim 3: 2,73 \%$ overall $) .{ }^{f}$ Crude reaction mixture $(E / Z$-124c, 4:96). ${ }^{g}$ Toluene/THF $(20: 1, \mathrm{v} / \mathrm{v})$ was used as solvent. ${ }^{h}$ Oil-bath. ${ }^{i}$ With toluene/DMF/ $\mathrm{H}_{2} \mathrm{O}(20: 1: 0.1, \mathrm{v} / \mathrm{v} / \mathrm{v})$ as solvents $E$-131a, $Z$-131a and 134a ( 2:2:1, 40\% overall) were obtained.

Analogous treatment of 128 with $\mathrm{Ph}_{3} \mathrm{GeH}$ by Method A in toluene/THF (20:1, v/v) gave Z131a and 134a (entry 12). Interestingly, analogous hydrogermylation of $\mathbf{1 2 8}$ in toluene/DMF with 
addition of a "measured" amount of water (14 equiv.) produced E/Z-131a $(\sim 1: 1)$ and 134a (entry 12 , footnote $i)$. Treatment of $\mathbf{1 2 8}$ with $\mathrm{Me}_{3} \mathrm{GeH}$ by Method $\mathrm{B}\left(0{ }^{\circ} \mathrm{C} \rightarrow 25^{\circ} \mathrm{C}\right)$ gave only $E / Z-\mathbf{1 3 1 b}$ (entry 13) but once again no germyl ketone product was observed. Deprotection of $E / Z$-129b with $\mathrm{MeONa} / \mathrm{MeOH}$ gave uridine analogue $E / Z-130 b$ in $71 \%$, while deprotection of $Z$-131a with $\mathrm{NH}_{3} / \mathrm{MeOH}$ yielded 2'-deoxyuridine analogue Z-132a $(65 \%)$, confirming the stability ${ }^{163}$ of the $\mathrm{C}\left(s p^{2}\right)-\mathrm{Ge}(\mathrm{alkyl})_{3}$ and $\mathrm{C}\left(s p^{2}\right)-\mathrm{Ge}(\operatorname{aryl})_{3}$ bonds.

It has been stated that hydrogermylation of the alkyl or aryl alkynes gives vinyl germanes in high yields; however, the detection of $\beta$-germylketones has not been reported yet. ${ }^{112,160,162,164}$ Thus, the hydrogermylation of phenylacetylene with $\mathrm{Ph}_{3} \mathrm{GeH}$ under the optimal conditions described in Method $\mathrm{A}$ and $\mathrm{B}$ has been reexamined. No $\beta$-germylketones were neither observed under such conditions, which is consistent with the literature report. I have also checked the hydrostannylation and hydrosilylation of 5-alkyne nucleoside 127 with $\mathrm{Ph}_{3} \mathrm{SnH}$ and $\mathrm{Ph}_{3} \mathrm{SiH}$ under the same reaction conditions, but again either 5-[2-(triphenylstannyl,- or silyl)acyl] products of type 129a were not observed, which suggest the formation of 129 a were exclusive for $\mathrm{Ph}_{3} \mathrm{GeH}$.

Intrigued by this interesting finding, 1-N-benzyl-5-ethynyluracil $\mathbf{1 3 5}$ was employed as the model substrate for hydrogermylation to examine the chemistry and mechanism involving the formation of 5-keto pyrimidine nucleosides 126a, 133a or 134a. The ${ }^{18}$ O-labeled alkyne 136 was also synthesized to elucidate the origin of the acetyl oxygen. The synthesis of $\mathbf{1 3 5}$ and $\left[{ }^{18} \mathrm{O}\right]-\mathbf{1 3 6}$ was depicted in Scheme 37. Treatment of 1- $\mathrm{N}$-benzyluracil 92 with Lawesson's reagent in THF at $56{ }^{\circ} \mathrm{C}$ for $1 \mathrm{~h}$ gave the $1-N$-benzyl-4-thiouracil 137 in $65 \%$. S-Methylation ${ }^{165}$ of the purified 137 by treatment with $\mathrm{MeI}$ in the presence $\mathrm{Et}_{3} \mathrm{~N}$ in $\mathrm{CH}_{2} \mathrm{Cl}_{2}$ led to the formation of thioether $\mathbf{1 3 8}$ in $93 \%$. The acid-catalyzed hydrolysis ${ }^{166}$ of $\mathbf{1 3 8}$ with $\mathrm{H}_{2}\left[{ }^{18} \mathrm{O}\right]\left(99.2 \%{ }^{18} \mathrm{O}\right)$ in anhydrous EtOH produced desired ${ }^{18} \mathrm{O}$-labeled $1-N$-benzyluracil analogue 139 in $90 \%$ with $85 \%$ of isotopic incorporation, which was calculated on the basis of the corresponding peak intensities in the mass spectra. Iodination of $\mathbf{9 2}$, as well as $\mathbf{1 3 9}$, with a solution of iodine monochloride ${ }^{30}\left(1 \mathrm{M}\right.$ in $\left.\mathrm{CH}_{2} \mathrm{Cl}_{2}\right)$ 
in dry $\mathrm{CH}_{2} \mathrm{Cl}_{2}$ afforded 5-iodouracils 140 and 141 in excellent yields (93\%). Sonogashira couplings of the 5-iodouracils 140 or 141 with trimethylsilylacetylene in $\mathrm{Et}_{3} \mathrm{~N}$ resulted in the formation of $142(80 \%)$ and $143(62 \%)$ respectively. The fluoride-promoted desilylation with TBAF furnished 5-ethynyluracil 135 and its ${ }^{18} \mathrm{O}$-labeled $\mathbf{1 3 6}$ in good yields $(60 \%$ and 58\%, respectively). It is noteworthy that desilylation with $\mathrm{NH}_{4} \mathrm{~F} / \mathrm{MeOH}^{167}$ offered similar results but substantially eased the purification from TBAF-derived residues.

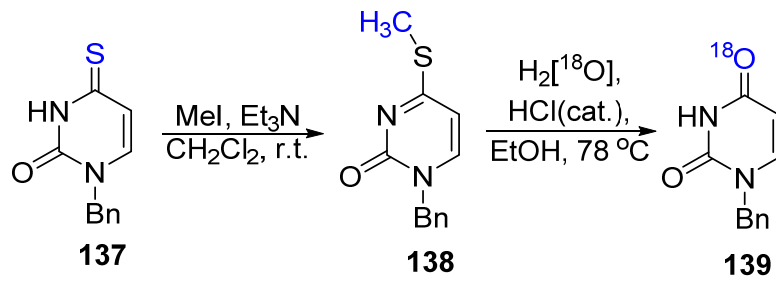

$\uparrow$ Lawesson's Reagent, THF, $56^{\circ} \mathrm{C}$
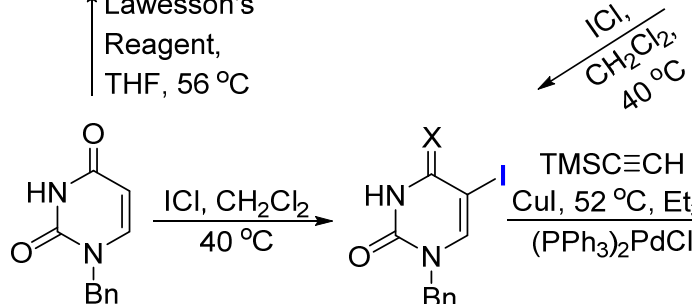
$\underset{\mathrm{ICl}, \mathrm{CH}_{2} \mathrm{Cl}_{2}}{40^{\circ} \mathrm{C}}$

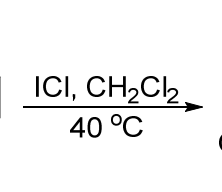

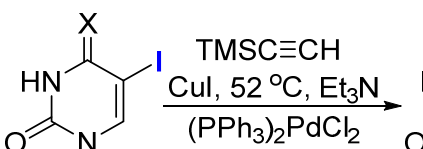

92

$\mathrm{Bn}$ $140 X=0$ $141 \mathrm{X}={ }^{18} \mathrm{O}$

(a) TBAF, THF, $0^{\circ} \mathrm{C}$; (b) $\mathrm{NH}_{4} \mathrm{~F}, \mathrm{MeOH}, 60^{\circ} \mathrm{C}$<smiles></smiles>
$142 \mathrm{R}=\mathrm{TMS}, \mathrm{X}=\mathrm{O}$

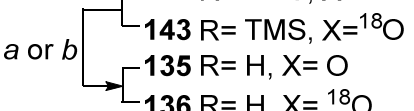

Scheme 37. Synthetic route for the preparation of 5-ethynyluracil and ${ }^{18} \mathrm{O}$-labeled 5-ethynyluracil

Hydrogermylation of $\mathbf{1 3 5}^{168,169}$ with $\mathrm{Ph}_{3} \mathrm{GeH}$ in the presence of $\mathrm{ACCN}$ in toluene at $90{ }^{\circ} \mathrm{C}$ for $2 \mathrm{~h}$ gave $Z$-vinyl germane 144 in $27 \%$ along with 5-[2-(triphenylgermyl)acetyl]uracil 146 in 13\% (Table 11, entry 1). Analogously, 135 was subjected to $\mathrm{Ph}_{3} \mathrm{GeH}$ in toluene at $100{ }^{\circ} \mathrm{C}$ for $10 \mathrm{~h}$ in the absence of ACCN to yield Z-144 and 146 in 34\% and 20\% yields (entry 2). However, analogous treatment of $\mathbf{1 3 5}$ with $\mathrm{Ph}_{3} \mathrm{GeH}$ in "moist" toluene gave syn-addition product $E-\mathbf{1 4 4}$ in $86 \%$ exclusively (entry 3 ). Hydrogermylation of 135 with $\mathrm{Ph}_{3} \mathrm{GeH}$ in the presence of $\mathrm{Et}_{3} \mathrm{~B} / \mathrm{THF}$ at $0{ }^{\circ} \mathrm{C}$ produced $Z-144$ in $52 \%$ as the only product (entry 4). Similar treatment of the ${ }^{18} \mathrm{O}$-labeled alkyne 136 with $\mathrm{Ph}_{3} \mathrm{GeH}$ in toluene at $100{ }^{\circ} \mathrm{C}$ for $10 \mathrm{~h}$ without $\mathrm{ACCN}$ afforded Z-145 as 
crystalline product in $31 \%$ as well as $\mathbf{1 1 4 7}$ in $18 \%$ (entry 5). On the basis of the mass spectroscopy, the incorporation $\left[{ }^{18} \mathrm{O}\right]$-isotopic for both $\mathbf{1 4 5}$ and $\mathbf{1 4 7}$ are the same as the $\mathbf{1 3 6}$.

Table 11. Hydrogermylation of 1- $\mathrm{N}$-benzyl-5-ethynyluracil with triphenylgermane

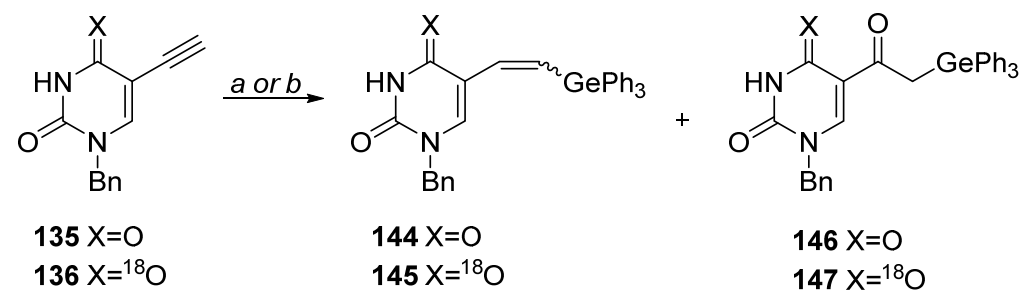

(a) $\mathrm{Ph}_{3} \mathrm{GeH} /(\mathrm{ACCN}) /$ toluene/ $\left(\mathrm{H}_{2} \mathrm{O}\right) / 100$ or $85^{\circ} \mathrm{C}$;

(b) $\mathrm{Ph}_{3} \mathrm{GeH} / \mathrm{Et}{ }_{3} \mathrm{~B} / \mathrm{THF} / 0^{\circ} \mathrm{C}$

\begin{tabular}{|c|c|c|c|c|c|c|c|c|c|}
\hline \multirow[b]{2}{*}{ Entry } & \multirow[b]{2}{*}{ Substrate } & \multirow[b]{2}{*}{ Method $^{a}$} & \multirow[b]{2}{*}{ Temp $\left({ }^{\circ} \mathrm{C}\right)$} & \multirow[b]{2}{*}{$\mathrm{R}_{3} \mathrm{GeH}$} & \multicolumn{3}{|c|}{ Vinyl Germanes } & \multicolumn{2}{|c|}{ Germyl Ketones } \\
\hline & & & & & Product & $\begin{array}{c}\text { Yield }^{b} \\
(\%)\end{array}$ & $\begin{array}{l}\text { Ratio }^{b} \\
(E / Z)\end{array}$ & Product & $\begin{array}{c}\text { Yield }^{b} \\
(\%)\end{array}$ \\
\hline 1 & 135 & A & 90 & $\mathrm{Ph}_{3} \mathrm{GeH}$ & 144 & 27 & $0: 100$ & 146 & 13 \\
\hline 2 & 135 & $\mathrm{~A}^{c}$ & 100 & $\mathrm{Ph}_{3} \mathrm{GeH}$ & 144 & 34 & $0: 100$ & 146 & 20 \\
\hline 3 & 135 & $\mathrm{~A}^{c, d}$ & 100 & $\mathrm{Ph}_{3} \mathrm{GeH}$ & 144 & 86 & 100:0 & - & - \\
\hline 4 & 135 & B & 0 & $\mathrm{Ph}_{3} \mathrm{GeH}$ & 144 & 52 & $0: 100$ & - & - \\
\hline 5 & 136 & A & 100 & $\mathrm{Ph}_{3} \mathrm{GeH}$ & 145 & 31 & $0: 100$ & 147 & 18 \\
\hline
\end{tabular}

${ }^{a}$ Method A: $\mathrm{R}_{3} \mathrm{GeH} / \mathrm{ACCN} /$ toluene/90 or $100{ }^{\circ} \mathrm{C} .{ }^{b}$ Isolated yield. ${ }^{c}$ Without the presence of ACCN. ${ }^{j}$ With addition of $25 \mu \mathrm{L} \mathrm{H}_{2} \mathrm{O}$ (14 equiv.).

\subsubsection{Mechanistic consideration and the origin of 5-acetyl oxygen}

The structures of the 5-[(2-triphenylgermyl)acetyl]uracil derivatives were established using NMR spectroscopic data and HRMS analysis. The absence of the vinyl unit for 133a at the expected downfield region and appearance of two doublets at 3.76 and $3.87 \mathrm{ppm}(J=9.0 \mathrm{~Hz})$ in the ${ }^{1} \mathrm{H}$ NMR spectrum supported the presence of the methylene adjacent to carbonyl and the Ge moiety. The peak at $193.3 \mathrm{ppm}$ in the ${ }^{13} \mathrm{C}$ NMR spectrum of 133a confirmed the presence of the ketone.

The $(+)$ ESI-MS analyses of $\mathbf{1 4 6}$ and the ${ }^{18} \mathrm{O}$-labeled $\mathbf{1 4 7}$ samples produced predominantly the $[\mathrm{M}+\mathrm{Na}]^{+}$ions of 146 and $\mathbf{1 4 7}$. The collision-induced dissociation (CID) of the $[\mathrm{M}-\mathrm{H}]^{-}$ions did produce ions indicative of the ${ }^{18} \mathrm{O}$-containing portion of the molecules (Figure 7). Thus, (-)ESI- 
MS/MS of the $[\mathrm{M}-\mathrm{H}]^{-}$ion of $146\left(\mathrm{~m} / \mathrm{z} 547\left[{ }^{74} \mathrm{Ge}\right]\right)$ showed the most abundant ion cluster containing Ge at $m / z 504\left[{ }^{74} \mathrm{Ge}\right]$ because of the loss of $43 \mathrm{u}(\mathrm{CONH})$ in addition to $\mathrm{m} / \mathrm{z} 158,200$ and 241 fragmentation ions which do not contain Ge. On the other hand (-)ESI-MS/MS of the [M - $\mathrm{H}]^{-}$ion of $\left[{ }^{18} \mathrm{O}\right]-147\left(\mathrm{~m} / \mathrm{z} 549\left[{ }^{74} \mathrm{Ge}\right]\right)$ showed a cluster at $\mathrm{m} / \mathrm{z} 506\left[{ }^{74} \mathrm{Ge}\right]$ in addition to $\mathrm{m} / \mathrm{z} 160$, 202, and 243 product ions $(M+2$ ions relative to 146). These results indicated that during hydrogermylation the ${ }^{18} \mathrm{O}$-isotope remained at $\mathrm{C} 4$ of the uracil ring and that the 4-carbonyl group did not participate in the reaction pathway leading to the formation of $\alpha$-(triphenylgermyl)methyl ketones.

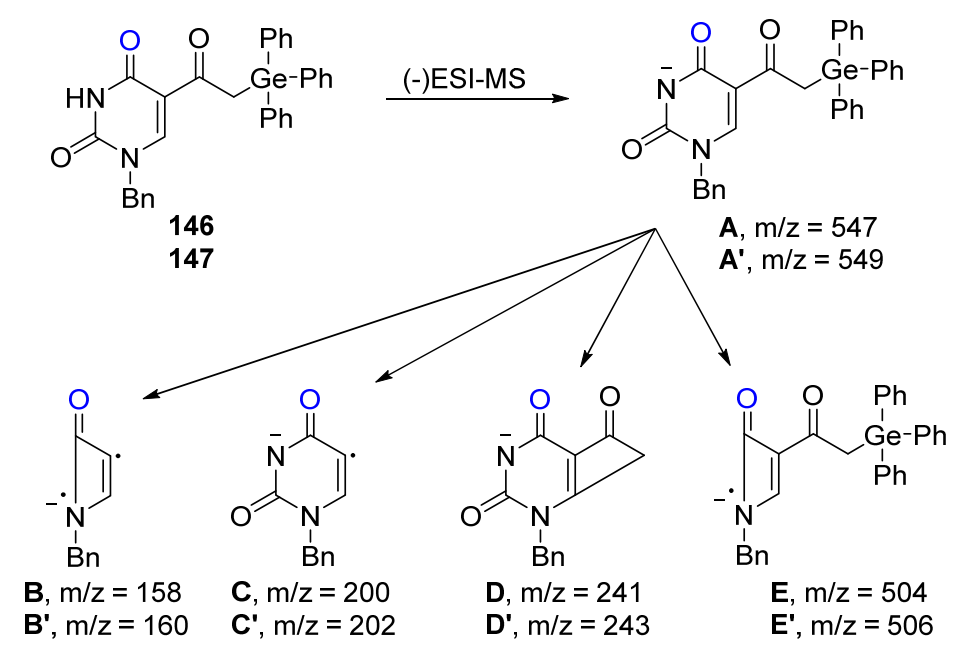

A, B, C, D, E for 146 with ${ }^{16} \mathrm{O} ; \mathrm{A}^{\prime}, \mathrm{B}^{\prime}, \mathrm{C}^{\prime}, \mathrm{D}^{\prime}, \mathrm{E}^{\prime}$ for 147 with ${ }^{18} \mathrm{O}$

Figure 7. Proposed decomposition route for 5-[2-(triphenylgermyl)acetyl]uracils 146 and 147

On the basis of the experimental results, it is believed that the formation of the 5-[2(triphenylgermyl)acetyl]uracil products (e.g., 146) should involve an initial attack of the triphenylgermyl radical at the triple bond of $\mathbf{1 3 5}$ to give a vinylic radical $\mathbf{1 4 8}$ (Scheme 38). Abstraction of hydrogen from triphenylgermane in an anti fashion would produce Z-vinyl germane 144 as a major product while the $s y n$ addition could produce the $E$ isomer of 144 (path a). Reaction of $\mathbf{1 4 8}$ with residual oxygen present in the reaction mixture might lead to the formation of peroxyl radical $\mathbf{1 4 9},{ }^{170}$ followed by the abstract of hydrogen from $\mathrm{Ph}_{3} \mathrm{GeH}^{171}$ to give 
hydroperoxide. The latter can be converted to enol 150, probably by a radical mechanism, and undergo tautomerization to yield the $\beta$-germylketone 146 (path $b$ ).

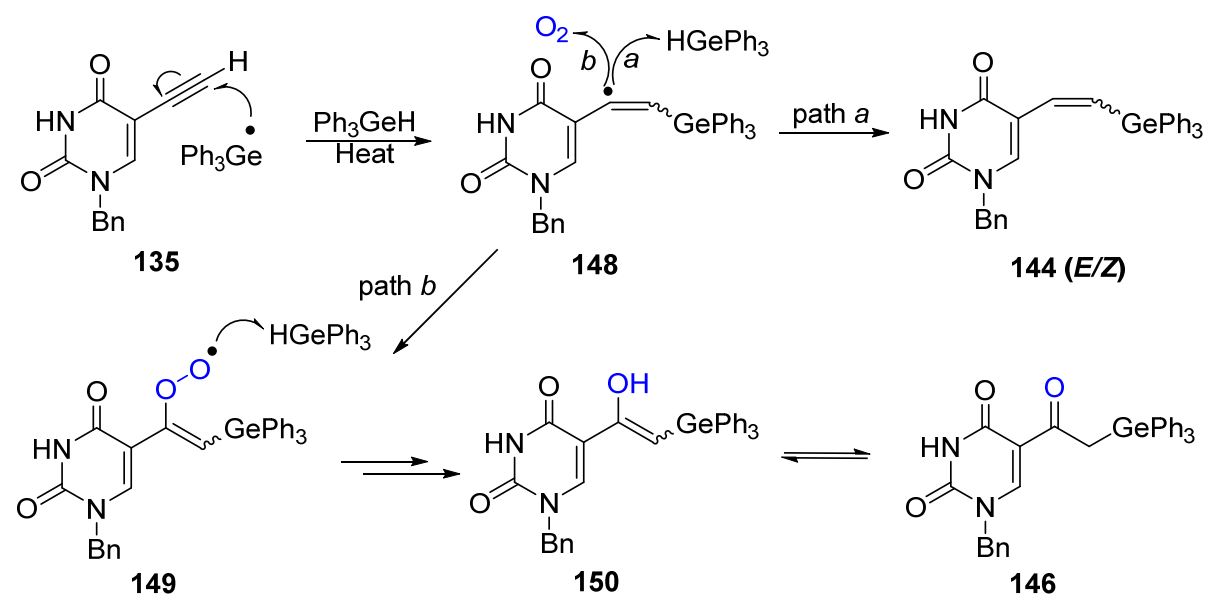

Scheme 38. A plausible pathway for the formation of 5-[(2-triphenylgermyl)acetyl]uracil 147 during radical addition of $\mathrm{Ph}_{3} \mathrm{GeH}$ to 5-acetylenic substrate 135

Efforts have been made to optimize conditions for the preparation 146 in higher yield from the reaction of 135 with $\mathrm{Ph}_{3} \mathrm{GeH}$. Thus, hydrogermylations have been performed varying several experimental parameters. Hydrogermylation of $\mathbf{1 3 5}$ under various condition, such as, $\operatorname{Ar} v s \mathrm{~N}_{2} v s$ aerobic conditions with dry $v s$ reagent-grade toluene $v s$ "moist" toluene (with the added measured amount of $\mathrm{H}_{2} \mathrm{O}$ or $\mathrm{D}_{2} \mathrm{O}$ ), did not improve the yield of 146. It is important to note that hydrogermylation of 135 with $\mathrm{Ph}_{3} \mathrm{GeH}$ in oxygenated toluene resulted in the recovery of unchanged $\mathbf{1 3 5}$, which is probably because of the oxygen induced radical termination. I have also attempted the hydrogermylation employing slow addition of $\mathrm{Ph}_{3} \mathrm{GeH}$ via syringe-pump over 24 hours, but the yield of $\mathbf{1 4 6}$ is not improved. Thus, the optimal conditions for the formation of $\beta$ germylketones would require very low rate of initiation with very low and nearly constant concentration of $\mathrm{Ph}_{3} \mathrm{GeH}$ and oxygen, and then for the germyl radical to react with the terminus of the acetylene group rather than oxygen to give the vinylic radical $\mathbf{1 4 8}$, which should react with oxygen rather than germane to give $\mathbf{1 4 6 .}$ 
During recrystallization of $\mathbf{1 4 6}$ from $\mathrm{MeOH}$, the formation of a new product was observed by TLC, which was characterized as 5 -acetyl-1- $N$-benzyluracil $\mathbf{1 5 2}$ both spectroscopically and by comparison with an authentic sample of $\mathbf{1 5 2}$ that was independently synthesized by acidcatalyzed hydration ${ }^{172}$ of $\mathbf{1 3 5}$. It has been noticed that (triphenylgermyl)methyl ketone 146 could be converted to the 5-acetyl product 152 quantitatively in $\mathrm{MeOH}$ at $65{ }^{\circ} \mathrm{C}$, which should involve intramolecular thermal isomerization via a four-membered ring rearrangement (Scheme 39). Hydrolysis of the resulting $O$-germyl substituted enol $\mathbf{1 5 1}$ led to the formation of the ketone $\mathbf{1 5 2}$. Analogous thermal rearrangements of the $\beta$-silylketones into $O$-silyl substituted enols have been noted as well. ${ }^{173}$ Heating 146 in either MeOD or MeOH- $d_{4}$ gave 1-deuteriomethyl ketone 153 in quantitative yield, which supports the proposed degradation pathway.

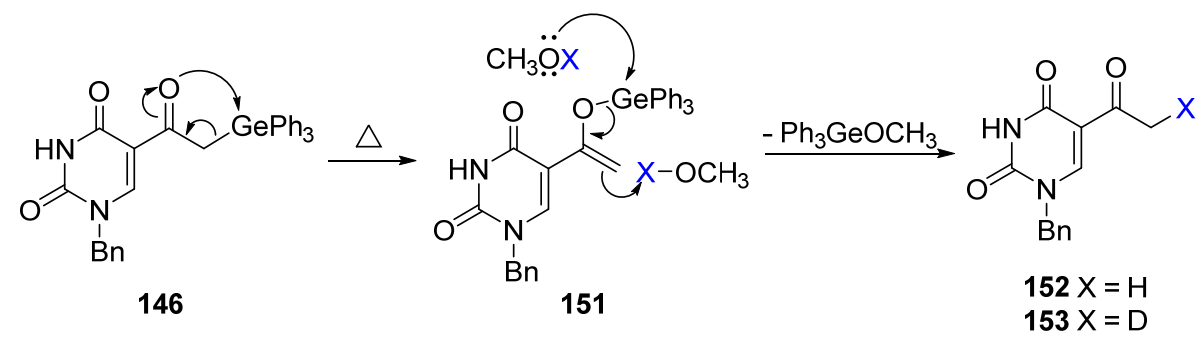

Scheme 39. Proposed route for the thermal degradation of 5-[(2-triphenylgermyl)acetyl]uracil 146 into the 5acetyl product 152

\subsubsection{Application of the 5-[2-(germyl)vinyl]uracil to organic synthesis}

\subsection{Towards Pd-catalyzed cross coupling reaction}

The vinyl tris(trimethylsilyl)germanes are known to be good substrates in the Pd-catalyzed cross-coupling reactions with alkenyl/aryl halides. ${ }^{112,113}$ Thus, various TTMSGe have been prepared under optimal conditions. Hydrogermylation of $\mathbf{1 2 3}$ with reactive $\left(\mathrm{Me}_{3} \mathrm{Si}\right)_{3} \mathrm{GeH}$ by Method A gave 5-[2-(tris(trimethylsilyl)germyl)ethenyl]arabino-uridine analogue $\mathbf{1 2 4 c}$ in $68 \%$ (Scheme 40). Treatment of 2',3',5'-tri-O-p-toluoyl protected 127 with $\left(\mathrm{Me}_{3} \mathrm{Si}\right)_{3} \mathrm{GeH}$ by Method B afforded TTMS-germyl vinyl uracil nucleoside product $Z$-129c in $61 \%$ as a single isomer. Analogously, 1-N-benzyl-5-ethynyluracil 135 was converted to Z-154. The couplings of 
synthesized 5-[2-(TTMS-germyl)vinyl]uracil nucleoside derivatives with the aryl halides via Pdcatalyzed cross-coupling were performed. However, the attempted Pd-catalyzed $\left[\mathrm{Pd}\left(\mathrm{PPh}_{3}\right)_{4}\right]$ coupling of 124c, 129c, or 154 with $\beta$-bromostyrene as well as aryl iodides or bromides under oxidative aqueous $\left(\mathrm{H}_{2} \mathrm{O}_{2} / \mathrm{NaOH} / \mathrm{H}_{2} \mathrm{O}\right)$ or anhydrous $(t$ - $\mathrm{BuOOH} / \mathrm{KH})$ conditions in $\mathrm{THF}^{112}$ gave a complex mixture with the desired coupling products 155 only in $0-15 \%$ (GC-MS). Thus, no additional studies were performed.

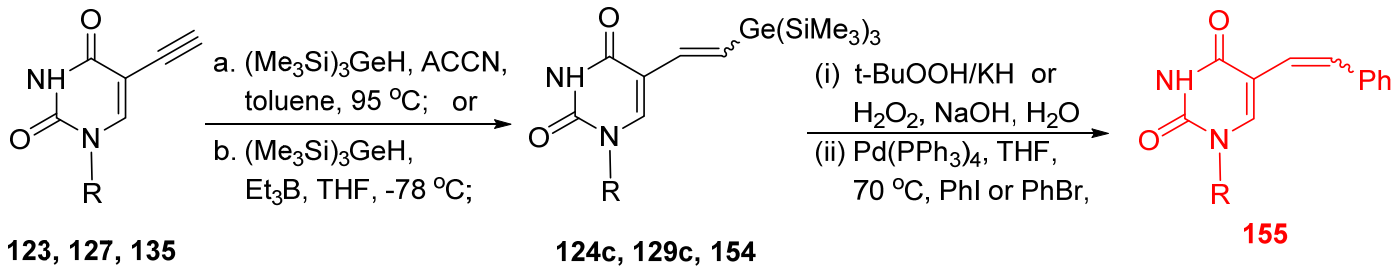

$123,127,135$

124c, 129c, 154

123 and 124c: $\mathrm{R}=2,3,5-$ Tri-O-acetyl- $\beta$-D-arabinofuranosyl

127 and 129c: $\mathrm{R}=2,3,5-T$ ri-O-toluoyl- $\beta$-D-ribofuranosyl

135 and 154: $\mathrm{R}=\mathrm{Bn}$

Scheme 40. Hydrogermylation of 5-ethynyluracil and uracil nucleosides 123, 127 and135 with $\left(\mathrm{Me}_{3} \mathrm{Si}\right)_{3} \mathrm{GeH}$ and attempted Pd-catalyzed cross-coupling of the resulting vinyl germanes with alkenyl or aryl halides

\subsection{Radical halodegermylation}

It is known that the 5(E)-[2-(tributylstannyl)vinyl]uracil nucleosides ${ }^{174-176}$ are good substrates for mild and rapid radiohalogenation via halodestannylation reactions. ${ }^{174-177}$ However, the tendency of 5(E)-[2-(tributylstannyl)vinyl]arabinosyl uridine ${ }^{176}$ and 5-trimethylstannyl $\operatorname{arabinouridine}^{177}$ to undergo protiodestannylation was noted. Lindlar hydrogenation of 5-[2(trimethylsilyl)ethynyl]uracil nucleoside substrates ${ }^{12,178}$ gave 5(Z)-[2-(trimethylsilyl)vinyl]uracil analogues in good yield, but underwent the solvent-dependent isomerization to give the 5-Eisomer analogue as the major component. ${ }^{179}$ Halogenative desilylation of 5-E-vinyl silane substrates ${ }^{180}$ with $\mathrm{XeF}_{2}$ and metal halides gave 5-(2-halovinyl)uracil products in good yield and short time, ${ }^{179}$ and such reactions have been utilized for radioiodination via iododesilylations reactions ${ }^{178,180}$ Germyldesulfonylation protocols have also been developed for the synthesis of vinyl and ( $\alpha$-fluoro)vinyl germanes. ${ }^{113}$ Thus, I carried out the radical halodegermylation of $\beta$ - 
TMSGe vinyl uracil substrates with electrophilic halogen as an alternative practical route for the preparation of $\beta$-halovinyl pyrimidine nucleoside derivatives.

Treatment of 5-[2-(trimethylgermyl)vinyl]uracil nucleoside 131c $(E / Z, 40: 60)$ with $\mathrm{N}$ bromosuccinimide (NBS) at ambient temperature gave 156 via a radical mechanism in high yield, followed by the deprotection with $\mathrm{NH}_{3} / \mathrm{MeOH}$ to afford a mixture of 5-(2-bromovinyl)-2'deoxyuridine 3 in $70 \%(E / Z, \sim 2: 3)$ with retention of the stereochemistry ${ }^{159,163,181}$ (Scheme 41). It indicated the potential application of 5-[2-(trimethylgermyl)vinyl]uracil nucleosides towards the synthesis 5-(2-halovinyl)uracil analogues as well as potential applications to radiolabeling. It is important to note that substitution of the trialkylgermyl group adjacent to an $s p^{182,183}$ or $s p^{2}$ carbon $^{181,182}$ with a halogen proceeded more easily than that of trialkylsilyl substrates and with better stereochemical outcome.

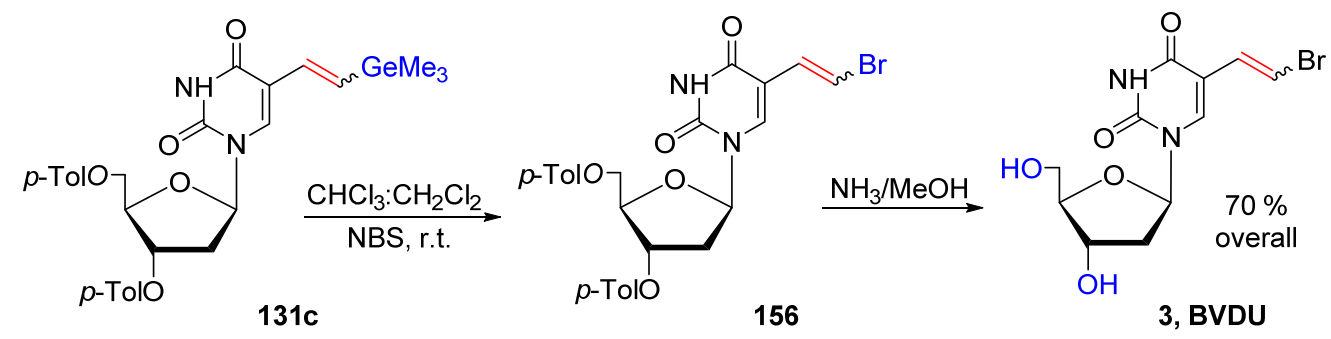

Scheme 41. Radical halodegermylation and deprotection of vinyl trimethylgermane uracil nucleoside with NBS and methanolic ammonia

\subsubsection{Iron-mediated regio- and stereoselective hydrosulfonylation of 5-ethynyluracil nucleosides}

Vinyl sulfones, which are also known as $\alpha, \beta$-unsaturated sulfones, could be synthesized by a broad variety of traditional synthetic methods, such as the ionic and radical addition to unsaturated alkenes, alkynes and allenes, the addition of sulfonyl-stabilized carbanions to carbonyl substrates, the manipulation of acetylenic sulfones or the use of organometallic reagents. ${ }^{184,185}$ As a result of the electron withdrawing property of the sulfonyl group and electron poor nature of their double bond, vinyl sulfones can be treated as excellent Michael acceptors, 
which could be attacked by nucleophiles via 1,4-addition. Since thiol and amine groups, which are good nucleophiles, naturally present or routinely introduced in most biomolecules, such units could be efficiently installed to the $\beta$-position of the vinyl sulfones. Thus, on this basis, the 1,4 addition of vinyl sulfones could be employed to synthesize $\beta$-heterosubstituted vinyl sulfones. Moreover, the sulfonyl moiety can either undergo subsequent functional group transformations or can be easily removed by treatment with $\mathrm{Mg}$ or $\mathrm{Hg} / \mathrm{Na}{ }^{186}$

Vinyl sulfones also play an important role in the biosciences. These molecules can act as irreversible inhibitors of many types of cysteine proteases through conjugate addition of the thiol group of the active site in the cysteine residue, which is the basis of some modern applications of this chemical function in Proteomics. There are two prominent features for vinyl sulfones: first, it is easy to introduce the vinyl sulfones functional group to proteins or nucleosides and the resulting functionalized reagents or intermediates are stable. Secondly, it is the possibility to carry out the Michael additions in physiological conditions (aqueous media, slightly alkaline $\mathrm{pH}$ and room temperature) that preserve the biological function of the proteins in the absence of catalysts and by-products.

Even though there are several reports about the chemical reactivity of vinyl sulfones which allow the functionalization of many organic substrates, the full potential applications of vinyl sulfones are only partially realized. In 2013 , Hocek $^{187}$ and coworkers reported the interaction between the vinylsulfone modified oligonucleotides/DNA and cysteine or glutathione from protein via the Michael addition (Figure 8). The research indicated that the Michael addition modified oligonucleotides/DNA are readily able to couple with cysteine or cysteine-containing peptides/proteins via the Michael addition under physiological conditions. The Michael addition modified nucleotides did not interfere with DNA polymerase, and the vinyl sulfone-modified nucleoside triphosphates are still suitable for the primer extension synthesis of modified 
oligonucleotides. Thus, vinyl sulfone-modified DNA could communicate with different constructs of $\mathrm{p} 53$ protein to form the covalent bond via Michael addition.

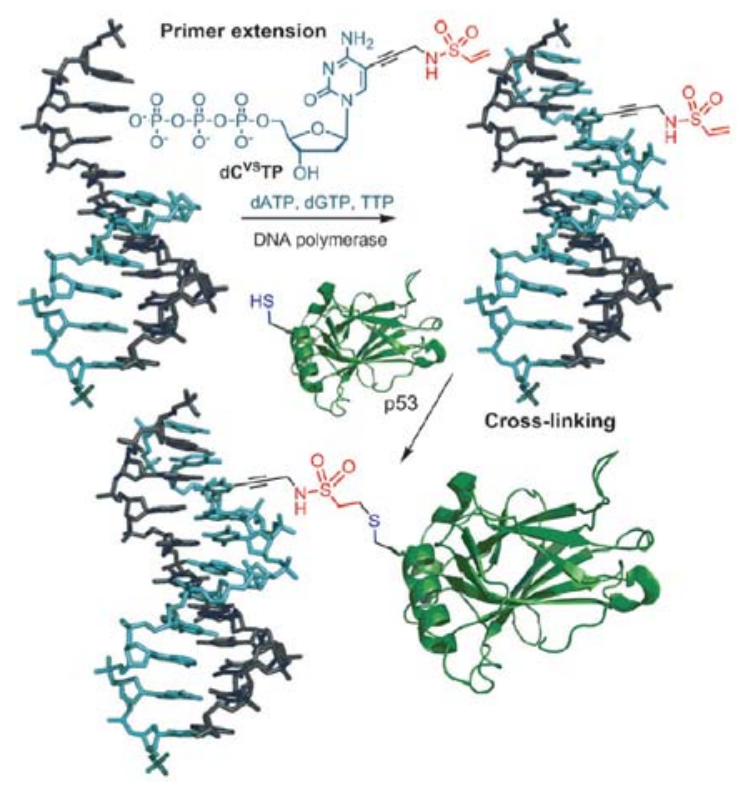

Figure 8. Synthesis of vinylsulfone modified DNA and cross coupling with p53 protein

\subsubsection{Synthesis of 5-(1-chloro-2-tosyl)vinyl uracil nucleosides}

My strategy for the synthesis of reactive vinylsulfone modified nucleosides exploit the iron catalyzed regio- and stereoselective radical halosulfonylation ${ }^{188,189}$ of 5-ethynyluracil nucleosides with sulfonylhydrazides. Compared to the vinylsulfones, there is an additional halogen atom attached to the $\beta$-carbon of the vinylsulfones, which makes the $\beta$-carbon even more prone to be attacked by nucleophiles. Treatment of 1- $N$-benzyl-5-ethynyluracil 135 with sulfonyl chloride 157 in the presence of $\mathrm{Fe}(\mathrm{acac})_{3}$ and triphenylphosphine at $100{ }^{\circ} \mathrm{C}$ for $10 \mathrm{~h}$ gave 5 -(1-chloro-2tosyl)vinyl uracil 158 with complete region- and stereoselectivity (Scheme 42), and this process could also tolerate the acetyl protection group. However, the usage of phosphine ligand and relatively harsh reaction conditions limited the application with temperature sensitive substrates. Moreover, only chlorine substituted vinyl sulfones could be obtained by this method. In order to explore other halogenated vinylsulfones and to compare the reactivity of the different 5-(1chloro-2-tosyl)vinyl uracil analogues, other reaction conditions will be explored. 


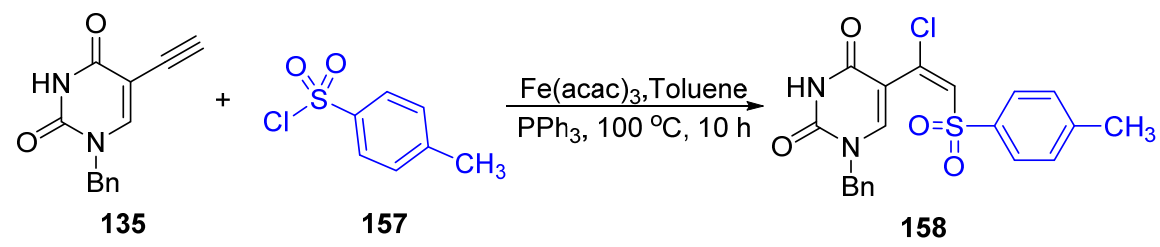

Scheme 42. Synthesis of 5-(1-chloro-2-tosyl)vinyl uracil via hydrosulfonylation of 1- $\mathrm{N}$-benzyl-5-ethynyluracil with tosyl chloride

It is known that $\mathrm{FeCl}_{3}$ could act as a chlorine source in some radical sulfonylation reaction. ${ }^{188,190}$ Thus, efforts have been made to improve the methodology for hydrosulfonylation of 5-ethynyluracil and uracil nucleosides as well as to achieve the synthesis of bromine substituted $\beta$-halovinyl sulfones. Thus, treatment of 1-N-benzyl-5-ethynyluracil $\mathbf{1 3 5}$ with sulfonylhydrozides 159 in the presence of $\mathrm{FeCl}_{3}$ and TBHP in acetonitrile at $80{ }^{\circ} \mathrm{C}$ for $4 \mathrm{~h}$ gave 5(1-chloro-2-tosyl)vinyl uracil 158 in 90\% with absolute regio and stereoselectivity (Scheme 43).

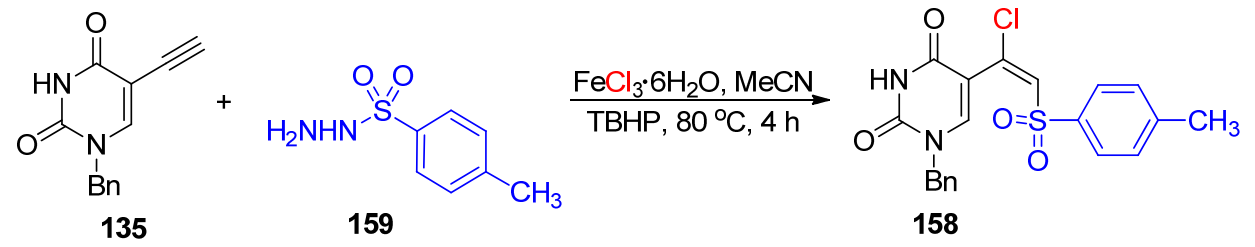

Scheme 43. Synthesis of 5-[(E)-( $\beta$-chloro)vinyl]sulfonyl uracil via hydrosulfonylation of 5-ethynyluracil with tosyl hydrazide in the presence of $\mathrm{FeCl}_{3}$

Similarly, the Fe(III) catalyzed hydrosulfonylation could be also extended to the synthesis of $\beta$-bromovinyl sulfones via addition of $\mathrm{FeBr}_{3}$ as the bromine source. Treatment of 1 - $N$-benzyl-5ethynyluracil 135 with sulfonylhydrozides 159 in the presence of $\mathrm{FeBr}_{3}$ and $\mathrm{TBHP}$ in acetonitrile at $80{ }^{\circ} \mathrm{C}$ for $4 \mathrm{~h}$ gave 5-(1-bromo-2-tosyl)vinyl uracil $\mathbf{1 6 0}$ as well as the dibromo substituted uracil analogue $\mathbf{1 6 1}$ as the byproduct (Scheme 44). It is worth mentioning that the formation of dihalo uracil analogues 161 is specific for $\mathrm{FeBr}_{3}$-promoted hydrosulfonylation and could be inhibited by the increase of the loading of $\mathbf{1 5 9}$. 


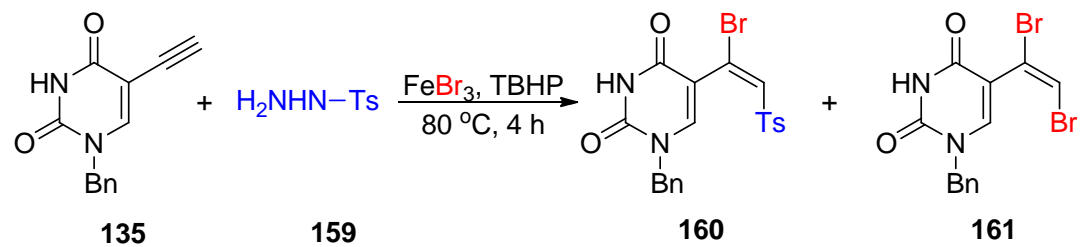

Scheme 44. Synthesis of 5-[(E)-( $\beta$-bromo)vinyl] sulfonyl uracil via hydrosulfonylation of 5-ethynyluracil with tosyl hydrazide in the presence of $\mathrm{FeBr}_{3}$

In order to check the generality of the hydrosulfonylation, the methodology was extended to 5-ethynyluracil nucleoside substrates, which share the same nucleobase. Thus, treatment of 2',3',5'-tri- $O$-acetyl-5-ethynyluridine $\quad \mathbf{1 6 2}, \quad$ or $\quad 2,3,5$-tri- $O$-acetyl-1-( $\beta$-D-arabinofuranosyl)-5ethynyluracil 123 with tosyl hydrazide 159 under the optimal conditions gave 5-(1-chloro-2tosyl)vinyluracil nucleosides 165 and 166 in 68\% and 66\% respectively (Scheme 45). Analogous treatment of 3',5'-di-O-acetyl-5-ethynyl-2'-deoxyuridine 163 with 159 gave the corresponding product 167 in $76 \%$. The hydrosulfonylation is also compatible with the unprotected 5ethynyluracil nucleosides. Thus, heating of 2'-deoxy-5-ethynyluridine 157 with 159 in the presence of $\mathrm{FeCl}_{3}$ and TBHP gave 168 in $69 \%$.

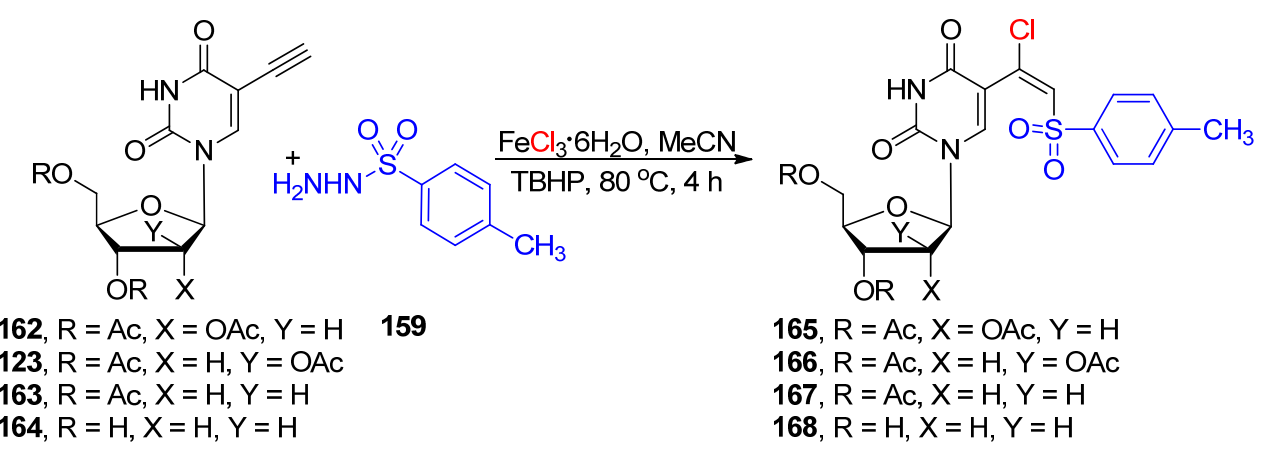

Scheme 45. Synthesis of 5-[(E)-( $\beta$-chloro)vinyl]sulfonyl uracil nucleosides via hydrosulfonylation

On the basis of the experimental results and literature reports, ${ }^{188,189}$ the proposed mechanism is summarized in Figure 9. 


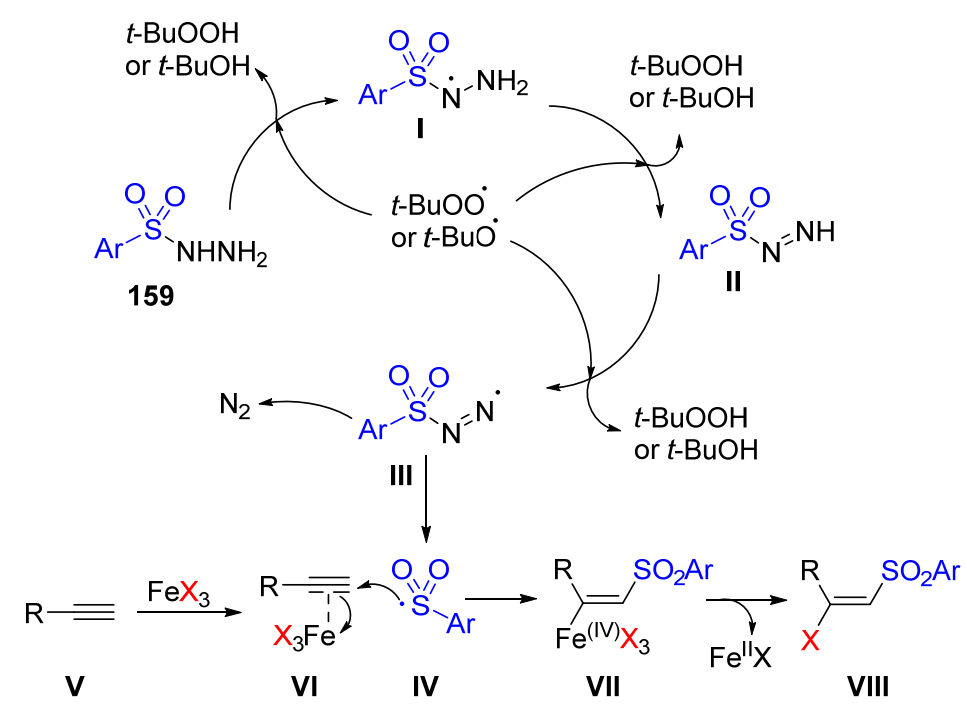

Figure 9.Proposed mechanism for the Fe(III) mediated hydrosulfonylation of 5-ethynyluracil nucleosides

Initially, hydrogen abstraction of sulfonylhydrazides 159 by the tert-butoxyl or tertbutylperoxy radicals, which were generated in situ from an iron-TBHP catalytic circle, gave sulfonylhydrazide radical intermediate $\mathbf{I}$, followed by another two hydrogen abstractions to give active sulfonyl radical IV with release of $\mathrm{N}_{2}$. Meanwhile, the 5-ethynyluracil nucleoside $\mathbf{V}$ is also activated by the iron halides to form the Fe-coordinated alkynes VI. Regio- and stereoselective addition of the sulfonyl radical IV to the terminal carbon of the Fe-coordinated acetylene intermediate VI leads to $\mathrm{Fe}^{(\mathrm{IV})}$ intermediate VII. Subsequent reductive elimination afforded the (E)- $\beta$-halovinylsulfones VIII with the generation of the $\mathrm{Fe}^{(\mathrm{II})}$ catalyst.

\subsubsection{Application of 5-(1-chloro-2-tosyl)vinyl uracil nucleosides to organic synthesis}

As it is known that vinyl sulfones are good acceptors for Michael addition reactions, treatment of vinylsulfones with nucleophiles should provide highly functionalized $\beta$-substituted vinylsulfones. Thus, it is interesting to contemplate what will ensure in such system when the $\beta$ position is occupied by halogen. Treatment of (E)-1-N-benzyl-5-(1-chloro-2-tosyl)vinyl uracil 158 with methanolic ammonia in $\mathrm{MeOH}$ at room temperature for $2 \mathrm{~h}$ led to the formation of a white suspension. Subsequent vacuum filtration gave a white precipitate which was characterized 
by NMR and HRMS as the (E)-1- $N$-benzyl-5-(1-amino-2-tosyl)vinyl uracil 169a (Scheme 46). It is worthy to note that only one isomer was isolated after the reaction, as the nucleophilic substitution maintained the stereochemical configuration of the starting vinyl sulfonyl substrates.

In order to check the generality of the reaction, $\mathbf{1 5 8}$ was subjected to $n$-butylamine under similar conditions to yield the corresponding product $\mathbf{1 6 9 b}$ in quantitative yield in $2 \mathrm{~h}$. However, analogous treatment of $\mathbf{1 5 8}$ with 1-propanethiol only gave unchanged starting substrate after stirring at room temperature for $24 \mathrm{~h}$. Considering the nucleophilicity of the thiol group $v s$ the thio anion, a catalytic amount of triethylamine was added as the external base to abstract the hydrogen from the thiol group; surprisingly, the reaction proceeded to completion in $1 \mathrm{~h}$ to give 169c as a single isomer in $99 \%$ yield.

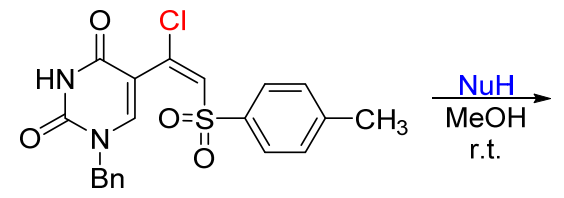

158

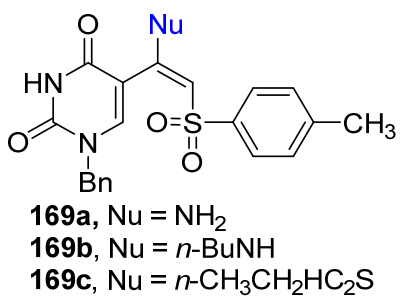

$169 \mathrm{~b}, \mathrm{Nu}=n-\mathrm{BuNH}$
$169 \mathrm{c}, \mathrm{Nu}=n-\mathrm{CH}_{3} \mathrm{CH}_{2} \mathrm{HC}_{2} \mathrm{~S}$

\section{Scheme 46. Nucleophilic substitution of (E)-1- $N$-benzyl-5-(1-chloro-2-tosyl)vinyluracil with methanolic ammonia}

The stability of the glycosidic bond as well as the protecting group of uracil nucleoside have also been tested. Thus, acetyl protected vinyl sulfonyl uridine 165 was subjected to methanolic ammonia for $48 \mathrm{~h}$ and gave 5-(1-amino-2-tosyl)vinyl uridine 170a as well as small amount of the partial deprotected 5'-O-acetyl-5-(1-amino-2-tosylvinyl)uridine (Scheme 47). It is obvious that both deacetylation and nucleophilic substitution took place even in the presence of $n$-butylamine. Similarly, the nucleophilic substitution of $\mathbf{1 6 5}$ with $n$-butylamine and propanethiol (with catalytic amount of $\mathrm{Et}_{3} \mathrm{~N}$ ) gave $\mathbf{1 7 0 b}$ and $\mathbf{1 7 0}$ in respectable yield. The nucleophilic substitution has also been applied to the 5-(1-chloro)vinyl-2'-deoxyuridine derivatives 167 and 168, which are relative more labile comparing to the ribosyl nucleoside. 


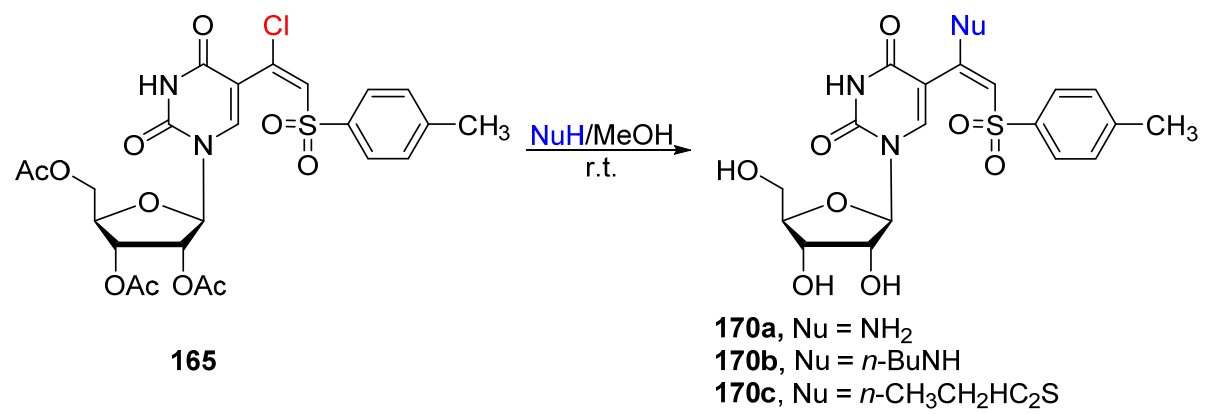

Scheme 47. Synthesis of nucleophile substituted vinyl sulfonyl uracil nucleoside analogues via additionelimination mechanism

On the basis of the experimental evidence, the nucleophilic substitution is believed to proceed through the addition-elimination mechanism. The proposed mechanism is depicted in Scheme 48. Initially, the nucleophile attacks the $\beta$-carbon of vinylsulfone 171, which is partially positive because of the electron withdrawing property of the sulfonyl group as well as the electronegativity of the halogen, followed by a rearrangement to give intermediate 172, which tautomerizes to $\mathbf{1 7 3}$, and ends up as $\beta$-substituted vinyl sulfone 166 by the elimination of halogen ion.

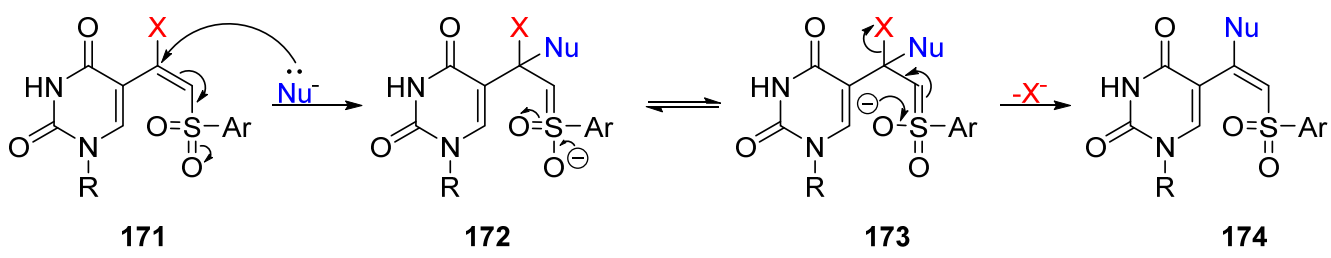

$\mathrm{R}=$ Benzyl, ribosyl, 2'-deoxyribosyl, arabinosyl

Scheme 48. Proposed mechanism for the nucleophilic substitution of 5-[(1-halo-2-tosyl)vinyl]uracil and uracil nucleosides

Since the 5-(1-halo-2-tosyl)vinyl uracil nucleosides are excellent substrates for substitution, they could be potentially incorporated into DNA or RNA and employed as a reactive site to study the interaction between oligonucleotide and peptide or protein in biological model systems. With the synthetic method in hand, ${ }^{191-193}$ my plan was to convert the 2'-deoxy-5-(1-halo-2-tosyl)vinyl uridine 168 to 5'-triphosphate product 175 by a modified Yoshikawa method, followed by exposure to polymerase to give functionalized nucleotide 176 (Scheme 49). 


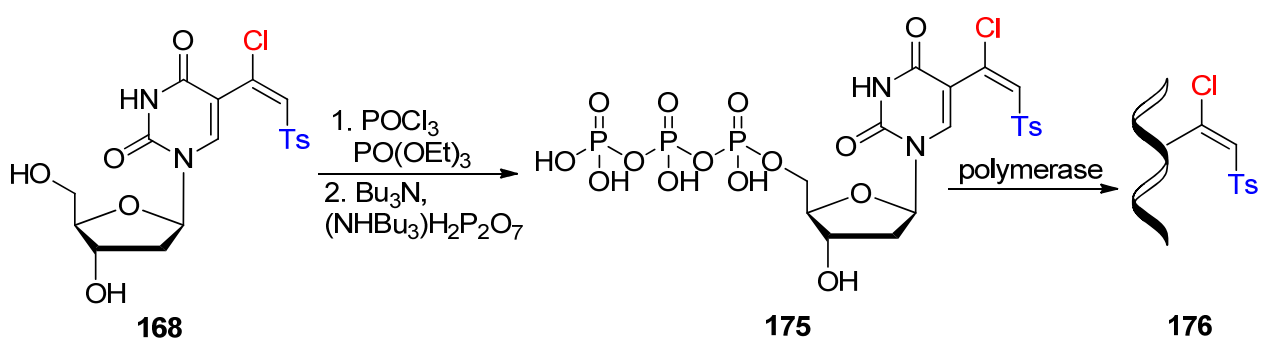

Scheme 49. Phosphorylation of 2'-deoxy-5-[(1-halo)-2-tosyl]vinyluridine 168 and the synthesis of functionalized nucleotide

\subsubsection{Aerobic difunctionalization of 5-ethynyluracil nucleosides}

$\beta$-Keto sulfones $\mathbf{1 7 7}$ are important synthetic intermediates and some of them have shown biological activity. ${ }^{194}$ The summary of the synthetic methods for $\beta$-keto sulfones is depicted in Scheme 50, which includes i) alkylation of sulfinates with either $\alpha$-halo ketones ${ }^{195}$ or $\alpha$-tosyloxy ketones $\mathbf{1 7 8},{ }^{196}$ (ii) oxidation of $\beta$-thioether ketones $\mathbf{1 7 9},{ }^{197}$ (iii) reactions of diazo sulfones $\mathbf{1 8 0}$ with aldehydes in the presence of $\mathrm{SnCl}_{2},{ }^{198}$ (iv) ruthenium(II) catalyzed reaction of sulfonyl chlorides with silylenol ethers $\mathbf{1 8 1},{ }^{199}$ and (v) acylation of alkyl sulfones $\mathbf{1 8 0}$, which could be converted into $\beta$-keto sulfones by $\mathrm{N}$-Acylbenzotriazoles ${ }^{200}$

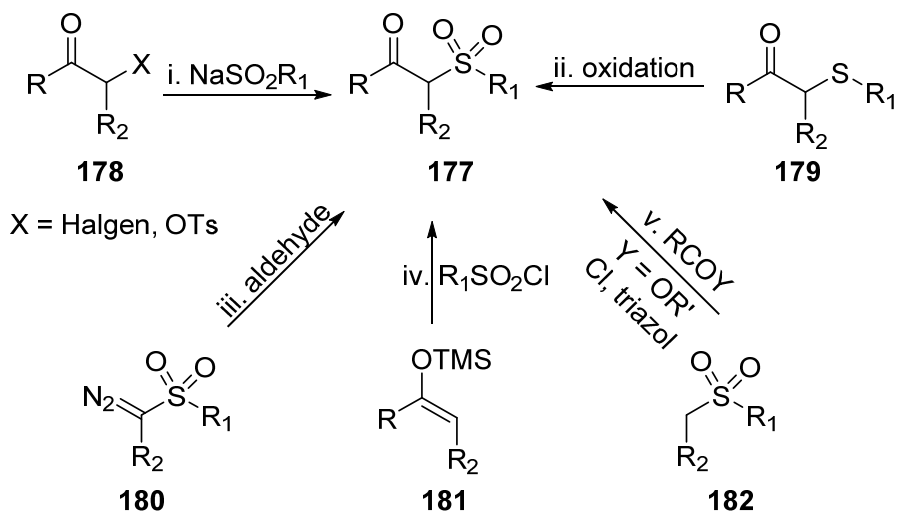

Scheme 50. Reported synthetic route for the preparation of $\beta$-keto sulfones

\subsubsection{Synthesis of 5-( $\beta$-keto)sulfonyluracil nucleosides}

Contrary to the 5-[(1-halo)-2-tosyl]vinyluracil nucleoside derivatives 171, which are excellent Michael acceptors, 5-( $\beta$-keto)sulfonyl pyrimidine nucleoside analogues 177 would be good electrophiles after abstraction of a methylene proton with base. They could be synthesized 
by direct aerobic difunctionalization of 5-ethynyl uracil nucleoside analogues with sulfinic acid in the presence of a catalytic amount of pyridine. Thus, these two types of 5-modified pyrimidine nucleosides will be excellent substrates for the study of both nucleophilic and electrophilic substitution. Treatment of 1-N-benzyl-5-ethynyluracil 135 with $p$-toluyl sufinic acid $\mathbf{1 8 3}$ in the presence of air (oxygen) with a catalytic amount of pyridine at $45{ }^{\circ} \mathrm{C}$ for $4 \mathrm{~h}$ gave the $5-(\beta$ keto)sulfonyl uracil derivative $\mathbf{1 8 4}$ in $50 \%$ (Scheme 51). Since the sulfinic acid is very easily to be oxidized in air, it is better to synthesize the sulfinic acid just before the hydrosulfonylation.

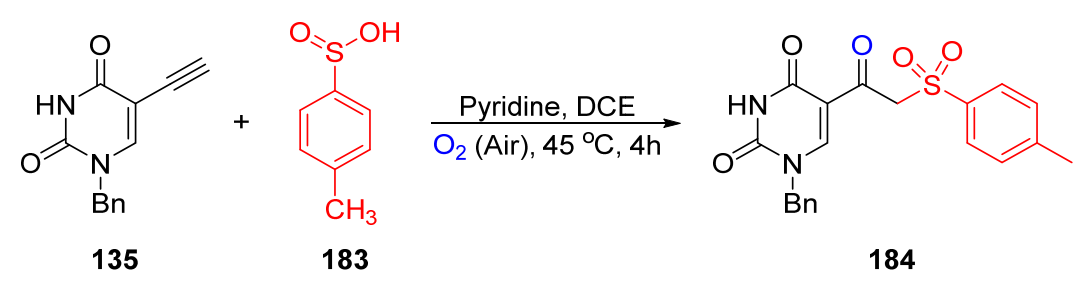

Scheme 51. Synthesis of 5-[( $\beta$-keto)sulfonyl]uracil via aerobic difunctionalization of 5-ethynyluracil 135

On the basis of the experimental result and literature reports, ${ }^{170}$ a proposed reaction pathway for the synthesis of 5-( $\beta$-keto)sulfonyl uracil derivatives is depicted in Figure 10. First, pyridine abstract the active hydrogen from sulfinic acid to give sulfinyl anion I, followed by the autoxidation with oxygen via a single electron transfer (SET) process to afford an oxygencentered radical II, which could tautomerize to the more stabilized sulfonyl radical III. Subsequently, the terminal carbon of such alkynes is attacked by the sulfonyl radical III to produce the reactive vinyl radical $\mathbf{I V}$, which could be trapped by dioxygen to give peroxide radical intermediate $\mathbf{V}$. Then, peroxide VII, which was obtained via another single electron transfer and proton transfer successively with sulfinyl anion I and pyridinium, undergoes reduction by sulfinic acid to give the $\beta$-hydroxyvinyl sulfonyl intermediate VII. Finally, subsequent tautomerization gave 5-( $\beta$ keto)sulfonyl uracil derivative $\mathbf{1 8 4}$. 


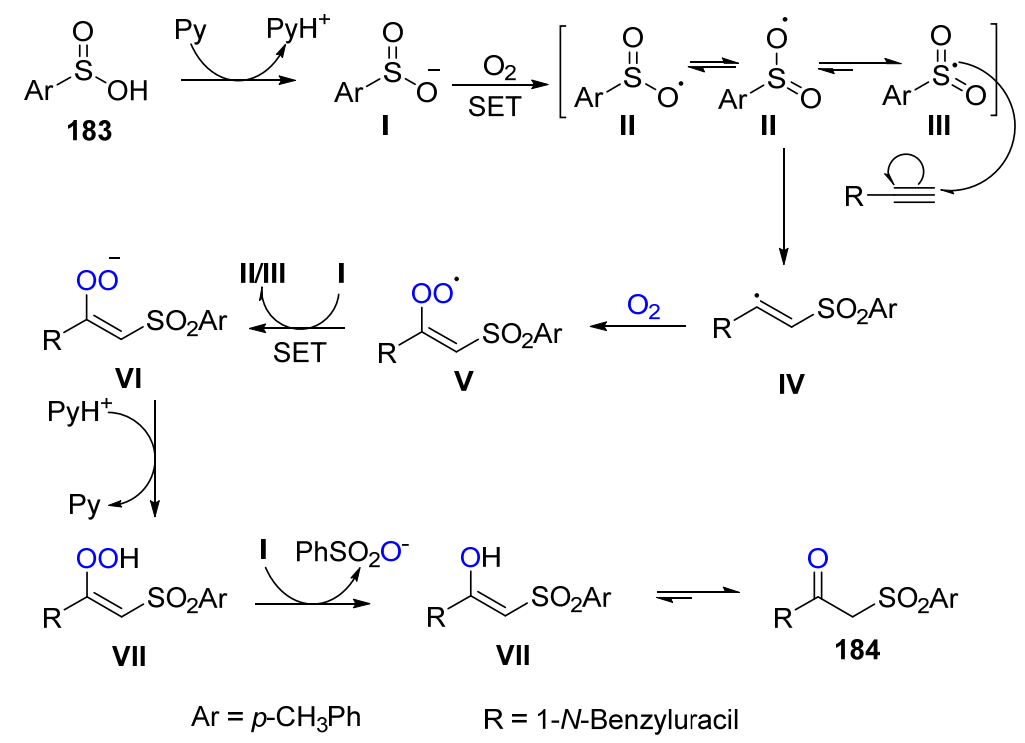

Figure 10. Proposed mechanism for the synthesis of 5-( $\beta$-keto)sulfonyluracil via aerobic difunctionalization

\subsubsection{Application of 5-( $\beta$-keto)sulfonyluracil nucleosides to organic synthesis}

The $\mathrm{p} K_{\mathrm{a}}$ of a methylene proton adjacent to a ketone and sulfonyl group is around 12 , which is quite acidic. Deprotonation with base should give a stabilized anion $\mathbf{1 8 5}$, which could act as the nucleophile (Scheme 52). Subsequent addition of an electrophile should provide the highly substituted 5-( $\beta$-keto)sulfones 187.

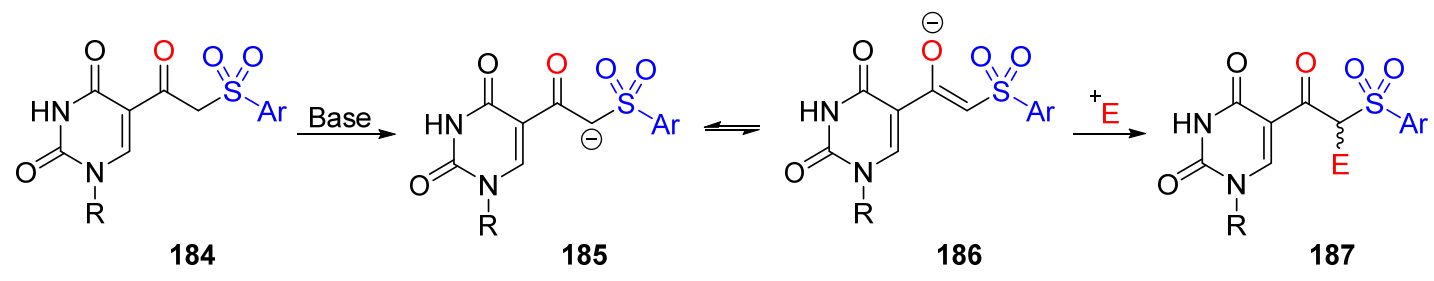

$\mathrm{R}=$ Benzyl, ribosyl, 2'-deoxyribosyl, arabinosyl

Scheme 52. Proposed mechanism for the electrophilic substitution of 5-[(2-sulfonyl)acetyl]uracil and uracil nucleosides

Thus, treatment of 1-N-benzyl-5-[(2-sulfonyl)acetyl]uracil 184 with $\mathrm{NaOH}$ at room temperature followed by the addition of benzylbromide gave $\mathbf{1 8 8}$ in $41 \%$ (Scheme 53). In the future, the protocol will be extended to nucleoside substrates as well to functionalized nucleotides. 


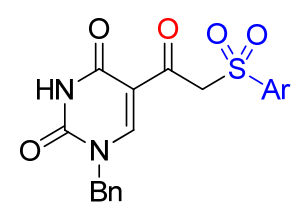

184

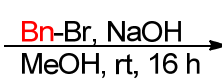



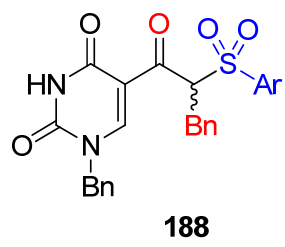

188

Scheme 53. Synthesis of 5-[(2-benzyl-2-sulfonyl)acetyl]uracil via the electrophilic substitution

\subsubsection{Silver catalyzed hydroazidation of 5-ethynyluracil nucleosides}

The size of the azido group is extremely small which is favorable for cell permeability, and this feature avoids perturbations. The azide is particularly bioorthogonal, because it is also metabolically stable, and does not naturally exist in cells, so, there are no competing biological side reactions. The incorporation of azido modified nucleoside analogues into living cells can enable sensitive detection of DNA replication through copper(I)-catalyzed azide-alkyne cycloaddition (CuAAC, first generation of click reaction) and strain-promoted azide-alkyne cycloaddition (SPAAC, second generation of click reaction). Since the cyclooctynes are the smallest stable cyclic alkynes which could increases reactivity through ring strain, this high reactivity resulted in the fact that there is no copper catalyst required and that the reaction is quantitative. Thus, cyclooctynes are the best candidate for the click reaction of the azido nucleoside analogues.

The photo-labile 5-azido-2'-deoxyuridine 192 has been synthesized ${ }^{201-203}$ via preparation and reduction of 5-nitro pyrimidine nucleosides $\mathbf{1 9 0}^{201,202}$ (path $\mathrm{A}$, Scheme 54). Due to the inefficiency and tedious preparation of 5-nitrouridine 190, Clivio and coworkers ${ }^{203}$ developed a new approach to synthesize the 5-azido-2'-deoxyuridine 192 in three steps and quantitative yield from the commercially available 5-bromo-2'-deoxyuridine nucleoside 193 via a benzylamination reduction sequence (path B, Scheme 54). Since 5-Azido-2'-deoxyuridine 192 is photo-sensitive and has the tendency to decompose when exposed to light ( $4 \mathrm{~h}$ half-life in water $\left.{ }^{204,205}\right)$. It is not surprising that up to seven products were detected, when 5-azido-2'-deoxyuridine 192 was irritated with UV light in water. ${ }^{205}$ 


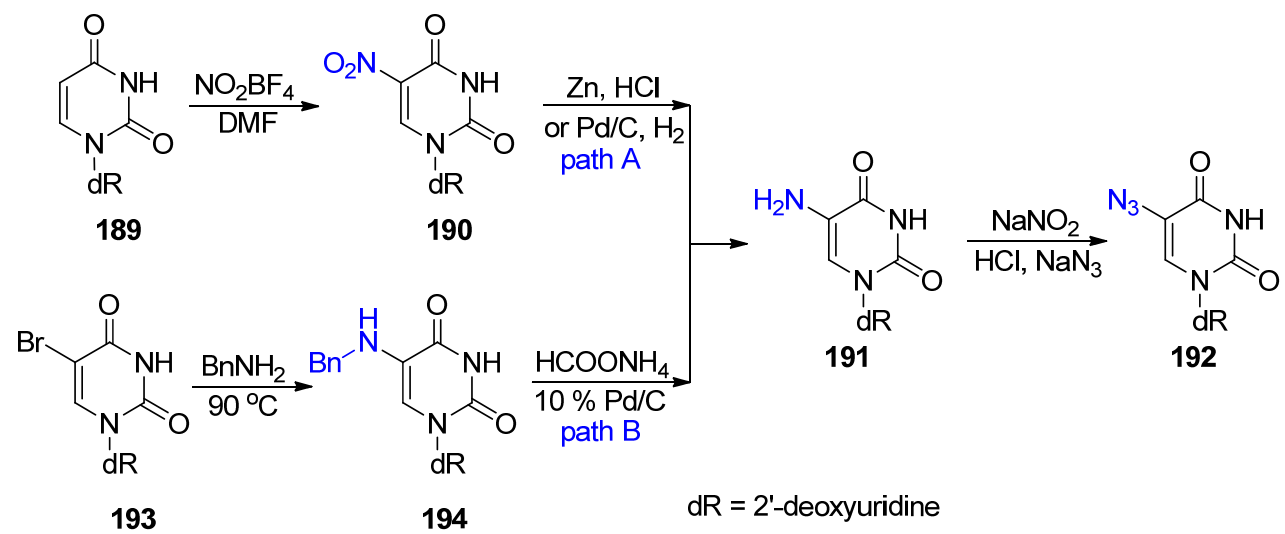

Scheme 54. Synthesis of 5-azido-2'-deoxyuridine via two different pathways

In order to overcome the poor chemical stability of 5-azido pyrimidine nucleoside analogues, Luedtke and coworker ${ }^{204}$ synthesized 5-(azidomethyl)-2'-deoxyuridine 197, which is stable in solution at $37^{\circ} \mathrm{C}$, and it gives robust labeling of cellular DNA upon addition of fluorescent alkyne derivatives (Scheme 55). However, the azido group and the pyrimidine ring are isolated by the methylene carbon which is $\mathrm{sp}^{3}$ hybridized. In other words, the pyrimidine is not conjugated with the 1,2,3-triazole ring that is the formed by the click reaction. As a result, the fluorescent intensity of 5-(azidomethyl)-2'-deoxyuridine 197 might be lower than a derivative whose two aromatic rings are connected by $\mathrm{sp}^{2}$ hybridized carbons.

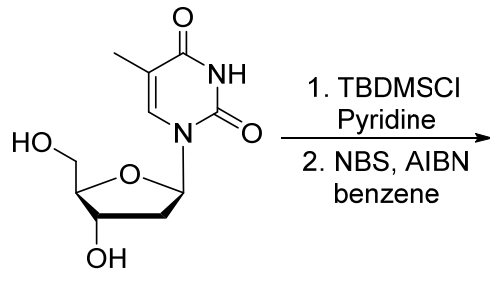

195

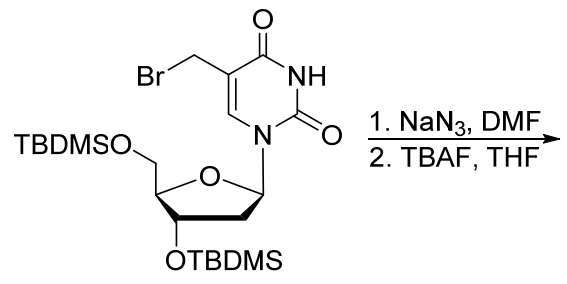

196

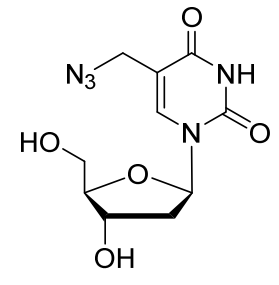

197

Scheme 55. Synthesis of 5-(azidomethyl)-2'-deoxyuridine from thymidine

\subsubsection{Synthesis of 5-( $\alpha$-azidovinyl)uracil nucleosides}

Keeping this goal in mind along with careful screening of the literature, ${ }^{206}$ I have synthesized the 5-( $\alpha$-azido)vinyl pyrimidine nucleoside analogues as the substrates for the click reaction. Since the pyrimidine and 1,2,3-triazole ring are conjugated (two aromatics rings are connected by 
the $\mathrm{sp}^{2}$ hybridized carbon), it is expected that higher fluorescent intensity will be observed. Treatment of 123 with TMS- $\mathrm{N}_{3}$ in the presence of silver carbonate with 2 equiv. of $\mathrm{H}_{2} \mathrm{O}$ in DMSO at $80{ }^{\circ} \mathrm{C}$ for $4 \mathrm{~h}$ gave 5-( $\alpha$-azidovinyl)uridine analogue $\mathbf{1 9 8}$, which is stable at room temperature in $\mathrm{MeOH}$ solution (Scheme 56).

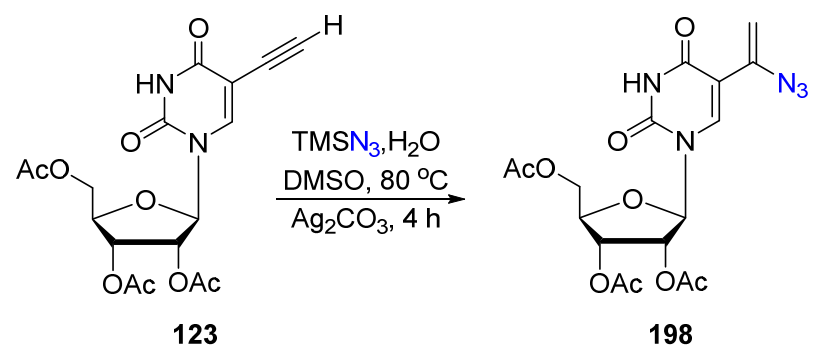

Scheme 56. Silver catalyzed hydroazidation of 5-ethynyluridine and click reaction

\subsubsection{Application of 5-( $\alpha$-azidovinyl)uracil nucleosides to organic synthesis}

The copper free Click reaction has been performed with acetyl protected 5- $(\alpha-$ azido)vinyluridine 198 to check the stability of the azido group. Thus, stirring of 198 with cyclooctyne 199 in $\mathrm{MeOH}$ at ambient temperature for $1 \mathrm{~h}$ gave the corresponding trizole 200 in $80 \%$ as a mixture of two regio-isomers with ratio of $1: 1$. Deprotection of $\mathbf{2 0 0}$ with $\mathrm{NH}_{3} / \mathrm{MeOH}$ gave 201 in quantitative yield (Scheme 57).

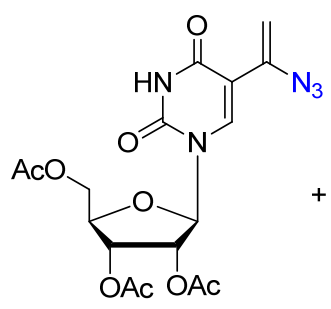

198

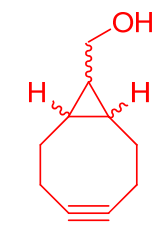

199
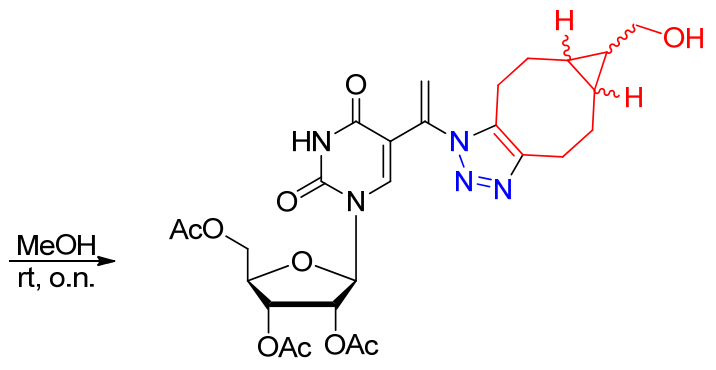

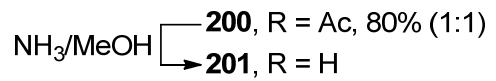

Scheme 57. Strain promoted copper free Click reaction of 5-[( $\alpha$-azido)vinyl]uridine 198 with cyclooctyne 199

It has been noted that clickable oligonucleotides with acetylene residues in the 5-position of pyrimidines (uridine and cytidine) have the tendency to hydrolyze to the acetyl substrates during solid-phase oligonucleotide synthesis and workup conditions. ${ }^{207}$ The 5 -azido pyrimidine 
nucleoside 192 is photo-labile. ${ }^{204,205}$ Thus, they are not good substrates for the preparation of base modified oligonucleotides. Even though the 5-methylazido uridine is fairly stable, the azido group and nucleic base are isolated by the methylene group, which will interfere with the conjugation of the system. Thus, it is not the perfect choice as well. Accordingly, it is desirable to synthesize the oligonucleotides with $\alpha$-azidovinyl in the 5-position of pyrimidines. Treatment of 5-ethynyl-2'deoxyuridine 164 with $\mathrm{TMSN}_{3}$ under the optimal conditions should provide 5- $(\alpha-$ azidovinyl)uridine analogues, and subsequent phosphorylation and proton exchange should give 202 (Scheme 58). The 5-( $\alpha$-azido)vinyl functionalized oligonucleotide 203 should be obtained by exposure of $\mathbf{2 0 2}$ to polymerase.

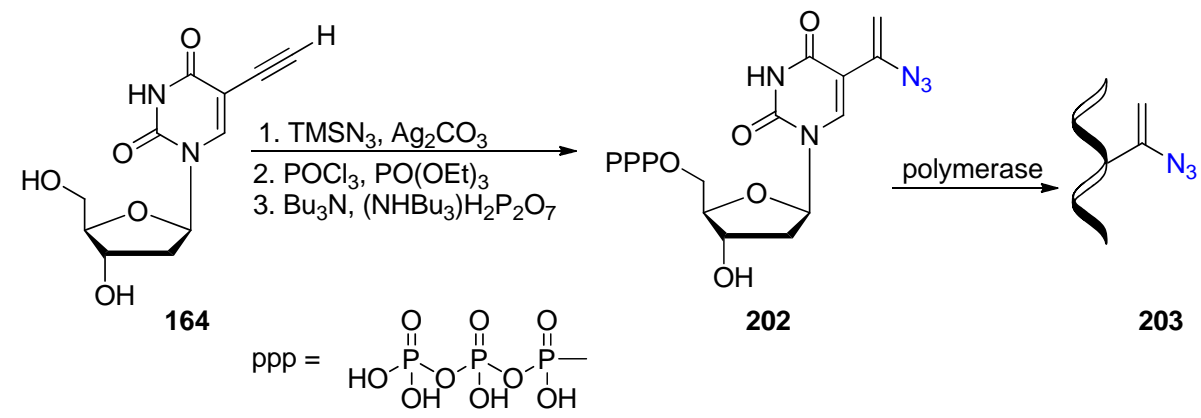

Scheme 58. Proposed route for the synthesis of 5-( $\alpha$-azido)vinyl functionalized nucleotide 


\section{EXPERIMENTAL SECTION}

\subsection{General Procedures}

${ }^{1} \mathrm{H}\left(\mathrm{Me}_{4} \mathrm{Si}\right)$ NMR spectra at $400 \mathrm{MHz},{ }^{13} \mathrm{C}\left(\mathrm{Me}_{4} \mathrm{Si}\right)$ at $100.6 \mathrm{MHz}$ and ${ }^{19} \mathrm{~F}\left(\mathrm{CCl}_{3} \mathrm{~F}\right)$ at 376.4 $\mathrm{MHz}$ were determined with solutions in $\mathrm{CDCl}_{3}$. TLC was performed on Merck kieselgel $60-\mathrm{F}_{254}$ and products were detected with $254 \mathrm{~nm}$ light or by development of color with $\mathrm{I}_{2}$. Merck kieselgel 60 (230-400 mesh) was used for column chromatography. Purity, yields and ratio of the products (crude and/or purified) were established using a GC-MS (EI) system with a mass selective detector [capillary column $(30 \mathrm{~m} \times 0.25 \mathrm{~mm} \times 25 \mu \mathrm{m})$ ] using calibrated standards for products or 2-ethylnaphthalene as internal standard. Mass spectra (MS) was obtained with atmospheric pressure chemical ionization (APCI) technique and HRMS in ESI-TOF mode unless otherwise noted. Tris(dibenzylidene-acetone)dipalladium $(0) \quad\left[\mathrm{Pd}_{2}(\mathrm{dba})_{3}\right]$ was purchased from Aldrich-Sigma Co (catalog number: 328774). Germane chlorides are commercially available from Gelest Co., Morrisville, PA, USA.

\subsection{Synthesis}

1-(Phenyl)naphthalene (55). TBAF (1M/THF, $0.98 \mathrm{~mL}, 0.98 \mathrm{mmol})$ was added to a stirred solution of dichlorodiphenylgermane $(76 ; 30.0 \mu \mathrm{L}, 42 \mathrm{mg}, 0.14 \mathrm{mmol}), 1$-iodonaphthalene (45 $\mu \mathrm{L}, 78 \mathrm{mg}, 0.31 \mathrm{mmol})$, water $(100 \mu \mathrm{L}, 5.7 \mathrm{mmol})$ and $\operatorname{Pd}_{2}(\mathrm{dba})_{3}(6.5 \mathrm{mg}, 0.007 \mathrm{mmol})$ in toluene $(3.0 \mathrm{~mL})$ at ambient temperature under nitrogen atmosphere. The resulting brownish mixture was heated at $100{ }^{\circ} \mathrm{C}$ (oil bath) for $15 \mathrm{~h}$. The volatiles were evaporated and the residue was partitioned $\left(\mathrm{H}_{2} \mathrm{O} / \mathrm{CH}_{2} \mathrm{Cl}_{2}\right)$. The organic layer was dried $\left(\mathrm{MgSO}_{4}\right)$, evaporated and purified by column chromatography (hexane) to give $\mathbf{5 5}(51 \mathrm{mg}, 89 \%)$ followed by homocoupling product binaphthlene (6.3 mg, 8\%; 16\% consumption of 1-iodonaphthalene).

Analogous treatment of trichlorophenylgermane $(\mathbf{7 5} ; 24.0 \mu \mathrm{L}, 35.9 \mathrm{mg}, 0.14 \mathrm{mmol})$ with 1 iodonaphthalene $(22.5 \mu \mathrm{L}, 39.1 \mathrm{mg}, 0.155 \mathrm{mmol})$, TBAF (1M/THF, $0.98 \mathrm{~mL}, 0.98 \mathrm{mmol})$, water 
$(100 \mu \mathrm{L}, 5.7 \mathrm{mmol})$, and $\mathrm{Pd}_{2}(\mathrm{dba})_{3}(6.5 \mathrm{mg}, 0.007 \mathrm{mmol})$ in toluene $(3.0 \mathrm{~mL})$ at $100{ }^{\circ} \mathrm{C}$ (oil bath) for $15 \mathrm{~h}$. gave $\mathbf{5 5}(27.4 \mathrm{mg}, 96 \%)$.

Analogous treatment of chlorotriphenylgermane (77; $47.5 \mathrm{mg}, 0.14 \mathrm{mmol})$ with 1iodonaphthalene $(67.5 \mu \mathrm{L}, 117 \mathrm{mg}, 0.46 \mathrm{mmol})$, TBAF (1M/THF, $0.98 \mathrm{~mL}, 0.98 \mathrm{mmol})$, water $(100 \mu \mathrm{L}, 5.7 \mathrm{mmol})$, and $\mathrm{Pd}_{2}(\mathrm{dba})_{3}(6.5 \mathrm{mg}, 0.007 \mathrm{mmol})$ in toluene $(3.0 \mathrm{~mL})$ at $100{ }^{\circ} \mathrm{C}$ (oil bath) for $15 \mathrm{~h}$. gave 55 (75 $\mathrm{mg}, 88 \%)$.

Triallyl(phenyl)germane (81). In a flame-dried round-bottom flask a solution of trichloro(phenyl)germane $(250 \mathrm{mg}, 160 \mu \mathrm{L}, 0.976 \mathrm{mmol})$ in $\mathrm{Et}_{2} \mathrm{O}(2 \mathrm{~mL})$ was treated with allylmagnesium bromide $\left(3.1 \mathrm{~mL}, 3.12 \mathrm{mmol}, 1 \mathrm{M}\right.$ solution in $\mathrm{Et}_{2} \mathrm{O}$ ) added dropwise for $20 \mathrm{~min}$ at $0{ }^{\circ} \mathrm{C}$. After $1 \mathrm{~h}$ stirring at $0{ }^{\circ} \mathrm{C}$ the reaction mixture was refluxed $\left(38{ }^{\circ} \mathrm{C}\right)$ overnight. The reaction was allowed to cool to room temperature and quenched with $\mathrm{NH}_{4} \mathrm{Cl}$ at $0{ }^{\circ} \mathrm{C}$. The organic layer was separated and the aqueous layer extracted with $\mathrm{Et}_{2} \mathrm{O}(2 \times 5 \mathrm{~mL})$. The combined extracts was washed (water and brine), dried $\left(\mathrm{MgSO}_{4}\right)$ and was concentrated in vacuo. The residue was chromatographed (hexanes) to give $81(227 \mathrm{mg}, 85 \%)$ as clear oil: ${ }^{1} \mathrm{H}$ NMR $\delta 2.04(\mathrm{~d}, J=8.3 \mathrm{~Hz}$, $6 \mathrm{H}), 4.89(\mathrm{~d}, J=10.0 \mathrm{~Hz}, 3 \mathrm{H}), 4.95(\mathrm{~d}, J=16.9 \mathrm{~Hz}, 3 \mathrm{H}), 5.88(\mathrm{~m}, 3 \mathrm{H}), 7.38(\mathrm{~m}, 3 \mathrm{H}), 7.47(\mathrm{~m}$, $2 \mathrm{H}) ;{ }^{13} \mathrm{C}$ NMR $\delta 19.54,113.67,127.99,128.74,133.87,134.84,137.95 ;$ GC-MS $\left(t_{\mathrm{R}} 19.1 \mathrm{~min}\right)$ $m / z 274\left(33, \mathrm{M}^{+}\left[{ }^{74} \mathrm{Ge}\right]\right), 151(100)$ and $\left(t_{\mathrm{R}} 16.2 \mathrm{~min}\right) \mathrm{m} / z 233$ (89, $\left.\mathrm{M}^{+}\left[{ }^{74} \mathrm{Ge}\right]-41\right), 151$ (100). Anal. Calcd for $\mathrm{C}_{15} \mathrm{H}_{20} \mathrm{Ge}$ (272.96): C, 66.00; H, 7.39. Found: C, 65.78; H, 7.44.

Diallyl(diphenyl)germane (82). Treatment of a solution of dichloro(diphenyl)germane (1.0 g, $0.707 \mu \mathrm{L}, 3.359 \mathrm{mmol})$ in $\mathrm{Et}_{2} \mathrm{O}(2 \mathrm{~mL})$, as reported for $\mathbf{8 1}$, afforded $\mathbf{8 2}(980 \mathrm{mg}, 94 \%)$ as clear oil: ${ }^{1} \mathrm{H}$ NMR $\delta 2.27(\mathrm{dt}, J=8.3,1.0 \mathrm{~Hz}, 4 \mathrm{H}), 4.90(\mathrm{dq}, J=9.2 \mathrm{~Hz}, 1.7 \mathrm{~Hz}, 2 \mathrm{H}), 4.95$ (d, $J=16.9 \mathrm{~Hz}$ 2H), 5.90 (m, 2H), 7.39 (m, 6H), $7.49(\mathrm{~m}, 4 \mathrm{H}) ;{ }^{13} \mathrm{C}$ NMR $\delta 20.08,114.12,128.08,128.90,134.48$, 134.62, 137.12; GC-MS ( $\left.t_{\mathrm{R}} 22.3 \mathrm{~min}\right) \mathrm{m} / \mathrm{z} 269$ (100, $\left.\mathrm{M}^{+}\left[{ }^{74} \mathrm{Ge}\right]-41\right), 227$ (29), $151(80)$.

Allyl(triphenyl)germane (83). Treatment of a solution of chloro(triphenyl)germane (260.0 $\mathrm{mg}, 0.77 \mathrm{mmol})$ in $\mathrm{Et}_{2} \mathrm{O}(2 \mathrm{~mL})$ with allylmagnesium bromide as reported for 81, (mixing at 
room temperature instead of $\left.0{ }^{\circ} \mathrm{C}\right)$ afforded $83(245 \mathrm{mg}, 92 \%)$ as white solid: ${ }^{1} \mathrm{H}$ NMR $\delta 2.52(\mathrm{~d}$, $J=8.1 \mathrm{~Hz}, 2 \mathrm{H}), 4.90(\mathrm{dq}, J=10.0 \mathrm{~Hz}, 1.0 \mathrm{~Hz}, 1 \mathrm{H}), 5.00(\mathrm{dq}, J=16.9 \mathrm{~Hz}, 1.6 \mathrm{~Hz}, 1 \mathrm{H}), 5.95(\mathrm{~m}$, 1H), $7.40(\mathrm{~m}, 9 \mathrm{H}), 7.51(\mathrm{~m}, 6 \mathrm{H}) ;{ }^{13} \mathrm{C}$ NMR $\delta 21.24,114.50,128.18,129.02,134.53,135.02$, 136.55; GC-MS ( $\left.t_{\mathrm{R}} 24.5 \mathrm{~min}\right) \mathrm{m} / \mathrm{z} 305$ (100, $\left.\mathrm{M}^{+}\left[{ }^{74} \mathrm{Ge}\right]-41\right), 227$ (14), 151 (23).

Treatment of a solution of allyltrichlorogermane $(855 \mathrm{mg}, 560 \mu \mathrm{L}, 3.89 \mathrm{mmol})$ in $\mathrm{Et}_{2} \mathrm{O}(2 \mathrm{~mL})$ with phenylmagnesium bromide $\left(4.0 \mathrm{~mL}, 12 \mathrm{mmol}, 3 \mathrm{M}\right.$ solution in $\left.\mathrm{Et}_{2} \mathrm{O}\right)$, following the procedure as described for $\mathbf{8 1}$, gave compound $\mathbf{8 3}$ (590 $\mathrm{mg}, 44 \%)$.

1-Phenylnaphthalene (88b). Method A: The antimony (V) fluoride (50 wt \% on graphite, $45 \mathrm{mg}, 0.105 \mathrm{mmol}$ ) was added to a stirring solution of triallyl(phenyl)germane (81; $38 \mathrm{mg}, 0.14$ mmol) in toluene $(3.0 \mathrm{~mL})$ at ambient temperature under nitrogen atmosphere in a plastic tube. The resulting mixture was heated at $50{ }^{\circ} \mathrm{C}$ (oil bath) for $1.5 \mathrm{~h}$. After cooled down the solution to ambient temperature, the graphite was filtered off and the mother solution was apply to the second step directly. TBAF (1M/THF, $0.42 \mathrm{~mL}, 0.42 \mathrm{mmol})$, 1-iodonaphthalene $(\mathbf{8 7} \mathbf{b} ; 35 \mathrm{mg}, 20$ $\mu \mathrm{L}, 0.14 \mathrm{mmol})$, water $25 \mu \mathrm{L}$, and $\mathrm{Pd}_{2}(\mathrm{dba})_{3}(6.5 \mathrm{mg}, 0.007 \mathrm{mmol})$ was added to the elute at ambient temperature under nitrogen atmosphere. The resulting brownish mixture was heated at $100^{\circ} \mathrm{C}$ (oil bath) for $15 \mathrm{~h}$. The volatiles were evaporated and the residue was partitioned $\left(\mathrm{H}_{2} \mathrm{O} / \mathrm{CH}_{2} \mathrm{Cl}_{2}\right)$. The organic layer was dried $\left(\mathrm{Na}_{2} \mathrm{SO}_{4}\right)$, evaporated and purified by column chromatography (hexane) to give $\mathbf{8 8 b}(13 \mathrm{mg}, 45 \%)$ followed by $\mathbf{8 9 b}[1.7 \mathrm{mg}, 5 \%, 10 \%$ consumption of the iodonaphthalene; GC-MS $\left(t_{\mathrm{R}} 25.02 \mathrm{~min}\right) \mathrm{m} / z 254\left(100, \mathrm{M}^{+}\right)$]. Compound $\mathbf{8 8 b}$ had: ${ }^{1} \mathrm{H}$ NMR $\delta 7.41-7.58(\mathrm{~m}, 9 \mathrm{H}), 7.89(\mathrm{~d}, J=8.2 \mathrm{~Hz}, 1 \mathrm{H}), 7.91-7.96(\mathrm{~m}, 2 \mathrm{H}) ;{ }^{13} \mathrm{C}$ NMR $\delta 125.5$, $125.9,126.15,126.18,127.1,127.4,127.8,128.4,130.2,131.8,134.0,140.4,140.9 ;$ GC-MS $\left(t_{\mathrm{R}}\right.$ $19.87 \mathrm{~min}) \mathrm{m} / \mathrm{z} 204\left(100, \mathrm{M}^{+}\right)$.

Analogous treatment of $\mathbf{8 2}(43 \mathrm{mg}, 0.14 \mathrm{mmol})$ and 1-iodonaphthalene $(\mathbf{8 7 b} ; 71 \mathrm{mg}, 41 \mu \mathrm{L}$, $0.28 \mathrm{mmol}$ ) with antimony (V) fluoride (50 wt \% on graphite, $30 \mathrm{mg}, 0.07 \mathrm{mmol}$ ) by general method A gave 88b (35 mg, 62\%) and 89b (8 mg, 11\%). 
Analogous treatment of $\mathbf{8 3}$ (48 mg, $0.14 \mathrm{mmol})$ and 1-iodonaphthalene (87b; $106 \mathrm{mg}, 61 \mu \mathrm{L}$, $0.42 \mathrm{mmol}$ ) antimony (V) fluoride (50 wt \% on graphite, $15 \mathrm{mg}, 0.035 \mathrm{mmol}$ ) by general method A gave $\mathbf{8 8 b}$ (54 mg, 63\%) and $\mathbf{8 9 b}(16.5 \mathrm{mg}, 15 \%)$.

Analogous treatment 81 (38 mg, $0.14 \mathrm{mmol})$ with 1-bromonaphthalene (87e; $29 \mathrm{mg}, 19 \mu \mathrm{L}$, $0.14 \mathrm{mmol}$ ) by general method A gave $\mathbf{8 8 b}(42 \%)$ and $\mathbf{8 9 b}(3 \%)$ based on the GC-MS analysis of the crude reaction mixture.

Analogous treatment of $\mathbf{8 2}(43 \mathrm{mg}, 0.14 \mathrm{mmol})$ and 1-bromonaphthalene (87e; $58 \mathrm{mg}, 39 \mu \mathrm{L}$, $0.28 \mathrm{mmol}$ ) with antimony (V) fluoride (50 wt \% on graphite, $30 \mathrm{mg}, 0.07 \mathrm{mmol}$ ) by general method A gave $\mathbf{8 8 b}$ (34\%) and $\mathbf{8 9 b}(15 \%)$ based on the GC-MS analysis of the crude reaction mixture.

Analogous treatment of $\mathbf{8 3}(48 \mathrm{mg}, 0.14 \mathrm{mmol})$ and 1-bromonaphthalene $(\mathbf{8 7 e} ; 87 \mathrm{mg}, 58 \mu \mathrm{L}$, $0.42 \mathrm{mmol}$ ) with antimony (V) fluoride (50 wt \% on graphite, $15 \mathrm{mg}, 0.035 \mathrm{mmol}$ ) by general method A gave $\mathbf{8 7 b}(14 \%)$ and $\mathbf{8 8 b}(4 \%)$ based on the GC-MS analysis of the crude reaction mixture.

1-Phenyl-4-methyloxybenzene (88c). Analogous treatment of 81 (38 mg, $0.14 \mathrm{mmol})$ with 4-iodoanisole (87c; 33mg, $0.14 \mathrm{mmol}$ ) by general method A give 88c (18 $\mathrm{mg}, 71 \%$ ) followed by 89c $\left[1 \mathrm{mg}, 3.5 \%, 7 \%\right.$ consumption of the 4-iodoanisole; GC-MS $\left(t_{\mathrm{R}} 20.81 \mathrm{~min}\right) \mathrm{m} / \mathrm{z} 214(100$, $\left.\mathrm{M}^{+}\right)$]. Compound 88c had: ${ }^{1} \mathrm{H}$ NMR $\delta 3.86(\mathrm{~s}, 3 \mathrm{H}), 7.98(\mathrm{~d}, J=7.8 \mathrm{~Hz}, 2 \mathrm{H}), 7.31(\mathrm{t}, J=7.8 \mathrm{~Hz}$, 1H), $7.42(\mathrm{t}, J=8.6 \mathrm{~Hz}, 2 \mathrm{H}), 7.50-7.58(\mathrm{~m}, 4 \mathrm{H}) ;{ }^{13} \mathrm{C} \mathrm{NMR} \delta 55.5,114.4,126.8,126.9,128.3$, 128.9, 134.0, 141.0, 159.3; GC-MS ( $\left.t_{\mathrm{R}} 17.41 \mathrm{~min}\right) \mathrm{m} / \mathrm{z} 184\left(100, \mathrm{M}^{+}\right)$.

Analogous treatment of $\mathbf{8 2}(43 \mathrm{mg}, 0.14 \mathrm{mmol})$ and 4-iodoanisole $(\mathbf{8 7 c} ; 66 \mathrm{mg}, 0.28 \mathrm{mmol})$ with antimony (V) fluoride (50 wt \% on graphite, $30 \mathrm{mg}, 0.07 \mathrm{mmol}$ ) by general method A gave 88c $(45 \%)$ and 89c (16\%) based on the GC-MS analysis of the crude reaction mixture. 
Analogous treatment of $\mathbf{8 3}$ (48 mg, $0.14 \mathrm{mmol})$ and 4-iodoanisole (87c; $98 \mathrm{mg}, 0.42 \mathrm{mmol})$ with antimony (V) fluoride (50 wt \% on graphite, $15 \mathrm{mg}, 0.035 \mathrm{mmol}$ ) by general method A gave 88c $(32 \%)$ and 89 c (20\%) based on the GC-MS analysis of the crude reaction mixture.

1-Phenyl-4-trifluoromethylbenzene (7d). Analogous treatment of $\mathbf{8 1}(38 \mathrm{mg}, 0.14 \mathrm{mmol})$ with 4-iodobenzotrifluoride (87d; $38 \mathrm{mg}, 21 \mu \mathrm{L}, 0.14 \mathrm{mmol}$ ) by general method A gave $\mathbf{8 8 d}$ (13 $\mathrm{mg}, 41 \%$ ) followed by $\mathbf{8 9 d}$ [ $8.7 \mathrm{mg}, 21.5 \%, 43 \%$ consumption of the 4-iodobenzotrifluoride; GCMS $\left.\left(t_{\mathrm{R}} 13.08 \mathrm{~min}\right) m / z 290\left(100, \mathrm{M}^{+}\right)\right]$. Compound 88d had: ${ }^{1} \mathrm{H}$ NMR $\delta$ 7.39-7.45 (m, 1H), $7.49(\mathrm{t}$, $J=7.6 \mathrm{~Hz}, 2 \mathrm{H}), 7.61(\mathrm{~d}, J=7.3 \mathrm{~Hz}, 2 \mathrm{H}), 7.71(\mathrm{~s}, 4 \mathrm{H}) ;{ }^{13} \mathrm{C} \mathrm{NMR} \delta 124.5\left(\mathrm{q},{ }^{1} J_{\mathrm{C}-\mathrm{F}}=271.5 \mathrm{~Hz}\right)$, $125.9\left(\mathrm{q},{ }^{3} J_{\mathrm{C}-\mathrm{F}}=3.6 \mathrm{~Hz}\right), 127.4,127.6,128.3,129.1,129.5\left(\mathrm{q},{ }^{2} J_{\mathrm{C}-\mathrm{F}}=32.7 \mathrm{~Hz}\right), 144.9\left(\mathrm{q},{ }^{5} J_{\mathrm{C}-\mathrm{F}}=\right.$ $1.1 \mathrm{~Hz})$; GC-MS $\left(t_{\mathrm{R}} 12.96 \mathrm{~min}\right) \mathrm{m} / z 222\left(100, \mathrm{M}^{+}\right)$.

Analogous treatment of $\mathbf{8 2}(43 \mathrm{mg}, 0.14 \mathrm{mmol})$ with 4-iodobenzotrifluoride $(\mathbf{8 7 d} ; 76 \mathrm{mg}, 41$ $\mu \mathrm{L}, 0.28 \mathrm{mmol}$ ) by general method A gave 88d (33\%) and 89d (33\%) based on the GC-MS analysis of the crude reaction mixture.

Analogous treatment of $\mathbf{8 3}$ (35 mg, $0.14 \mathrm{mmol})$ and 4-iodobenzotrifluoride (87d; $114 \mathrm{mg}, 61$ $\mu \mathrm{L}, 0.42 \mathrm{mmol}$ ) by general method A gave 88d (22\%) and 89d (33\%) based on the GC-MS analysis of the crude reaction mixture.

1- $N$-Benzyl-3- $N$-methyl-5-iodouracil (78c). Freshly distilled diazomethane solution in ether $(10 \mathrm{~mL})$, generated from Diazald $(3.0 \mathrm{~g}, 14.0 \mathrm{mmol})$, was added dropwise to a stirred solution of 78a ${ }^{168}(357 \mathrm{mg}, 1.09 \mathrm{mmol})$ in $\mathrm{CH}_{2} \mathrm{Cl}_{2}(20 \mathrm{~mL})$ at $0{ }^{\circ} \mathrm{C}$. After $18 \mathrm{~h}$, the volatiles were evaporated to give 78c (354 mg, 95\%) as white powder: ${ }^{1} \mathrm{H}$ NMR $\delta 3.34(\mathrm{~s}, 3 \mathrm{H}), 4.86(\mathrm{~s}, 2 \mathrm{H}), 7.21-7.30(\mathrm{~m}$, 5H), $7.57(\mathrm{~s}, 1 \mathrm{H}) ;{ }^{13} \mathrm{C} \mathrm{NMR} \delta 29.7,52.7,68.0,128.2,128.8,129.3,135.0,146.4,151.5,160.2$; GC-MS ( $\left.t_{\mathrm{R}} 21.70 \mathrm{~min}.\right) \mathrm{m} / \mathrm{z} 342\left(85, \mathrm{M}^{+}\right), 91$ (100); HRMS calcd for $\mathrm{C}_{12} \mathrm{H}_{12} \mathrm{IN}_{2} \mathrm{O}_{2}[\mathrm{M}+\mathrm{H}]^{+}$ 342.9938, found 342.9935 .

1-N-Benzyl-5-(2-, 3-, and 4-methylphenyl)uracil (o/m/p-91a). Procedure A. Toluene $(0.2$ $\mathrm{mL}, 173 \mathrm{mg}, 1.89 \mathrm{mmol})$, TBAF (1M/THF solution containing ca $5 \%$ wt of water; $980 \mu \mathrm{L}, 0.98$ 
mmol) and $\mathrm{Pd}_{2}(\mathrm{dba})_{3}(6.4 \mathrm{mg}, 0.007 \mathrm{mmol})$ were added to a stirring solution of $1-N$-benzyl-5iodouracil $^{168}$ (78a, $\left.46 \mathrm{mg}, 0.14 \mathrm{mmol}\right)$ in DMF $(1.8 \mathrm{~mL})$ under the $\mathrm{N}_{2}$ atmosphere at ambient temperature. The resulting suspension was stirred for $1 \mathrm{~h}$ at $100{ }^{\circ} \mathrm{C}$ (oil bath). Volatiles were evaporated, and the oily residue was dissolved in EtOAc or $\mathrm{MeOH}$ and filtrated through Celite or Whatman GF/A filter paper. The filtrate was partitioned $\left(\right.$ EtOAc $\left./ \mathrm{H}_{2} \mathrm{O}\right)$. The organic layer was then washed (brine), dried $\left(\mathrm{Na}_{2} \mathrm{SO}_{4}\right)$ and evaporated. GC-MS of this material showed peaks at $t_{\mathrm{R}}$ 31.46, 32.38 and $32.70 \mathrm{~min} .\left(\mathrm{m} / \mathrm{z} 292, \mathrm{M}^{+}\right)$for the three isomers of 91a (ortho/meta/para with relative intensities of $\sim 3: 2: 1$, respectively). Column chromatography (hexane/EtOAc, 8:2 $\rightarrow 6: 4$ ) gave a mixture of $o / \mathrm{m} / \mathrm{p}$-91a $(\mathrm{o} / \mathrm{m} / \mathrm{p}, 3: 2: 1 ; 29 \mathrm{mg}, 71 \%$ overall yield) followed by $92(1 \mathrm{mg}, 4 \%)$. Mixture of $o / m / p$-91a had: GC-MS $t_{\mathrm{R}} 31.46(o-91 \mathbf{a}), 32.38(\mathrm{~m}-91 \mathrm{a})$ and $32.70(p-91 \mathbf{a}) \mathrm{min} .(\mathrm{m} / \mathrm{z}$ 292, $\mathrm{M}^{+}$); ${ }^{1} \mathrm{H}$ NMR $\delta 2.21$ (s, 1.5H, o-91a), 2.35 (s, 0.5H, p-91a), 2.36 (s, 1H, m-91a), 4.97 (s, 1H, o-91a), $4.985(\mathrm{~s}, 0.33 \mathrm{H}, p-91 \mathrm{a}), 4.990(\mathrm{~s}, 0.67 \mathrm{H}, m-91 \mathrm{a}), 7.07-7.41(\mathrm{~m}, 10 \mathrm{H}), 8.91(\mathrm{~s}, 1 \mathrm{H})$; HRMS calcd for $\mathrm{C}_{18} \mathrm{H}_{17} \mathrm{~N}_{2} \mathrm{O}_{2}[\mathrm{M}+\mathrm{H}]^{+}$293.1285, found 293.1294.

Attempted purification of the $o / m / p$-91a mixture on a long silica gel column (hexane/EtOAc, $8: 2 \rightarrow 7: 3$ ) gave partial separation of the $o / \mathrm{m} / \mathrm{p}$ isomers of 91a but failed to yield single isomers.

Note: Treatment of 78a (46 mg, $0.14 \mathrm{mmol})$ with toluene/TBAF/Pd $(\mathrm{dba})_{3}$ in $\mathrm{DMF}$ for $18 \mathrm{~h}$ at $100{ }^{\circ} \mathrm{C}$, as described above (column chromatography; hexane/EtOAc, 98:2 $\rightarrow$ 95:5) gave mixture of 1- $N$-benzyl-3- $N$-butyl-5-(2-methylphenyl)uracil (o-79a), 1- $N$-benzyl-3- $N$-butyl-5-(3methylphenyl)uracil (m-79a) and 1- $N$-benzyl-3- $N$-butyl-5-(4-methylphenyl)uracil ( $p$-79a) (36.6 $\mathrm{mg}, 75 \%$ overall yield; $o-79 \mathbf{a} / m-79 \mathbf{a} / p-79 \mathbf{a}, 3: 2: 1)$ : GC-MS $t_{\mathrm{R}} 27.29(o-79 \mathbf{a}), 28.27(m-79 \mathbf{a})$ and 28.74 (p-79a) min. $\left(m / z\right.$ 348, $\left.\mathrm{M}^{+}\right)$; ${ }^{1} \mathrm{H}$ NMR $\delta 0.92$ (t, $\left.J=7.3 \mathrm{~Hz}, 3 \mathrm{H}\right), 1.36$ ("sextet", $J=7.4 \mathrm{~Hz}$, 2H), 1.67 ("quint", $J=7.6, \mathrm{~Hz}, 2 \mathrm{H}), 2.18$ (s, 1.5H, o-79a), 2.30 (s, 0.5H, $p-79 \mathrm{a}), 2.32$ (s, 1H, $m$ 79a), 4.00 ("t", $J=7.6 \mathrm{~Hz}, 2 \mathrm{H}), 4.94$ (s, 1H, o-79a), 4.95 (s, 0.33H, p-79a), 4.96 (s, 0.67H, m79a), 7.02-7.37 (m, 10H); HRMS calcd for $\mathrm{C}_{22} \mathrm{H}_{25} \mathrm{~N}_{2} \mathrm{O}_{2}[\mathrm{M}+\mathrm{H}]^{+}$349.1911, found 349.1920. 
1-N-Benzyl-5-(3-methylphenyl)uracil (m-91a). Suzuki Coupling: ${ }^{54}$ 3-Tolylboronic acid (29 $\mathrm{mg}, 0.21 \mathrm{mmol})$ and $\mathrm{PPh}_{3}(9 \mathrm{mg}, 0.034 \mathrm{mmol})$ were added to a stirring solution of 1- $N$-benzyl-5iodouracil (78a, $46 \mathrm{mg}, 0.14 \mathrm{mmol})$ in $\mathrm{CH}_{3} \mathrm{CN} / \mathrm{H}_{2} \mathrm{O}(3 \mathrm{~mL} ; \mathrm{v} / \mathrm{v}, 2: 1)$ under the $\mathrm{N}_{2}$ atmosphere at ambient temperature, followed by the addition of $\mathrm{Na}_{2} \mathrm{CO}_{3}(22 \mathrm{mg}, 0.21 \mathrm{mmol})$ and $\mathrm{Pd}(\mathrm{OAc})_{2}(3$ $\mathrm{mg}, 0.013 \mathrm{mmol}$ ). The resulting suspension was stirred for $4 \mathrm{~h}$ at $80{ }^{\circ} \mathrm{C}$ (oil bath). Volatiles were evaporated, and the residue was partitioned between EtOAc and $\mathrm{H}_{2} \mathrm{O}$. The organic layer was then washed (brine), dried $\left(\mathrm{Na}_{2} \mathrm{SO}_{4}\right)$ and evaporated. Column chromatography (hexane/EtOAc, 6:4 $\rightarrow$ 5:5) gave $m$-91a (21.7 mg, 53\%): ${ }^{1} \mathrm{H}$ NMR $\delta 2.38(\mathrm{~s}, 3 \mathrm{H}), 5.01(\mathrm{~s}, 2 \mathrm{H}), 7.16(\mathrm{dt}, J=6.8,2.0 \mathrm{~Hz}$, 1H), 7.23-7.29 (m, 2H), $7.30(\mathrm{t}, J=1.7 \mathrm{~Hz}, 1 \mathrm{H}), 7.32(\mathrm{~s}, 1 \mathrm{H}), 7.34-7.46(\mathrm{~m}, 5 \mathrm{H}), 9.35(\mathrm{~s}, 1 \mathrm{H})$; ${ }^{13} \mathrm{C}$ NMR $\delta 21.6,51.5,116.1,125.3,128.2,128.5,128.7,128.97,129.01,129.3,132.1,135.4$, 138.3, 141.2, 150.9, 162.5; GC-MS ( $t_{\mathrm{R}} 32.38$ min.) $\mathrm{m} / z 292\left(85, \mathrm{M}^{+}\right), 91$ (100); HRMS calcd for $\mathrm{C}_{18} \mathrm{H}_{17} \mathrm{~N}_{2} \mathrm{O}_{2}[\mathrm{M}+\mathrm{H}]^{+}$293.1285, found 293.1293.

1-N-Benzyl-5-(4-methylphenyl)uracil (p-91a). Suzuki Coupling: ${ }^{54}$ Treatment of 78a (46 mg, $0.14 \mathrm{mmol}$ ) with 4-tolylboronic acid (29 $\mathrm{mg}, 0.21 \mathrm{mmol})$, as described above for $m$-91a, gave $p$ 91a (20.0 mg, 49\%): ${ }^{1} \mathrm{H}$ NMR $\delta 2.34$ (s, 3H), 4.98 (s, 2H), 7.17 (d, $\left.J=7.9 \mathrm{~Hz}, 2 \mathrm{H}\right), 7.28(\mathrm{~s}, 1 \mathrm{H})$, 7.32-7.41 (m, 7H), $9.03(\mathrm{~s}, 1 \mathrm{H}) ;{ }^{13} \mathrm{C} \mathrm{NMR} \delta 21.3,51.5,115.9,128.1,128.2,128.7,129.2,129.3$, 129.4, 135.4, 138.2, 140.8, 150.8, 162.4; GC-MS ( $t_{\mathrm{R}} 32.70$ min.) $m / z 292\left(85, \mathrm{M}^{+}\right), 91$ (100); HRMS calcd for $\mathrm{C}_{18} \mathrm{H}_{17} \mathrm{~N}_{2} \mathrm{O}_{2}[\mathrm{M}+\mathrm{H}]^{+}$293.1285, found 293.1291.

1- $N$-Benzyl-5-phenyluracil (91b). Treatment of 78a (46 mg, $0.14 \mathrm{mmol})$ with benzene $(0.2$ $\mathrm{mL}, 175 \mathrm{mg}, 2.24 \mathrm{mmol})$ by procedure A gave $91 \mathrm{~b}(25.3 \mathrm{mg}, 59 \%):{ }^{1} \mathrm{H}$ NMR $\delta 4.99(\mathrm{~s}, 2 \mathrm{H}), 7.32$ (s, 1H), 7.33-7.49 (m, 10H), $9.02(\mathrm{~s}, 1 \mathrm{H}) ;{ }^{13} \mathrm{C}$ NMR $\delta 51.6,115.9,128.2,128.3,128.7,128.8$, 129.4, 132.2, 135.3, 141.2, 150.7, 162.3; GC-MS ( $t_{\mathrm{R}} 24.52$ min.) $\mathrm{m} / z 278\left(80, \mathrm{M}^{+}\right), 91$ (100); HRMS calcd for $\mathrm{C}_{17} \mathrm{H}_{14} \mathrm{~N}_{2} \mathrm{NaO}_{2}[\mathrm{M}+\mathrm{Na}]^{+}$301.0947, found 301.0945. 
Analogues treatment of 1- $N$-benzyl-5-bromouracil ${ }^{208}(\mathbf{7 8 b}, 39 \mathrm{mg}, 0.14 \mathrm{mmol})$ with benzene (0.2 mL, $175 \mathrm{mg}, 2.24 \mathrm{mmol})$ by procedure A (14 equiv. of TBAF) gave $91 \mathbf{b}(27.6 \mathrm{mg}, 71 \%)$ with spectroscopic data as described above.

1- $N$-Benzyl-5-(2,4-dimethylphenyl)uracil (91c). Treatment of 78a (46 mg, $0.14 \mathrm{mmol}$ ) with $m$-xylene $(0.2 \mathrm{~mL}, 172 \mathrm{mg} 1.62 \mathrm{mmol})$ by procedure A gave the desired product which was recrystallized from hexane/EtOAc to give a single isomer 91c (23.6 mg, 55\%): ${ }^{1} \mathrm{H}$ NMR $\delta 2.16$ (s, 3H), $2.31(\mathrm{~s}, 3 \mathrm{H}), 4.95$ (s, 2H), $6.95(\mathrm{~d}, J=8.0 \mathrm{~Hz}, 1 \mathrm{H}), 6.99$ (br d, $J=8.1 \mathrm{~Hz}, 1 \mathrm{H}), 7.05$ (s, 1H), $7.11(\mathrm{~s}, 1 \mathrm{H}), 7.30-7.41(\mathrm{~m}, 5 \mathrm{H}), 8.30(\mathrm{~s}, 1 \mathrm{H}) ;{ }^{13} \mathrm{C}$ NMR $\delta 20.1,21.2,51.4,116.5,126.8,128.3$, $128.7,128.8,129.4,130.5,131.4,135.3,137.6,138.8,142.2,150.8,161.9 ;$ GC-MS $\left(t_{\mathrm{R}} 27.34\right.$ min.) $m / z 306\left(70, \mathrm{M}^{+}\right), 91$ (100); HRMS calcd for $\mathrm{C}_{19} \mathrm{H}_{19} \mathrm{~N}_{2} \mathrm{O}_{2}[\mathrm{M}+\mathrm{H}]^{+}$307.1441, found 307.1442 .

GC-MS of the crude reaction mixture showed peaks for three isomers with $t_{\mathrm{R}}$ at $27.34,27.90$ and $28.33 \mathrm{~min}$. with relative intensities of 14:5:1 $\left(\mathrm{m} / \mathrm{z} 306, \mathrm{M}^{+}\right)$.

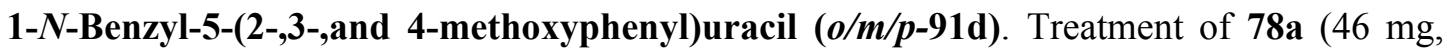
$0.14 \mathrm{mmol})$ with anisole $(0.2 \mathrm{~mL}, 199 \mathrm{mg}, 1.84 \mathrm{mmol})$ by procedure A gave 91d $(\mathrm{o} / \mathrm{m} / \mathrm{p}, 4: 1: 1$; $29.3 \mathrm{mg}, 68 \%)$ : GC-MS $t_{\mathrm{R}} 25.52$ (o-91d), $26.68(\mathrm{~m}-\mathbf{9 1 d})$ and $27.31(p-91 \mathrm{~d}) \mathrm{min} .\left(\mathrm{m} / \mathrm{z} 308, \mathrm{M}^{+}\right)$; ${ }^{1} \mathrm{H}$ NMR $\delta 3.73$ (s, 2H, o-91d), 3.80 (s, 0.5H, p-91d), 3.81 (s, 0.5H, m-91d), 4.96 (s, $1.3 \mathrm{H}, o-91$ d), $4.98(\mathrm{~s}, 0.7 \mathrm{H}, m, p-91 \mathrm{~d}), 6.86-7.34(\mathrm{~m}, 10 \mathrm{H}), 9.01(\mathrm{~s}, 0.67 \mathrm{H}, o-91 \mathrm{~d}) 9.14(\mathrm{~s}, 0.33 \mathrm{H}, m, p-91 \mathrm{~d})$; HRMS calcd for $\mathrm{C}_{18} \mathrm{H}_{17} \mathrm{~N}_{2} \mathrm{O}_{3}[\mathrm{M}+\mathrm{H}]^{+}$309.1234, found 309.1247.

1-N-Benzyl-5-(3-methoxyphenyl)uracil (m-91d). Suzuki Coupling: ${ }^{54}$ Treatment of 78a (46 $\mathrm{mg}, 0.14 \mathrm{mmol}$ ) with 3-methoxyphenylboronic acid (32 $\mathrm{mg}, 0.21 \mathrm{mmol})$, as described above for $m$-91a, gave $m$-91d (22 mg, 51\%): ${ }^{1} \mathrm{H}$ NMR $\delta 3.80(\mathrm{~s}, 3 \mathrm{H}), 4.98(\mathrm{~s}, 2 \mathrm{H}), 6.88(\mathrm{dd}, J=8.8,2.5 \mathrm{~Hz}$, 1H), 7.03 ("dt", $J=7.6,2.0 \mathrm{~Hz}, 1 \mathrm{H}), 7.10$ ("t", $J=2.0 \mathrm{~Hz}, 1 \mathrm{H}), 7.26$ (t, $J=8.0 \mathrm{~Hz}, 1 \mathrm{H}), 7.33-$ $7.40(\mathrm{~m}, 6 \mathrm{H}), 9.33(\mathrm{~s}, 1 \mathrm{H}) ;{ }^{13} \mathrm{C} \mathrm{NMR} \delta 51.4,55.3,113.6,114.0,115.5,121.4,128.1,128.6,129.2$, 
129.5, 133.4, 135.2, 141.3, 150.7, 159.6, 162.2; GC-MS ( $\left.t_{\mathrm{R}} 26.68 \mathrm{~min}.\right) \mathrm{m} / z 308\left(75, \mathrm{M}^{+}\right), 91$ (100); HRMS calcd for $\mathrm{C}_{18} \mathrm{H}_{17} \mathrm{~N}_{2} \mathrm{O}_{3}[\mathrm{M}+\mathrm{H}]^{+}$309.1234, found 309.1238.

1-N-Benzyl-5-(4-methoxyphenyl)uracil (p-91d). Suzuki Coupling: ${ }^{54}$ Treatment of 78a (46 $\mathrm{mg}, 0.14 \mathrm{mmol}$ ) with 4-methoxyphenylboronic acid (32 $\mathrm{mg}, 0.21 \mathrm{mmol})$, as described above for $m$-91a, gave $p$-91d $(23.7 \mathrm{mg}, 55 \%):{ }^{1} \mathrm{H}$ NMR $\delta 3.80(\mathrm{~s}, 3 \mathrm{H}), 4.98(\mathrm{~s}, 2 \mathrm{H}), 6.90(\mathrm{~d}, J=8.8 \mathrm{~Hz}$, 2H), $7.25(\mathrm{~s}, 1 \mathrm{H}), 7.32-7.39(\mathrm{~m}, 7 \mathrm{H}), 8.64(\mathrm{~s}, 1 \mathrm{H}) ;{ }^{13} \mathrm{C}$ NMR $\delta 51.5,55.5,114.2,115.7,124.5$, $128.2,128.7,129.3,129.5,135.4,140.3,150.8,159.7,162.5$; GC-MS $\left(t_{\mathrm{R}} 27.31 \mathrm{~min}.\right) \mathrm{m} / \mathrm{z} 308(80$, $\mathrm{M}^{+}$), 91 (100); HRMS calcd for $\mathrm{C}_{18} \mathrm{H}_{17} \mathrm{~N}_{2} \mathrm{O}_{3}[\mathrm{M}+\mathrm{H}]^{+}$309.1234, found 309.1241.

1-N-Benzyl-5-(fur-2-yl)uracil (91e). Method A. Treatment of 78a (46 mg, $0.14 \mathrm{mmol}$ ) with furan $(0.2 \mathrm{~mL}, 187 \mathrm{mg}, 2.75 \mathrm{mmol})$ by procedure A (3.5 equiv. of TBAF) gave 91e $(29.3 \mathrm{mg}$, 78\%): ${ }^{1} \mathrm{H}$ NMR $\delta 5.01(\mathrm{~s}, 2 \mathrm{H}), 6.43(\mathrm{dd}, J=3.0,1.9 \mathrm{~Hz}, 1 \mathrm{H}), 7.05(\mathrm{~d}, J=3.0 \mathrm{~Hz}, 1 \mathrm{H}), 7.28-7.43$ (m, 6H), 7.69 (s, 1H), $9.19(\mathrm{~s}, 1 \mathrm{H}) ;{ }^{13} \mathrm{C}$ NMR $\delta$ 51.9, 107.6, 109.7, 112.1, 128.2, 128.8, 129.3, 135.3, 137.7, 141.3, 145.7, 150.2, 160.4; GC-MS ( $\left.t_{\mathrm{R}} 27.41 \mathrm{~min}.\right) \mathrm{m} / \mathrm{z} 268\left(60, \mathrm{M}^{+}\right), 91$ (100); HRMS calcd for $\mathrm{C}_{15} \mathrm{H}_{13} \mathrm{~N}_{2} \mathrm{O}_{3}[\mathrm{M}+\mathrm{H}]^{+}$269.0921, found 269.0934.

Analogues treatment of $\mathbf{7 8 b}(39 \mathrm{mg}, 0.14 \mathrm{mmol})$ with furan $(0.2 \mathrm{~mL}, 187 \mathrm{mg}, 2.75 \mathrm{mmol})$ by procedure A (14 equiv. of TBAF) gave 91e (31.9 mg, 85\%) with spectroscopic data as described above.

Method B. Procedure B. Furan $(0.2 \mathrm{~mL}, 187 \mathrm{mg}, 2.75 \mathrm{mmol}), \mathrm{Cs}_{2} \mathrm{CO}_{3}(91.2 \mathrm{mg}, 0.28 \mathrm{mmol})$ and $\mathrm{Pd}(\mathrm{OAc})_{2}(1.6 \mathrm{mg}, 0.007 \mathrm{mmol})$ were added to a stirring solution of 78a $(46 \mathrm{mg}, 0.14 \mathrm{mmol})$ in DMF $(1.8 \mathrm{~mL})$ under the $\mathrm{N}_{2}$ atmosphere at ambient temperature. The resulting suspension was stirred for $2 \mathrm{~h}$ at $100{ }^{\circ} \mathrm{C}$ (oil bath) and after cooling down to ambient temperature was diluted with EtOAc $(3 \mathrm{~mL})$. The resulting mixture was vacuum filtered using Whatman GF/A filter paper and the filtrates were evaporated. The oily residue was dissolved in EtOAc and partitioned $\left(\mathrm{EtOAc} / \mathrm{H}_{2} \mathrm{O}\right)$. The organic layer was then washed (brine), dried $\left(\mathrm{Na}_{2} \mathrm{SO}_{4}\right)$ and evaporated. 
Column chromatography (hexane/EtOAc, $8: 2 \rightarrow 6: 4)$ gave 91e $(24.5 \mathrm{mg}$, 65\% yield) with the spectroscopic data as above and 94 (5 $\mathrm{mg}, 17 \%)$.

Procedure C. Analogous treatment of 78a $(46 \mathrm{mg}, 0.14 \mathrm{mmol})$ with furan $(0.2 \mathrm{~mL}, 187 \mathrm{mg}$, $2.75 \mathrm{mmol})$ and $\mathrm{Cs}_{2} \mathrm{CO}_{3}(91.2 \mathrm{mg}, 0.28 \mathrm{mmol})$ in the presence of PivOH (17.9 $\left.\mathrm{mg}, 0.175 \mathrm{mmol}\right)$ and $\mathrm{Pd}(\mathrm{OAc})_{2}(1.6 \mathrm{mg}, 0.007 \mathrm{mmol})$ by Procedure $\mathrm{B}$ gave $91 \mathrm{e}(27 \mathrm{mg}, 73 \%$ yield $)$.

Analogues treatment of $\mathbf{7 8 b}(39 \mathrm{mg}, 0.14 \mathrm{mmol})$ with furan $(0.2 \mathrm{~mL}, 187 \mathrm{mg}, 2.75 \mathrm{mmol})$ by procedure B gave 91e (5 mg, 13\% yield) with the spectroscopic data as above.

1- $N$-Benzyl-5-(benzo[b]fur-2-yl)uracil (91f). Treatment of 78a (46 mg, $0.14 \mathrm{mmol}$ ) with benzo[b]furan $(23.1 \mu \mathrm{L}, 24.8 \mathrm{mg}, 0.21 \mathrm{mmol})$ by procedure A (3.5 equiv. of TBAF) gave $91 \mathbf{f}$ (29.4 mg, 66\%): ${ }^{1} \mathrm{H}$ NMR $\delta 5.06(\mathrm{~s}, 2 \mathrm{H}), 7.2(\mathrm{td}, J=7.3,1.2 \mathrm{~Hz}, 1 \mathrm{H}), 7.26(\mathrm{dt}, J=7.3,1.4 \mathrm{~Hz}$, 1H), 7.37-7.42 (m, 6H), $7.47(\mathrm{~d}, J=0.6 \mathrm{~Hz}, 1 \mathrm{H}), 7.56(\mathrm{ddd}, J=7.3,1.5,0.8 \mathrm{~Hz}, 1 \mathrm{H}), 7.95(\mathrm{~s}, 1 \mathrm{H})$, $8.67(\mathrm{~s}, 1 \mathrm{H}) ;{ }^{13} \mathrm{C}$ NMR $\delta 52.2,106.1,107.0,110.7,121.6,123.3,124.8,128.2,128.9,129.3$, 129.4, 135.1, 139.5, 147.6, 149.9, 153.9, 160.1; HRMS calcd for $\mathrm{C}_{19} \mathrm{H}_{15} \mathrm{~N}_{2} \mathrm{O}_{3}[\mathrm{M}+\mathrm{H}]^{+} 319.1077$, found 319.1081 .

1- $\mathrm{N}$-Benzyl-5-(thiophen-2-yl)uracil (91g). Method A. Treatment of 78a (46 mg, $0.14 \mathrm{mmol}$ ) with thiophene $(0.2 \mathrm{~mL}, 210 \mathrm{mg}, 2.5 \mathrm{mmol})$ by procedure A (3.5 equiv. of TBAF) gave $\mathbf{9 1 g}^{209}$ (36.2 mg, 91\%): ${ }^{1} \mathrm{H}$ NMR (DMSO- $\left.d_{6}\right) \delta 4.98(\mathrm{~s}, 2 \mathrm{H}), 7.06(\mathrm{dd}, J=5.1,3.7 \mathrm{~Hz}, 1 \mathrm{H}), 7.29-7.32(\mathrm{~m}$, 1H), 7.34-7.37 (m, 4H), 7.44-7.47 (m, 2H), $8.45(\mathrm{~s}, 1 \mathrm{H}), 11.72(\mathrm{~s}, 1 \mathrm{H}) ;{ }^{13} \mathrm{C}$ NMR (DMSO- $\left.d_{6}\right) \delta$ $50.8,108.1,122.7,125.6,126.4,127.4,127.6,128.6,133.7,136.7,140.9,149.9,161.7$; HRMS calcd for $\mathrm{C}_{15} \mathrm{H}_{13} \mathrm{~N}_{2} \mathrm{O}_{2} \mathrm{~S}[\mathrm{M}+\mathrm{H}]^{+}$285.0692, found 285.0691 .

Method B. Analogues treatment of 78a (46 mg, $0.14 \mathrm{mmol})$ with thiophene $(0.2 \mathrm{~mL}, 210 \mathrm{mg}$, $2.5 \mathrm{mmol}$ ) by procedure B gave $\mathbf{9 1 g}$ ( $30.2 \mathrm{mg}$, 76\% yield) with the spectroscopic data as above.

Analogues treatment of $\mathbf{7 8 b}(39 \mathrm{mg}, 0.14 \mathrm{mmol})$ with thiophene $(0.2 \mathrm{~mL}, 210 \mathrm{mg}, 2.5 \mathrm{mmol})$ by procedure B gave $\mathbf{9 1 g}$ ( $6 \mathrm{mg}, 16 \%$ yield) with the spectroscopic data as above. 
1-N-Benzyl-5-(5-methylthiophen-2-yl)uracil (91h). Treatment of 78a (46 mg, $0.14 \mathrm{mmol})$ with 2-methylthiophene $(0.2 \mathrm{~mL}, 203 \mathrm{mg}, 2.1 \mathrm{mmol})$ by procedure A (3.5 equiv. of TBAF) gave 91h (29.2 mg, 70\%): ${ }^{1} \mathrm{H}$ NMR $\delta 2.46(\mathrm{~d}, J=0.8 \mathrm{~Hz}, 3 \mathrm{H}), 4.98(\mathrm{~s}, 2 \mathrm{H}), 6.66(\mathrm{dd}, J=3.6,1.1 \mathrm{~Hz}$, $1 \mathrm{H}), 7.15(\mathrm{~d}, J=3.6 \mathrm{~Hz}, 1 \mathrm{H}), 7.30-7.40(\mathrm{~m}, 5 \mathrm{H}), 7.42(\mathrm{~s}, 1 \mathrm{H}), 9.06(\mathrm{~s}, 1 \mathrm{H}) ;{ }^{13} \mathrm{C} \mathrm{NMR} \delta 15.3,51.7$, $110.9,125.0,125.5,128.2,128.8,129.4,130.8,135.2,138.2,140.4,152.2,161.4$; HRMS calcd for $\mathrm{C}_{16} \mathrm{H}_{14} \mathrm{~N}_{2} \mathrm{O}_{2} \mathrm{SNa}[\mathrm{M}+\mathrm{Na}]^{+}$321.0668, found 321.0674.

1- $N$-Benzyl-5-(5-acetylthiophen-2-yl)uracil (91i). Treatment of 78a (46 mg, $0.14 \mathrm{mmol})$ with 2-acetylthiophene $(0.2 \mathrm{~mL}, 234 \mathrm{mg}, 2.1 \mathrm{mmol})$ by procedure A (3.5 equiv. of TBAF) gave 91i (25 mg, 54\%): ${ }^{1} \mathrm{H}$ NMR (DMSO-d 6 ) $\delta 2.50$ (s, 3H), 4.99 (s, 2H), 7.29-7.34 (m, 1H), 7.37 (d, $J$ $=4.3 \mathrm{~Hz}, 4 \mathrm{H}), 7.59(\mathrm{~d}, J=4.1 \mathrm{~Hz}, 1 \mathrm{H}), 7.87(\mathrm{~d}, J=4.1 \mathrm{~Hz}, 1 \mathrm{H}), 8.76(\mathrm{~s}, 1 \mathrm{H}), 11.89(\mathrm{~s}, 1 \mathrm{H}) ;{ }^{13} \mathrm{C}$ NMR $\left(\right.$ DMSO-d $\left._{6}\right) \delta 26.4,51.2,107.1,123.0,127.4,127.7,128.6,133.1,136.5,141.9,142.5$, 143.2, 149.7, 161.5, 190.6; GC-MS ( $t_{\mathrm{R}} 31.00$ min.) $\mathrm{m} / z 326\left(20, \mathrm{M}^{+}\right), 91$ (100); HRMS calcd for $\mathrm{C}_{17} \mathrm{H}_{15} \mathrm{~N}_{2} \mathrm{O}_{3} \mathrm{~S}[\mathrm{M}+\mathrm{H}]^{+}$327.0798, found 327.0801.

1- $N$-Benzyluracil (92). Treatment of 78a (46 mg, $0.14 \mathrm{mmol})$ with toluene $(0.2 \mathrm{~mL}, 173 \mathrm{mg}$, $1.89 \mathrm{mmol})$ by procedure A [using $\mathrm{KOSiMe}_{3}(53.8 \mathrm{mg}, 0.42 \mathrm{mmol})$ instead of TBAF] gave $\mathbf{9 2}^{210}$ (18.4 mg, 65\%): ${ }^{1} \mathrm{H}$ NMR $\delta 4.92(\mathrm{~s}, 1 \mathrm{H}), 5.70(\mathrm{dd}, J=7.9,1.5 \mathrm{~Hz}, 1 \mathrm{H}), 7.16(\mathrm{~d}, J=7.9 \mathrm{~Hz}, 1 \mathrm{H})$, 7.25-7.44 (m, 3H), 9.46 (s, 1H); ${ }^{13} \mathrm{C}$ NMR $\delta 51.4,102.8,128.2,128.7,129.3,135.2,144.0,151.3$, 163.7; GC-MS ( $t_{\mathrm{R}} 24.38$ min.) $m / z 202\left(35, \mathrm{M}^{+}\right), 91$ (100); HRMS calcd for $\mathrm{C}_{11} \mathrm{H}_{11} \mathrm{~N}_{2} \mathrm{O}_{2}[\mathrm{M}+\mathrm{H}]^{+}$ 203.0815, found 203.0817.

1- $N$-Benzyl-3- $N$-methyl-5-(fur-2-yl)uracil (93e). Treatment of 78c (48 $\mathrm{mg}, 0.14 \mathrm{mmol}$ ) with furan $(0.2 \mathrm{~mL}, 187 \mathrm{mg}, 2.75 \mathrm{mmol})$ by procedure B (column chromatography; hexane/EtOAc, 8:2 $\rightarrow 7: 3)$ gave 93e (19 mg, 48\% yield): GC-MS ( $\left.t_{\mathrm{R}} 17.67 \mathrm{~min}.\right) \mathrm{m} / z 282\left(75, \mathrm{M}^{+}\right), 91(100) ;{ }^{1} \mathrm{H}$ NMR $\delta 3.45(\mathrm{~s}, 3 \mathrm{H}), 5.03(\mathrm{~s}, 2 \mathrm{H}), 6.45(\mathrm{dd}, J=3.4,1.8 \mathrm{~Hz}, 1 \mathrm{H}), 7.06(\mathrm{~d}, J=3.3 \mathrm{~Hz}, 1 \mathrm{H}), 7.35(\mathrm{~d}$, $J=5.9 \mathrm{~Hz}, 1 \mathrm{H}), 7.33-7.39(\mathrm{~m}, 3 \mathrm{H}), 7.36(\mathrm{~d}, J=8.1 \mathrm{~Hz}, 2 \mathrm{H}), 7.72(\mathrm{~s}, 1 \mathrm{H}) ;{ }^{13} \mathrm{C} \mathrm{NMR} \delta 28.5,53.0$, 
106.6, 109.3, 112.0, 128.1, 128.7, 129.3, 135.4, 136.0, 141.2, 146.3, 151.0, 160.2; HRMS calcd for $\mathrm{C}_{16} \mathrm{H}_{15} \mathrm{~N}_{2} \mathrm{O}_{3}[\mathrm{M}+\mathrm{H}]^{+}$283.1077, found 283.1065.

1- $N$-Benzyl-3- $N$-methyl-5-(thiophen-2-yl)uracil (93g). Treatment of 78c (48 $\mathrm{mg}, 0.14$ $\mathrm{mmol}$ ) with thiophene $(0.2 \mathrm{~mL}, 210 \mathrm{mg}, 2.5 \mathrm{mmol})$ by procedure $\mathrm{B}$ (column chromatography; hexane/EtOAc, 8:2 $\rightarrow$ 7:3) gave 93g (17 mg, 41\% yield): GC-MS $\left(t_{\mathrm{R}} 23.66 \mathrm{~min}\right.$.) $\mathrm{m} / z 298$ (75, $\left.\mathrm{M}^{+}\right), 91(100)$ ) ${ }^{1} \mathrm{H}$ NMR $\delta 3.46$ (s, 3H), 5.03 (s, 2H), $7.02(\mathrm{dd}, J=5.1,3.7 \mathrm{~Hz}, 1 \mathrm{H}), 7.28-7.39$ (m, 7H), $7.55(\mathrm{~s}, 1 \mathrm{H}) .{ }^{13} \mathrm{C}$ NMR $\delta 28.7,52.8,109.6,124.0,125.8,126.9,128.2,128.8,129.3$, 134.9, 135.3, 137.0, 151.1, 161.4; HRMS calcd for $\mathrm{C}_{16} \mathrm{H}_{15} \mathrm{~N}_{2} \mathrm{O}_{2} \mathrm{~S}[\mathrm{M}+\mathrm{H}]^{+}$299.0849, found 299.0852 .

1- $N$-benzyl-3- $N$-methyluracil (94). Treatment of 78c (48 mg, $0.14 \mathrm{mmol})$ with toluene $(0.2$ $\mathrm{mL}, 173 \mathrm{mg}, 1.89 \mathrm{mmol}$ ) by procedure A (column chromatography; hexane/EtOAc, 6:4 $\rightarrow$ 4:6) gave $94^{211}$ (29 mg, 73\%): ${ }^{1} \mathrm{H}$ NMR $\delta 3.36(\mathrm{~s}, 3 \mathrm{H}), 4.94(\mathrm{~s}, 2 \mathrm{H}), 5.75(\mathrm{~d}, J=7.9 \mathrm{~Hz}, 1 \mathrm{H}), 7.17$ (d, $J=7.9 \mathrm{~Hz}, 1 \mathrm{H}), 7.2-7.48(\mathrm{~m}, 5 \mathrm{H}) ;{ }^{13} \mathrm{C} \mathrm{NMR} \delta 28.0,52.4,102.0,128.1,128.6,129.2,135.4$, 141.7, 152.0, 163.2; GC-MS ( $\left.t_{\mathrm{R}} 20.49 \mathrm{~min}.\right) \mathrm{m} / z 216$ (50, $\left.\mathrm{M}^{+}\right), 91$ (100); HRMS calcd for $\mathrm{C}_{12} \mathrm{H}_{13} \mathrm{~N}_{2} \mathrm{O}_{2}[\mathrm{M}+\mathrm{H}]^{+}$217.0972, found 217.0976.

Analogous treatment (TBAF 3.5 equiv.) of 78c $(48 \mathrm{mg}, 0.14 \mathrm{mmol})$ with furan $(0.2 \mathrm{~mL}, 187$ $\mathrm{mg}, 2.75 \mathrm{mmol})$ by procedure A gave $94^{211}(24 \mathrm{mg}, 60 \%)$.

1-(2,3,5-Tri- $\boldsymbol{O}$-acetyl- $\boldsymbol{\beta}$-D-arabinofuranosyl)-5-(fur-2-yl)uracil (101). Treatment (TBAF 3.5 equiv.) of 1-(2,3,5-tri- $O$-acetyl- $\beta$-D-arabinofuranosyl)-5-iodouracil (95, $69.5 \mathrm{mg}, 0.14 \mathrm{mmol})$ with furan $(0.2 \mathrm{~mL}, 187 \mathrm{mg}, 2.75 \mathrm{mmol})$ by procedure A (column chromatography; hexane/EtOAc, $6: 4 \rightarrow 5: 5)$ gave $\mathbf{1 0 1}(37.3 \mathrm{mg}, 61 \%)$ as a slightly yellow solid: ${ }^{1} \mathrm{H}$ NMR $\delta 2.01$ (s, $3 \mathrm{H}), 2.18(\mathrm{~s} 3 \mathrm{H}), 2.19(\mathrm{~s}, 3 \mathrm{H}), 4.24(\mathrm{dt}, J=5.2,3.9 \mathrm{~Hz}, 1 \mathrm{H}), 4.44(\mathrm{dd}, J=12.0,5.2 \mathrm{~Hz}, 1 \mathrm{H}), 4.53$ $(\mathrm{dd}, J=12.0,4.2 \mathrm{~Hz}, 1 \mathrm{H}), 5.22(\mathrm{dd}, J=3.6,1.7 \mathrm{~Hz}, 1 \mathrm{H}), 5.48(\mathrm{dd}, J=4.1,1.7 \mathrm{~Hz}, 1 \mathrm{H}), 6.43(\mathrm{~d}, J$ $=4.1 \mathrm{~Hz}, 1 \mathrm{H}), 6.49(\mathrm{dd}, J=3.4,1.8 \mathrm{~Hz}, 1 \mathrm{H}), 7.09(\mathrm{~d}, J=3.2 \mathrm{~Hz}, 1 \mathrm{H}), 7.39(\mathrm{dd}, J=1.8,0.6 \mathrm{~Hz}$, 1H), 7.97 (s, 1H), 9.39 (s, 1H); ${ }^{13} \mathrm{C}$ NMR $\delta 20.4,20.65,20.68,62.7,74.7,76.5,80.5,84.2,106.6$, 
$109.7,112.0,134.1,141.3,145.5,149.0,159.6,168.6,169.6,170.5$; HRMS calcd for $\mathrm{C}_{19} \mathrm{H}_{21} \mathrm{~N}_{2} \mathrm{O}_{10}[\mathrm{M}+\mathrm{H}]^{+}$437.1191, found 437.1176.

3',5'-Di-O-acetyl-5-(fur-2-yl)-2'-deoxyuridine (102). Treatment of 3',5'-di-O-acetyl-2'deoxy-5-iodouridine ${ }^{212}(\mathbf{9 6}, 61.3 \mathrm{mg}, 0.14 \mathrm{mmol})$ with furan $(0.2 \mathrm{~mL}, 187 \mathrm{mg}, 2.75 \mathrm{mmol})$ by procedure A (column chromatography; hexane/EtOAc, 6:4 $\rightarrow 5: 5)$ gave $102(38.1 \mathrm{mg}, 72 \%)$ : ${ }^{1} \mathrm{H}$ NMR $\delta 2.12(\mathrm{~s}, 3 \mathrm{H}), 2.15(\mathrm{~s}, 3 \mathrm{H}), 2.54(\mathrm{ddd}, J=14.4,6.5,2.1 \mathrm{~Hz}, 1 \mathrm{H}), 2.54$ (ddd, $J=14.2,5.6$, $1.6 \mathrm{~Hz}, 1 \mathrm{H}), 4.31$ ("q", $J=2.7 \mathrm{~Hz}, 1 \mathrm{H}), 4.38-4.39$ (m, 2H), 5.28 (dt, $J=6.6,1.7 \mathrm{~Hz}, 1 \mathrm{H}), 6.44$ (dd, $J=6.5,5.6 \mathrm{~Hz}, 1 \mathrm{H}), 6.45(\mathrm{dd}, J=3.4,1.8 \mathrm{~Hz}, 1 \mathrm{H}), 7.08(\mathrm{~d}, J=3.2 \mathrm{~Hz}, 1 \mathrm{H}), 7.32(\mathrm{dd}, J=1.8,0.6$ $\mathrm{Hz}, 1 \mathrm{H}), 7.99$ (s, 1H), $9.63(\mathrm{~s}, 1 \mathrm{H}) ;{ }^{13} \mathrm{C} \mathrm{NMR} \delta 20.8,21.0,38.1,64.2,74.6,82.7,85.4,107.9$, $109.9,112.2,132.5,141.2,145.8,149.6,160.0,170.4,170.5$; HRMS calcd for $\mathrm{C}_{17} \mathrm{H}_{19} \mathrm{~N}_{2} \mathrm{O}_{8}[\mathrm{M}+$ $\mathrm{H}]^{+} 379.1136$, found 379.1136 .

2',3',5'-Tri-O-acetyl-5-(fur-2-yl)uridine (103). Ttreatment of $\quad 2^{\prime}, 3^{\prime}, 5^{\prime}$-tri- $O$-acetyl-5iodouridine $(97,69.5 \mathrm{mg}, 0.14 \mathrm{mmol})$ with furan $(0.2 \mathrm{~mL}, 187 \mathrm{mg}, 2.75 \mathrm{mmol})$ by procedure A (column chromatography; hexane/EtOAc, 6:4 $\rightarrow$ 5:5) gave 103 (40.8 mg, 67\%): ${ }^{1} \mathrm{H}$ NMR $\delta 2.07$ (s, 3H), $2.10(\mathrm{~s}, 3 \mathrm{H}), 2.14(\mathrm{~s}, 3 \mathrm{H}), 4.33-4.36(\mathrm{~m}, 3 \mathrm{H}), 5.33-5.44(\mathrm{~m}, 2 \mathrm{H}), 6.16(\mathrm{~d}, J=5.6 \mathrm{~Hz}, 1 \mathrm{H})$, $7.04(\mathrm{dd}, J=5.1,3.7 \mathrm{~Hz}, 1 \mathrm{H}), 7.30(\mathrm{dd}, J=5.1,1.1 \mathrm{~Hz}, 1 \mathrm{H}), 7.42(\mathrm{dd}, J=3.6,1.1 \mathrm{~Hz}, 1 \mathrm{H}), 7.75$ (s, 1H), 9.39 (s, 1H); ${ }^{13} \mathrm{C}$ NMR $\delta 20.5,20.7,20.8,64.6,70.9,73.0,80.6,86.8,108.4,110.2,112.3$, 132.5, 141.3, 145.6, 149.6, 157.8, 169.77, 169.83, 170.4; HRMS calcd for $\mathrm{C}_{19} \mathrm{H}_{21} \mathrm{~N}_{2} \mathrm{O}_{10}[\mathrm{M}+\mathrm{H}]^{+}$ 437.1191, found 437.1178.

2',3',5'-Tri-O-acetyl-5-(thiophen -2-yl)uridine (104). Ttreatment of 2',3',5'-tri- $O$-acetyl-5iodouridine $(97,69.5 \mathrm{mg}, 0.14 \mathrm{mmol})$ with thiophene $(0.2 \mathrm{~mL}, 210 \mathrm{mg}, 2.5 \mathrm{mmol})$ by procedure A (column chromatography; hexane/EtOAc, 6:4 $\rightarrow 5: 5)$ gave $104(40 \mathrm{mg}, 63 \%):{ }^{1} \mathrm{H}$ NMR $\delta 2.07$ (s, 3H), $2.10(\mathrm{~s}, 3 \mathrm{H}), 2.14(\mathrm{~s}, 3 \mathrm{H}), 4.33-4.46(\mathrm{~m}, 3 \mathrm{H}), 5.33-5.44(\mathrm{~m}, 2 \mathrm{H}), 6.16(\mathrm{~d}, J=5.6 \mathrm{~Hz}, 1 \mathrm{H})$, $7.04(\mathrm{dd}, J=5.1,3.7 \mathrm{~Hz}, 1 \mathrm{H}), 7.30(\mathrm{dd}, J=5.1,1.1 \mathrm{~Hz}, 1 \mathrm{H}), 7.42(\mathrm{dd}, J=3.6,1.1 \mathrm{~Hz}, 1 \mathrm{H}), 7.75$ (s, 1H), 9.39 (s, $1 \mathrm{H}) ;{ }^{13} \mathrm{C}$ NMR $\delta 20.5,50.6,20.8,63.4,70.5,73.0,80.5,87.3,111.3,125.4,125.9$, 
127.3, 133.1, 134.2, 149.6, 160.9, 169.8, 170.3; HRMS calcd for $\mathrm{C}_{19} \mathrm{H}_{21} \mathrm{~N}_{2} \mathrm{O}_{9} \mathrm{~S}[\mathrm{M}+\mathrm{H}]^{+}$ 453.0962, found 453.0966.

2',3',5'-Tri-O-acetyl-5-(methylthiophen-2-yl)uridine (105). Ttreatment of 2',3',5'-tri-Oacetyl-5-iodouridine $(97,69.5 \mathrm{mg}, 0.14 \mathrm{mmol})$ with 2-methylthiophene $(0.2 \mathrm{~mL}, 203 \mathrm{mg}, 2.1$ $\mathrm{mmol}$ ) by procedure A (column chromatography; hexane/EtOAc, 6:4 $\rightarrow$ 5:5) gave 105 (35.9 mg, 55\%): ${ }^{1} \mathrm{H}$ NMR $\delta 2.09(\mathrm{~s}, 3 \mathrm{H}), 2.10(\mathrm{~s}, 3 \mathrm{H}), 2.14(\mathrm{~s}, 3 \mathrm{H}), 2.47$ (d, $\left.J=0.7 \mathrm{~Hz}, 3 \mathrm{H}\right), 4.33-4.45$ (m, $3 \mathrm{H}), 5.34-5.40(\mathrm{~m}, 2 \mathrm{H}), 6.16(\mathrm{~d}, J=5.4 \mathrm{~Hz}, 1 \mathrm{H}), 6.68(\mathrm{dd}, J=3.6,1.1 \mathrm{~Hz}, 1 \mathrm{H}), 7.21(\mathrm{~d}, J=3.6$ $\mathrm{Hz}, 1 \mathrm{H}), 7.65$ (s, 1H), 9.18 (s, 1H); ${ }^{13} \mathrm{C}$ NMR $\delta 15.3,20.5,20.7,20.9,63.4,70.5,72.9,80.5,87.2$, 111.6, 125.56, 125.57, 130.7, 133.5, 140.6, 149.6, 160.9, 169.76, 169.78, 170.4; HRMS calcd for $\mathrm{C}_{20} \mathrm{H}_{23} \mathrm{~N}_{2} \mathrm{O}_{9} \mathrm{~S}[\mathrm{M}+\mathrm{H}]^{+}$467.1119, found 467.1108.

1-( $\beta$-D-Arabinofuranosyl)-5-(fur-2-yl)uracil (106). Method A. Treatment of 1-( $\beta$-Darabinofuranosyl)-5-iodouracil $^{213}(\mathbf{9 8}, 52 \mathrm{mg}, 0.14 \mathrm{mmol})$ with furan $(0.2 \mathrm{~mL}, 187 \mathrm{mg}, 2.75$ mmol) by procedure A (column chromatography; $\mathrm{CH}_{2} \mathrm{Cl}_{2} / \mathrm{MeOH}, 15: 1 \rightarrow 10: 1$ ) gave 106 (30.5 mg, 70\%) as off-white solid. The analytical sample was obtained by precipitation from minimum amount of $\mathrm{MeOH}: \mathrm{CH}_{2} \mathrm{Cl}_{2}(1: 1, \mathrm{v} / \mathrm{v})$ with hexane: ${ }^{1} \mathrm{H}$ NMR (DMSO- $\left.d_{6}\right) \delta 3.60(\mathrm{dt}, J=10.3,5.0$ $\mathrm{Hz}, 1 \mathrm{H}), 3.68$ (dt, $J=10.3,5.1 \mathrm{~Hz}, 1 \mathrm{H}), 3.78$ ("q", $J=4.6 \mathrm{~Hz}, 1 \mathrm{H}), 3.97$ (dd, $J=7.3,3.8 \mathrm{~Hz}, 1 \mathrm{H})$, $4.04(\mathrm{dt}, J=7.8,3.9 \mathrm{~Hz}, 1 \mathrm{H}), 5.09(\mathrm{t}, J=5.2 \mathrm{~Hz}, 1 \mathrm{H}), 5.51(\mathrm{~d}, J=4.4 \mathrm{~Hz}, 1 \mathrm{H}), 5.64(\mathrm{~d}, J=5.0$ $\mathrm{Hz}, 1 \mathrm{H}), 6.07(\mathrm{~d}, J=4.3 \mathrm{~Hz}, 1 \mathrm{H}), 6.52(\mathrm{dd}, J=3.3,1.9 \mathrm{~Hz}, 1 \mathrm{H}), 6.85(\mathrm{dd}, J=3.3,0.5 \mathrm{~Hz}, 1 \mathrm{H})$, $7.63(\mathrm{dd}, J=1.8,0.7 \mathrm{~Hz}, 1 \mathrm{H}), 8.07(\mathrm{~s}, 1 \mathrm{H}), 11.65(\mathrm{~s}, 1 \mathrm{H}) ;{ }^{13} \mathrm{C}$ NMR $\left(\mathrm{DMSO}-d_{6}\right) \delta 60.7,75.3$, $75.6,84.8,85.3,104.0,107.6,111.5,136.5,141.4,146.5,149.4,160.2$. HRMS calcd for $\mathrm{C}_{13} \mathrm{H}_{15} \mathrm{~N}_{2} \mathrm{O}_{7}[\mathrm{M}+\mathrm{H}]^{+}$311.0784, found 311.0811.

Method B. Compound 101 (43.6 mg, $0.10 \mathrm{mmol})$ was dissolved in $\mathrm{NH}_{3} / \mathrm{MeOH}(3 \mathrm{~mL})$ at 0 ${ }^{\circ} \mathrm{C}$ (ice bath), and the resulting solution was stirred overnight. Volatiles were removed under the reduced pressure and the residue was column chromatographed $\left(\mathrm{CH}_{2} \mathrm{Cl}_{2} / \mathrm{MeOH}, 15: 1 \rightarrow 10: 1\right)$ to give 106 (27.9 mg, 90\%) with the spectroscopic data as above. 
5-(Fur-2-yl)-2'-deoxyuridine (107). Method A. Treatment of 2'-deoxy-5-iodourdine ${ }^{212}$ (99, $49.6 \mathrm{mg}, 0.14 \mathrm{mmol})$ with furan $(0.2 \mathrm{~mL}, 187 \mathrm{mg}, 2.75 \mathrm{mmol})$ by procedure A (column chromatography; $\left.\mathrm{CH}_{2} \mathrm{Cl}_{2} / \mathrm{MeOH}, 15: 1 \rightarrow 10: 1\right)$ gave $107(30.1 \mathrm{mg}, 73 \%)$ as yellow solid: ${ }^{1} \mathrm{H}$ NMR (DMSO- $\left.d_{6}\right) \delta 2.18(\mathrm{dd}, J=6.6,4.8 \mathrm{~Hz}, 2 \mathrm{H}), 3.61(\mathrm{dd}, J=8.8,5.0 \mathrm{~Hz}, 2 \mathrm{H}), 3.84(\mathrm{q}, J=3.3$ $\mathrm{Hz}, 1 \mathrm{H}), 4.28$ ("quint", $J=4.0 \mathrm{~Hz}, 1 \mathrm{H}), 5.08(\mathrm{t}, J=4.8 \mathrm{~Hz}, 1 \mathrm{H}), 5.27$ (d, $J=4.2 \mathrm{~Hz}, 1 \mathrm{H}), 6.22$ (t, $J=6.7 \mathrm{~Hz}, 1 \mathrm{H}), 6.52(\mathrm{dd}, J=3.3,1.8 \mathrm{~Hz}, 1 \mathrm{H}), 6.85(\mathrm{dd}, J=3.3,0.5 \mathrm{~Hz}, 1 \mathrm{H}), 7.61(\mathrm{dd}, J=1.8$ $0.7 \mathrm{~Hz}, 1 \mathrm{H}), 8.33(\mathrm{~s}, 1 \mathrm{H}), 11.62(\mathrm{~s}, 1 \mathrm{H}) ;{ }^{13} \mathrm{C}$ NMR (DMSO- $\left.d_{6}\right) \delta 40.1,61.1,70.4,84.7,87.6$, 105.6, 107.8, 111.5, 134.6, 141.5, 146.4, 149.4, 160.1. HRMS calcd for $\mathrm{C}_{13} \mathrm{H}_{13} \mathrm{~N}_{2} \mathrm{O}_{6}[\mathrm{M}-\mathrm{H}]^{-}$ 293.0779, found 293.0788.

Method B. Treatment of $102\left(38 \mathrm{mg}, 0.10 \mathrm{mmol}\right.$ ) with $\mathrm{NH}_{3} / \mathrm{MeOH}$, as described for 106 (Method B), gave 107 (26 mg, 90\%) with the spectroscopic data as above.

5-(Fur-2-yl)uridine (108). Method A. Treatment of 5-iodouridine ${ }^{212}$ (100, $52 \mathrm{mg}, 0.14$ mmol) with furan $(0.2 \mathrm{~mL}, 187 \mathrm{mg}, 2.75 \mathrm{mmol})$ by procedure A (column chromatography; $\mathrm{CH}_{2} \mathrm{Cl}_{2} / \mathrm{MeOH}, 15: 1 \rightarrow$ 10:1) gave $\mathbf{1 0 8}(34.7 \mathrm{mg}, 80 \%)$ as off-white solid. Precipitation of $\mathbf{1 0 8}$ from $\mathrm{MeOH}: \mathrm{CH}_{2} \mathrm{Cl}_{2}(1: 1, \mathrm{v} / \mathrm{v})$ solution with hexane gave analytical sample of 108: $\mathrm{UV}(\mathrm{MeOH})$ $\lambda_{\max }=314 \mathrm{~nm} ;{ }^{1} \mathrm{H}$ NMR $\left(\mathrm{DMSO}-d_{6}\right) \delta 3.60(\mathrm{ddd}, J=11.9,4.6,2.9 \mathrm{~Hz}, 1 \mathrm{H}), 3.68(\mathrm{ddd}, J=11.9$, 4.7, $2.9 \mathrm{~Hz}, 1 \mathrm{H}), 3.90$ ("q", $J=3.2 \mathrm{~Hz}, 1 \mathrm{H}), 4.02$ ("q", $J=4.5 \mathrm{~Hz}, 1 \mathrm{H}), 4.12$ ("q", $J=5.1 \mathrm{~Hz}, 1 \mathrm{H})$, $5.11(\mathrm{~d}, J=5.0 \mathrm{~Hz}, 1 \mathrm{H}), 5.21(\mathrm{t}, J=4.7 \mathrm{~Hz}, 1 \mathrm{H}), 5.43(\mathrm{~d}, J=5.5 \mathrm{~Hz}, 1 \mathrm{H}), 5.87(\mathrm{~d}, J=5.1 \mathrm{~Hz}$, $1 \mathrm{H}), 6.52(\mathrm{dd}, J=3.3,1.8 \mathrm{~Hz}, 1 \mathrm{H}), 6.86(\mathrm{dd}, J=3.3,0.6 \mathrm{~Hz}, 1 \mathrm{H}), 7.60(\mathrm{dd}, J=1.8,0.7 \mathrm{~Hz}, 1 \mathrm{H})$, $8.42(\mathrm{~s}, 1 \mathrm{H}), 11.64(\mathrm{~s}, 1 \mathrm{H}) ;{ }^{13} \mathrm{C} \mathrm{NMR}\left(\mathrm{DMSO}_{-}{ }_{6}\right) \delta 60.6,69.9,74.0,85.0,88.2,105.7,108.0$, 111.6, 134.9, 141.6, 146.4, 149.7, 160.1; HRMS calcd for $\mathrm{C}_{13} \mathrm{H}_{13} \mathrm{~N}_{2} \mathrm{O}_{7}[\mathrm{M}-\mathrm{H}]^{-}$309.0728, found 309.0734 .

Analogous treatment of $\mathbf{1 0 0}(310 \mathrm{mg}, 1.0 \mathrm{mmol})$ with furan $(1.1 \mathrm{~mL}, 1.03 \mathrm{~g}, 15 \mathrm{mmol})$ by procedure A gave 108 (273 mg, 88\%). 
Method B. Treatment of $\mathbf{1 0 0}(52 \mathrm{mg}, 0.14 \mathrm{mmol})$ with furan $(0.2 \mathrm{~mL}, 187 \mathrm{mg}, 2.75 \mathrm{mmol})$ by procedure $\mathrm{B}$ (column chromatography; $\left.\mathrm{CH}_{2} \mathrm{Cl}_{2} / \mathrm{MeOH}, 15: 1 \rightarrow 10: 1\right)$ gave $108(10 \mathrm{mg}, 23 \%$ yield) with the spectroscopic data as above.

5-(Thiophen-2-yl)uridine (109). Method A. Treatment of 5-iodouridine (100, $52 \mathrm{mg}, 0.14$ $\mathrm{mmol}$ ) with thiophene $(0.2 \mathrm{~mL}, 210 \mathrm{mg}, 2.5 \mathrm{mmol})$ by procedure A (column chromatography; $\mathrm{CH}_{2} \mathrm{Cl}_{2} / \mathrm{MeOH}, 15: 1 \rightarrow$ 10:1) gave $\mathbf{1 0 9}(44.7 \mathrm{mg}, 98 \%)$ as off-white solid. Precipitation of 109 from $\mathrm{MeOH}: \mathrm{CH}_{2} \mathrm{Cl}_{2}(1: 1, \mathrm{v} / \mathrm{v})$ solution with hexane gave analytical sample of 109: $\mathrm{UV}(\mathrm{MeOH})$ $\lambda_{\max }=318 \mathrm{~nm} ;{ }^{1} \mathrm{H}$ NMR $\left(\mathrm{DMSO}-d_{6}\right) \delta 3.64(\mathrm{ddd}, J=12.0,4.4,2.3 \mathrm{~Hz}, 1 \mathrm{H}), 3.76(\mathrm{ddd}, J=12.0$, 4.7, $2.8 \mathrm{~Hz}, 1 \mathrm{H}), 3.92$ (dt, $J=4.8,2.7 \mathrm{~Hz}, 1 \mathrm{H}), 4.06$ ("q", $J=5.1 \mathrm{~Hz}, 1 \mathrm{H}), 4.13$ ("q", $J=4.8 \mathrm{~Hz}$ $1 \mathrm{H}), 5.09(\mathrm{~d}, J=5.5 \mathrm{~Hz}, 1 \mathrm{H}), 5.42(\mathrm{t}, J=4.6 \mathrm{~Hz}, 1 \mathrm{H}), 5.46(\mathrm{~d}, J=5.3 \mathrm{~Hz}, 1 \mathrm{H}), 5.84(\mathrm{~d}, J=4.2$ $\mathrm{Hz}, 1 \mathrm{H}), 7.05(\mathrm{dd}, J=5.1,3.7 \mathrm{~Hz}, 1 \mathrm{H}), 7.40(\mathrm{dd}, J=3.7,1.1 \mathrm{~Hz}, 1 \mathrm{H}), 7.46(\mathrm{dd}, J=5.1,1.1 \mathrm{~Hz}$, 1H), 8.65 (s, 1H), $11.69(\mathrm{~s}, 1 \mathrm{H}) ;{ }^{13} \mathrm{C} \mathrm{NMR}\left(\mathrm{DMSO}-d_{6}\right) \delta 60.2,69.4,74.3,84.7,88.7,108.3,122.5$, 125.7, 126.4, 133.9, 135.7, 149.6, 161.3; HRMS calcd for $\mathrm{C}_{13} \mathrm{H}_{14} \mathrm{~N}_{2} \mathrm{NaO}_{6} \mathrm{~S}[\mathrm{M}+\mathrm{Na}]^{+} 349.0465$, found 349.0465 .

Method B. Treatment of 100 (52 mg, $0.14 \mathrm{mmol})$ with thiophene (0.2 mL, $210 \mathrm{mg}, 2.5 \mathrm{mmol})$ by procedure $\mathrm{B}$ (column chromatography; $\left.\mathrm{CH}_{2} \mathrm{Cl}_{2} / \mathrm{MeOH}, 15: 1 \rightarrow 10: 1\right)$ gave $109(8 \mathrm{mg}, 17 \%$ yield) with the spectroscopic data as above.

5-(5-Methylthiophen-2-yl)uridine (110). Treatment of 5-iodouridine (100, $52 \mathrm{mg}, 0.14$ mmol) with 2-methylthiophene $(0.2 \mathrm{~mL}, 203 \mathrm{mg}, 2.1 \mathrm{mmol})$ by procedure A (column chromatography; $\left.\mathrm{CH}_{2} \mathrm{Cl}_{2} / \mathrm{MeOH}, 15: 1 \rightarrow 10: 1\right)$ gave $110(36.5 \mathrm{mg}, 76 \%)$ as off-white solid. Precipitation of $\mathbf{1 1 0}$ from $\mathrm{MeOH}: \mathrm{CH}_{2} \mathrm{Cl}_{2}(1: 1, \mathrm{v} / \mathrm{v})$ solution with hexane gave analytical sample of 110: ${ }^{1} \mathrm{H}$ NMR (DMSO- $\left.d_{6}\right) \delta 2.42(\mathrm{~s}, 3 \mathrm{H}), 3.63(\mathrm{ddd}, J=12.0,4.4,2.3 \mathrm{~Hz}, 1 \mathrm{H}), 3.74$ (ddd, $J=$ 12.0, 4.6, 2.8 Hz, 1H), 3.91 ("dt", $J=4.8,2.4 \mathrm{~Hz}, 1 \mathrm{H}), 4.05$ ("q", $J=5.0 \mathrm{~Hz}, 1 \mathrm{H}), 4.11$ ("q", $J=$ $4.8 \mathrm{~Hz}, 1 \mathrm{H}), 5.08(\mathrm{~d}, J=5.4 \mathrm{~Hz}, 1 \mathrm{H}), 5.38(\mathrm{t}, J=4.6 \mathrm{~Hz}, 1 \mathrm{H}), 5.44(\mathrm{~d}, J=5.4 \mathrm{~Hz}, 1 \mathrm{H}), 5.83(\mathrm{~d}, J$ $=4.4 \mathrm{~Hz}, 1 \mathrm{H}), 6.72(\mathrm{dd}, J=3.6,1.1 \mathrm{~Hz}, 1 \mathrm{H}), 7.19(\mathrm{~d}, J=3.6 \mathrm{~Hz}, 1 \mathrm{H}), 8.53(\mathrm{~s}, 1 \mathrm{H}), 11.63(\mathrm{~s}, 1 \mathrm{H})$; 
${ }^{13} \mathrm{C}$ NMR (DMSO- $\left.d_{6}\right) \delta 14.7,60.2,69.4,74.2,84.7,88.6,108.6,122.6,124.7,131.5,134.9,138.8$, 149.5, 161.3; HRMS calcd for $\mathrm{C}_{14} \mathrm{H}_{17} \mathrm{~N}_{2} \mathrm{O}_{6} \mathrm{~S}[\mathrm{M}+\mathrm{H}]^{+}$341.0802, found 341.0803.

5-(Pyrrol-2-yl)uridine (111). Treatment of 5-iodouridine (100, $52 \mathrm{mg}, 0.14 \mathrm{mmol})$ with pyrrole $(0.2 \mathrm{~mL}, 193 \mathrm{mg}, 2.88 \mathrm{mmol})$ by procedure A [reaction was carried out in a flask covered in aluminum foil under $\mathrm{N}_{2}$ atmosphere; column chromatography $\left.\left(\mathrm{CH}_{2} \mathrm{Cl}_{2} / \mathrm{MeOH}, 15: 1 \rightarrow 10: 1\right)\right]$ gave $111(19.4 \mathrm{mg}, 45 \%)$ as brownish amorphous powder. This material is stable when stored in refrigerator under the inert condition for at least 1 month: ${ }^{1} \mathrm{H}$ NMR (DMSO- $\left.d_{6}\right) \delta 3.60$ (ddd, $J=$ 12.0, 4.4, $3.3 \mathrm{~Hz}, 1 \mathrm{H}$ ), 3.70 (ddd, $J=11.8,4.6,3.5 \mathrm{~Hz}, 1 \mathrm{H}$ ), 3.87 ("q", $J=3.5 \mathrm{~Hz}, 1 \mathrm{H}$ ), 4.03 ("q", $J=4.7 \mathrm{~Hz}, 1 \mathrm{H}), 4.14(" \mathrm{q} ", J=5.2 \mathrm{~Hz}, 1 \mathrm{H}), 5.10(\mathrm{~d}, J=5.2 \mathrm{~Hz}, 1 \mathrm{H}), 5.27(\mathrm{t}, J=4.8 \mathrm{~Hz}, 1 \mathrm{H}), 5.42$ $(\mathrm{d}, J=5.6 \mathrm{~Hz}, 1 \mathrm{H}), 5.83(\mathrm{~d}, J=5.1 \mathrm{~Hz}, 1 \mathrm{H}), 6.03(\mathrm{dd}, J=5.8,2.6 \mathrm{~Hz}, 1 \mathrm{H}), 6.39(\mathrm{dd}, J=4.5,2.7$ $\mathrm{Hz}, 1 \mathrm{H}), 6.76(\mathrm{dd}, J=4.1,2.5 \mathrm{~Hz}, 1 \mathrm{H}), 8.22(\mathrm{~s}, 1 \mathrm{H}), 10.85$ (s, 1H), 11.54 (bs, $1 \mathrm{H}) ;{ }^{13} \mathrm{C}$ NMR $\left(\mathrm{DMSO}-d_{6}\right) \delta 60.6,69.6,73.6,84.7,88.2,105.5,107.2,108.0,118.2,123.8,133.6,149.7,162.0$ HRMS calcd for $\mathrm{C}_{13} \mathrm{H}_{16} \mathrm{~N}_{3} \mathrm{O}_{6}[\mathrm{M}+\mathrm{H}]^{+}$310.1034, found 310.1034 .

2',3',5'-Tri-O-acetylcytidine hydrochloride. Cytidine (112, $486 \mathrm{mg}, 2 \mathrm{mmol})$ was dissolved in the mixture of $\mathrm{CH}_{3} \mathrm{COOH} / \mathrm{CHCl}_{3}(9 \mathrm{~mL}, 1: 2, \mathrm{v} / \mathrm{v})$, followed by the addition of acetyl chloride $(0.6 \mathrm{~mL})$. The resulting clear solution was stirred at ambient temperature for $40 \mathrm{~h}$. Volatiles was removed under the reduced pressure and the oily residue was column chromatographed $\left(\mathrm{CHCl}_{3}: \mathrm{MeOH}=9: 1\right)$ to give product 112 as white precipitate $(776 \mathrm{mg}, 96 \%) .{ }^{1} \mathrm{H}$ NMR (400 MHz, DMSO-d $\left.d_{6}\right) \delta 2.05(\mathrm{~s}, 3 \mathrm{H}), 2.06(\mathrm{~s}, 3 \mathrm{H}), 2.07(\mathrm{~s}, 3 \mathrm{H}), 4.18-4.37(\mathrm{~m}, 3 \mathrm{H}), 5.32(\mathrm{t}, J=6.0 \mathrm{~Hz}$ $1 \mathrm{H}), 5.48(\mathrm{dd}, J=6.1,4.4 \mathrm{~Hz}, 1 \mathrm{H}), 5.90(\mathrm{~d}, J=4.3 \mathrm{~Hz}, 1 \mathrm{H}), 6.20(\mathrm{~d}, J=7.8 \mathrm{~Hz}, 1 \mathrm{H}), 7.97(\mathrm{~d}, J=$ $7.8 \mathrm{~Hz}, 1 \mathrm{H}), 8.70(\mathrm{~s}, 1 \mathrm{H}), 9.70(\mathrm{~s}, 1 \mathrm{H}) ;{ }^{13} \mathrm{C}$ NMR (101 MHz, DMSO-d 6 ) $\delta 20.27,20.31,20.6$, $62.8,69.4,72.4,79.3,89.2,94.8,144.7,148.1,160.6,169.3,170.1$.

2',3',5'-Tri-O-acetyl-5-iodocytidine (113). 2',3',5'-Tri- $O$-acetylcytidine hydrochloride (405 $\mathrm{mg}, 1 \mathrm{mmol})$ was dissolved in the mixture of $\mathrm{CCl}_{4} / \mathrm{CH}_{3} \mathrm{COOH}(8 \mathrm{~mL}, 1: 1, \mathrm{v} / \mathrm{v})$, followed by the addition of $\mathrm{I}_{2}(152 \mathrm{mg}, 0.6 \mathrm{mmol})$ and $\mathrm{HIO}_{3}(153 \mathrm{mg}, 0.87 \mathrm{mmol})$. The resulting red solution was 
stirred at $40{ }^{\circ} \mathrm{C}$ for $12 \mathrm{~h}$. After cool down to ambient temperature, reaction mixture was washed with water and saturated $\mathrm{NaHCO}_{3}$. The color of iodine was reduced with $5 \%$ of $\mathrm{NaHSO}_{3}$, and the organic was dried over the $\mathrm{Na}_{2} \mathrm{SO}_{4}$. Volatiles was removed under the reduced pressure and the residue was column chromatographed $\left(\mathrm{CHCl}_{3}: \mathrm{MeOH}=95: 5\right)$ to give product $\mathbf{1 1 3}$ as white precipitate (361 mg, 73\%). ${ }^{1} \mathrm{H}$ NMR (400 MHz, DMSO-d $\left.d_{6}\right) \delta 2.05(\mathrm{~s}, 3 \mathrm{H}), 2.06(\mathrm{~s}, 3 \mathrm{H}), 2.07$ (s, $3 \mathrm{H}), 4.13-4.27(\mathrm{~m}, 2 \mathrm{H}), 4.27-4.37(\mathrm{~m}, 1 \mathrm{H}), 5.30-5.39(\mathrm{~m}, 1 \mathrm{H}), 5.45(\mathrm{dd}, J=6.4,4.4 \mathrm{~Hz}, 1 \mathrm{H})$, $5.80(\mathrm{~d}, J=4.3 \mathrm{~Hz}, 1 \mathrm{H}), 6.83(\mathrm{~s}, 1 \mathrm{H}), 8.04(\mathrm{~s}, 1 \mathrm{H}), 8.07(\mathrm{~s}, 1 \mathrm{H}) ;{ }^{13} \mathrm{C}$ NMR $\left(101 \mathrm{MHz}, \mathrm{DMSO}-d_{6}\right)$ $\delta 20.3,20.7,48.6,57.8,63.0,69.7,72.5,78.9,98.8,148.6,153.6,164.1,169.4,170.0$.

3-(Fur-2-yl)pyridin-2(1H)-one (120). Method A. Treatment of 119 (24.36 mg, 0.14 mmol) with furan $(0.2 \mathrm{~mL}, 187 \mathrm{mg}, 2.75 \mathrm{mmol})$ by procedure A (14 equiv. of TBAF) gave $120(7 \mathrm{mg}$, 31\%) followed by 119 (11 mg, 45\%). Compound 120 had: UV (MeOH) $\lambda_{\max }=332 \mathrm{~nm} ;{ }^{1} \mathrm{H}$ NMR $\left(\mathrm{CD}_{3} \mathrm{CN}\right) \delta 6.33(\mathrm{t}, J=6.9 \mathrm{~Hz}, 1 \mathrm{H}), 6.53(\mathrm{dd}, J=3.3,1.8 \mathrm{~Hz}, 1 \mathrm{H}), 7.27-7.29(\mathrm{~m}, 2 \mathrm{H}), 7.54(\mathrm{dd}, J$ $=1.8,0.7 \mathrm{~Hz}, 1 \mathrm{H}), 7.89(\mathrm{dd}, J=7.1,2.0 \mathrm{~Hz}, 1 \mathrm{H}), 10.33(\mathrm{~s}, 1 \mathrm{H}) ;{ }^{13} \mathrm{C} \mathrm{NMR}\left(\mathrm{CD}_{3} \mathrm{CN}\right) \delta 106.5$, $111.1,112.7,122.2,133.7,134.6,143.0,150.4,160.2$; HRMS calcd for $\mathrm{C}_{9} \mathrm{H}_{8} \mathrm{NO}_{2}[\mathrm{M}+\mathrm{H}]^{+}$ 162.0550, found 162.0553 .

Method B. Treatment of $119(24.36 \mathrm{mg}, 0.14 \mathrm{mmol})$ with furan $(0.2 \mathrm{~mL}, 187 \mathrm{mg}, 2.75 \mathrm{mmol})$ by procedure B gave $\mathbf{1 2 0}$ (15.3 $\mathrm{mg}, 68 \%$ yield) with the spectroscopic data as above.

3-(Thiophen-2-yl)pyridin-2(1H)-one (121). Treatment of 119 (24.36 mg, $0.14 \mathrm{mmol})$ with thiophene $(0.2 \mathrm{~mL}, 210 \mathrm{mg}, 2.5 \mathrm{mmol})$ by procedure A (14 equiv. of TBAF) gave $121(7 \mathrm{mg}$, 27\%) followed by 119 (12 mg, 49\%). Compound $22 \mathrm{had}$ : UV (MeOH) $\lambda_{\max }=346 \mathrm{~nm} ;{ }^{1} \mathrm{H}$ NMR $\left(\mathrm{CD}_{3} \mathrm{CN}\right) \delta 6.32(\mathrm{dd}, J=7.0,6.6 \mathrm{~Hz}, 1 \mathrm{H}), 7.09(\mathrm{dd}, J=5.1,3.8 \mathrm{~Hz}, 1 \mathrm{H}), 7.28(\mathrm{dd}, J=6.5,1.9 \mathrm{~Hz}$, 1H), $7.40(\mathrm{dd}, J=5.1,1.1 \mathrm{~Hz}, 1 \mathrm{H}), 7.67(\mathrm{dd}, J=3.8,1.1 \mathrm{~Hz}, 1 \mathrm{H}), 7.97(\mathrm{dd}, J=7.1,1.9 \mathrm{~Hz}, 1 \mathrm{H})$, $9.98(\mathrm{~s}, 1 \mathrm{H}) ;{ }^{13} \mathrm{C} \mathrm{NMR}\left(\mathrm{CD}_{3} \mathrm{CN}\right) \delta 105.4,123.6,126.2,126.4,128.2,129.2,132.4,134.5,159.6$; HRMS calcd for $\mathrm{C}_{9} \mathrm{H}_{8} \mathrm{NOS}[\mathrm{M}+\mathrm{H}]^{+}$178.0321, found 178.0320. 
1-N-Benzyl-6-(4-methoxyphenyl)uracil (122). $\mathrm{AgCl}(60 \mathrm{mg}, 0.42 \mathrm{mmol}), \mathrm{Pd}(\mathrm{OAc})_{2}(3.2$ $\mathrm{mg}, 0.014 \mathrm{mmol}$ ) and tetrabutylammonium bromide (TBABr, $67.7 \mathrm{mg}, 0.21 \mathrm{mmol}$ ) were added to a stirred solution of 1- $N$-benzyluraci2 ${ }^{210}(\mathbf{9 2}, 28.3 \mathrm{mg}, 0.14 \mathrm{mmol})$ and 4-iodoanisole $(98.3 \mathrm{mg}$, $0.42 \mathrm{mmol})$ in DMSO $(1 \mathrm{~mL})$ under the $\mathrm{N}_{2}$ atmosphere at ambient temperature. The resulting suspension was stirred for $16 \mathrm{~h}$ at $100{ }^{\circ} \mathrm{C}$ (oil bath). Volatiles were evaporated, and the oily residue was dissolved in EtOAc and filtrated through Whatman GF/A filter paper. The filtrate was column chromatographed (hexane/EtOAc, 5:5 $\rightarrow 4: 6)$ to give $p$-91d (10 mg, 23\%) and 122 (14 mg, 33\%) followed by 92 (12 mg, 41\%). Compound 23 had: ${ }^{1} \mathrm{H}$ NMR $\delta 3.84$ (s, 1H), 4.96 (s, $1 \mathrm{H}), 5.65(\mathrm{~s}, 1 \mathrm{H}), 6.87(\mathrm{~d}, J=8.6 \mathrm{~Hz}, 1 \mathrm{H}), 6.90-6.95(\mathrm{~m}, 1 \mathrm{H}), 7.08(\mathrm{~d}, J=8.5 \mathrm{~Hz}, 1 \mathrm{H}), 7.19-7.26$ $(\mathrm{m}, 1 \mathrm{H}), 9.73(\mathrm{~s}, 1 \mathrm{H}) ;{ }^{13} \mathrm{C} \mathrm{NMR} \delta 48.6,55.5,104.1,114.2,125.3,127.0,127.7,128.7,129.5$, 136.5, 152.3, 157.3, 161.0, 163.1; GC-MS ( $t_{\mathrm{R}} 24.77$ min.) $\mathrm{m} / \mathrm{z} 308\left(70, \mathrm{M}^{+}\right), 91$ (100); HRMS calcd for $\mathrm{C}_{18} \mathrm{H}_{17} \mathrm{~N}_{2} \mathrm{O}_{3}[\mathrm{M}+\mathrm{H}]^{+}$309.1234, found 309.1229.

\section{1-(2,3,5-Tri- $O$-acetyl- $\beta$-D-arabinofuranosyl)-5-(E/Z)-[2-(triphenylgermyl)ethenyl]uracil}

\section{(124a) and 1-(2,3,5-tri- $O$-acetyl- $\beta$-D-arabinofuranosyl)-5-[2-(triphenylgermyl)acetyl]uracil}

(126a). Method A. ACCN-induced hydrogermylation. Nucleoside $\mathbf{1 2 3}^{161}$ (50 mg, $\left.0.13 \mathrm{mmol}\right)$ was added to freshly distilled toluene $(6 \mathrm{~mL})$ and the suspension was stirred and degassed with $\mathrm{N}_{2}$ for $30 \mathrm{~min}$. The mixture was then pre-heated at $80{ }^{\circ} \mathrm{C}$ and $\mathrm{Ph}_{3} \mathrm{GeH}(50 \mathrm{mg}, 0.16 \mathrm{mmol})$ was added followed by ACCN (4 mg, $0.02 \mathrm{mmol}$ ). The temperature was increased to $90{ }^{\circ} \mathrm{C}$ and the solution was stirred until 123 was completely consumed (TLC; 14 h). The volatiles were removed in vacuo and the oily residue was chromatographed (hexane/EtOAc, 2:3) to give a separable mixture of $Z$-124a (43 mg, 47\%) and 126a (10.5 mg, 12\%). Compound $Z$-124a had: ${ }^{1} \mathrm{H}$ NMR $\delta$ 1.99 (s, 3H), 2.09 (s, 3H), $2.11(\mathrm{~s}, 3 \mathrm{H}), 3.70(\mathrm{dd}, J=13.7,7.7 \mathrm{~Hz}, 1 \mathrm{H}), 3.91-3.98(\mathrm{~m}, 2 \mathrm{H}), 4.97$ $(\mathrm{dd}, J=3.2,2.0 \mathrm{~Hz}, 1 \mathrm{H}), 5.27(\mathrm{dd}, J=4.1,1.9 \mathrm{~Hz}, 1 \mathrm{H}), 5.71(\mathrm{~d}, J=4.1 \mathrm{~Hz}, 1 \mathrm{H}), 6.56(\mathrm{~d}, J=13.5$ $\mathrm{Hz}, 1 \mathrm{H}), 7.08$ (d, J=1.0 Hz, 1H), 7.36 (m, 10H), 7.52 (m, 6H), 8.30 (br. s, 1H); ${ }^{13} \mathrm{C}$ NMR $\delta 20.4$, $20.6,20.7,62.3,74.6,76.1,79.8,84.4,113.4,128.4,129.1,131.7,134.8,136.38,136.41,138.2$ 
148.6, 161.3, 168.5, 169.4, 170.2; MS $m / z 701\left(100, \mathrm{MH}^{+},{ }^{74} \mathrm{Ge}\right), 699\left(71, \mathrm{MH}^{+},{ }^{72} \mathrm{Ge}\right) 698(51$, $\mathrm{MH}^{+},{ }^{70} \mathrm{Ge}$ ); Anal. Calcd for $\mathrm{C}_{35} \mathrm{H}_{34} \mathrm{GeN}_{2} \mathrm{O}_{9}$ (699.29): C, 60.11; H, 4.90; N, 4.01. Found: C, 59.63; $\mathrm{H}, 4.92 ; \mathrm{N}, 4.00$.

${ }^{1} \mathrm{H}$ NMR of the crude reaction mixture showed also a presence $(\sim 5 \%)$ of the $E-\mathbf{1 2 4 a}$ with the characteristic peaks at $\delta 6.31\left(\mathrm{~d}, J=4.0 \mathrm{~Hz}, \mathrm{H} 1^{\prime}\right), 6.69(\mathrm{~d}, J=18.8 \mathrm{~Hz}, \mathrm{CH})$.

Compound 126a had: ${ }^{1} \mathrm{H}$ NMR $\delta 1.90(\mathrm{~s}, 3 \mathrm{H}), 2.14$ (s, 3H), 2.15 (s, 3H), 3.48 (d, $J=9.3 \mathrm{~Hz}$, 1H), 4.16-4.19 (m, 1H), 4.17 (d, $J=9.3 \mathrm{~Hz}, 1 \mathrm{H}), 4.33$ (dd, $J=12.1,4.5 \mathrm{~Hz}, 1 \mathrm{H}), 4.44$ (dd, $J=$ $12.1,4.9 \mathrm{~Hz}, 1 \mathrm{H}), 5.12(\mathrm{dd}, J=3.3,1.6 \mathrm{~Hz}, 1 \mathrm{H}), 5.33(\mathrm{dd}, J=4.1,1.6 \mathrm{~Hz}, 1 \mathrm{H}), 6.23(\mathrm{~d}, J=4.1$ $\mathrm{Hz}, 1 \mathrm{H}), 7.21-7.37$ (m, 9H), 7.50-7.55 (m, 6H), 8.08 (s, 1H), 8.49 (br. s, $1 \mathrm{H}) ;{ }^{13} \mathrm{C}$ NMR $\delta 20.4$, $20.7,20.8,33.0,62.4,74.6,76.6,80.8,83.9,113.3,128.4,129.5,135.1,135.3,146.6,148.8$, 160.4, 168.8, 169.6, 170.8, 194.2; HRMS calcd for $\mathrm{C}_{35} \mathrm{H}_{34}{ }^{74} \mathrm{GeN}_{2} \mathrm{NaO}_{10}[\mathrm{M}+\mathrm{Na}]^{+} 739.1323$, found 739.1311 .

Treatment of $123(100 \mathrm{mg}, 0.26 \mathrm{mmol})$ and $\mathrm{Ph}_{3} \mathrm{GeH}(94 \mathrm{mg}, 0.30 \mathrm{mmol})$ in toluene without $\operatorname{ACCN}\left(85^{\circ} \mathrm{C}, 14 \mathrm{~h}\right.$; column chromatography $(50 \rightarrow 60 \%$ EtOAc/hexane) gave $E / Z-124 a(110$ $\mathrm{mg}, 60 \% ; E / Z, 3: 97)$ and 126a (26 mg, 15\%).

Method B. Et $t_{3} B$-induced hydrogermylation. A solution of $\mathrm{Et}_{3} \mathrm{~B}$ in $\mathrm{THF}(1 \mathrm{M} ; 140 \mu \mathrm{L}, 0.14$ mmol) was added to a stirred solution of $123(50 \mathrm{mg}, 0.127 \mathrm{mmol})$ and $\mathrm{Ph}_{3} \mathrm{GeH}(43 \mathrm{mg}, 0.14$ mmol) in dry THF $(5 \mathrm{~mL})$ at $-78{ }^{\circ} \mathrm{C}$ placed in a screw-capped glass tube. The resulting mixture was stirred for 3 hours at $-78{ }^{\circ} \mathrm{C}$ until TLC showed appearance of a less polar spot. The reaction mixture was slowly warmed up to $-60{ }^{\circ} \mathrm{C}$ and was stirred for another $1.5 \mathrm{~h}$. The volatiles were evaporated and the resulting oil was column chromatographed (hexane/EtOAc, 2:3) to give Z124a (49 mg, 55\%).

Treatment of 123 (49 mg, $0.12 \mathrm{mmol}$ ) with $\mathrm{Ph}_{3} \mathrm{GeH}(42 \mathrm{mg}, 0.14 \mathrm{mmol}$ ) by Method B $\left(0{ }^{\circ} \mathrm{C} / 6 \mathrm{~h}\right)$ gave a mixture of $Z$-124a and 126a $\left(39 \mathrm{mg}, \sim 46 \% ; \mathbf{1 2 4 a} / \mathbf{1 2 6 a}, \sim 59: 41,{ }^{1} \mathrm{H} \mathrm{NMR}\right)$. Recrystallization (hexane/ $\mathrm{Et}_{2} \mathrm{O}$ ) gave $Z \mathbf{- 1 2 4 a}$ as a white powder (22 $\mathrm{mg}, 25 \%$ from 123). 
Method C. $P$ d-catalyzed hydrogermylation. $\mathrm{Ph}_{3} \mathrm{GeH}(59 \mathrm{mg}, 0.2 \mathrm{mmol})$ and $\mathrm{Pd}\left(\mathrm{PPh}_{3}\right)_{4}(8 \mathrm{mg}$, $0.08)$ was added to stirred suspension of $\mathbf{1 2 3}(70 \mathrm{mg}, 0.18 \mathrm{mmol})$ in THF ( $3 \mathrm{~mL})$ in a flamed dried round bottle flask at ambient temperature under $\mathrm{N}_{2}$. After $5 \mathrm{~h}$, the volatiles were evaporated in vacuo and the resulting oil was column chromatographed (hexane/EtOAc, 1:1) to give inseparable mixture of the $E$-isomer of $\mathbf{1 2 4}$ and the corresponding regioisomer resulting from the addition to $\alpha$-carbon (90 mg, 73\%; E-124/ $\alpha$-addition product, $3: 2 ;{ }^{1} \mathrm{H}$ NMR;): MS (ESI) $m / z 701$ $\left(100, \mathrm{MH}^{+},{ }^{74} \mathrm{Ge}\right), 699\left(70, \mathrm{MH}^{+},{ }^{72} \mathrm{Ge}\right), 697\left(50, \mathrm{MH}^{+},{ }^{70} \mathrm{Ge}\right)$. Compound $E$-124a had: ${ }^{1} \mathrm{H}$ NMR $\delta$ $1.88(\mathrm{~s}, 3 \mathrm{H}), 1.98(\mathrm{~s}, 3 \mathrm{H}), 2.14(\mathrm{~s}, 3 \mathrm{H}), 4.23(\mathrm{~m}, 2 \mathrm{H}), 4.35-4.39(\mathrm{~m}, 1 \mathrm{H}), 5.09$ (dd, $J=3.4,1.5 \mathrm{~Hz}$ 1H), $5.43(\mathrm{dd}, J=3.9,1.5 \mathrm{~Hz}, 1 \mathrm{H}), 6.31(\mathrm{~d}, J=4.0 \mathrm{~Hz}, 1 \mathrm{H}), 6.69$ (d, $J=18.8 \mathrm{~Hz}, 1 \mathrm{H}), 7.60$ (s, 1H), 7.33-7.40 (m, 10H), 7.51-7.55 (m, 6H), 9.29 (br. s, $1 \mathrm{H})$. The $\alpha$-addition product 1-(2,3,5-tri$O$-acetyl- $\beta$-D-arabinofuranosyl)-5-[1-(triphenylgermyl)ethenyl] uracil had: ${ }^{1} \mathrm{H}$ NMR $\delta 1.80$ (s, 3H), $2.07(\mathrm{~s}, 3 \mathrm{H}), 2.11(\mathrm{~s}, 3 \mathrm{H}), 4.00-4.23(\mathrm{~m}, 2 \mathrm{H}), 4.45-4.49(\mathrm{~m}, 1 \mathrm{H}), 4.98(\mathrm{dd}, J=3.5,1.9 \mathrm{~Hz}$, $1 \mathrm{H}), 5.35(\mathrm{dd}, J=4.1,1.5 \mathrm{~Hz}, 1 \mathrm{H}), 5.72(\mathrm{~d}, J=2.0 \mathrm{~Hz}, 1 \mathrm{H}), 6.17(\mathrm{~d}, J=4.1 \mathrm{~Hz}, 1 \mathrm{H}), 6.41(\mathrm{~d}, J=$ 2.0 Hz, 1H), 7.33-7.40 (m, 9H), $7.42(\mathrm{~s}, 1 \mathrm{H}), 7.51-7.55$ (m, 6H), 8.98 (br. s, $1 \mathrm{H})$.

\section{1-(2,3,5-Tri- $O$-acetyl- $\beta$-D-arabinofuranosyl)-5-(E/Z)-[2-(trimethylgermyl)ethenyl]uracil}

(124b). Nucleoside 123 (50 mg, $0.13 \mathrm{mmol}$ ) was treated with $\mathrm{Me}_{3} \mathrm{GeH}(30 \mathrm{mg}, 29.6 \mu \mathrm{L}, 0.25$ mmol) in dry THF $(5 \mathrm{~mL})$ as described in Method B (with injection of $\mathrm{Me}_{3} \mathrm{GeH}$ into the reaction mixture via syringe and progressive warming from $0{ }^{\circ} \mathrm{C}$ to ambient temperature) for $14 \mathrm{~h}$. The volatiles were removed under reduced pressure and the residue was column chromatographed (hexane/EtOAc, 2:3) to give $E / Z-124 b(27 \mathrm{mg}, 40 \%$; $E / Z, 13: 87) .{ }^{1} \mathrm{H}$ NMR $\delta 0.26(\mathrm{~s}, 7.83 \mathrm{H})$, $0.28(\mathrm{~s}, 1.17 \mathrm{H}), 2.02(\mathrm{~s}, 3 \mathrm{H}), 2.12(\mathrm{~s}, 2.61 \mathrm{H}), 2.15(\mathrm{~s}, 0.39 \mathrm{H}), 2.16(\mathrm{~s}, 2.61 \mathrm{H}), 2.17(\mathrm{~s}, 0.39 \mathrm{H})$, 4.19-4.25 (m, 1H), $4.34(\mathrm{dd}, J=11.9,6.2 \mathrm{~Hz}, 0.87 \mathrm{H}), 4.37-4.45(\mathrm{~m}, 0.13 \mathrm{H}), 4.44(\mathrm{dd}, J=11.9$, $4.2 \mathrm{~Hz}, 0.87 \mathrm{H}), 4.52(\mathrm{dd}, J=11.9,6.2 \mathrm{~Hz}, 0.13 \mathrm{H}), 5.11(\mathrm{dd}, J=3.8,1.4 \mathrm{~Hz}, 0.87 \mathrm{H}), 5.15(\mathrm{dd}, J=$ 3.4, $1.6 \mathrm{~Hz}, 0.13 \mathrm{H}), 5.44-5.48(\mathrm{~m}, 1 \mathrm{H}), 6.10(\mathrm{~d}, J=13.8 \mathrm{~Hz}, 0.87 \mathrm{H}), 6.24(\mathrm{~d}, J=3.8 \mathrm{~Hz}, 0.87 \mathrm{H})$, $6.33(\mathrm{~d}, J=4.0 \mathrm{~Hz}, 0.13 \mathrm{H}), 6.60(\mathrm{~d}, J=18.9 \mathrm{~Hz}, 0.13 \mathrm{H}), 6.80(\mathrm{~d}, J=19.0 \mathrm{~Hz}, 0.13 \mathrm{H}), 6.98(\mathrm{dd}, J$ 
$=13.8,1.0 \mathrm{~Hz}, 0.87 \mathrm{H}), 7.45(\mathrm{~d}, J=1.0 \mathrm{~Hz}, 0.87,1 \mathrm{H}), 7.59(\mathrm{~s}, 0.13 \mathrm{H}), 8.97$ (br. s, $0.13 \mathrm{H}), 9.09$ (br. s, 0.87H); ${ }^{13} \mathrm{C}$ NMR $\delta-1.7,-0.2,20.5,20.6,20.8,20.87,20.92,62.7,63.2,74.7,74.8,76.4$, $76.5,80.4,80.8,84.6,112.9,114.2,132.1,133.6,134.3,136.1,136.4,137.6,149.2,149.6,161.8$ 162.2, 168.6, 168.7, 169.7, 169.8, 170.5; HRMS calcd for $\mathrm{C}_{20} \mathrm{H}_{28}{ }^{74} \mathrm{GeNaN}_{2} \mathrm{O}_{9}[\mathrm{M}+\mathrm{Na}]^{+}$ 537.0899, found 537.0888.

\section{1-(2,3,5-Tri- $O$-acetyl- $\beta$-D-arabinofuranosyl)-5-(Z)-[2-(tris(trimethylsilyl)germyl)ethenyl]}

uracil (124c). Nitrogen gas was bubbled through a heterogeneous mixture of $\mathbf{1 2 3}$ (127 mg, 0.32 $\mathrm{mmol})$ in dry toluene $(10 \mathrm{~mL})$ for $30 \mathrm{~min}$. The suspension was pre-heated up to $90{ }^{\circ} \mathrm{C}(\sim 5 \mathrm{~min})$ and $\left(\mathrm{Me}_{3} \mathrm{Si}\right)_{3} \mathrm{GeH}(115 \mathrm{mg}, 123 \mu \mathrm{L}, 0.39 \mathrm{mmol})$ was added via syringe in one portion followed by ACCN ( $8 \mathrm{mg}, 0.04 \mathrm{mmol})$ dissolved in degassed toluene $(1 \mathrm{~mL})$. The solution was heated at $95{ }^{\circ} \mathrm{C}$ over $30 \mathrm{~min}$ as TLC revealed total consumption of $\mathbf{1 2 3}$. The mixture was cooled down to ambient temperature. Volatiles were evaporated and the residue was column chromatographed (hexane/EtOAc, 3:2) to give Z-124c (152 mg, 68\%): ${ }^{1} \mathrm{H}$ NMR $\delta 0.20$ (s, 27H), $2.01(\mathrm{~s}, 3 \mathrm{H}), 2.10$ (s, 3H), $2.14(\mathrm{~s}, 3 \mathrm{H}), 4.17-4.24(\mathrm{~m}, 1 \mathrm{H}), 4.34(\mathrm{dd}, J=12.0,5.5 \mathrm{~Hz}, 1 \mathrm{H}), 4.38(\mathrm{dd}, J=12.0,5.2 \mathrm{~Hz}$, $1 \mathrm{H}), 5.14(\mathrm{dd}, J=3.8,1.6 \mathrm{~Hz}, 1 \mathrm{H}), 5.47(\mathrm{dd}, J=3.8,1.7 \mathrm{~Hz}, 1 \mathrm{H}), 6.16(\mathrm{~d}, J=3.9 \mathrm{~Hz}, 1 \mathrm{H}), 6.28$ $(\mathrm{d}, J=13.5 \mathrm{~Hz}, 1 \mathrm{H}), 6.90$ (dd, $J=13.5,1.4 \mathrm{~Hz}, 1 \mathrm{H}), 7.29$ (d, $J=1.4 \mathrm{~Hz}, 1 \mathrm{H}), 8.27$ (br. s, $1 \mathrm{H}) ;{ }^{13} \mathrm{C}$ NMR $\delta 1.95,20.7,20.9,21.0,63.1,75.0,76.5,80.7,85.4,116.1,133.9,134.1,136.2,149.6$, 162.0, 168.9, 169.7, 170.6; HRMS calcd for $\mathrm{C}_{26} \mathrm{H}_{47}{ }^{74} \mathrm{GeN}_{2} \mathrm{O}_{9} \mathrm{Si}_{3}[\mathrm{M}+\mathrm{H}]^{+}$689.1801, found 689.1798 .

${ }^{1} \mathrm{H}$ NMR of the crude reaction mixture showed 4:96 mixture of $E / Z$ isomers of 124c. The $E-$ 124c had the characteristic peaks on the ${ }^{1} \mathrm{H}$ NMR spectrum at: $\delta 6.36(\mathrm{~d}, J=3.5 \mathrm{~Hz}, \mathrm{H} 1$ '), 6.63 (d, $J=18.7 \mathrm{~Hz}, \mathrm{CH}), 6.86(\mathrm{~d}, J=18.5 \mathrm{~Hz}, \mathrm{CH})$.

1-( $\beta$-D-Arabinofuranosyl)-5-(Z)-[2-(triphenylgermyl)ethenyl]uracil (125a). A saturated solution of $\mathrm{MeOH} / \mathrm{NH}_{3}(2 \mathrm{~mL})$ was added to a suspension of $\mathrm{Z-124a}(40.0 \mathrm{mg}, 0.057 \mathrm{mmol})$ in 
$\mathrm{MeOH}(2 \mathrm{~mL})$ and the reaction mixture stirred for $6 \mathrm{~h}$ at $0{ }^{\circ} \mathrm{C}$. An additional portion of $\mathrm{MeOH} / \mathrm{NH}_{3}$ solution $(1 \mathrm{~mL})$ was then added and the solution was stirred overnight at ambient temperature. Volatiles were evaporated under vacuum and the residue was column chromatographed (EtOAc/MeOH, 98:2) to give Z-125a (28.2 mg, 86\%). ${ }^{1} \mathrm{H}$ NMR $\left(\mathrm{MeOH}-d_{4}\right) \delta$ $3.28(\mathrm{dd}, J=11.3,4.0 \mathrm{~Hz}, 1 \mathrm{H}), 3.37(\mathrm{dd}, J=11.3,5.6 \mathrm{~Hz}, 1 \mathrm{H}), 3.76(\mathrm{ddd}, J=5.8,4.1,2.1 \mathrm{~Hz}$, 1H), 3.98-4.02 (m, 2H), 5.59 (d, $J=3.3 \mathrm{~Hz}, 1 \mathrm{H}), 6.50(\mathrm{~d}, J=13.2 \mathrm{~Hz}, 1 \mathrm{H}), 7.30$ (d, $J=13.3 \mathrm{~Hz}$ 1H), $7.35(\mathrm{~m}, 10 \mathrm{H}), 7.51(\mathrm{~m}, 6 \mathrm{H}) ;{ }^{13} \mathrm{C} \mathrm{NMR}\left(\mathrm{MeOH}-d_{4}\right) \delta$ 62.6, 76.6, 78.4, 87.0, 88.3, 113.8, $129.3, \quad 130.0, \quad 131.5, \quad 136.0, \quad 138.2, \quad 139.9, \quad 140.7,151.3, \quad 165.0 ;$ HRMS calcd for $\mathrm{C}_{29} \mathrm{H}_{28}{ }^{74} \mathrm{GeNaN}_{2} \mathrm{O}_{6}[\mathrm{M}+\mathrm{Na}]^{+}$597.1051, found 597.1076. Anal. Calcd for $\mathrm{C}_{29} \mathrm{H}_{28} \mathrm{GeN}_{2} \mathrm{O}_{6} \bullet$ $\mathrm{CH}_{3} \mathrm{OH} \cdot \mathrm{H}_{2} \mathrm{O}$ (623.24): C, 57.81; H, 5.50; N, 4.49. Found: C, 57.84; H, 5.41; N, 4.69.

5-Ethynyl-2',3',5'-tri-O-p-toluoyluridine (127). The $p$-toluoyl chloride $(86 \mu \mathrm{L}, 101 \mathrm{mg}$, $0.65 \mathrm{mmol})$ was added to a stirred solution of 5-ethynyluridine $\mathrm{e}^{214}(50 \mathrm{mg}, 0.19 \mathrm{mmol})$ in the dry pyridine $(5 \mathrm{~mL})$. After $24 \mathrm{~h}$, the volatiles were evaporated and the residue was partitioned between $\mathrm{NaHCO}_{3} / \mathrm{H}_{2} \mathrm{O} / / \mathrm{CHCl}_{3}$. The organic layer was washed with diluted $\mathrm{HCl} / \mathrm{H}_{2} \mathrm{O}$, $\mathrm{NaHCO}_{3} / \mathrm{H}_{2} \mathrm{O}$, brine, and was dried $\left(\mathrm{MgSO}_{4}\right)$, and evaporated. The residue was column chromatographed (hexane/EtOAc, 7:3 $\rightarrow 6: 4)$ to give $127(85 \mathrm{mg}, 73 \%):{ }^{1} \mathrm{H}$ NMR $\delta 2.40(\mathrm{~s}, 3 \mathrm{H})$, $2.44(\mathrm{~s}, 6 \mathrm{H}, 2$ x Me), $2.94(\mathrm{~s}, 1 \mathrm{H}), 4.69-4.76(\mathrm{~m}, 2 \mathrm{H}), 4.78-4.84(\mathrm{~m}, 1 \mathrm{H}), 5.70$ ("t", $J=6.0 \mathrm{~Hz}$, 1H), $5.84(\mathrm{dd}, J=5.9,3.6 \mathrm{~Hz}, 1 \mathrm{H}, \mathrm{H} 3), 6.37(\mathrm{~d}, J=6.1 \mathrm{~Hz}, 1 \mathrm{H}), 7.18(\mathrm{~d}, J=8.0 \mathrm{~Hz}, 2 \mathrm{H}), 7.24$ (d, $J=8.0 \mathrm{~Hz}, 2 \mathrm{H}), 7.31(\mathrm{~d}, J=8.0 \mathrm{~Hz}, 2 \mathrm{H}), 7.81(\mathrm{~s}, 1 \mathrm{H}), 7.84(\mathrm{~d}, J=8.2 \mathrm{~Hz}, 2 \mathrm{H}), 7.91(\mathrm{~d}, J=8.2$ $\mathrm{Hz}, 2 \mathrm{H}), 8.02(\mathrm{~d}, J=8.2 \mathrm{~Hz}, 2 \mathrm{H}), 8.18(\mathrm{~s}, 1 \mathrm{H}) ;{ }^{13} \mathrm{C} \mathrm{NMR} \delta 21.8,21.9,63.8,71.5,73.76,73.77$, $81.4,82.5,87.9,100.6,125.7,126.1,126.5,129.4,129.5,129.7,129.9,130.1,130.2,143.2,144.6$, 144.8, 144.9, 148.8, 160.6, 165.4, 165.5, 166.3; HRMS calcd for $\mathrm{C}_{35} \mathrm{H}_{31} \mathrm{~N}_{2} \mathrm{O}_{9}[\mathrm{M}+\mathrm{H}]^{+} 623.2024$, found 623.2033 .

5-(Z)-[2-(Triphenylgermyl)ethenyl]-2',3',5'-tri-O-p-toluoyluridine (129a) and 5-[2(triphenylgermyl)acetyl]-2',3',5'-tri- $\boldsymbol{O}$-p-toluoyluridine (133a). Nucleoside 127 (49 mg, 0.08 
mmol; prepared by treatment of 5-ethynyluridine ${ }^{214}$ with para-toluoyl chloride in pyridine as described in $\mathrm{SI}$ ) was treated with $\mathrm{Ph}_{3} \mathrm{GeH}(26 \mathrm{mg}, 0.085 \mathrm{mmol})$ in dry THF (5 mL) as described in Method B. After $6 \mathrm{~h}$ at $-78{ }^{\circ} \mathrm{C}$, TLC revealed slow progression towards product. The reaction mixture was slowly warmed to $0{ }^{\circ} \mathrm{C}$ until TLC showed approximately $95 \%$ consumption of the substrate 127 ( $\sim 24 \mathrm{~h})$. The volatiles were removed under vacuum and the residue was column chromatographed (hexane/EtOAc, 1:1) to give a separable mixture of Z-129a (29 mg, 40\%) and 133a (10 mg, 13\%). Compound Z-129a had: ${ }^{1} \mathrm{H}$ NMR $\delta 2.40$ (s, 6H), 2.42 (s, 3H), 4.34 (dd, $J=$ 12.2, $5.4 \mathrm{~Hz}, 1 \mathrm{H}), 4.40(\mathrm{dd}, J=12.2,3.4 \mathrm{~Hz}, 1 \mathrm{H}), 4.47$ (ddd, $J=5.8,5.4,3.5 \mathrm{~Hz}, 1 \mathrm{H}), 5.38(\mathrm{dd}, J$ $=6.2,4.5 \mathrm{~Hz}, 1 \mathrm{H}), 5.51$ (“t”, $J=6.0 \mathrm{~Hz}, 1 \mathrm{H}), 5.52(\mathrm{~d}, J=4.4 \mathrm{~Hz}, 1 \mathrm{H}), 6.50(\mathrm{~d}, J=13.6 \mathrm{~Hz}, 1 \mathrm{H})$, $7.11(\mathrm{~d}, J=0.9 \mathrm{~Hz}, 1 \mathrm{H}), 7.16(\mathrm{~d}, J=8.1 \mathrm{~Hz}, 2 \mathrm{H}), 7.19(\mathrm{~d}, J=8.0 \mathrm{~Hz}, 2 \mathrm{H}), 7.22(\mathrm{dd}, J=13.5,0.9$ $\mathrm{Hz}, 1 \mathrm{H}), 7.24(\mathrm{~d}, J=8.0 \mathrm{~Hz}, 2 \mathrm{H}), 7.31-7.36(\mathrm{~m}, 9 \mathrm{H}), 7.50-7.55(\mathrm{~m}, 6 \mathrm{H}), 7.80(\mathrm{~d}, J=8.2 \mathrm{~Hz}, 4 \mathrm{H})$, $7.96(\mathrm{~d}, J=8.2 \mathrm{~Hz}, 2 \mathrm{H}), 8.09$ (br. s, $1 \mathrm{H}) ;{ }^{13} \mathrm{C}$ NMR $\delta 21.67,21.69,21.72,63.5,70.5,73.6,79.9$, $89.8,115.0,125.9,126.0,126.7,128.5,129.1,129.2,129.3,129.7,129.8,129.9,131.4,134.7$, 136.6, 137.0, 138.2, 144.2, 144.4, 144.5, 148.8, 161.4, 165.0, 165.1, 166.1; HRMS calcd for $\mathrm{C}_{53} \mathrm{H}_{46}{ }^{74} \mathrm{GeN}_{2} \mathrm{NaO}_{9}[\mathrm{M}+\mathrm{Na}]^{+}$951.2307, found 951.2315.

Compound 133a had: UV (MeOH) $\lambda_{\max }=282 \mathrm{~nm} ;{ }^{1} \mathrm{H}$ NMR $\delta 2.35(\mathrm{~s}, 3 \mathrm{H}), 2.40(\mathrm{~s}, 3 \mathrm{H}), 2.42$ (s, 3H), $3.76(\mathrm{~d}, J=9.0 \mathrm{~Hz}, 1 \mathrm{H}), 3.87(\mathrm{~d}, J=9.0 \mathrm{~Hz}, 1 \mathrm{H}), 4.67-4.75(\mathrm{~m}, 3 \mathrm{H}), 5.66(\mathrm{dd}, J=5.9,5.1$ $\mathrm{Hz}, 1 \mathrm{H}), 5.83$ ("t", $J=5.7 \mathrm{~Hz}, 1 \mathrm{H}), 6.01(\mathrm{~d}, J=5.0 \mathrm{~Hz}, 1 \mathrm{H}), 7.16-7.22(\mathrm{~m}, 6 \mathrm{H}), 7.31-7.36$ (m, 9H), 7.50-7.55 (m, 6H), $7.83(\mathrm{~d}, J=8.2 \mathrm{~Hz}, 2 \mathrm{H}), 7.87(\mathrm{~d}, J=8.2 \mathrm{~Hz}, 2 \mathrm{H}), 8.02(\mathrm{~d}, J=8.2 \mathrm{~Hz}$, 2H), 8.05 (s, 1H); ${ }^{13} \mathrm{C}$ NMR $\delta 21.7,33.0,63.5,71.0,73.9,80.9,90.4,113.7,125.7,126.0,126.6$, $128.2,129.21,129.24,129.3,129.4,129.8,129.9,135.0,135.1,144.1,144.5,144.7,146.6,148.5$, 160.2, 165.19, 165.21, 166.3, 193.3; HRMS calcd for $\mathrm{C}_{53} \mathrm{H}_{47}{ }^{74} \mathrm{GeN}_{2} \mathrm{O}_{10}[\mathrm{M}+\mathrm{H}]^{+}$945.2437, found 945.2456 .

5-(E/Z)-[2-(Trimethylgermyl)ethenyl]-2',3',5'-tri-O-p-toluoyluridine (129b). Nucleoside $127(50.0 \mathrm{mg}, 0.08 \mathrm{mmol})$ was treated with $\mathrm{Me}_{3} \mathrm{GeH}(19.0 \mathrm{mg}, 18.8 \mu \mathrm{L} 0.16 \mathrm{mmol})$ in dry THF 
$(5 \mathrm{~mL})$ as described in Method $\mathrm{B}$ (with injection of $\mathrm{Me}_{3} \mathrm{GeH}$ into the reaction mixture via syringe and progressive warming from $0{ }^{\circ} \mathrm{C}$ to $25^{\circ} \mathrm{C}$ ) for $10 \mathrm{~h}$. The volatiles were evaporated and the oily residue was column chromatographed (hexane/EtOAc, 3:2) to give $E / Z-129 b$ (24.5 mg, 41\%; $E / Z$, 45:55). ${ }^{1} \mathrm{H}$ NMR $\delta 0.12$ (s, 4.05H), 0.20 (s, 4.95H), 2.40, 2.43, 2.44 (singlets, 9H), 4.68-4.82 (m, $3 \mathrm{H}), 5.72$ (“t”, $J=6.0 \mathrm{~Hz}, 0.55 \mathrm{H}), 5.78$ (“t”, $J=6.3 \mathrm{~Hz}, 0.45 \mathrm{H}), 5.82$ (dd, $J=6.1,3.9 \mathrm{~Hz}, 0.55 \mathrm{H})$, $5.88(\mathrm{dd}, J=5.8,2.8 \mathrm{~Hz}, 0.45 \mathrm{H}), 5.98(\mathrm{~d}, J=13.7 \mathrm{~Hz}, 0.55 \mathrm{H}), 6.34(\mathrm{~d}, J=5.9 \mathrm{~Hz}, 0.55 \mathrm{H}), 6.37$ $(\mathrm{d}, J=19.0 \mathrm{~Hz}, 0.45 \mathrm{H}), 6.50(\mathrm{~d}, J=6.8 \mathrm{~Hz}, 0.45 \mathrm{H}), 6.69(\mathrm{~d}, J=19.0 \mathrm{~Hz}, 0.45 \mathrm{H}), 6.72(\mathrm{dd}, J=$ 13.7, $1.0 \mathrm{~Hz}, 0.55 \mathrm{H}), 7.16-7.32(\mathrm{~m}, 6 \mathrm{H}), 7.34(\mathrm{~d}, J=1.0 \mathrm{~Hz}, 0.55 \mathrm{H}), 7.54(\mathrm{~s}, 0.45 \mathrm{H}), 7.83-8.04$ (m, 6H), 8.24 (br. s, 0.45H), 8.27 (br. s, 0.55H); ${ }^{13} \mathrm{C}$ NMR $\delta$-2.0, -0.2, 21.7, 63.7, 64.2, 71.1, 71.5, $73.45,73.53,80.7,81.0,86.9,88.0,114.4,116.0,125.65,125.70,125.96,125.97,126.3,126.5$, $129.24,129.25,129.29,129.4,129.6,129.71,129.73,129.88,129.9,129.95,130.0,131.8,134.1$, $134.4,135.1,135.8,138.7,144.3,144.5,144.57,144.63,144.64,144.7,149.3,149.7,161.3$, 161.7, 165.3, 165.35, 165.38, 165.5, 166.1; $\mathrm{MS}\left(\mathrm{ESI}^{+}\right) \mathrm{m} / \mathrm{z} 765\left(100, \mathrm{MNa}^{+},{ }^{74} \mathrm{Ge}\right), 763\left(71, \mathrm{MNa}^{+}\right.$, $\left.{ }^{72} \mathrm{Ge}\right), 762\left(52 \mathrm{MNa}^{+},{ }^{70} \mathrm{Ge}\right)$; Anal. Calcd for $\mathrm{C}_{38} \mathrm{H}_{40} \mathrm{GeN}_{2} \mathrm{O}_{9} \cdot \mathrm{H}_{2} \mathrm{O}$ (759.39): C, 60.10; H, 5.57; N, 3.69. Found: C, 60.39; H, 5.38; N, 3.87.

5-(E/Z)-[2-(Trimethylgermyl)ethenyl]uridine (130b). A $0.1 \mathrm{~N}$ solution of $\mathrm{MeONa}$ in anhydrous $\mathrm{MeOH}(2 \mathrm{~mL})$ was added to $129 \mathrm{~b}(18.8 \mathrm{mg}, 0.025 \mathrm{mmol} ; E / Z, \sim 45: 55)$ and the resulting mixture stirred for $6 \mathrm{~h}$. An additional portion of $0.1 \mathrm{~N} \mathrm{MeONa} / \mathrm{MeOH}$ was added $(0.75$ $\mathrm{mL}$ ) and stirring was continued until the substrate 129b was consumed (TLC). The reaction mixture was carefully neutralized by addition of Dowex $50 \mathrm{WX} 2-200\left(\mathrm{H}^{+}\right)$to $\mathrm{pH} \sim 6.2$. The mixture was filtered, and the resin washed with $\mathrm{MeOH}$. The combined filtrate was evaporated under reduced pressure and the residue partitioned between $\mathrm{Et}_{2} \mathrm{O} / \mathrm{H}_{2} \mathrm{O}$. The organic layer was extensively washed with water. The combined aqueous layer was evaporated to yield $E / Z-\mathbf{1 3 0 b}$ (7 mg, 71\%; E/Z, 40:60): ${ }^{1} \mathrm{H}$ NMR $\left(\mathrm{D}_{2} \mathrm{O}\right) \delta 0.27$ (s, 5.4H), $0.32(\mathrm{~s}, 3.6 \mathrm{H}), 3.84-3.91(\mathrm{~m}, 1 \mathrm{H}), 3.95$ (dd, $J=12.7,2.7 \mathrm{~Hz}, 0.6 \mathrm{H}), 4.05$ (dd, $J=12.9,2.4 \mathrm{~Hz}, 0.4 \mathrm{H}), 4.18-4.24$ (m, 1H), 4.29 (“t”, $J=$ 
$5.0 \mathrm{~Hz}, 0.6 \mathrm{H}), 4.34$ (“t”, $J=5.7 \mathrm{~Hz}, 0.4 \mathrm{H}), 4.39-4.44(\mathrm{~m}, 1 \mathrm{H}), 6.00(\mathrm{~d}, J=3.8 \mathrm{~Hz}, 0.4 \mathrm{H}), 6.05$ (d, $J=5.3 \mathrm{~Hz}, 0.6 \mathrm{H}), 6.36(\mathrm{~d}, J=13.6 \mathrm{~Hz}, 0.6 \mathrm{H}), 6.70(\mathrm{~d}, J=19.0 \mathrm{~Hz}, 0.4 \mathrm{H}), 6.83(\mathrm{~d}, J=19.0 \mathrm{~Hz}$, $0.4 \mathrm{H}), 6.93(\mathrm{~d}, J=13.6 \mathrm{~Hz}, 0.6 \mathrm{H}), 7.77(\mathrm{~s}, 0.6 \mathrm{H}), 8.20(\mathrm{~s}, 0.4 \mathrm{H}) ;{ }^{13} \mathrm{C} \mathrm{NMR}\left(\mathrm{MeOH}-d_{4}\right) \delta-2.9$, $1.2,60.1,61.0,68.9,69.8,73.7,74.1,84.0,84.7,88.8,89.7,113.8,115.7,132.1,134.1,134.7$, 137.6, 137.8, 140.8, 151.1, 151.6, 164.6, 165.3; HRMS calcd for $\mathrm{C}_{14} \mathrm{H}_{23}{ }^{74} \mathrm{GeN}_{2} \mathrm{O}_{6}[\mathrm{M}+\mathrm{H}]^{+}$ 389.0762, found 389.0775 .

1-(2-Deoxy-3,5-di-O-p-toluoyl- $\beta$-D-erythro-pentofuranosyl)-5-(Z)-[2-(triphenylgermyl) ethenyl]uracil (131a) and 1-(2-deoxy-3,5-di-O-p-toluoyl- $\beta$-D-erythro-pentofuranosyl)-5-[2(triphenylgermyl)acetyl]uracil (134a). Nucleoside $\mathbf{1 2 8}^{178}$ (44 $\left.\mathrm{mg}, 0.09 \mathrm{mmol}\right)$ was treated with $\mathrm{Ph}_{3} \mathrm{GeH}(30 \mathrm{mg}, 0.1 \mathrm{mmol})$ in dry THF $(5 \mathrm{~mL})$ as described in Method B. After $6 \mathrm{~h}$ at $-78{ }^{\circ} \mathrm{C}$ TLC revealed slow progression towards product. Thus, the reaction mixture was slowly warmed to $0{ }^{\circ} \mathrm{C}$ until TLC showed approximately $95 \%$ consumption of the starting $\mathbf{1 2 8}$. The volatiles were evaporated under vacuum and the residue was column chromatographed (hexane/EtOAc, 3:2) to give a separable mixture of $Z$-131a (43 mg, 61\%) and 134a (9 mg, 12\%). Compound $Z$-131a had: ${ }^{1} \mathrm{H}$ NMR $\delta 1.68(\mathrm{ddd}, J=14.9,8.1,7.0 \mathrm{~Hz}, 1 \mathrm{H}), 2.31$ (ddd, $\left.J=14.5,5.7,1.8 \mathrm{~Hz}, 1 \mathrm{H}\right), 2.41(\mathrm{~s}$, $3 \mathrm{H}), 2.45(\mathrm{~s}, 3 \mathrm{H}), 4.16(\mathrm{dd}, J=11.1,3.5 \mathrm{~Hz}, 1 \mathrm{H}), 4.26-4.30(\mathrm{~m}, 1 \mathrm{H}), 4.32(\mathrm{dd}, J=11.1,5.0 \mathrm{~Hz}$, 1H), 5.15 (“dt”, $J=6.8,1.8 \mathrm{~Hz}, 1 \mathrm{H}), 5.84$ (dd, $J=8.1,5.7 \mathrm{~Hz}, 1 \mathrm{H}), 6.51$ (d, $J=13.5 \mathrm{~Hz}, 1 \mathrm{H})$, $7.11(\mathrm{~d}, J=1.0 \mathrm{~Hz}, 1 \mathrm{H}), 7.21-7.27(\mathrm{~m}, 5 \mathrm{H}), 7.36-7.40(\mathrm{~m}, 9 \mathrm{H}), 7.52-7.56(\mathrm{~m}, 6 \mathrm{H}), 7.88(\mathrm{~d}, J=8.2$ $\mathrm{Hz}, 2 \mathrm{H}), 7.91(\mathrm{~d}, J=8.2 \mathrm{~Hz}, 2 \mathrm{H}) ;{ }^{13} \mathrm{C}$ NMR $\delta 21.68,21.72,37.3,63.9,74.5,82.3,85.5,114.8$, $126.4,126.7,128.5,129.2,129.25,129.28,129.6,129.8,131.0,134.8,135.6,136.6,138.8,144.2$ 144.5, 149.3, 161.7, 165.8, 166.0; HRMS calcd for $\mathrm{C}_{45} \mathrm{H}_{41}{ }^{74} \mathrm{GeN}_{2} \mathrm{O}_{7}[\mathrm{M}+\mathrm{H}]^{+}$795.2120, found 795.2131

Compound 134a had: ${ }^{1} \mathrm{H}$ NMR $\delta$ 2.18-2.27 (m, 1H), $2.36(\mathrm{~s}, 3 \mathrm{H}), 2.45$ (s, 3H), 2.64 (ddd, $J=$ 14.3, 5.7, $1.8 \mathrm{~Hz}, 1 \mathrm{H}), 3.81(\mathrm{~d}, J=9.1 \mathrm{~Hz}, 1 \mathrm{H}), 3.85(\mathrm{~d}, J=9.1 \mathrm{~Hz}, 1 \mathrm{H}), 4.53-4.60(\mathrm{~m}, 2 \mathrm{H}), 4.74-$ $4.80(\mathrm{~m}, 1 \mathrm{H}), 5.54$ (“d”, $J=6.6 \mathrm{~Hz}, 1 \mathrm{H}), 6.16$ (dd, $J=8.3,5.7 \mathrm{~Hz}, 1 \mathrm{H}), 7.16$ (d, $J=8.0 \mathrm{~Hz}, 2 \mathrm{H})$, 
$7.28(\mathrm{~d}, J=8.1 \mathrm{~Hz}, 2 \mathrm{H}), 7.32-7.39(\mathrm{~m}, 9 \mathrm{H}), 7.53-7.57(\mathrm{~m}, 6 \mathrm{H}), 7.94(\mathrm{~d}, J=8.2 \mathrm{~Hz}, 2 \mathrm{H}), 7.95(\mathrm{~d}, J$ $=8.2 \mathrm{~Hz}, 2 \mathrm{H}), 8.15(\mathrm{~s}, 1 \mathrm{H}) ;{ }^{13} \mathrm{C} \mathrm{NMR} \delta 21.70,21.73,32.8,38.4,63.8,74.5,83.2,86.2,113.6$, $126.3,126.6,128.2,129.25,129.28,129.3,129.8,135.1,135.2,144.1,144.5,145.2,148.8,160.3$, 165.8, 166.2, 193.5; HRMS calcd for $\mathrm{C}_{45} \mathrm{H}_{41}{ }^{74} \mathrm{GeN}_{2} \mathrm{O}_{8}[\mathrm{M}+\mathrm{H}]^{+}$811.2075, found 811.2063.

Note: Treatment of 128 (50 mg, $0.10 \mathrm{mmol})$ with $\mathrm{Ph}_{3} \mathrm{GeH}(36 \mathrm{mg}, 0.12 \mathrm{mmol})$ in toluene (4 $\mathrm{mL})$ as described in Method A [DMF $(0.2 \mathrm{~mL})$ and water $(25 \mu \mathrm{L}, 25 \mathrm{mg}, 1.4 \mathrm{mmol})$ were added to the pre-heated reaction mixture] gave partially separated $E-\mathbf{1 3 1 a}(13 \mathrm{mg}, 16 \%), \mathbf{1 3 4 a}(6.5 \mathrm{mg}$, 8\%) and Z-131a (13 mg, 16\%). Compound $E$-131a had characteristic peaks for trans vinylic protons at $\delta 6.63(\mathrm{~d}, J=18.8 \mathrm{~Hz}, 1 \mathrm{H})$ and within the envelope of aromatic protons at $\delta 7.20-7.50$ (Cosy).

\section{1-(2-Deoxy-3,5-di-O-p-toluoyl- $\beta$-D-erythro-pentofuranosyl)-5-(E/Z)-[2-(trimethylgermyl)}

ethenyl]uracil (131b). Nucleoside $\mathbf{1 2 8}^{178}$ (45.0 mg, $\left.0.092 \mathrm{mmol}\right)$ was treated with $\mathrm{Me}_{3} \mathrm{GeH}(21.8$ $\mathrm{mg}, 21.6 \mu \mathrm{L}, 0.18 \mathrm{mmol}$ ) in dry THF $(5 \mathrm{~mL})$ as described in Method B (with injection of $\mathrm{Me}_{3} \mathrm{GeH}$ into the reaction mixture via syringe and progressive warming from $0{ }^{\circ} \mathrm{C}$ to $25^{\circ} \mathrm{C}$ ) for $10 \mathrm{~h}$. The volatiles were evaporated under vacuum and the residue was column chromatographed (hexane/EtOAc, $1: 1)$ to give $E / Z-131 b(16.5 \mathrm{mg}, 35 \%$; $E / Z, 40: 60):{ }^{1} \mathrm{H}$ NMR $\delta 0.14(\mathrm{~s}, 3.6 \mathrm{H})$, $0.21(\mathrm{~s}, 5.4 \mathrm{H}), 2.25-2.34(\mathrm{~m}, 1 \mathrm{H}), 2.42,2.43,2.45$ (singlets, $6 \mathrm{H}), 2.78$ (ddd, $J=14.2,5.5,1.6 \mathrm{~Hz}$, $0.6 \mathrm{H}), 2.80(\mathrm{ddd}, J=14.3,5.1,1.2 \mathrm{~Hz}, 0.4 \mathrm{H}), 4.56-4.61(\mathrm{~m}, 1 \mathrm{H}), 4.65(\mathrm{dd}, J=12.2,3.2 \mathrm{~Hz}, 0.6 \mathrm{H})$, 4.73-4.77 (m, 0.8H), 4.75 (dd, $J=12.2,3.8 \mathrm{~Hz}, 0.6 \mathrm{H}), 4.59$ (“dt”, $J=4.9,1.9 \mathrm{~Hz}, 0.6 \mathrm{H}), 4.63$ (“d”, $J=6.4 \mathrm{~Hz}, 0.4 \mathrm{H}), 6.00(\mathrm{~d}, J=13.7 \mathrm{~Hz}, 0.6 \mathrm{H}), 6.40(\mathrm{dd}, J=8.7,5.4 \mathrm{~Hz}, 0.6 \mathrm{H}), 6.41(\mathrm{~d}, J=$ $19.2 \mathrm{~Hz}, 0.4 \mathrm{H}), 6.46(\mathrm{~d}, J=8.9,5.2 \mathrm{~Hz}, 0.4 \mathrm{H}), 6.72(\mathrm{~d}, J=19.0 \mathrm{~Hz}, 0.4 \mathrm{H}), 6.78(\mathrm{dd}, J=13.7,1.0$ $\mathrm{Hz}, 0.6 \mathrm{H}), 7.22-7.32(\mathrm{~m}, 4 \mathrm{H}), 7.48(\mathrm{~d}, J=1.0 \mathrm{~Hz}, 0.6 \mathrm{H}), 7.67(\mathrm{~s}, 0.4 \mathrm{H}), 7.85-7.99(\mathrm{~m}, 4 \mathrm{H}), 8.51$ (br. s, 0.4H), 8.57 (br. s, 0.6H); ${ }^{13} \mathrm{C}$ NMR $\delta-2.0,-0.2,21.70,21.73,38.5,64.1,64.4,74.7,75.0$, $82.9,83.1,85.6,113.9,115.4,126.3,126.4,126.5,129.30,129.34,129.50,129.54129 .6,129.8$, 
$131.9,133.9,134.2,134.9,135.1,138.3,144.4,144.5,144.6,149.2,149.7,161.5,161.9,166.0$, 166.1; HRMS calcd for $\mathrm{C}_{30} \mathrm{H}_{34}{ }^{74} \mathrm{GeN}_{2} \mathrm{NaO}_{7}[\mathrm{M}+\mathrm{Na}]^{+}$631.1470, found 631.1482.

Note. Treatment of 131b (E/Z, 40:60; $12 \mathrm{mg} ; 0.02 \mathrm{mmol}$;) with NBS (5 mg, $0.028 \mathrm{mmol})$ in $\mathrm{CHCl}_{3} / \mathrm{CH}_{2} \mathrm{Cl}_{2}(1: 1.5, \mathrm{v} / \mathrm{v} ; 2.5 \mathrm{~mL})$ for $6 \mathrm{~h}$ at $0{ }^{\circ} \mathrm{C}$ (ice-bath) followed by deprotections with $\mathrm{NH}_{3} / \mathrm{MeOH}\left(0{ }^{\circ} \mathrm{C}\right.$ to ambient temperature, $\left.12 \mathrm{~h}\right)$ gave give $E$ and $Z$ 5-(2-bromovinyl)-2'deoxyuridine $(2: 3,70 \%$ overall from $\mathbf{1 3 1 b})$ with data as reported. ${ }^{64,215}$

1-( $\beta$-D-Erythro-pentofuranosyl)-5-(Z)-[2-(triphenylgermyl)ethenyl]uracil $\quad(132 a) . \quad A$ saturated solution of $\mathrm{MeOH} / \mathrm{NH}_{3}(2 \mathrm{~mL})$ was added to a suspension of Z-131a (33 mg, 0.042 $\mathrm{mmol})$ in $\mathrm{MeOH}(2 \mathrm{~mL})$ and the resulting mixture was stirred for $20 \mathrm{~h}$ at ambient temperature. An additional portion of $\mathrm{MeOH} / \mathrm{NH}_{3}$ solution $(1 \mathrm{~mL})$ was added and the solution was stirred for $48 \mathrm{~h}$ at ambient temperature. The volatiles were evaporated and the residue was column chromatographed (dry method, EtOAc) to give Z-132a (15 mg, 65\%): ${ }^{1} \mathrm{H}$ NMR $\left(\mathrm{MeOH}-d_{4}\right) \delta$ 1.44 (ddd, $J=14.2,7.9,6.6 \mathrm{~Hz}, 1 \mathrm{H}), 1.87$ (ddd, $J=13.6,5.9,2.7 \mathrm{~Hz}, 1 \mathrm{H}), 3.38$ (“d”, $J=4.4 \mathrm{~Hz}$, 2H), 3.70 (“"q", $J=3.8 \mathrm{~Hz}, 1 \mathrm{H}), 3.97$ (ddd, $J=6.0,3.3,2.8 \mathrm{~Hz}, 1 \mathrm{H}), 5.81$ (dd, $J=8.0,6.0 \mathrm{~Hz}, 1 \mathrm{H}$ ), $6.52(\mathrm{~d}, J=13.3 \mathrm{~Hz}, 1 \mathrm{H}), 7.28(\mathrm{~d}, J=1.1 \mathrm{~Hz}, 1 \mathrm{H}), 7.31(\mathrm{dd}, J=13.3,1.1 \mathrm{~Hz}, 1 \mathrm{H}), 7.36-7.41(\mathrm{~m}$, 9H), 7.49-7.54 (m, 6H); ${ }^{13} \mathrm{C}$ NMR $\left(\mathrm{MeOH}-d_{4}\right) \delta 40.3,63.0,72.3,86.3,88.6,115.8,129.5,130.2$,

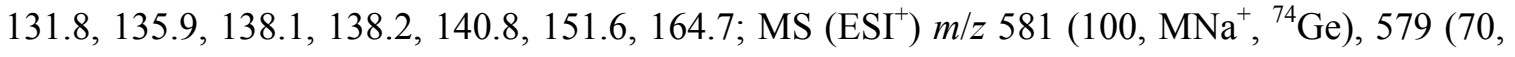
$\left.\mathrm{MNa}^{+},{ }^{70} \mathrm{Ge}\right), 577$ (49, $\left.\mathrm{MNa}^{+},{ }^{70} \mathrm{Ge}\right)$; Anal. Calcd for $\mathrm{C}_{29} \mathrm{H}_{28} \mathrm{GeN}_{2} \mathrm{O}_{5}$ (557.18): C, 62.51; H, 5.07; N, 5.03. Found: C, 62.14; H, 5.28; N, 4.86.

1- $N$-Benzyluracil (92). In a flame-dried $100 \mathrm{~mL}$ round-bottomed flask uracil (1.8 g, 16.0 mmol) was suspended in 1,1,1,3,3,3-hexamethyldisilazane (HMDS; $20 \mathrm{~mL}$ ) and stirred for 10 min under nitrogen. Trimethylsilyl chloride $(687 \mathrm{mg}, 800 \mu \mathrm{L}, 6.33 \mathrm{mmol})$ was added via syringe and the resulting mixture was refluxed $\left(125^{\circ} \mathrm{C}\right.$, oil bath) for $2 \mathrm{~h}$ until it became a clear solution. Volatiles were evaporated in vacuum and the resulting white solid was dissolved in 1,2dichloroethane $(70 \mathrm{~mL})$. Benzyl bromide $(3.29 \mathrm{~g}, 2.29 \mathrm{~mL}, 19.25 \mathrm{mmol})$ followed by $\mathrm{I}_{2}(100 \mathrm{mg}$, 
$0.39 \mathrm{mmol}$ ) were added and the resulting orange solution was refluxed for $5 \mathrm{~h}$. Volatiles were evaporated and the brownish solidified residue was washed with small amount of cold $\mathrm{MeOH}$ (2 $\times 2 \mathrm{~mL})$. The resulting orange solid was recrystallized from EtOH to give $92(2.75 \mathrm{~g}, 75 \%$; two crops) as a white solid with data identical as reported: ${ }^{210}{ }^{1} \mathrm{H}$ NMR $\delta 4.92\left(\mathrm{~s}, 2 \mathrm{H}, \mathrm{CH}_{2}\right), 5.70$ (dd, $\left.{ }^{3} J_{5-6}=7.9 \mathrm{~Hz}, 1 \mathrm{H}, \mathrm{H} 5\right), 7.15\left(\mathrm{~d},{ }^{3} J_{6-5}=7.9 \mathrm{~Hz}, 1 \mathrm{H}, \mathrm{H} 6\right), 7.27-7.41(\mathrm{~m}, 5 \mathrm{H}, \mathrm{Ph}) . \mathrm{GC}-\mathrm{MS}\left(t_{\mathrm{R}}\right.$ $21.90 \mathrm{~min}) \mathrm{m} / \mathrm{z} 202\left(27, \mathrm{M}^{+}\right), 200(<1), 91(100)$.

1-N-Benzyl-4-thiouracil (137). Compound 92 (501 mg, $2.48 \mathrm{mmol})$ was placed in a flameddry round-bottomed flask under a $\mathrm{N}_{2}$ atmosphere and dissolved in dry THF (40 mL). Dried Lawesson's reagent (1.02 $\mathrm{g}, 2.52 \mathrm{mmol})$ was added and the resulting suspension was heated at $56{ }^{\circ} \mathrm{C}$ for about $1 \mathrm{~h}$ until TLC showed $\sim 95 \%$ consumption of the substrate 92 . Volatiles were evaporated and the residue was partitioned between $\mathrm{NaHCO}_{3}$ and EtOAc. The organic phase was washed with brine and was dried over anhydrous $\mathrm{Na}_{2} \mathrm{SO}_{4}$. Column chromatography (hexanes/EtOAc, 3:2) gave $137^{216}(315 \mathrm{mg}, 65 \%)$ as a yellowish solid: ${ }^{1} \mathrm{H}$ NMR $\delta 4.92$ (s, $2 \mathrm{H}$, $\left.\mathrm{CH}_{2}\right), 6.36\left(\mathrm{~d},{ }^{3} J_{5-6}=7.5 \mathrm{~Hz}, 1 \mathrm{H}, \mathrm{H} 5\right), 6.98\left(\mathrm{~d},{ }^{3} J_{6-5}=7.5 \mathrm{~Hz}, 1 \mathrm{H}, \mathrm{H} 6\right), 7.28-7.33(\mathrm{~m}, 2 \mathrm{H}, \mathrm{Ph})$, 7.34-7.43 (m, 3 H, Ph), 9.86 (br. s, 1 H, NH). ${ }^{13} \mathrm{C}$ NMR $\delta 51.9,113.5,128.3,128.9,129.3,134.4$, 138.6, 148.4, 189.8. GC-MS ( $\left.t_{\mathrm{R}} 27.26 \mathrm{~min}.\right) \mathrm{m} / \mathrm{z} 218\left(39, \mathrm{M}^{+}\right), 91(100)$.

1-Benzyl-4-(methylthio)-2(1H)-pyrimidinone (138). Freshly distilled $\mathrm{Et}_{3} \mathrm{~N}$ (146 mg, 203 $\mu \mathrm{L}, 1.44 \mathrm{mmol})$ was added to a stirred solution of $137(314.8 \mathrm{mg}, 1.44 \mathrm{mmol})$ in dry $\mathrm{CH}_{2} \mathrm{Cl}_{2}(42$ $\mathrm{mL}$ ) at ambient temperature under $\mathrm{N}_{2}$. After $10 \mathrm{~min}$, methyl iodide $(410 \mathrm{mg}, 180 \mu \mathrm{L}, 2.89 \mathrm{mmol})$ was added via syringe and the reaction vessel was covered with aluminum foil. After $1.5 \mathrm{~h}$, the volatiles were evaporated and the residue was dissolved in $\mathrm{CH}_{2} \mathrm{Cl}_{2}$ and was washed with $\mathrm{H}_{2} \mathrm{O}$ $(2 \times)$. The organic layer was dried $\left(\mathrm{Na}_{2} \mathrm{SO}_{4}\right)$ and was evaporated to give $\mathbf{1 3 8}^{217}(320 \mathrm{mg}, 93 \%):{ }^{1} \mathrm{H}$ NMR $\delta 2.57(\mathrm{~s}, 3 \mathrm{H}, \mathrm{Me}), 5.04\left(\mathrm{~s}, 2 \mathrm{H}, \mathrm{CH}_{2}\right), 6.16\left(\mathrm{~d},{ }^{3} J_{5-6}=6.8 \mathrm{~Hz}, 1 \mathrm{H}, \mathrm{H} 5\right), 7.22\left(\mathrm{~d},{ }^{3} J_{6-5}=6.8\right.$ 
$\mathrm{Hz}, 1 \mathrm{H}, \mathrm{H} 6), 7.29-7.40$ (m, $5 \mathrm{H}, \mathrm{Ph}) ;{ }^{13} \mathrm{C}$ NMR $\delta 12.9,52.9,103.8,128.5,128.5,129.1,135.4$, 143.1, 154.9, 177.7. GC-MS ( $t_{\mathrm{R}} 24.39$ min.) $\mathrm{m} / z 232\left(44, \mathrm{M}^{+}\right), 91(100)$.

4-[ $\left.{ }^{18} \mathrm{O}\right]-1-N$-benzyluracil (139). Compound $137(248 \mathrm{mg}, 1.07 \mathrm{mmol})$ was suspended in anhydrous absolute EtOH $(6 \mathrm{~mL})$ and stirred at room temperature for $5 \mathrm{~min}$ in a screw-capped glass tube. Isotope enriched $\mathrm{H}_{2}\left[{ }^{18} \mathrm{O}\right]\left(277 \mathrm{mg}, 250 \mu \mathrm{L}, 12.5 \mathrm{mmol}, 99.2 \%{ }^{18} \mathrm{O}\right)$ was added via syringe followed by three drops of concentrated $\mathrm{HCl}$ and the mixture was refluxed until TLC showed consumption of the all substrate 138. The volatiles were evaporated and the residue was partitioned between $\mathrm{CHCl}_{3}$ and $\mathrm{NaHCO}_{3}$ solution. The organic layer was washed with brine, dried $\left(\mathrm{MgSO}_{4}\right)$, evaporated and the residue was column chromatographed (hexanes/EtOAc, 2:3) to give 139 (197 $\mathrm{mg}, 90 \%)$ as a puffy white powder with data identical to the reported above for 92; except for GC-MS ( $\left.t_{\mathrm{R}} 21.91 \mathrm{~min}\right) \mathrm{m} / z 204\left(22, \mathrm{M}^{+}\right), 202(3.3, \mathrm{M}-2), 91$ (100). The ${ }^{18} \mathrm{O} /{ }^{16} \mathrm{O}$ ratio in 6 (85:15) was calculated from the peak intensities at $\mathrm{m} / \mathrm{z} 204$ and 202.

1- $N$-Benzyl-5-iodouracil (140). Iodine monochloride (ICl; $361 \mathrm{mg}, 2.22 \mathrm{mmol}$ ) was added to a stirred solution of $92(297.6 \mathrm{mg}, 1.47 \mathrm{mmol})$ in dry $\mathrm{CH}_{2} \mathrm{Cl}_{2}(30 \mathrm{~mL})$ at ambient temperature under $\mathrm{N}_{2}$. The resulting red-wine solution was refluxed until TLC showed complete consumption of 92. The reaction mixture was diluted with $\mathrm{CH}_{2} \mathrm{Cl}_{2}(30 \mathrm{~mL})$ and decolorized with the minimum amount of $2 \% \mathrm{NaHSO}_{3}$ aqueous solution. The organic phase was washed with $\mathrm{H}_{2} \mathrm{O}(20 \mathrm{~mL})$, dried $\left(\mathrm{Na}_{2} \mathrm{SO}_{4}\right)$ and was evaporated to give crude $\mathbf{1 4 0}$ as a slightly yellow solid. Washing of this material with small amount of cold $\mathrm{MeOH}(3 \times 2 \mathrm{~mL})$ yielded $1400^{168}(446 \mathrm{mg}, 93 \%)$ as white powder: ${ }^{1} \mathrm{H}$ NMR $\delta 4.92$ (s, $2 \mathrm{H}, \mathrm{CH}_{2}$ ), 7.28-7.32 (m, $\left.2 \mathrm{H}, \mathrm{Ph}\right)$, 7.35-7.44 (m, $\left.3 \mathrm{H}, \mathrm{Ph}\right), 7.59$ (s, 1 H, H6), 8.42 (br. s, $1 \mathrm{H}, \mathrm{NH}) ;{ }^{13} \mathrm{C}$ NMR $\delta 51.6,68.2,128.1,128.9,129.3,134.6,148.3,150.4$, 159.9. GC-MS $\left(t_{\mathrm{R}} 25.90 \mathrm{~min}.\right) \mathrm{m} / z 328\left(30, \mathrm{M}^{+}\right), 91(100)$, with no peak at $m / z 326(\mathrm{M}-2)^{+}$.

4- $\left[{ }^{18} \mathrm{O}\right]-1-N$-benzyl-5-iodouracil (141). Treatment of $139(257 \mathrm{mg}, 1.26 \mathrm{mmol})$ with ICl (310 mg, $1.9 \mathrm{mmol})$, as described for 140, afforded 141 (394 mg, 95\%) as a white powder with data identical to that reported above for 140, except for GC-MS $\left(t_{\mathrm{R}} 25.90 \mathrm{~min}\right.$.) $\mathrm{m} / z 330\left(24, \mathrm{M}^{+}\right)$, 
328 (5, M-2), 91 (100). The ${ }^{18} \mathrm{O} /{ }^{16} \mathrm{O}$ ratio in 141 (83:17) was calculated from peak intensities at $m / z 330$ and 328.

1- $N$-Benzyl-5-[(trimethylsilyl)ethynyl]uracil (142). Compound 140 (602 mg, $1.83 \mathrm{mmol})$ was suspended in freshly distilled $\mathrm{Et}_{3} \mathrm{~N}(56 \mathrm{~mL})$ and the mixture degassed for $1 \mathrm{~h}$. Trimethylsilylacetylene $(723 \mathrm{mg}, 1.04 \mathrm{~mL}, 7.36 \mathrm{mmol})$ was added followed by $\left(\mathrm{PPh}_{3}\right)_{2} \mathrm{PdCl}_{2}(30$ $\mathrm{mg}, 0.043 \mathrm{mmol})$ and $\mathrm{CuI}(22 \mathrm{mg}, 0.12 \mathrm{mmol})$. The resulting mixture was then heated at $50{ }^{\circ} \mathrm{C}$ until TLC showed consumption of the substrate 140. Volatiles were evaporated and the brownish residue was chromatographed $\left(\mathrm{CH}_{2} \mathrm{Cl}_{2} /\right.$ EtOAc, $\left.10: 1\right)$ to give $\mathbf{1 4 2}{ }^{169}(438 \mathrm{mg}, 80 \%)$ as a off white powder: ${ }^{1} \mathrm{H}$ NMR $\delta 0.21\left(\mathrm{~s}, 9 \mathrm{H}, \mathrm{Me}_{3}\right), 4.92\left(\mathrm{~s}, 2 \mathrm{H}, \mathrm{CH}_{2}\right)$, 7.28-7.32 (m, $\left.2 \mathrm{H}, \mathrm{Ph}\right), 7.35-7.43(\mathrm{~m}, 3$ $\mathrm{H}, \mathrm{Ph}), 7.47$ (s, $1 \mathrm{H}, \mathrm{H} 6), 8.35$ (br. s, $1 \mathrm{H}, \mathrm{NH}) ;{ }^{13} \mathrm{C}$ NMR $\delta$-0.2 (Me), $51.7\left(\mathrm{CH}_{2}\right), 94.8,100.1$, 100.6, 128.1, 128.9, 129.3, 134.6, 147.1, 149.7, 161.0. GC-MS ( $\left.t_{\mathrm{R}} 26.68 \mathrm{~min}.\right) \mathrm{m} / z 298\left(29, \mathrm{M}^{+}\right)$, 283 (29, M-15), 91 (100), with no peak at $m / z 296(\mathrm{M}-2)^{+}$.

4-[ ${ }^{18}$ O]-1- $N$-Benzyl-5-[(trimethylsilyl)ethynyl]uracil (143). Treatment of 141 (388 mg, 1.18 $\mathrm{mmol})$, as described for $\mathbf{1 4 2}$, gave $143(218 \mathrm{mg}, 62 \%)$ as a off white powder with data identical to that reported above for 142, except for GC-MS ( $\left.t_{\mathrm{R}} 26.67 \mathrm{~min}.\right) \mathrm{m} / z 300\left(23, \mathrm{M}^{+}\right), 298(4, \mathrm{M}-2)$, 285 (23, M-15), 91 (100). The ${ }^{18} \mathrm{O} /{ }^{16} \mathrm{O}$ ratio in 143 (14:86) was calculated from the peak intensities at $\mathrm{m} / \mathrm{z} 300$ and 298.

1-N-Benzyl-5-ethynyluracil (135). Procedure A. TBAF (1 M/THF; $1.88 \mathrm{~mL}, 1.88 \mathrm{mmol}$,) was added via syringe to a stirred solution of $142(560 \mathrm{mg}, 1.88 \mathrm{mmol})$ in dry THF $(32 \mathrm{~mL})$ at 0 ${ }^{\circ} \mathrm{C}$ (ice-bath). After $1 \mathrm{~h}$, the volatiles were evaporated and the oily yellowish residue was dissolved in $\mathrm{CHCl}_{3}(30 \mathrm{~mL})$ and successively washed with saturated $\mathrm{NaHCO}_{3}$ and brine. The organic layer was dried $\left(\mathrm{Na}_{2} \mathrm{SO}_{4}\right)$ and was column chromatographed $\left(\mathrm{CH}_{2} \mathrm{Cl}_{2} / \mathrm{EtOAc}, 5: 1\right)$ to give $\mathbf{1 3 5}^{169}$ (390 mg, 92\%) as white powder: UV (MeOH) $\max 292 \mathrm{~nm}(\varepsilon 12600)$, $\min 251$ (ع 2000); ${ }^{1} \mathrm{H}$ NMR $\left(\mathrm{DMSO}-d_{6}\right) \delta 4.15(\mathrm{~s}, 1 \mathrm{H}, \mathrm{C} \equiv \mathrm{CH}), 4.92\left(\mathrm{~s}, 2 \mathrm{H}, \mathrm{CH}_{2}\right), 7.35-7.42(\mathrm{~m}, 5 \mathrm{H}, \mathrm{Ph}), 8.31$ (s, 1 H, H6), 11.71 (br. s, $1 \mathrm{H}, \mathrm{NH}) ;{ }^{13} \mathrm{C}$ NMR (DMSO- $\left.d_{6}\right) \delta 50.8\left(\mathrm{CH}_{2}\right), 76.1,83.7,97.2,127.5,127.8$, 
128.6, 136.4, 149.5, 150.0, 162.1. GC-MS ( $\left.t_{\mathrm{R}} 26.63 \mathrm{~min}\right) \mathrm{m} / \mathrm{z} 226\left(19, \mathrm{M}^{+}\right), 91(100)$, no peak at $m / z 224(\mathrm{M}-2)^{+}$; HRMS calcd for $\mathrm{C}_{13} \mathrm{H}_{11} \mathrm{~N}_{2} \mathrm{O}_{2}[\mathrm{M}+\mathrm{H}]^{+}$227.0815, found 227.0805.

Procedure B. $\mathrm{NH}_{4} \mathrm{~F}(1.05 \mathrm{~g}, 28.1 \mathrm{mmol})$ was added to a stirred solution of $\mathbf{1 4 2}$ (645 mg, 2.16 $\mathrm{mmol})$ in $\mathrm{MeOH}(25 \mathrm{~mL})$ and the resulting suspension was refluxed until TLC showed total consumption of $142(10 \mathrm{~h})$. The reaction mixture was allowed to cool down to ambient temperature and was filtered off. The mother liquor was evaporated and the residue was column chromatographed $\left(\mathrm{CHCl}_{3}\right)$ to afford $135(330 \mathrm{mg}, 67 \%)$.

4-[ ${ }^{18}$ O]-1-N-Benzyl-5-ethynyluracil (136). Treatment of 143 (209 mg, $\left.0.70 \mathrm{mmol}\right)$ by Procedure A gave 136 (123 mg, 78\%) as a white powder with data identical to the reported above for 135, except for GC-MS ( $\left.t_{\mathrm{R}} 26.73 \mathrm{~min}\right) \mathrm{m} / z, 228\left(16, \mathrm{M}^{+}\right), 226(3, \mathrm{M}-2), 91(100)$. The ${ }^{18} \mathrm{O} /{ }^{16} \mathrm{O}$ ratio in 136 (14:86) was calculated from the peak intensities at $m / z 228$ and 226. HRMS calcd for $\mathrm{C}_{13} \mathrm{H}_{11} \mathrm{~N}_{2} \mathrm{O}^{18} \mathrm{O}[\mathrm{M}+\mathrm{H}]^{+}$229.0857, found 229.0848.

1- $N$-Benzyl-5-(Z)-[2-(triphenylgermyl)ethenyl]uracil (144). Alkyne 135 ${ }^{168,169}$ (50 mg, 0.22 mmol) was dissolved in dry THF ( $5 \mathrm{~mL})$ and the resulting solution was stirred for 20 min under $\mathrm{N}_{2}$ at $0{ }^{\circ} \mathrm{C}$ in a screw-capped glass tube. $\mathrm{Ph}_{3} \mathrm{GeH}(73 \mathrm{mg}, 0.24 \mathrm{mmol})$ and $\mathrm{Et}_{3} \mathrm{~B}(1 \mathrm{M} / \mathrm{THF} 265 \mathrm{uL}$, $0.265 \mathrm{mmol}$,) were added and the resulting solution was stirred at $0{ }^{\circ} \mathrm{C}$ for $7 \mathrm{~h}$. The volatiles were evaporated and the resulting bright-yellow liquid was column chromatographed (hexane/EtOAc, 1:1) to give Z-144 (61 mg, 52\%) as a white powder: M.p. 202-204 ${ }^{\circ} \mathrm{C}(\mathrm{MeOH})$; UV (MeOH) $\max$ $296 \mathrm{~nm}(\varepsilon 11000), \min 255$ ( $\varepsilon$ 3500); ${ }^{1} \mathrm{H}$ NMR $\delta 4.03$ (s, 2H), $6.30(\mathrm{~d}, J=13.5 \mathrm{~Hz}, 1 \mathrm{H}), 6.69$ (“d”, $J=7.0 \mathrm{~Hz}, 2 \mathrm{H}), 6.84$ (s, 1H), 7.09 (“t”, $J=7.5 \mathrm{~Hz}, 2 \mathrm{H}), 7.16$ (“t”, $J=7.1 \mathrm{~Hz}, 1 \mathrm{H}), 7.23-7.35$ (m, 10H), 7.37-7.46 (m, 6H), 8.51 (br. s, $1 \mathrm{H}) ;{ }^{13} \mathrm{C}$ NMR $\delta 51.2,113.7,128.3,128.3,128.4,128.8$, $129.1, \quad 129.5, \quad 134.8, \quad 135.0, \quad 136.7,138.7,141.0,150.1,162.4$; HRMS calcd for $\mathrm{C}_{31} \mathrm{H}_{26}{ }^{74} \mathrm{GeN}_{2} \mathrm{NaO}_{2}[\mathrm{M}+\mathrm{Na}]^{+}$555.1105, found 555.1113.

1- $\mathrm{N}$-Benzyl-5-(E)-[2-(triphenylgermyl)ethenyl]uracil (144). $\mathrm{Ph}_{3} \mathrm{GeH} \quad(118.6 \mathrm{mg}, \quad 0.38$ mmol) and $\mathrm{H}_{2} \mathrm{O}(25 \mu \mathrm{L}, 25 \mathrm{mg}, 1.4 \mathrm{mmol})$ were added to a stirred solution of $\mathbf{1 3 5}$ (80 mg, 0.35 
mmol) in toluene $(5 \mathrm{~mL})$ at ambient temperature. The resulting mixture was heated $100{ }^{\circ} \mathrm{C}$ (oilbath) for $12 \mathrm{~h}$ and was cooled down to ambient temperature. The volatiles were removed in vacuo and the resulting oily residue was column chromatographed $\left(\mathrm{CH}_{2} \mathrm{Cl}_{2} / \mathrm{EtOAc}, 10: 1\right)$ to give $E-\mathbf{1 4 4}$ (126 mg, 86\%) as white solid. Recrystallization from $\mathrm{MeOH}$ gave white crystals: M.p. 185-186 ${ }^{\circ} \mathrm{C}$; UV (MeOH) max $300 \mathrm{~nm}\left(\varepsilon 13\right.$ 900), $251 \mathrm{~nm}\left(\varepsilon 15\right.$ 500), min 272 (ع 7100); ${ }^{1} \mathrm{H}$ NMR $\delta 4.92$ (s, 2H), $6.56(\mathrm{~d}, J=18.7 \mathrm{~Hz}, 1 \mathrm{H}), 7.21(\mathrm{~s}, 1 \mathrm{H}), 7.28-7.30(\mathrm{~m}, 2 \mathrm{H}), 7.33(\mathrm{~d}, J=18.7 \mathrm{~Hz}, 1 \mathrm{H})$, 7.35-7.39 (m, 12H), 7.49-7.51 (m, 6H), 8.78 (br. s, $1 \mathrm{H}) ;{ }^{13} \mathrm{C}$ NMR $\delta 51.5,113.8,127.2,127.9$, $128.3,128.6,129.1,129.2,135.1,135.2,136.1,136.9,141.7,150.1,161.8$; HRMS calcd for $\mathrm{C}_{31} \mathrm{H}_{26}{ }^{74} \mathrm{GeN}_{2} \mathrm{NaO}_{2}[\mathrm{M}+\mathrm{Na}]^{+}$555.1105, found 555.1111. Anal. Calcd for $\mathrm{C}_{31} \mathrm{H}_{26} \mathrm{GeN}_{2} \mathrm{O}_{2}$ (531.19): C, 70.09; H, 4.93; N, 5.27. Found: C, 69.82; H, 4.64; N, 5.35.

1- $N$-Benzyl-5-[2-(triphenylgermyl)acetyl]uracil (146). Alkyne 135 (50 mg, $0.22 \mathrm{mmol})$ was suspended in dry toluene $(5 \mathrm{~mL})$ and the suspension was degassed with $\mathrm{N}_{2}$ for 45 min at ambient temperature in a screw-capped glass tube. $\mathrm{Ph}_{3} \mathrm{GeH}(73 \mathrm{mg}, 0.24 \mathrm{mmol})$ and ACCN (10 $\mathrm{mg}, 0.041 \mathrm{mmol}$ ) were added and the suspension was heated at $85{ }^{\circ} \mathrm{C}$ for $2 \mathrm{~h}$ (TLC showed approximately $80 \%$ consumption of $\mathbf{1 3 5}$ ). The volatiles were evaporated under vacuum and the resulting yellow oil was slowly column chromatographed (hexane/EtOAc, 3:2) to give 146 (15 $\mathrm{mg}, 13 \%$ ) followed by $Z-144$ (31 mg, 27\%): The compound 146 was recrystallized from warm MeOH to give colorless crystals: M.p. $205-207{ }^{\circ} \mathrm{C}$; UV (MeOH) $\max 294 \mathrm{~nm}(\varepsilon 10600)$, min 255 (ع 3800); ${ }^{1} \mathrm{H}$ NMR $\delta 3.81(\mathrm{~s}, 2 \mathrm{H}), 4.77(\mathrm{~s}, 2 \mathrm{H}), 7.24-7.40(\mathrm{~m}, 14 \mathrm{H}), 7.48-7.54(\mathrm{~m}, 6 \mathrm{H}), 7.79$ (br. s, 1H), 7.85 (s, $1 \mathrm{H}) ;{ }^{13} \mathrm{C}$ NMR $\delta 33.1,52.4,113.3,128.3,128.5,129.1,129.3,129.5,134.5,135.2$, 135.3, 149.7, 149.9, 160.7, 194.3; HRMS calcd for $\mathrm{C}_{31} \mathrm{H}_{26}{ }^{74} \mathrm{GeN}_{2} \mathrm{NaO}_{3}[\mathrm{M}+\mathrm{Na}]^{+}$571.1054, found 571.1068; Anal. Calcd for $\mathrm{C}_{31} \mathrm{H}_{26} \mathrm{GeN}_{2} \mathrm{O}_{3}$ (547.2): C, 68.04; H, 4.79; N, 5.12. Found: $\mathrm{C}$, 68.26; H, 4.60; N, 4.81. 
Analogous treatment of 135 (40 mg, $0.18 \mathrm{mmol})$ with $\mathrm{Ph}_{3} \mathrm{GeH}(59 \mathrm{mg}, 0.20 \mathrm{mmol})$ without ACCN $\left[100{ }^{\circ} \mathrm{C}\right.$ (oil-bath)/10 h] gave an oily residue that was column chromatographed $\left(\mathrm{CH}_{2} \mathrm{Cl}_{2} /\right.$ EtOAc, $\left.10: 1\right)$ to give $146(19 \mathrm{mg}, 20 \%)$ as a white powder and $\mathrm{Z}-144$ (33 $\left.\mathrm{mg}, 34 \%\right)$.

1- $N$-Benzyl-5-acetyluracil (152). Procedure A. A solution of $146(15 \mathrm{mg}, 0.03 \mathrm{mmol})$ in $\mathrm{CH}_{3} \mathrm{OH}(3 \mathrm{~mL})$ was heated for $12 \mathrm{~h}$ at $65{ }^{\circ} \mathrm{C}$ (oil-bath). Volatiles were evaporated and the residue was column chromatographed $\left(\mathrm{CH}_{2} \mathrm{Cl}_{2} /\right.$ EtOAc, 2:1) to give $\mathbf{1 5 2}^{218}(6.5 \mathrm{mg}, 95 \%)$ as a white powder: UV (MeOH) max $290 \mathrm{~nm}$ ( $\varepsilon 12200), 226 \mathrm{~nm}\left(\varepsilon\right.$ 8100), $\min 249$ ( $\varepsilon$ 1400); ${ }^{1} \mathrm{H}$ NMR $\delta$ $2.61(\mathrm{~s}, 3 \mathrm{H}), 5.01(\mathrm{~s}, 2 \mathrm{H}), 7.33-7.41(\mathrm{~m}, 5 \mathrm{H}), 8.28(\mathrm{~s}, 1 \mathrm{H}), 8.59$ (br. s, $1 \mathrm{H}) ;{ }^{13} \mathrm{C} \mathrm{NMR} \delta 30.6,52.5$, $112.8,128.3,129.0,129.3,134.3,150.2,150.6,161.2,193.9$. GC-MS $\left(t_{\mathrm{R}} 26.87 \mathrm{~min}\right) \mathrm{m} / \mathrm{z} 244(20$ $\mathrm{M}^{+}$), 91 (100); HRMS calcd for $\mathrm{C}_{13} \mathrm{H}_{12} \mathrm{~N}_{2} \mathrm{NaO}_{3}[\mathrm{M}+\mathrm{Na}]^{+}$267.0740, found 267.0739.

Procedure B. $\mathrm{H}_{2} \mathrm{SO}_{4}(0.5 \mathrm{M} ; 7 \mathrm{~mL})$ was added dropwise to a stirred solution of $\mathbf{1 3 5}(100 \mathrm{mg}$, $0.44 \mathrm{mmol})$ in THF $(5 \mathrm{~mL})$ at ambient temperature and the resulting mixture was heated at $70{ }^{\circ} \mathrm{C}$ (oil-bath) for $7 \mathrm{~h} . \mathrm{CH}_{2} \mathrm{Cl}_{2}(15 \mathrm{~mL})$ was added to the cooled down reaction mixture and the separated organic layer was washed with saturated $\mathrm{NaHCO}_{3}$, brine, and was dried over anhydrous $\mathrm{Na}_{2} \mathrm{SO}_{4}$. Volatiles were evaporated and the residue was column chromatographed $\left(\mathrm{CH}_{2} \mathrm{Cl}_{2} / \mathrm{EtOAc}\right.$, 2:1) to give $152(95 \mathrm{mg}, 88 \%)$ with data as reported above.

1-N-Benzyl-5-(2-deuterioacetyl)uracil (153). Treatment $\left[18 \mathrm{~h}, 65{ }^{\circ} \mathrm{C}\right.$ (oil-bath)] of $146(10$ $\mathrm{mg}, 0.02 \mathrm{mmol}$ ) as described above for 152 (Procedure A) using MeOD or $\mathrm{MeOH}-d_{4}$ instead of MeOH gave 153 (4.2 mg, 94\%): GC-MS ( $\left.t_{\mathrm{R}} 26.87 \mathrm{~min}\right) \mathrm{m} / \mathrm{z} 245\left(20, \mathrm{M}^{+}\right), 91(100) .{ }^{1} \mathrm{H}$ NMR spectrum of 153 corresponded to this of the above 152 with 1/3 reduction of the integrated intensity for the signal from methyl group at $2.61 \mathrm{ppm}$.

(E)-1-N-benzyl-5-(1-chloro-2-tosylvinyl)uracil (158). Method A: Fe(acac) $)_{3}(3 \mathrm{mg}, 0.01$ $\mathrm{mmol}), \mathrm{Ph}_{3} \mathrm{P}(3 \mathrm{mg}, 0.01 \mathrm{mmol})$ and tosylchloride $157(29 \mathrm{mg}, 0.15 \mathrm{mmol})$ was added to a stirring solution of 1- $\mathrm{N}$-benzyl-5-ethynyluracil $135(22.6 \mathrm{mg}, 0.1 \mathrm{mmol})$ in $2 \mathrm{~mL}$ toluene at ambient temperature. The resulting solution was stirred at $100{ }^{\circ} \mathrm{C}$ (oil bath) for $16 \mathrm{~h}$. Volatiles 
were removed under the reduced pressure and the residue was chromatographed (Hexane : EtOAc $=1: 1)$ to give $158(24.8 \mathrm{mg}, 60 \%)$ as white solid. Compound 158 had: ${ }^{1} \mathrm{H}$ NMR $\delta 2.23(\mathrm{~s}, 3 \mathrm{H})$, $4.82(\mathrm{~s}, 2 \mathrm{H}), 6.70(\mathrm{~s}, 1 \mathrm{H}), 7.09(\mathrm{~d}, J=8.1 \mathrm{~Hz}, 2 \mathrm{H}), 7.32-7.18(\mathrm{~m}, 5 \mathrm{H}), 7.41(\mathrm{~d}, J=8.4 \mathrm{~Hz}, 2 \mathrm{H})$, $7.42(\mathrm{~s}, 1 \mathrm{H}), 8.99(\mathrm{~s}, 1 \mathrm{H}) ;{ }^{13} \mathrm{C}$ NMR $\delta 21.8,52.4,108.9,128.0,128.7,129.1,129.4,130.1,134.2$, 134.5, 136.7, 139.7, 145.4, 145.8, 150.1, 159.6; HRMS calcd for $\mathrm{C}_{20} \mathrm{H}_{18} \mathrm{ClN}_{2} \mathrm{O}_{4} \mathrm{~S}[\mathrm{M}+\mathrm{H}]^{+}$ 417.0670, found 417.0664.

Method B: $\mathrm{FeCl}_{3} \cdot 6 \mathrm{H}_{2} \mathrm{O}(108 \mathrm{mg}, 0.4 \mathrm{mmol})$, TBHP $(80 \mu \mathrm{L}, 0.4 \mathrm{mmol} ; 5-6 \mathrm{M}$ in Hexane) and tosylhydrazide $159(52.2 \mathrm{mg}, 0.28 \mathrm{mmol})$ was added to a stirring solution of 1- $N$-benzyl-5ethynyluracil $135(45.2 \mathrm{mg}, 0.2 \mathrm{mmol})$ in $2 \mathrm{~mL} \mathrm{CH}_{3} \mathrm{CN}$ at ambient temperature. The resulting solution was stirred at $80{ }^{\circ} \mathrm{C}$ (oil bath) for $4.5 \mathrm{~h}$. Volatiles were removed under the reduced pressure and the residue was chromatographed (Hexane:EtOAc $=1: 1)$ to give $158(64.9 \mathrm{mg}, 65 \%)$ as white solid with the same spectroscopic data as above.

(E)-1- $N$-benzyl-5-(1-bromo-2-tosylvinyl)uracil (160) and $\quad 1-N$-benzyl-5-(1,2dibromovinyl)uracil (161) $\mathrm{FeBr}_{3}(118.2 \mathrm{mg}, 0.4 \mathrm{mmol})$ and $\mathrm{TBHP}(80 \mu \mathrm{L}, 0.4 \mathrm{mmol} ; 5-6 \mathrm{M}$ in Hexane) and tosylhydrazide $159(149.1 \mathrm{mg}, 0 . .8 \mathrm{mmol})$ was added to a stirring solution of $1-\mathrm{N}$ benzyl-5-ethynyluracil 135 (45.2 $\mathrm{mg}, 0.2 \mathrm{mmol})$ in $2 \mathrm{~mL} \mathrm{CH} \mathrm{CH}_{3} \mathrm{CN}$ at ambient temperature. The resulting solution was stirred at $80{ }^{\circ} \mathrm{C}$ (oil bath) for $4.5 \mathrm{~h}$. volatiles were removed under the reduced pressure and the residue was chromatographed to give $\mathbf{1 6 0}(37.8 \mathrm{mg}, 41 \%)$ as well as 1N-benzyl-5-(1,2-dibromovinyl)uracil 161 (8.2 mg, 12\%). Compound 160 had ${ }^{1} \mathrm{H}$ NMR $\delta 2.40$ (s, 3H), $4.99(\mathrm{~s}, 2 \mathrm{H}), 7.09(\mathrm{~s}, 1 \mathrm{H}), 7.27(\mathrm{~d}, J=8.0 \mathrm{~Hz}, 2 \mathrm{H}), 7.40-7.45(\mathrm{~m}, 5 \mathrm{H}), 7.58(\mathrm{~s}, 1 \mathrm{H}), 7.58(\mathrm{~d}$, $J=8.2 \mathrm{~Hz}, 2 \mathrm{H}), 9.29(\mathrm{~s}, 1 \mathrm{H}) ;{ }^{13} \mathrm{C}$ NMR $\delta 21.8,52.4,110.4,128.0,128.6,128.7,129.1,129.4$, $130.1,134.5,136.6,137.8,145.1,145.4,150.2,159.6$.

Compound 161 had ${ }^{1} \mathrm{H}$ NMR $\delta 4.69$ (s, 2H), 6.54 (s, 1H), 6.99 (s, 1H), 7.04-7.13 (m, 5H), $8.93(\mathrm{~s}, 1 \mathrm{H}) ;{ }^{13} \mathrm{C}$ NMR $\delta 51.9,109.0,112.1,112.5,128.3,129.0,129.4,134.6,145.3,150.4$, 159.7. 
2,3,5-Tri-O-acetyl-5-(1-chloro-2-tosylvinyl)uracil (165). $\mathrm{FeCl}_{3} \cdot 6 \mathrm{H}_{2} \mathrm{O}(108 \mathrm{mg}, 0.4 \mathrm{mmol})$, TBHP $(80 \mu \mathrm{L}, 0.4 \mathrm{mmol} ; 5-6 \mathrm{M}$ in Hexane) and tosylhydrazide 159 (52.2 $\mathrm{mg}, 0.28 \mathrm{mmol})$ was added to a stirring solution of 2,3,5-tri- $O$-acetyl-5-ethynyluridine 162 (78.9 $\mathrm{mg}, 0.2 \mathrm{mmol})$ in 2 $\mathrm{mL} \mathrm{CH}_{3} \mathrm{CN}$ at ambient temperature. The resulting solution was stirred at $80{ }^{\circ} \mathrm{C}$ (oil bath) for $4.5 \mathrm{~h}$. After cooled down to room temperature, volatiles were removed under the reduced pressure and the residue was chromatographed (Hexane $:$ EtOAc $=1: 1 \rightarrow 4: 6)$ to give $\mathbf{1 6 5}(80 \mathrm{mg}, 68 \%)$ as white solid. ${ }^{1} \mathrm{H}$ NMR $\delta 2.12$ (s, 3H), 2.14 (s, 3H), 2.18 (s, 3H), 2.42 (s, 3H), 4.37-4.47 (m, 3H), 5.36-5.41 (m, 1H), $5.44(\mathrm{t}, J=5.5 \mathrm{~Hz}, 1 \mathrm{H}), 6.10(\mathrm{~d}, J=5.3 \mathrm{~Hz}, 1 \mathrm{H}), 6.94(\mathrm{~s}, 1 \mathrm{H}), 7.32(\mathrm{~d}, J=8.1$ $\mathrm{Hz}, 2 \mathrm{H}), 7.71(\mathrm{~d}, J=8.2 \mathrm{~Hz}, 2 \mathrm{H}), 7.82(\mathrm{~s}, 1 \mathrm{H}), 8.63(\mathrm{~s}, 1 \mathrm{H}) ;{ }^{13} \mathrm{C}$ NMR $\delta$ 20.6, 20.7, 21.0, 21.8, $63.2,70.4,73.4,80.7,88.0,109.4,128.1,130.2,135.3,136.7,139.6,141.6,145.5,149.2,159.6$, 169.6, 169.7, 170.5; HRMS calcd for $\mathrm{C}_{24} \mathrm{H}_{25} \mathrm{ClN}_{2} \mathrm{NaO}_{11} \mathrm{~S}[\mathrm{M}+\mathrm{Na}]^{+}$607.0760, found 607.0755.

\section{2,3,5-Tri- $O$-acetyl-1-( $\beta$-D-arabinofuranosyl)-5-(1-chloro-2-tosylvinyl)uracil}

(166).

$\mathrm{FeCl}_{3} \cdot 6 \mathrm{H}_{2} \mathrm{O}(108 \mathrm{mg}, 0.4 \mathrm{mmol})$, TBHP $(80 \mu \mathrm{L}, 0.4 \mathrm{mmol} ; 5-6 \mathrm{M}$ in Hexane $)$ and tosylhydrazide $159(52.2 \mathrm{mg}, 0.28 \mathrm{mmol})$ was added to a stirring solution of 2,3,5-tri- $O$-acetyl-1- $(\beta$-Darabinofuranosyl)-5-ethynyluracil $123(78.9 \mathrm{mg}, 0.2 \mathrm{mmol})$ in $2 \mathrm{~mL} \mathrm{CH} \mathrm{CH}_{3} \mathrm{CN}$ at ambient temperature. The resulting solution was stirred at $80{ }^{\circ} \mathrm{C}$ (oil bath) for $4.5 \mathrm{~h}$. After cooled down to room temperature, volatiles were removed under the reduced pressure and the residue was chromatographed (Hexane $:$ EtOAc $=1: 1 \rightarrow 4: 6)$ to give $166(77 \mathrm{mg}, 66 \%)$ as white solid. ${ }^{1} \mathrm{H}$ NMR $\delta 2.11(\mathrm{~s}, 3 \mathrm{H}) .2 .15(\mathrm{~s}, 6 \mathrm{H}), 2.41(\mathrm{~s}, 3 \mathrm{H}), 4.22-4.28(\mathrm{~m}, 1 \mathrm{H}), 4.41(\mathrm{dd}, J=4.2,12.0 \mathrm{~Hz}, 1 \mathrm{H})$, $4.48(\mathrm{dd}, J=6.3,12.0 \mathrm{~Hz}, 1 \mathrm{H}), 5.13(\mathrm{dd}, J=1.3,2.7 \mathrm{~Hz}, 1 \mathrm{H}), 5.45(\mathrm{dd}, J=1.5,4.0 \mathrm{~Hz}, 1 \mathrm{H}), 6.30$ $(\mathrm{d}, J=4.0 \mathrm{~Hz}, 1 \mathrm{H}), 6.84(\mathrm{~s}, 1 \mathrm{H}), 7.33(\mathrm{~d}, J=8.1 \mathrm{~Hz}, 2 \mathrm{H}), 7.75(\mathrm{~d}, J=8.3 \mathrm{~Hz}, 2 \mathrm{H}), 7.80(\mathrm{~s}, 1 \mathrm{H})$, 9.36 (s, 1H); ${ }^{13} \mathrm{C}$ NMR $\delta 20.8,20.9,21.8,62.6,74.3,76.5,81.3,85.0,109.8,128.1,130.2,134.2$, $136.7,138.5,141.5,145.5,149.1,159.3,169.2,169.7,180.8$; HRMS calcd for $\mathrm{C}_{24} \mathrm{H}_{26} \mathrm{ClN}_{2} \mathrm{O}_{11} \mathrm{~S}$ $[\mathrm{M}+\mathrm{H}]^{+}$585.0940, found 585.0918. 
3,5-Di-O-acetyl-5-(1-chloro-2-tosylvinyl)uridine (167). $\mathrm{FeCl}_{3} \cdot 6 \mathrm{H}_{2} \mathrm{O}(540 \mathrm{mg}, 2 \mathrm{mmol})$, TBHP (400 $\mu \mathrm{L}, 2 \mathrm{mmol}$; 5-6 M in Hexane) and tosylhydrazide 159 (372 mg, 2 mmol) was added to a stirring solution of 3,5-di- $O$-acetyl-2'-deoxy-5-ethynyluridine $\mathbf{1 6 3}$ (336 mg, $1 \mathrm{mmol})$ in $6 \mathrm{~mL}$ $\mathrm{CH}_{3} \mathrm{CN}$ at ambient temperature. The resulting solution was stirred at $80{ }^{\circ} \mathrm{C}$ (oil bath) for $4.5 \mathrm{~h}$. After cooled down to room temperature, volatiles were removed under the reduced pressure and the residue was chromatographed (Hexane $:$ EtOAc $=1: 1 \rightarrow 4: 6)$ to give $167(400 \mathrm{mg}, 76 \%)$ as white solid. ${ }^{1} \mathrm{H}$ NMR $\delta 2.12(\mathrm{~s}, 3 \mathrm{H}), 2.16(\mathrm{~s}, 3 \mathrm{H}), 2.27-2.37$ (m, 1H), 2.42 (s, 3H), 2.58 (ddd, $J=$ 1.7, 5.5, $14.3 \mathrm{~Hz}, 1 \mathrm{H}), 4.30-4.35(\mathrm{~m}, 2 \mathrm{H}), 4.46(\mathrm{td}, J=2.3,5.0 \mathrm{~Hz}, 1 \mathrm{H}), 5.27(\mathrm{~d}, J=6.4 \mathrm{~Hz}, 1 \mathrm{H})$, $6.35(\mathrm{dd}, J=5.5,8.5 \mathrm{~Hz}, 1 \mathrm{H}), 6.89(\mathrm{~s}, 1 \mathrm{H}), 7.32(\mathrm{~d}, J=8.0 \mathrm{~Hz}, 1 \mathrm{H}), 7.69(\mathrm{~d}, J=8.3 \mathrm{~Hz}, 1 \mathrm{H})$, $7.88(\mathrm{~s}, 1 \mathrm{H}), 8.83(\mathrm{~s}, 1 \mathrm{H}) ;{ }^{13} \mathrm{C} \mathrm{NMR} \delta 21.02,21.04,21.8,28.8,38.2,64.0,74.4,83.1,85.7,109.2$ $127.9,130.2,134.7,136.7,139.9,141.5,145.6,149.3,158.9,170.5,170.6$; HRMS calcd for $\mathrm{C}_{22} \mathrm{H}_{24} \mathrm{ClN}_{2} \mathrm{O}_{9} \mathrm{~S}[\mathrm{M}+\mathrm{H}]^{+}$527.0886, found 527.0863.

2'-deoxyl-5-(1-chloro-2-tosylvinyl)uracil (168). $\mathrm{FeCl}_{3} \cdot 6 \mathrm{H}_{2} \mathrm{O}$ (108 mg, $\left.0.4 \mathrm{mmol}\right)$, TBHP (80 $\mu \mathrm{L}, 0.4 \mathrm{mmol}$; 5-6 $\mathrm{M}$ in Hexane) and tosylhydrazide 159 (52.2 $\mathrm{mg}, 0.28 \mathrm{mmol}$ ) was added to a stirring solution of 5-ethynyl-2'-deoxyuridine $164(50.5 \mathrm{mg}, 0.2 \mathrm{mmol})$ in $2 \mathrm{~mL} \mathrm{CH}_{3} \mathrm{CN}$ at ambient temperature. The resulting solution was stirred at $80{ }^{\circ} \mathrm{C}$ (oil bath) for $4.5 \mathrm{~h}$. After cooled down to room temperature, volatiles were removed under the reduced pressure and the residue was chromatographed $\left(\mathrm{CHCl}_{3}: \mathrm{MeOH}=9: 1 \rightarrow 85: 15\right)$ to give $\mathbf{1 6 8}(60.8 \mathrm{mg}, 69 \%)$ as white solid. ${ }^{1} \mathrm{H}$ NMR MeOD- $d_{6} \delta 2.25-2.34(\mathrm{~m}, 1 \mathrm{H}), 2.38(\mathrm{ddd}, J=13.4,6.0,4.1 \mathrm{~Hz}, 1 \mathrm{H}), 2.45(\mathrm{~s}, 3 \mathrm{H}), 3.78$ $(\mathrm{dd}, J=12.0,3.5 \mathrm{~Hz}, 1 \mathrm{H}), 3.84(\mathrm{dd}, J=12.0,2.9 \mathrm{~Hz}, 1 \mathrm{H}), 3.99(\mathrm{dd}, J=6.3,3.0 \mathrm{~Hz}, 1 \mathrm{H}), 4.37-$ 4.53(m, 1H), $6.31(\mathrm{t}, J=6.4 \mathrm{~Hz}, 1 \mathrm{H}), 7.23(\mathrm{~s}, 1 \mathrm{H}), 7.39$ (d, $J=7.8 \mathrm{~Hz}, 2 \mathrm{H}), 7.69$ (d, $J=7.8 \mathrm{~Hz}$, 2H), $8.31(\mathrm{~s}, 1 \mathrm{H}) ;{ }^{13} \mathrm{C}$ NMR MeOD- $d_{6} \delta 21.6,41.8,62.7,72.0,87.0,89.3,109.7,129.1,131.0$, 136.0, 138.3, 142.0, 143.9, 146.8, 151.3, 161.6; HRMS calcd for $\mathrm{C}_{18} \mathrm{H}_{19} \mathrm{ClN}_{2} \mathrm{NaO}_{7} \mathrm{~S}\left[\mathrm{M}+\mathrm{Na}^{+}\right.$ 465.0494, found 465.0493 . 
(E)-5-(1-amino-2-tosylvinyl)-1- $N$-benzyluracil (169a). (E)-1- $N$-benzyl-5-(1-chloro-2tosylvinyl)uracil $158(41.6 \mathrm{mg}, 0.1 \mathrm{mmol})$ was dissolved in $\mathrm{NH}_{3} / \mathrm{MeOH}(3 \mathrm{~mL})$ at $0{ }^{\circ} \mathrm{C}$ (ice bath). After kept stirring for $24 \mathrm{~h}$, volatiles was removed under the reduced pressure and the residue was dried under the high vacuum pump to give (E)-1-N-benzyl-5-(1-(butylamino)-2-tosylvinyl)uracil 169a (27 mg, 67\%) as white solid. UV (MeOH) $\lambda_{\max }=272 \mathrm{~nm} ;{ }^{1} \mathrm{H}$ NMR $\left(400 \mathrm{MHz}, \mathrm{DMSO}-d_{6}\right) \delta$ $2.37(\mathrm{~s}, 3 \mathrm{H}), 4.92(\mathrm{~s}, 2 \mathrm{H}), 5.26(\mathrm{~s}, 1 \mathrm{H}), 7.08(\mathrm{~s}, 2 \mathrm{H}), 7.28-7.36(\mathrm{~m}, 7 \mathrm{H}), 7.75(\mathrm{~d}, J=8.2 \mathrm{~Hz}, 2 \mathrm{H})$, $8.35(\mathrm{~s}, 1 \mathrm{H}) ;{ }^{1} \mathrm{H}$ NMR (400 MHz, DMSO-d $\left.{ }_{6}+\mathrm{D}_{2} \mathrm{O}\right) \delta 2.35(\mathrm{~s}, 3 \mathrm{H}), 4.90(\mathrm{~s}, 2 \mathrm{H}), 5.24(\mathrm{~s}, 1 \mathrm{H})$, 7.28-7.36 (m, 7H), $7.73(\mathrm{~d}, J=8.2 \mathrm{~Hz}, 2 \mathrm{H}), 8.28(\mathrm{~s}, 1 \mathrm{H}) ;{ }^{13} \mathrm{C} \mathrm{NMR}(101 \mathrm{MHz}, \mathrm{DMSO}) \delta 21.2$, $51.6,106.9,125.7,127.6,128.1,128.9,129.8,136.5,142.3,142.9,157.1,150.0,150.7,162.3$; HRMS calcd for $\mathrm{C}_{20} \mathrm{H}_{19} \mathrm{~N}_{3} \mathrm{NaO}_{4} \mathrm{~S}[\mathrm{M}+\mathrm{Na}]^{+}$420.0994, found 420.0939 .

(E)-1-N-benzyl-5-[1-(n-butylamino)-2-tosylvinyl]uracil (169b). $n$-Butylamine $(100 \mu \mathrm{L}, 1$ mmol) was added to a stirring solution of (E)-1- $N$-benzyl-5-(1-chloro-2-tosylvinyl)uracil 158 (41.6 mg, $0.1 \mathrm{mmol}$ ) in $3 \mathrm{~mL}$ of $\mathrm{MeOH}$ at ambient temperature. After kept stirring for $2 \mathrm{~h}$, white precipitates showed up. The solid was collected by vacuum filtrated, wash with cold $\mathrm{MeOH}$ and dried under the high vacuum pump to give 1-N-benzyl-5-[1-(butylamino)-2-tosylvinyl]uracil 169b (32 mg, 71\% )as a mixture of two regioisomers with ratio 15:85 (Z:E). ${ }^{1} \mathrm{H}$ NMR (400 MHz, DMSO- $\left.d_{6}\right) \delta 0.75(\mathrm{t}, J=7.3 \mathrm{~Hz}, 0.45 \mathrm{H}), 0.85(\mathrm{~d}, J=7.3 \mathrm{~Hz}, 2.55 \mathrm{H}), 1.08-1.14(\mathrm{~m}, 0.3 \mathrm{H}), 1.26-$ $1.36(\mathrm{~m}, 2 \mathrm{H}), 1.42-1.47(\mathrm{~m}, 1.7 \mathrm{H}), 2.33(\mathrm{~s}, 2.55 \mathrm{H}), 2.33(\mathrm{~s}, .45 \mathrm{H}), 2.89(\mathrm{dd}, J=6.8,12.0 \mathrm{~Hz}$, 1.7H), $2.96(\mathrm{dd}, J=6.6,13.1 \mathrm{~Hz}, 0.3 \mathrm{H}), 4.87(\mathrm{~s}, 1.7 \mathrm{H}), 4.91(\mathrm{~s}, 0.3 \mathrm{H}), 7.19$ (d, $J=8.0 \mathrm{~Hz}, 2 \mathrm{H})$, 7.24-7.42 (m, 6), $7.47(\mathrm{~d}, J=8.2 \mathrm{~Hz}, 2 \mathrm{H}), 7.67(\mathrm{~s}, 1 \mathrm{H}), 11.41(\mathrm{~s}, 1 \mathrm{H}) ;{ }^{13} \mathrm{C}$ NMR $(101 \mathrm{MHz}$, DMSO- $\left.d_{6}\right) \delta 13.7,19.7,20.9,42.8,50.7,93.0,125.6,125.8,127.3,127.5,127.7,128.5,128.6$, $129.1,129.5,136.7,141.4,143.2,150.6,161.4 ;$ HRMS calcd for $\mathrm{C}_{24} \mathrm{H}_{28} \mathrm{~N}_{3} \mathrm{O}_{4} \mathrm{~S}[\mathrm{M}+\mathrm{H}]^{+}$ 454.1795, found 454.1793 .

(E)-1-N-Benzyl-5-(1-(propylthio)-2-tosylvinyl)uracil (169c). $n$-Propylthiol $(90 \mu \mathrm{L}, 1 \mathrm{mmol})$ and $\mathrm{Et}_{3} \mathrm{~N}(279 \mu \mathrm{L}, 20 \mathrm{mmol})$ were added to a stirring solution of $(E)-1-N$-benzyl-5-(1-chloro-2- 
tosylvinyl)uracil $158(41.6 \mathrm{mg}, 0.1 \mathrm{mmol})$ in $3 \mathrm{~mL}$ of $\mathrm{MeOH}$ at ambient temperature. After the reaction mixture was kept stirring for $2 \mathrm{~h}$, white precipitates showed up. The solid was collected by vacuum filtrated, wash with cold $\mathrm{MeOH}$ and dried under the high vacuum pump to give 1-Nbenzyl-5-[1-(propylthio)-2-tosylvinyl]uracil 169c (28.1 mg, $62 \%)$ as white solid. ${ }^{1} \mathrm{H}$ NMR (400 MHz, DMSO- $\left.d_{6}\right) \delta 0.92(\mathrm{t}, J=7.3 \mathrm{~Hz}, 3 \mathrm{H}), 1.50-1.59(\mathrm{~m}, 2 \mathrm{H}), 2.38(\mathrm{~s}, 3 \mathrm{H}), 2.80(\mathrm{t}, J=7.2 \mathrm{~Hz}$, 3H), $4.92(\mathrm{~s}, 2 \mathrm{H}), 6.48(\mathrm{~s}, 1 \mathrm{H}), 7.31-7.41(\mathrm{~m}, 7 \mathrm{H}), 7.60(\mathrm{~d}, J=8.3 \mathrm{~Hz}, 2 \mathrm{H}), 7.86(\mathrm{~s}, 1 \mathrm{H}), 11.56(\mathrm{~s}$, $1 \mathrm{H}) ;{ }^{13} \mathrm{C}$ NMR (101 MHz, DMSO) $\delta 13.2,20.6,21.1,33.6,50.6,108.9,122.0,127.1,127.4$, $127.8,128.6,129.5,136.7,138.8,143.68,143.73,147.6,150.4,160.7$; HRMS calcd for $\mathrm{C}_{23} \mathrm{H}_{25} \mathrm{~N}_{2} \mathrm{O}_{4} \mathrm{~S}_{2}[\mathrm{M}+\mathrm{H}]^{+} 457.1250$, found 457.1229.

1- $N$-benzyl-5-(2-tosylacetyl)uracil (184). Fresh prepared sulfinic acid 183 (156 mg, 1.0 mmol) was added to a stirring solution of 1- $N$-benzyl-5-ethynyluracil 135 (45.2 $\mathrm{mg}, 0.2 \mathrm{mmol})$ in 1,2-dichloroethane (DCE, $2 \mathrm{~mL}$ ) at ambient temperature. A balloon filled with oxygen was connected to the flask, followed by the addition of pyridine ( $66 \mu \mathrm{L}, 64.9 \mathrm{mg}, 0.82 \mathrm{mmol})$. The resulting solution was stirred at $45{ }^{\circ} \mathrm{C}$ for $4 \mathrm{~h}$. Then the reaction mixture was cooled down to room temperature and volatiles were removed under the reduced pressure. The oily residue was column chromatographed (Hexane $:$ EtOAc $=1: 1)$ to give $184(39.8 \mathrm{mg}, 50 \%)$ as white solid. ${ }^{1} \mathrm{H}$ NMR $\delta$ 2.42 (s, 3H), 4.98 ("s", 4H), 7.29 (d, $J=8.0 \mathrm{~Hz}, 2 \mathrm{H})$, 7.34-7.31 (m, 2H), 7.45-7.37 (m, 3H), 7.79 $(\mathrm{d}, J=8.3 \mathrm{~Hz}, 2 \mathrm{H}), 8.23(\mathrm{~s}, 1 \mathrm{H}), 8.46(\mathrm{~s}, 1 \mathrm{H}) ;{ }^{13} \mathrm{C} \mathrm{NMR} \delta 21.8,52.9,65.4,112.0,128.58,128.61$, $129.4,129.6,129.9,133.9,137.0,145.3,149.6,151.7,160.5,183.8$; HRMS calcd for $\mathrm{C}_{20} \mathrm{H}_{19} \mathrm{~N}_{2} \mathrm{O}_{5} \mathrm{~S}[\mathrm{M}+\mathrm{H}]^{+}$399.1009, found 399.1017.

1- $N$-benzyl-5-(2-benzyl-2-tosylacetyl)uracil (188). Sodium hydroxide ( $8 \mathrm{mg}, 0.2 \mathrm{mmol})$ was added to a stirring solution of 1- $N$-benzyl-5-(2-tosylacetyl)uracil 184 (20 mg, $0.05 \mathrm{mmol})$ in $\mathrm{MeOH}(2 \mathrm{~mL})$ at ambient temperature. After stirring for $5 \mathrm{~min}$, benzyl bromide $(9.4 \mathrm{mg}, 6.5 \mu \mathrm{L}$, $0.055 \mathrm{mmol}$ ) was injected to the clear solution via the syringe. The resulting solution was stirred 
at ambient temperature for $16 \mathrm{~h}$. Volatiles were removed under the reduced pressure and the residue was dissolved in EtOAc $(5 \mathrm{~mL})$ and washed with $5 \% \mathrm{HCl}$ solution, saturated $\mathrm{NaHCO}_{3}$ and brine. The volatiles was removed under the reduced pressure and the residue was column chromatographed $($ Hexane $:$ EtOAc $=6: 4)$ to give $188(10 \mathrm{mg}, 50 \%)$ as white solid. Compound $188 \mathrm{Had}{ }^{1} \mathrm{H}$ NMR $\delta 2.41(\mathrm{~s}, 3 \mathrm{H}), 3.14(\mathrm{dd}, J=3.5,13.9 \mathrm{~Hz}, 1 \mathrm{H}), 3.44(\mathrm{dd}, J=11.6,13.9 \mathrm{~Hz}, 1 \mathrm{H})$, $4.91(\mathrm{~d}, J=14.7 \mathrm{~Hz}, 1 \mathrm{H}), 4.95(\mathrm{~d}, J=14.7 \mathrm{~Hz}, 1 \mathrm{H}), 6.57(\mathrm{dd}, J=3.5,11.2 \mathrm{~Hz}, 1 \mathrm{H}), 7.03-7.05(\mathrm{~m}$, 2H), 7.09-7.15 (m, 3H), 7.26-7.30 (m, 4H), 7.38-7.41 (m, 3H), $7.80(\mathrm{~d}, J=8.3 \mathrm{~Hz}, 2 \mathrm{H}), 8.17(\mathrm{~s}$, $1 \mathrm{H}), 8.83(\mathrm{~s}, 1 \mathrm{H}) ;{ }^{13} \mathrm{C}$ NMR $\delta 21.8,32.7,52.9,71.4,112.6,126.9,128.6,128.7,129.0,129.3$, $129.4,129.5,129.9,133.9,135.3,136.2,145.4,149.6,151.6,161.0,187.0$; HRMS calcd for $\mathrm{C}_{27} \mathrm{H}_{25} \mathrm{~N}_{2} \mathrm{O}_{5} \mathrm{~S}[\mathrm{M}+\mathrm{H}]^{+}$489.1479, found 489.1458.

2,3,5-Tri- $\boldsymbol{O}$-acetyl-5-( $\boldsymbol{\alpha}$-azido)vinyl uridine (198). $\mathrm{TMSN}_{3}(46 \mathrm{mg}, 0.4 \mathrm{mmol})$ and $\mathrm{H}_{2} \mathrm{O}(7$ $\mu \mathrm{L}, 0.4 \mathrm{mmol})$ were added to a stirring solution of 2,3,5-tri- $O$-acetyl-5-ethynyl uridine $\mathbf{1 3 5}$ (78.7 $\mathrm{mg}, 0.2 \mathrm{mmol}$ ) in $2 \mathrm{~mL}$ of DMSO at ambient temperature. Followed by the addition of $\mathrm{Ag}_{2} \mathrm{CO}_{3}$ (5.5 mg, $0.02 \mathrm{mmol}$ ), the suspension was heated and stirred at $80{ }^{\circ} \mathrm{C}$ for $1.5 \mathrm{~h}$. After cooled down to roon temperature, the volatiles were removed under the reduced pressure and oily residue was dilute with EtOAc, washed with $\mathrm{H}_{2} \mathrm{O}$, and brine. Organic layer was dried over anhydrous $\mathrm{Na}_{2} \mathrm{SO}_{4}$ and column chromatographied (Hexan:EtOAc $=1: 1)$ to give white solid $198(47 \mathrm{mg}, 54 \%) .{ }^{1} \mathrm{H}$ NMR $\delta 2.08(\mathrm{~s}, 3 \mathrm{H}), 2.13(\mathrm{~s}, 3 \mathrm{H}), 2.18(\mathrm{~s}, 3 \mathrm{H}), 4.21-4.47(\mathrm{~m}, 3 \mathrm{H}), 5.09(\mathrm{~d}, J=2.2 \mathrm{~Hz}, 1 \mathrm{H}), 5.22-$ $5.42(\mathrm{~m}, 2 \mathrm{H}), 6.12(\mathrm{~d}, J=5.8 \mathrm{~Hz}, 1 \mathrm{H}), 6.37(\mathrm{~d}, J=2.2 \mathrm{~Hz}, 1 \mathrm{H}), 7.76(\mathrm{~s}, 1 \mathrm{H}), 9.57(\mathrm{~s}, 1 \mathrm{H}),{ }^{13} \mathrm{C}$ NMR 20.50, 20.56, 20.65, 63.5, 70.1, 72.9, 80.5, 87.1, 102.5, 113.7, 137.2, 146.2, 149.6, 160.5, 169.81, 169.83, 170.7; HRMS calcd for $\mathrm{C}_{17} \mathrm{H}_{19} \mathrm{~N}_{5} \mathrm{NaO}_{9}[\mathrm{M}+\mathrm{Na}]^{+} 460.1075$, found 460.1062.

2,3,5-Tri- $O$-acetyl-5- $\{\alpha-[(5 \mathrm{aR}, 6 \mathrm{R}, 6 \mathrm{aS})-1,4,5,5 \mathrm{a}, 6,6 \mathrm{a}, 7,8$-octahydrocyclopropa $[5,6]$ cycloocta[1,2-d][1,2,3]triazol-6-yl]methanol\}vinyl $\quad$ uridine $\quad(200) . \quad(1 \mathrm{R}, 8 \mathrm{~S}, 9 \mathrm{~S})-$ Bicyclo[6.1.0]non-4-yn-9-ylmethanol 199 (9.6 mg, $0.064 \mathrm{mmol})$ was added to a solution of 2,3,5Tri-O-acetyl-5-( $\alpha$-azido)vinyl uridine $198(28 \mathrm{mg}, 0.064 \mathrm{mmol})$ in $2 \mathrm{~mL}$ of $\mathrm{MeOH}$ at ambient 
temperature. The resulting clear solution was stirred for $8 \mathrm{~h}$ and the volatiles were removed under the reduced pressure to give clear oily residue. Followed column chromatography $\left(\mathrm{CHCl}_{3} \rightarrow\right.$ $\left.\mathrm{CHCl}_{3}: \mathrm{MeOH}=100 \rightarrow 95: 5\right)$ gave corresponding product $\mathbf{2 0 0}$ as a mixture of two regioisomers as a white solid $(80 \%, 30 \mathrm{mg}, 0.051 \mathrm{mmol}) .{ }^{1} \mathrm{H}$ NMR $\delta$ 0.99-1.12 $(\mathrm{m}, 2 \mathrm{H}), 1.17-1.22(\mathrm{~m}, 1 \mathrm{H})$, 1.48-1.60 (m, 2H), 2.067-2.073 (d, 3H), $2.10(\mathrm{~s}, 3 \mathrm{H}), 2.137-2.142(\mathrm{~d}, 3 \mathrm{H}), 2.22-2.29(\mathrm{~m}, 2 \mathrm{H})$, 2.61-2.67 (m, 1H), 2.87-2.94 (m, 2H), 3.17-3.22 (m, 1H), 3.68-3.74 (m, 2H), 4.13-4.15 (m, 1H), 4.16-4.27 (m, 2H), 5.23-5.26 (m, 2H), $5.51(\mathrm{~s}, 1 \mathrm{H}), 5.78(\mathrm{~d}, J=4.5 \mathrm{~Hz}, 1 \mathrm{H}), 5.81(\mathrm{~d}, J=4.9 \mathrm{~Hz}$ $1 \mathrm{H}), 6.55(\mathrm{~d}, J=4.0 \mathrm{~Hz}, 1 \mathrm{H}), 6.95(\mathrm{~d}, 1 \mathrm{H}), 9.38(\mathrm{~s}, 1 \mathrm{H}) ;{ }^{13} \mathrm{C}$ NMR $\delta 14.2,19.8,19.92,19.94$, $20.1,20.5,20.6,21.0,21.5,21.6,22.4,22.5,22.6,22.77,22.81,23.5,25.9,26.0,31.7,53.6,59.79$, $59.81,63.17,63.20,70.5,73.0,73.1,80.4,89.2,89.6,110.9,111.0,119.7,119.8,134.0,135.1$, $135.2,139.1,138.3,144.7,144.8,149.0,149.1,160.4,169.68,169.69,169.8,169.9,170.60$ 170.62; HRMS calcd for $\mathrm{C}_{27} \mathrm{H}_{34} \mathrm{~N}_{5} \mathrm{O}_{10}[\mathrm{M}+\mathrm{H}]^{+}$588.2300, found 588.2312.

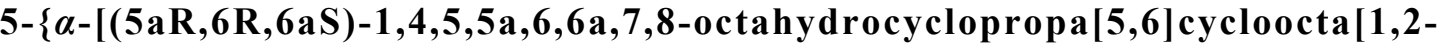
d] [1,2,3]triazol-6-yl]methanol\} vinyl uridine (201). Compound 200 (30.6 mg, $0.05 \mathrm{mmol}$ ) was dissolved in $\mathrm{NH}_{3} / \mathrm{MeOH}(3 \mathrm{~mL})$ at $0{ }^{\circ} \mathrm{C}$ (ice bath), and the resulting solution was stirred overnight. Volatiles were removed under the reduced pressure and the residue was column chromatographed $\left(\mathrm{CHCl}_{3}: \mathrm{MeOH}, 9: 1 \rightarrow 8: 2\right)$ to give $201(15 \mathrm{mg}, 64 \%)$ as white solid. UV $(\mathrm{MeOH}) \lambda_{\max }=283 \mathrm{~nm} ;{ }^{1} \mathrm{H}$ NMR $\left(\mathrm{DMSO}_{-} d_{6}\right) \delta$ 0.84-0.89 (m, 2H), 0.94-1.00 (m, 1H), 1.49-1.58 (m, 2H), 2.02-2.11 (d, 2H), 2.55-2.61 (m, 1H), 2.80-2.84 (m, 2H), 3.00-3.05 (m, 1H), 3.37-3.41 (m, 1H), 3.46-3.48 (m, 2H), 3.78-3.81 (m, 2H), 3.84-3.90 (m, 1H), $4.32(\mathrm{t}, J=4.59 \mathrm{~Hz}, 1 \mathrm{H}), 4.84$ $(\mathrm{dt}, J=5.25,8.38 \mathrm{~Hz}, 1 \mathrm{H}), 5.11(\mathrm{~s}, 1 \mathrm{H}), 5.38(\mathrm{~s}, 1 \mathrm{H}), 5.44(\mathrm{~d}, J=4.41 \mathrm{~Hz}, 1 \mathrm{H}), 5.75-5.77(\mathrm{~m}$, 1H), 6.27-6.31 (m, 1H), 7.34-7.43 (m, 1H), $11.65(\mathrm{~s}, 1 \mathrm{H}) ;{ }^{13} \mathrm{C}$ NMR (DMSO- $\left.d_{6}\right) \delta 18.61,18.64$ $18.7,18.9,20.85,20.90,21.3,21.8,22.5,22.87,22.97,25.5,25.6,48.6,54.9,57.35,57.38,60.97$, $61.03,69.95,69.99,74.03,85.0,88.2,88.4,109.7,116.3,116.4,134.3,134.4,135.3,135.4$, 
$138.89,138.92,143.59,143.63,149.69,149.71,160.8,141.5 ;$ HRMS calcd for $\mathrm{C}_{21} \mathrm{H}_{27} \mathrm{~N}_{5} \mathrm{NaO}_{7}[\mathrm{M}$ $+\mathrm{Na}]^{+}$484.1803, found 484.1810 . 


\section{CONCLUSION}

I have developed a method for efficient transfer of one, two, or three phenyl groups from chloro(phenyl)germanes to the Pd catalyzed aryl halides to give the access to various biaryls. These cross-coupling reactions were mediated by TBAF and facilitated by adding of measured amount of water in toluene as solvent. The TBAF promoted Pd-catalyzed cross-coupling of organogermanes have been attempted to extend to the 5-halo pyrimidine nucleoside analogues for the synthesis of 5-aryl derivatives by transfer of phenyl groups from the germane center. However, during the coupling of 5-halo uracil with chloro(phenyl)germanes in toluene, in addition to the desired 5-phenyluracil product (formed in small quantity), an unexpected mixture of 5-(o,m,p-methylphenyl)uracil has been observed as the major product. In order to investigate the formation of such unexpected 5-aryluracil derivatives, which were formed by direct activation of toluene (simple arene) without necessary of using organometallic component, I have further studied the reaction of 1-N-benzyl-5-iodouracil with regular arenes.

To further apply the organogermane substrates to cross-coupling reaction with 5-halouracil, I have also developed a method to selective transfer of phenyl group(s) from allyl(phenyl)germanes in Pd catalyzed cross-coupling processes. I have shown that selective cleavage of allyl-Ge bond upon treatment with $\mathrm{SbF}_{5} / \mathrm{C}$ can serve as an alternative method for the generation of active coupling species fluoro(phenyl)germanes in situ, followed by the Pd-catalyzed cross-coupling with aryl halides in the presence of TBAF gave various biaryls.

I have demonstrated that TBAF-mediated Pd-catalyzed direct arylation of 5-halouracil and uracil nucleosides with simple arenes (e.g., benzene, toluene, and anisole) and electron rich heteroarenes (e.g., furan, thiophene, and pyrrole) in DMF undergoes smoothly to give 5-arylated analogues in high to excellent yields. This methodology has been extended to other enolizable heterocyclic systems, such as 3-bromo-2-pyridone. Similarly, the base-promoted Pd-catalyzed 
direct arylation of 5-halouracils also proceeds with the $\pi$-excessive heteroarenes in the presence of pivalic acid.

It is worth to mention that the TBAF-promoted direct $\mathrm{C}-\mathrm{H}$ arylation protocol developed here differs from the existing routes to 5-aryluracils as outlined below. First, our protocol eliminates organometallic precursors required in Suzuki, Hiyama or Stille couplings. Secondly, no ligands or any other additives are required for the direct arylation to proceed smoothly. Thirdly, it is efficient with a variety of uracils and uracil nucleosides, which are important and the basis of the DNA or RNA. In addition, the protocol does not induce glycosidic bond cleavage, avoiding a major drawback with other methodologies.

In my research efforts to study the chemistry of 5-ethynyl pyrimidine nucleosides, I have shown that the trialkyl or triphenylgermanes add across a triple bond of 5-acetylene pyrimidine via radical or thermal hydrogermylation. Interestingly, Z-vinylgermanyl products were obtained exclusively in good yields at elevated temperature; while, the $E$ isomers are formed exclusively with the addition of "measured" amount of water. During the hydrogermylation of 5ethynyluracil nucleosides with triphenylgermane in toluene, unexpected 5-[2(triphenylgermyl)acetyl]uracil nucleosides were isolated up to $20 \%$ along with the desired vinylgermane products. The $4-\left[{ }^{18} \mathrm{O}\right]-1-N$-benzyl-5-ethynyluracil was synthesized to clarify the formation of the unexpected $\beta$-germyl ketone as well as confirming the origin of the oxygen in the 5-acetyl moiety. A plausible mechanism had been proposed for the formation of the unexpected $\beta$-germyl ketone on the basis of literature, NMR spectroscopy and HRMS fragmentation analysis, which indicates that the origin of the oxygen atom in the 5-acetyl moiety is from the residual oxygen in the reaction solution. Interestingly, thermodegradation of the $\beta$ ketogermyl uracil analogues in $\mathrm{MeOH}$ give 5-acetyluracil nucleosides in quantitative yield via hydrolysis of the $O$-germyl substituted enols. Bromodegermylation of the 5[(trimethyl)vinyl]germyl substrates with NBS produced 5-(2-bromovinyl) analogues with the 
retention of the stereochemistry in high yields. However, Pd-catalyzed cross-coupling reaction of 5-[(trimethyl)vinyl]germyl substrates with aryl halides gave corresponding products in only 10$30 \%$.

I have also demonstrated that hydrosulfonylation of 5-ethynyluracil nucleoside analogues with either sulfinic acid or sulfonylhydrazide in the presence of iron catalyst give 5 - $(\beta$-halo)vinyl sulfonyl uracil nucleoside analogues in moderate to high yield. It is worth mentioning that only 5$E$-( $\beta$-chloro)vinyl sulfonyl products are obtained when the reactions were performed in the presence of $\mathrm{FeCl}_{3}$. Moreover, when the reactions are carried out in the presence of $\mathrm{FeBr}_{3}, \mathrm{a}$ mixture of $E / Z$ isomers is obtained with the ratio of 15:85 as well as the 5-( $\alpha, \beta$-dibromo)vinyl substrate in small quantity. I have showed the 5-( $\beta$-halo)vinyl sulfonyl analogues can serve as excellent Michael acceptors and various of nucleophiles (e.g., $n$-butylamine, propanethiol, ammonia) have been added across the double to give the corresponding $\beta$-substituted vinylsulfones in high yields. Triethylamine was required as a catalyst for the addition of thiol due to the week nucleophilicity. Similarly, 1- $N$-benzyl-5-(2-sulfonylketo)uracil has been synthesized via the direct aerobic difunctionalization of 5-ethynyl substrate with sulfinic acid in the presence of pyridine in moderate yield. I have also demonstrated that hydroazidation of the acetyl protected 5-ethynyluridine with $\mathrm{TMSN}_{3}$ in the presence of silver salt and catalytic amount of water produced novel 5-( $\alpha$-azido)vinyluridine derivatives. Comparing to the light sensitive 5azidouridine with half-life of $4 \mathrm{~h}$ in the $3 \% \mathrm{DMSO} /$ water solution, the 5 -( $\alpha$-azido)vinyluridine turned out to be fairly stable. These 5-( $\alpha$-azido)vinyluridine analogues have been showed to be an excellent substrates for the strain-promoted click reaction with cyclooctyne to provide novel 5- $(\alpha-$ 1,2,3-triazole)vinyluridine as a possible fluorescence probe. 


\section{REFERENCES}

(1) In Nucleic Acids in Chemistry and Biology; $3^{\text {rd }}$ ed.; Blackburn, G. M., Gait, M. J., Loakes, D., Williams, D. M., Eds.; The Royal Society of Chemistry: 2006, p 1-12.

(2) Ahmadian, M.; Bergstrom, D. E. In Modified Nucleosides: in Biochemistry, Biotechnology and Medicine; Herdewijn, P., Ed.; Wiley-VCH Verlag GmbH \& Co. KGaA: 2008, p 249276.

(3) Damaraju, V. L.; Damaraju, S.; Young, J. D.; Baldwin, S. A.; Mackey, J.; Sawyer, M. B.; Cass, C. E. Oncogene 2003, 22, 7524-7536.

(4) Parker, W. B. Chem. Rev. 2009, 109, 2880-2893.

(5) Wiley, J. S.; Jones, S. P.; Sawyer, W. H. Eur. J. Cancer Clin. Oncol. 1983, 19, 1067-1074.

(6) Galmarini, C. M.; Thomas, X.; Calvo, F.; Rousselot, P.; Rabilloud, M.; El Jaffari, A.; Cros, E.; Dumontet, C. Br. J. Haematol. 2002, 117, 860-868.

(7) Owens, J. K.; Shewach, D. S.; Ullman, B.; Mitchell, B. S. Cancer Res. 1992, 52, 23892393.

(8) Heinemann, V.; Hertel, L. W.; Grindey, G. B.; Plunkett, W. Cancer Res. 1988, 48, 40244031.

(9) Fram, R. J.; Egan, E. M.; Kufe, D. W. Leuk. Res. 1982, 7, 243-249.

(10) Wright, K. Nature 1986, 323, 283.

(11) Jeffries, D. J. BMJ 1989, 298, 1132-1133.

(12) Agrofoglio, L. A.; Gillaizeau, I.; Saito, Y. Chem. Rev. 2003, 103, 1875-1916.

(13) Goodchild, J.; Porter, R. A.; Raper, R. H.; Sim, I. S.; Upton, R. M.; Viney, J.; Wadsworth, H. J. J. Med. Chem. 1983, 26, 1252-1257.

(14) Regan, C. F.; Guo, Z.; Chen, Y.; Huang, C. Q.; Chen, M.; Jiang, W.; Rueter, J. K.; Coon, T.; Chen, C.; Saunders, J.; Brown, M. S.; Betz, S. F.; Struthers, R. S.; Yang, C.; Wen, J.; Madan, A.; Zhu, Y.-F. Bioorg. Med. Chem. Lett. 2008, 18, 4503-4507.

(15) Chen, C.; Wu, D.; Guo, Z.; Xie, Q.; Reinhart, G. J.; Madan, A.; Wen, J.; Chen, T.; Huang, C. Q.; Chen, M.; Chen, Y.; Tucci, F. C.; Rowbottom, M.; Pontillo, J.; Zhu, Y.-F.; Wade, W.; Saunders, J.; Bozigian, H.; Struthers, R. S. J. Med. Chem. 2008, 51, 7478-7485.

(16) Medda, F.; Russell, R. J. M.; Higgins, M.; McCarthy, A. R.; Campbell, J.; Slawin, A. M. Z.; Lane, D. P.; Lain, S.; Westwood, N. J. J. Med. Chem. 2009, 52, 2673-2682.

(17) Crisp, G. T.; Macolino, V. Synth. Commun. 1990, 20, 413-422. 
(18) Machida, H.; Sakata, S. In Nucleosides and Nucleotides as Antitumor and Antiviral Agents; Chu, C. K., Baker, D. C., Eds.; Plenum Press: New York, 1993, p 245-264.

(19) Jordheim, L. P.; Durantel, D.; Zoulim, F.; Dumontet, C. Nat. Rev. Drug Discov. 2013, 12, 447-464.

(20) Horwitz, J. P.; Chua, J.; Noel, M. J. Org. Chem. 1964, 29, 2076-2078.

(21) Ostertag, W.; Roesler, G.; Krieg, C. J.; Kind, J.; Cole, T.; Crozier, T.; Gaedicke, G.; Steinheider, G.; Kluge, N.; Dube, S. Proc. Natl. Acad. Sci. USA 1974, 71, 4980-4985.

(22) Clercq, E. D.; Descamps, J.; De Somer, P.; Barr, P. J.; Jones, A. S.; Walker, R. T. Proc. Natl. Acad. Sci. USA 1979, 76, 2947-2951.

(23) Suzutani, T.; Machida, H.; Sakuma, T.; Azuma, M. Antimicrob. Agents Chemother. 1988, $32,1547-1551$.

(24) Machida, H.; Sakata, S.; Kuninaka, A.; Yoshino, H. Antimicrob. Agents Chemother. 1981, 20, 47-52.

(25) Kantarjian, H. M.; O'Brien, S.; Cortes, J.; Giles, F. J.; Faderl, S.; Issa, J.-P.; Garcia-Manero, G.; Rios, M. B.; Shan, J.; Andreeff, M.; Keating, M.; Talpaz, M. Cancer 2003, 98, 522-528.

(26) Krim, J.; Grunewald, C.; Taourirte, M.; Engels, J. W. Bioorg. Med. Chem. 2012, 20, 480486.

(27) Elwell, L. P.; Ferone, R.; Freeman, G. A.; Fyfe, J. A.; Hill, J. A.; Ray, P. H.; Richards, C. A.; Singer, S. C.; Knick, V. B.; Rideout, J. L. Antimicrob. Agents Chemother. 1987, 31, 274-280.

(28) De Clercq, E.; Descamps, J.; De Somer, P.; Barr, P. J.; Jones, A. S.; Walker, R. T. Proc. Natl. Acad. Sci. USA 1979, 76, 2947-2951.

(29) Machida, H.; Kuninaka, A.; Yoshino, H.; Ikeda, K.; Mizuno, Y. Antimicrob. Agents Chemother. 1980, 17, 1030-1031.

(30) Robins, M. J.; Barr, P. J. J. Org. Chem. 1983, 48, 1854-1862.

(31) De Clercq, E. J. Med. Chem. 2009, 53, 1438-1450.

(32) McGuigan, C.; Barucki, H.; Blewett, S.; Carangio, A.; Erichsen, J. T.; Andrei, G.; Snoeck, R.; De Clercq, E.; Balzarini, J. J. Med. Chem. 2000, 43, 4993-4997.

(33) http://www.cancer.gov/cancertopics/druginfo/fda-decitabine

(34) Noé, M. S.; Sinkeldam, R. W.; Tor, Y. J. Org. Chem. 2013, 78, 8123-8128.

(35) Piton, N.; Mu, Y.; Stock, G.; Prisner, T. F.; Schiemann, O.; Engels, J. W. Nucleic Acids Res. 2007, 35, 3128-3143. 
(36) Srivatsan, S. G.; Tor, Y. Tetrahedron 2007, 63, 3601-3607.

(37) Amann, N.; Wagenknecht, H.-A. Synlett 2002, 5, 687-691.

(38) Amann, N.; Pandurski, E.; Fiebig, T.; Wagenknecht, H.-A. Chem. Eur. J. 2002, 8, 48774883.

(39) Amann, N.; Pandurski, E.; Fiebig, T.; Wagenknecht, H.-A. Angew. Chem. Int. Ed. 2002, 41, 2978-2980.

(40) Greco, N. J.; Sinkeldam, R. W.; Tor, Y. Org. Lett. 2009, 11, 1115-1118.

(41) Sinkeldam, R. W.; Greco, N. J.; Tor, Y. Chem. Rev. 2010, 110, 2579-2619.

(42) Greco, N. J.; Tor, Y. J. Am. Chem. Soc. 2005, 127, 10784-10785.

(43) Srivatsan, S. G.; Tor, Y. J. Am. Chem. Soc. 2007, 129, 2044-2053.

(44) Hocek, M.; Fojta, M. Org. Biomol. Chem. 2008, 6, 2233-2241.

(45) Cahová, H.; Havran, L.; Brázdilová, P.; Pivoňková, H.; Pohl, R.; Fojta, M.; Hocek, M. Angew. Chem. Int. Ed. 2008, 47, 2059-2062.

(46) Raindlová, V.; Pohl, R.; Šanda, M.; Hocek, M. Angew. Chem. Int. Ed. 2010, 49, 1064-1066.

(47) Heck, R. F.; Nolley, J. P. J. Org. Chem. 1972, 37, 2320-2322.

(48) The Nobel Prize in Chemistry Announcement. http://www.nobelprize.org/nobel_prizes/chemistry/laureates/2010/\#

(49) Al-Razzak, L. A.; Schwepler, D.; Decedue, C. J.; Balzarini, J.; De Clercq, E.; Mertes, M. P. J. Med. Chem. 1987, 30, 409-419.

(50) Al-razzak, L.; Hassan, M. E.; Mertes, M. P. Nucleos. Nucleot. 1983, 2, 243-248.

(51) Bigge, C. F.; Mertes, M. P. J. Org. Chem. 1981, 46, 1994-1997.

(52) Chang, G.; Mertes, M. P. J. Org. Chem. 1987, 52, 3625-3631.

(53) Western, E. C.; Daft, J. R.; Johnson, E. M.; Gannett, P. M.; Shaughnessy, K. H. J. Org. Chem. 2003, 68, 6767-6774.

(54) Fresneau, N.; Hiebel, M.-A.; Agrofoglio, L.; Berteina-Raboin, S. Molecules 2012, 17, $14409-14417$.

(55) Ruth, J. L.; Bergstrom, D. E. J. Org. Chem. 1978, 43, 2870-2876.

(56) Bergstrom, D. E.; Ogawa, M. K. J. Am. Chem. Soc. 1978, 100, 8106-8112.

(57) Farina, V.; Hauck, S. I. Synlett 1991, 1991, 157-159. 
(58) Herdewijn, P.; Kerremans, L.; Wigerinck, P.; Vandendriessche, F.; Van Aerschot, A. Tetrahedron Lett. 1991, 32, 4397-4400.

(59) Gutierrez, A. J.; Terhorst, T. J.; Matteucci, M. D.; Froehler, B. C. J. Am. Chem. Soc. 1994, $116,5540-5544$.

(60) Peyron, C.; Benhida, R.; Bories, C.; Loiseau, P. M. Bioorg. Chem. 2005, 33, 439-447.

(61) Bergstrom, D. E. Nucleos. Nucleot. 1982, 1, 1-34.

(62) Bergstrom, D. E.; Ruth, J. L. J. Am. Chem. Soc. 1976, 98, 1587-1589.

(63) Dieck, H. A.; Heck, R. F. J. Am. Chem. Soc. 1974, 96, 1133-1136.

(64) Jones, A. S.; Verhelst, G.; Walker, R. T. Tetrahedron Lett. 1979, 20, 4415-4418.

(65) Sonogashira, K.; Tohda, Y.; Hagihara, N. Tetrahedron Lett. 1975, 16, 4467-4470.

(66) De Clercq, E.; Descamps, J.; Verhelst, G.; Walker, R. T.; Jones, A. S.; Torrence, P. F.; Shugar, D. J. Infect. Dis. 1980, 141, 563-574.

(67) McGuigan, C.; Yarnold, C. J.; Jones, G.; Velázquez, S.; Barucki, H.; Brancale, A.; Andrei, G.; Snoeck, R.; De Clercq, E.; Balzarini, J. J. Med. Chem. 1999, 42, 4479-4484.

(68) Kumar, R.; Wiebe, L. I.; Knaus, E. E. Can. J. Chem. 1996, 74, 1609-1615.

(69) Miyaura, N.; Yamada, K.; Suzuki, A. Tetrahedron Lett. 1979, 20, 3437-3440.

(70) Miyaura, N.; Suzuki, A. J. Chem. Soc., Chem. Commun. 1979, 866-867.

(71) Miyaura, N.; Yanagi, T.; Suzuki, A. Synth. Commun. 1981, 11, 513-519.

(72) Hatanaka, Y.; Hiyama, T. J. Org. Chem. 1988, 53, 918-920.

(73) Denmark, S. E.; Regens, C. S. Acc. Chem. Res. 2008, 41, 1486-1499.

(74) Hatanaka, Y.; Hiyama, T. Synlett 1991, 12, 845-853.

(75) Pitteloud, J.-P.; Zhang, Z.-T.; Liang, Y.; Cabrera, L.; Wnuk, S. F. J. Org. Chem. 2010, 75, 8199-8212.

(76) Denmark, S. E.; Sweis, R. F. In Metal-Catalyzed Cross-Coupling Reactions; Wiley-VCH Verlag GmbH: 2008, p 163-216.

(77) Matsuhashi, H.; Hatanaka, Y.; Kuroboshi, M.; Hiyama, T. Heterocycles 1996, 42, 375-384.

(78) Mitchell, T. N. In Metal-Catalyzed Cross-Coupling Reactions; Wiley-VCH Verlag GmbH: 2008, p 125-161.

(79) Stille, J. K. Angew. Chem. Int. Ed. 1986, 25, 508-524. 
(80) Alberico, D.; Scott, M. E.; Lautens, M. Chem. Rev. 2007, 107, 174-238.

(81) Campeau, L.-C.; Stuart, D. R.; Fagnou, K. Aldrich. Chim. Acta 2007, 40, 35-41.

(82) Ackermann, L.; Vicente, R.; Kapdi, A. R. Angew. Chem. Int. Ed. 2009, 48, 9792-9826.

(83) Fagnou, K. Top. Curr. Chem. 2010, 292, 35-56.

(84) Metal-Catalyzed Cross-Coupling Reactions; de Meijere, A.; Diederich, F., Eds.; WileyVCH: Weinheim, Germany, 2004.

(85) Hassan, J.; Sévignon, M.; Gozzi, C.; Schulz, E.; Lemaire, M. Chem. Rev. 2002, 102, 13591470 .

(86) Campeau, L.-C.; Parisien, M.; Leblanc, M.; Fagnou, K. J. Am. Chem. Soc. 2004, 126, 91869187.

(87) Parisien, M.; Valette, D.; Fagnou, K. J. Org. Chem. 2005, 70, 7578-7584.

(88) García-Cuadrado, D.; Braga, A. A. C.; Maseras, F.; Echavarren, A. M. J. Am. Chem. Soc. 2006, 128, 1066-1067.

(89) Campeau, L.-C.; Rousseaux, S.; Fagnou, K. J. Am. Chem. Soc. 2005, 127, 18020-18021.

(90) Kalyani, D.; Deprez, N. R.; Desai, L. V.; Sanford, M. S. J. Am. Chem. Soc. 2005, 127, $7330-7331$.

(91) Yanagisawa, S.; Sudo, T.; Noyori, R.; Itami, K. J. Am. Chem. Soc. 2006, 128, 11748-11749.

(92) Gorelsky, S. I.; Lapointe, D.; Fagnou, K. J. Org. Chem. 2012, 77, 658-668.

(93) Yan, T.; Chen, L.; Bruneau, C.; Dixneuf, P. H.; Doucet, H. J. Org. Chem. 2013, 78, 41774183.

(94) Cheng, C.; Shih, Y.-C.; Chen, H.-T.; Chien, T.-C. Tetrahedron 2013, 69, 1387-1396.

(95) Liu, X.-W.; Shi, J.-L.; Yan, J.-X.; Wei, J.-B.; Peng, K.; Dai, L.; Li, C.-G.; Wang, B.-Q.; Shi, Z.-J. Org. Lett. 2013, 15, 5774-5777.

(96) Kim, K. H.; Lee, H. S.; Kim, J. N. Tetrahedron Lett. 2011, 52, 6228-6233.

(97) Mondal, B.; Hazra, S.; Roy, B. Tetrahedron Lett. 2014, 55, 1077-1081.

(98) Ćerňová, M.; Pohl, R.; Klepetářová, B.; Hocek, M. Heterocycles 2014, 89, 1159-1171.

(99) Sokolovs, I.; Lubriks, D.; Suna, E. J. Am. Chem. Soc. 2014, 136, 6920-6928.

(100) Kim, K. H.; Lee, H. S.; Kim, S. H.; Kim, J. N. Tetrahedron Lett. 2012, 53, 1323-1327. 
(101)Kianmehr, E.; Rezaeefard, M.; Rezazadeh Khalkhali, M.; Khan, K. M. RSC Advances 2014, 4, 13764-13767.

(102) Yu, Y.-Y.; Georg, G. I. Chem. Commun. 2013, 49, 3694-3696.

(103) Xi, P.; Yang, F.; Qin, S.; Zhao, D.; Lan, J.; Gao, G.; Hu, C.; You, J. J. Am. Chem. Soc. 2010, 132, 1822-1824.

(104) Stuart, D. R.; Fagnou, K. Science 2007, 316, 1172-1175.

(105)Meng, G.; Niu, H.-Y.; Qu, G.-R.; Fossey, J. S.; Li, J.-P.; Guo, H.-M. Chem. Commun. 2012, 48, 9601-9603.

(106) Grimster, N. P.; Gauntlett, C.; Godfrey, C. R. A.; Gaunt, M. J. Angew. Chem. Int. Ed. 2005, 44, 3125-3129.

(107) Jia, C.; Lu, W.; Kitamura, T.; Fujiwara, Y. Org. Lett. 1999, 1, 2097-2100.

(108) Köhler, K.; Wussow, K.; Wirth, A. S. In Palladium-Catalyzed Coupling Reactions; WileyVCH Verlag GmbH \& Co. KGaA: 2013, p 1-30.

(109) The Chemistry of Organic Germanium, Tin and Lead Compounds; Patai, S.; Rappoport, Z., Eds.; John Wiley \& Sons: Chichester, UK, 1995; Vol. 1 \& 2002; Vol 2.

(110) Kosugi, M.; Tanji, T.; Tanaka, Y.; Yoshida, A.; Fugami, K.; Kameyama, M.; Migita, T. J. Organomet. Chem. 1996, 508, 255-257.

(111) Nakamura, T.; Kinoshita, H.; Shinokubo, H.; Oshima, K. Org. Lett. 2002, 4, 3165-3167.

(112) Wang, Z.; Wnuk, S. F. J. Org. Chem. 2005, 70, 3281-3284.

(113) Wnuk, S. F.; Garcia, P. I.; Wang, Z. Org. Lett. 2004, 6, 2047-2049.

(114) Spivey, A. C.; Tseng, C.-C.; Hannah, J. P.; Gripton, C. J. G.; de Fraine, P.; Parr, N. J.; Scicinski, J. J. Chem. Commun. 2007, 2926-2928.

(115)Spivey, A. C.; Gripton, C. J. G.; Hannah, J. P.; Tseng, C.-C.; de, F. P.; Parr, N. J.; Scicinski, J. J. Appl. Organomet. Chem. 2007, 21, 572-589.

(116) Torres, N. M.; Lavis, J. M.; Maleczka Jr, R. E. Tetrahedron Lett. 2009, 50, 4407-4410.

(117) Lukevics, E.; Arsenyan, P.; Germane, S.; Shestakova, I. Appl. Organomet. Chem. 1999, 13, 795-798.

(118) Lukevics, E.; Ignatovich, L. In Metallotherapeutic Drugs and Metal-Based Diagnostic Agents; Gielen, M., Tiekink, E. R. T., Eds. 2005, p 279-295.

(119) Yao, S.; Jiang, J.; Yang, P.; Cai, J. Bull. Korean Chem. Soc. 2012, 33, 1121-1122. 
(120) Jiang, J.; Yao, S.; Cai, H.-H.; Yang, P.-H.; Cai, J. Bioorg. Med. Chem. Lett. 2013, 23, 5727-5732.

(121) Mel'nik, S. 1.; Bakhmedova, A. A.; Nedorezova, T. P.; Iartseva, I. V.; Zhukova, O. S.; Dobrynin, Y. V.; Preobrazhenskaya, M. N.; Kolesnikov, S. P.; Li, V. Y. Bioorg. Khim. 1985, 11, 1248-1252.

(122) Miyamoto, T. K.; Sugita, N.; Matsumoto, Y.; Sasaki, Y.; Konno, M. Chem. Lett. 1983, 12, 1695-1698.

(123) Li, F.; Zhang, Z.; Gao, H. Met.-Based Drugs 1996, 3, 241-242.

(124) Yang, F.; Jin, H.; Pi, J.; Jiang, J.-h.; Liu, L.; Bai, H.-h.; Yang, P.-h.; Cai, J.-Y. Bioorg. Med. Chem. Lett. 2013, 23, 5544-5551.

(125) Shangguan, G. Q.; Huang, L. L.; Qu, X. G. Chin. Chem. Lett. 2007, 18, 1347-1350.

(126) Li, J.; Zhai, F.; Wang, X.; Li, E.; Zhang, S.; Zhang, Q.; Du, X. Polyhedron 2008, 27, 11501154.

(127) Lukevics, E.; Ignatovich, L.; Shestakova, I. Appl. Organomet. Chem. 2003, 17, 898-905.

(128) Mirabelli, C. K.; Badger, A. M.; Sung, C. P.; Hillegass, L.; Sung, C. M.; Johnson, R. K.; Picker, D.; Schwartz, D.; Dorman, J.; Martellucci, S. Anticancer Drug Des. 1989, 3, 231242.

(129) Slavik, M.; Blanc, O.; Davis, J. Invest. New Drugs 1983, 1, 225-234.

(130)DiMartino, M. J.; Lee, J. C.; Badger, A. M.; Muirhead, K. A.; Mirabelli, C. K.; Hanna, N. J. Pharmacol. Exp. Ther. 1986, 236, 103-110.

(131) Lukevics, E.; Ignatovich, L. Appl. Organomet. Chem. 1992, 6, 113-126.

(132) Menchikov, L. G.; Ignatenko, M. A. Pharm. Chem. J. 2013, 46, 635-638.

(133) Trushule, M.; Kupche, É.; Augustane, I.; Verovskii, N. V.; Lukevits, É.; Baumane, L.; Gavar, R.; Stradyn, Y. Chem. Heterocycl. Compd. 1991, 27, 1358-1364.

(134) Zhang, Z.-T.; Pitteloud, J.-P.; Cabrera, L.; Liang, Y.; Toribio, M.; Wnuk, S. F. Org. Lett. 2010, $12,816-819$.

(135) Pitteloud, J.-P.; Liang, Y.; Wnuk, S. F. Chem. Lett. 2011, 40, 967-969.

(136) Pitteloud, J.-P., Florida International University, 2011.

(137) Prince, P. D.; Sean McGrady, G.; Steed, J. W. New J. Chem. 2002, 26, 457-461.

(138) Liang, Y.; Pitteloud, J.-P.; Wnuk, S. F. J. Org. Chem. 2013. 
(139)Akiyama, T. In Main Group Metals in Organic Synthesis; Yamamoto, H., Oshima, K., Eds.; Wiley-VCH: Weinheim, 2004; Vol. 2, p 593-619.

(140) Spivey, A. C.; Diaper, C. M. Sci. Syn. 2003, 5, 181-188.

(141) Corriu, R. J. P.; Fernandez, J. M.; Guerin, C. J. Organomet. Chem. 1980, 192, 347-352.

(142) Čerňová, M.; Čerňa, I.; Pohl, R.; Hocek, M. J. Org. Chem. 2011, 76, 5309-5319.

(143) Spivey, A. C.; Gripton, C. J. G.; Hannah, J. P. Curr. Org. Synth. 2004, 1, 211-226.

(144) Denmark, S. E.; Sweis, R. F.; Wehrli, D. J. Am. Chem. Soc. 2004, 126, 4865-4875.

(145) Rayala, R.; Wnuk, S. F. Tetrahedron Lett. 2012, 53, 3333-3336.

(146) Lafrance, M.; Fagnou, K. J. Am. Chem. Soc. 2006, 128, 16496-16497.

(147) Wicke, L.; Engels, J. W. Bioconjugate Chem. 2012, 23, 627-642.

(148) Kobayashi, Y.; Yamamoto, K.; Asai, T.; Nakano, M.; Kumadaki, I. J. Chem. Soc., Perkin Trans. 1 1980, 0, 2755-2761.

(149) Bobek, M.; Kavai, I.; Sharma, R. A.; Grill, S.; Dutschman, G.; Cheng, Y. C. J. Med. Chem. 1987, 30, 2154-2157.

(150) Conreaux, D.; Bossharth, E.; Monteiro, N.; Desbordes, P.; Vors, J.-P.; Balme, G. Org. Lett. 2007, 9, 271-274.

(151) Bengtsson, C.; Almqvist, F. J. Org. Chem. 2009, 75, 972-975.

(152) Singh, B. K.; Cavalluzzo, C.; De Maeyer, M.; Debyser, Z.; Parmar, V. S.; Van der Eycken, E. Eur. J. Org. Chem. 2009, 27, 4589-4592.

(153) Shimizu, H.; Manabe, K. Tetrahedron Lett. 2006, 47, 5927-5931.

(154) Lafrance, M.; Rowley, C. N.; Woo, T. K.; Fagnou, K. J. Am. Chem. Soc. 2006, 128, 87548756.

(155) Čerňová, M.; Pohl, R.; Hocek, M. Eur. J. Org. Chem. 2009, 22, 3698-3701.

(156) Ichinose, Y.; Oda, H.; Oshima, K.; Utimoto, K. Bull. Chem. Soc. Jpn. 1987, 60, 3468-3470.

(157) Kinoshita, H.; Nakamura, T.; Kakiya, H.; Shinokubo, H.; Matsubara, S.; Oshima, K. Org. Lett. 2001, 3, 2521-2524.

(158) Nozaki, K.; Ichinose, Y.; Wakamatsu, K.; Oshima, K.; Utimoto, K. Bull. Chem. Soc. Jpn. 1990, 63, 2268-2272.

(159) Schwier, T.; Gevorgyan, V. Org. Lett. 2005, 7, 5191-5194. 
(160) Bernardoni, S.; Lucarini, M.; Pedulli, G. F.; Valgimigli, L.; Gevorgyan, V.; Chatgilialoglu, C. J. Org. Chem. 1997, 62, 8009-8014.

(161) Sharma, R. A.; Kavai, I.; Hughes, R. G.; Bobek, M. J. Med. Chem. 1984, 27, 410-412.

(162) Ichinose, Y.; Nozaki, K.; Wakamatsu, K.; Oshima, K.; Utimoto, K. Tetrahedron Lett. 1987, 28, 3709-3712.

(163) Wnuk, S. F.; Sacasa, P. R.; Restrepo, J. Nucleos. Nucleot. Nucl. 2009, 28, 537-549.

(164) David-Quillot, F.; Thiery, V.; Abarbri, M.; Thibonnet, J.; Besson, T.; Duchene, A. Main Group Met. Chem. 2007, 30, 235-244.

(165) Brancale, A.; McGuigan, C.; Algain, B.; Savy, P.; Benhida, R.; Fourrey, J.-L.; Andrei, G.; Snoeck, R.; De Clercq, E.; Balzarini, J. Bioorg. Med. Chem. Lett. 2001, 11, 2507-2510.

(166) Thurber, T. C.; Townsend, L. B. J. Org. Chem. 1976, 41, 1041-1051.

(167) Zhang, W.; Robins, M. J. Tetrahedron Lett. 1992, 33, 1177-1180.

(168) Prachayasittikul, S.; Sornsongkhram, N.; Pingaew, R.; Worachartcheewan, A.; Ruchirawat, S.; Prachayasittikul, V. Molecules 2009, 14, 2768-2779.

(169) Fahrig, R.; Eger, K.; Fuehrer, M.; Heinze, N.; Klemm, M.; Heinrich, J.-C. US, 2009; Vol. 0166096 A1.

(170) Lu, Q.; Zhang, J.; Zhao, G.; Qi, Y.; Wang, H.; Lei, A. J. Am. Chem. Soc. 2013, 135, 1148111484.

(171) Chatgilialoglu, C.; Timokhin, V. I.; Zaborovskiy, A. B.; Lutsyk, D. S.; Prystansky, R. E. J. Chem. Soc., Perkin Trans. 2 2000, 577-582.

(172) Barr, P. J.; Chananont, P.; Hamor, T. A.; Jones, A. S.; O'Leary, M. K.; Walker, R. T. Tetrahedron 1980, 36, 1269-1273.

(173) Lutsenko, I. F.; I. Baukov, Y.; Dudukina, O. V.; Kramarova, E. N. J. Organomet. Chem. 1968, 11, 35-48.

(174) Dougan, H.; Rennie, B. A.; Lyster, D. M.; Sacks, S. L. Appl. Radiat. Isot. 1994, 45, 795801.

(175) Yu, C.-S.; Oberdorfer, F. Synlett 2000, 86-88.

(176) Yu, C.-S.; Wu, C.-H.; Chiang, L.-W.; Wang, R.-T.; Wang, H.-Y.; Yeh, C.-H.; Lin, K.-I. Chem. Lett. 2005, 34, 1390-1391.

(177) Yu, C.-S.; Chiang, L.-W.; Wu, C.-H.; Wang, R.-T.; Chen, S.-W.; Wang, H.-Y.; Yeh, C.-H. Nucl. Med. Biol. 2006, 33, 367-370. 
(178) Robins, M. J.; Manfredini, S.; Wood, S. G.; Wanklin, R. J.; Rennie, B. A.; Sacks, S. L. J. Med. Chem. 1991, 34, 2275-2280.

(179) Robins, M. J.; Manfredini, S. Tetrahedron Lett. 1990, 31, 5633-5636.

(180) Morin, K. W.; Atrazheva, E. D.; Knaus, E. E.; Wiebe, L. I. J. Med. Chem. 1997, 40, 21842190.

(181) Oda, H.; Morizawa, Y.; Oshima, K.; Nozaki, H. Tetrahedron Lett. 1984, 25, 3221-3224.

(182) Oda, H.; Oshima, K.; Nozaki, H. Chem. Lett. 1985, 53-56.

(183) Cai, C.; Vasella, A. Helv. Chim. Acta 1996, 79, 255-268.

(184) Forristal, I. J. Sulfur Chem. 2005, 26, 163-185.

(185) Meadows, D. C.; Gervay-Hague, J. Med. Res. Rev. 2006, 26, 793-814.

(186) Nájera, C.; Yus, M. Tetrahedron 1999, 55, 10547-10658.

(187) Dadová, J.; Orság, P.; Pohl, R.; Brázdová, M.; Fojta, M.; Hocek, M. Angew. Chem. Int. Ed. 2013, 52, 10515-10518.

(188) Li, X.; Shi, X.; Fang, M.; Xu, X. J. Org. Chem. 2013, 78, 9499-9504.

(189) Zeng, X.; Ilies, L.; Nakamura, E. Org. Lett. 2012, 14, 954-956.

(190) Taniguchi, T.; Fujii, T.; Ishibashi, H. J. Org. Chem. 2010, 75, 8126-8132.

(191) MacPherson, I. S.; Temme, J. S.; Habeshian, S.; Felczak, K.; Pankiewicz, K.; Hedstrom, L.; Krauss, I. J. Angew. Chem. Int. Ed. 2011, 50, 11238-11242.

(192) Macíčková-Cahová, H.; Pohl, R.; Hocek, M. ChemBioChem 2011, 12, 431-438.

(193) Borsenberger, V.; Kukwikila, M.; Howorka, S. Org. Biomol. Chem. 2009, 7, 3826-3835.

(194) Wolf, W. M. J. Mol. Struct. 1999, 474, 113-124.

(195) Wildeman, J.; Van Leusen, A. M. Synthesis 1979, 9, 733-734.

(196) Xie, Y.-Y.; Chen, Z.-C. Synth. Commun. 2001, 31, 3145-3149.

(197) Fan, A.-L.; Cao, S.; Zhang, Z. J. Heterocycl. Chem. 1997, 34, 1657-1660.

(198) Holmquist, C. R.; Roskamp, E. J. Tetrahedron Lett. 1992, 33, 1131-1134.

(199) Kamigata, N.; Udodaira, K.; Shimizu, T. J. Chem. Soc., Perkin Trans. 1 1997, 5, 783-786.

(200) Katritzky, A. R.; Abdel-Fattah, A. A. A.; Wang, M. J. Org. Chem. 2003, 68, 1443-1446. 
(201)Rechtin, T. M.; Black, M. E.; Mao, F.; Lewis, M. L.; Drake, R. R. J. Biol. Chem. 1995, 270, 7055-7060.

(202) Evans, R. K.; Haley, B. E. Biochemistry 1987, 26, 269-276.

(203) Gourdain, S.; Petermann, C.; Harakat, D.; Clivio, P. Nucleos. Nucleot. Nucl. 2010, 29, 542546.

(204) Neef, A. B.; Luedtke, N. W. ChemBioChem 2014, 15, 789-793.

(205) Gourdain, S.; Martinez, A.; Petermann, C.; Harakat, D.; Clivio, P. J. Org. Chem. 2009, 74, 6885-6887.

(206) Liu, Z.; Liao, P.; Bi, X. Org. Lett. 2014, 16, 3668-3671.

(207) Ingale, S. A.; Mei, H.; Leonard, P.; Seela, F. J. Org. Chem. 2013, 78, 11271-11282.

(208) Shelke, S. A.; Sigurdsson, S. T. Angew. Chem. Int. Ed. 2010, 49, 7984-7986.

(209) Balaji, V. N. I.; Prasanna, M. D.; Samiron, P.; Singh, S. K.; PCT/IN2007/000157: 2009, p 30pp., Cont.-in-part of Appl. No. PCT/IN2007/000157.

(210) Malik, V.; Singh, P.; Kumar, S. Tetrahedron 2005, 61, 4009-4014.

(211) Sako, M.; Hirota, K.; Maki, Y. Tetrahedron 1983, 39, 3919-3921.

(212) Asakura, J.; Robins, M. J. J. Org. Chem. 1990, 55, 4928-4933.

(213) Schinazi, R. F.; Chen, M. S.; Prusoff, W. H. J. Med. Chem. 1979, 22, 1273-1277.

(214) Barr, P. J.; Jones, A. S.; Serafinowski, P.; Walker, R. T. J. Chem. Soc., Perkin Trans. 1 1978, 10, 1263-1267.

(215) Jones, A. S.; Rahim, S. G.; Walker, R. T.; De Clercq, E. J. Med. Chem. 1981, 24, 759-760.

(216) Baker, B. R.; Kelley, J. L. J. Med. Chem. 1970, 13, 461-467.

(217) Doub, L.; Krolls, U.; Vandenbelt, J. M.; Fisher, M. W. J. Med. Chem. 1970, 13, 242-246.

(218) Nair, V.; Chi, G.; Uchil, V. R. USA, 2007; Vol. WO 2007/106450 A2. 
VITA

YONG LIANG

EDUCATION

Born, Beijing, China

$2003-2007$

B.S., Chemistry

Shaanxi Normal University, Xi'an, Shaanxi, China

$2007-2010$

M.S., Chemistry

Shaanxi Normal University Xi'an, Shaanxi, China

$2010-2014$

Doctoral Candidate

Florida International University, Miami, Florida, USA

February 2012

SoFLACS Graduate Travel Award

May 2012

Graduate Student Research Award

FIU Chemistry Department

October 2013

Dissertation Year Fellowship

FIU Graduate School

\section{PUBLICATIONS AND PRESENTATIONS}

Liang, Y.; Gloudeman, J.; Wnuk, S. F. Palladium-catalyzed direct arylation of 5-halouracils and 5-halouracil nucleosides promoted by TBAF or base. J. Org. Chem. 2014, 79, 4094-4103.

Zhu, M.-L.; Zhang, Z.-T.; Xue, D.; Hua, H.-L.; Liang, Y.; Wnuk, S. F. Synthesis of 1-amino-5,6diaryl-3-cyano- $1 H$-pyridin-2-ones and 6,7-diaryl-4-cyano-3-hydroxy-1 $H$-[1,2]diazepines from isoflavones. Helv. Chim. Acta. 2014, 97, 561-568.

Adhikary, A.; Kumar, A.; Heizer, A. N.; Palmer, B. J.; Pottiboyina, V.; Liang, Y.; Wnuk, S. F. Hydroxyl ion addition to one-electron oxidized thymine: Unimolecular interconversion of C5 to C6 OH-adducts. J. Am. Chem. Soc. 2013, 135, 3121-3135.

Liang, Y.; Gloudeman, J.; Akinniyi, O.; Wnuk, S. F. TBAF-promoted Pd-catalyzed direct arylation of 5-iodouracil nucleosides. $247^{\text {th }}$ ACS National Meeting \& Exposition, Dallas, TX, United States, 2014, March 16-20.

Liang, Y.; Pitteloud, J.-P.; Herrandez, E.; Wnuk, S. F. Unexpected hydrogermylaytion of 5ethynyluracil nucleosides: Mechanistic consideration. $89^{\text {th }}$ Florida Annual Meeting and Exposition (FAME), Tampa, FL, United States, 2013, May 9-11.

Liang, Y.; Pitteloud, J.-P.; Wnuk, S. F. Hydrogermylation of 5-ethynyluracil nucleosides: Formation of 5-(2-germylvinyl)uracil and 5-(2-germylacetyl)uracil nucleosides. J. Org. Chem. $2013,78,5761-5767$. 
Liang, Y.; Pitteloud, J.-P.; Wnuk, S. F. Conversion of 5-ethynyluracil nucleosides to 5-(2germylvinyl) and 5-(2-germylacetyl)uracil nucleosides via hydrogermylation. 245 ${ }^{\text {th }}$ ACS National Meeting \& Exposition, New Orleans, LA, United States, 2013, April 7-11.

Liang, Y.; Pitteloud, J.-P.; Wnuk, S. F. Chemoselective transfer of allyl or phenyl group from allyl(phenyl)germanes in Pd-catalyzed reactions with aryl halides. $243^{\text {rd }}$ ACS National Meeting \& Exposition, San Diego, CA, United States, 2012 March 25-29, 600.

Liang, Y.; Zhang, Z.-T.; The synthesis of diphenylpyrazole[3,4-b]pyridine compound and single crystal structure analysis. CCS $6^{\text {th }}$ national organic chemistry conference. 2009, 6, 60.

Zhu, M.; Zhang, Z.; Xue, D.; Qiao, J.; Liang, Y.; Wnuk, S. F. Synthesis of 5,6-diarylpyridin2(1H)-ones from isoflavones. Chin. J. Chem. 2013, 31, 1027-1032.

Pitteloud, J.-P.; Liang, Y.; Wnuk, S. F. Chemoselective transfer of allyl or phenyl group from allyl(phenyl)germanes in Pd-catalyzed reactions with aryl halides. Chem. Lett. 2011, 40, 967-969.

Zhang, Z.-T.; Ma, Y.-Q.; Liang, Y.; Xue, D.; He, Q.. An efficient one-pot synthesis of diarylpyrazolo[1,5-a]pyrimidine from isoflavones. J. Heterocyclic Chem. 2011, 48, 279-285.

Pitteloud, J.-P.; Zhang, Z.-T.; Liang, Y.; Cabrera, L.; Wnuk, S. F. Fluoride-promoted crosscoupling of chloro(mono-, di-, or triphenyl)germanes with aryl halides in "moist" toluene. Multiple transfer of the phenyl group from organogermane substrates and comparison of the coupling efficiencies of chloro(phenyl)germanes with their corresponding stannane and silane counterparts. J. Org. Chem. 2010, 75, 8199-8212.

Zhang, Z.-T.; Pitteloud, J.-P.; Cabrera, L.; Liang, Y.; Toribio, M.; Wnuk, S. F., Arylchlorogermanes/TBAF/"moist" toluene: A promising combination for Pd-catalyzed germylstille cross-coupling. Org. lett. 2010, 12, 816-819.

Zhang, Z.-T.; Liang, Y.; Ma, Y.-Q.; Xue, D.; Yang, J.-L. A one-step synthesis of diarylpyrazolo[3,4-b]pyridines from isoflavones. J. Comb. Chem. 2010, 12, 600-603.

Zhang, X.-L.; Zhang, Z.-T.; Liang, Y. Synthesis and single crystal X-ray structure of $\left[\mathrm{Na}\left(\mathrm{H}_{2} \mathrm{O}\right)_{2}\left(\mathrm{C}_{18} \mathrm{H}_{15} \mathrm{O}_{6} \mathrm{SO}_{3}\right)\right]_{2}$. J. Chem. Crystallogr. 2008, 38, 861-865. 